SB 389

M68

LIBRARY OF CONGRESS

||||||||||||||||||||||||||||||||||||||||||||||||||

00005060862 
管

(1) a 年 (1)

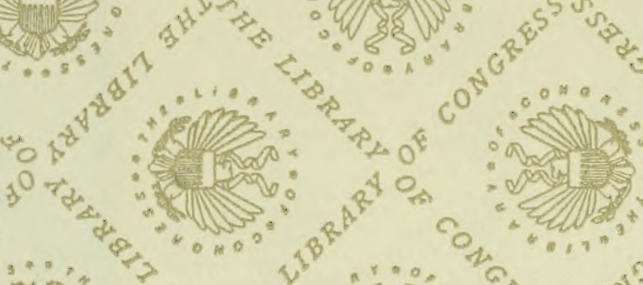
(1) 40 $s_{20}$

Nons : 




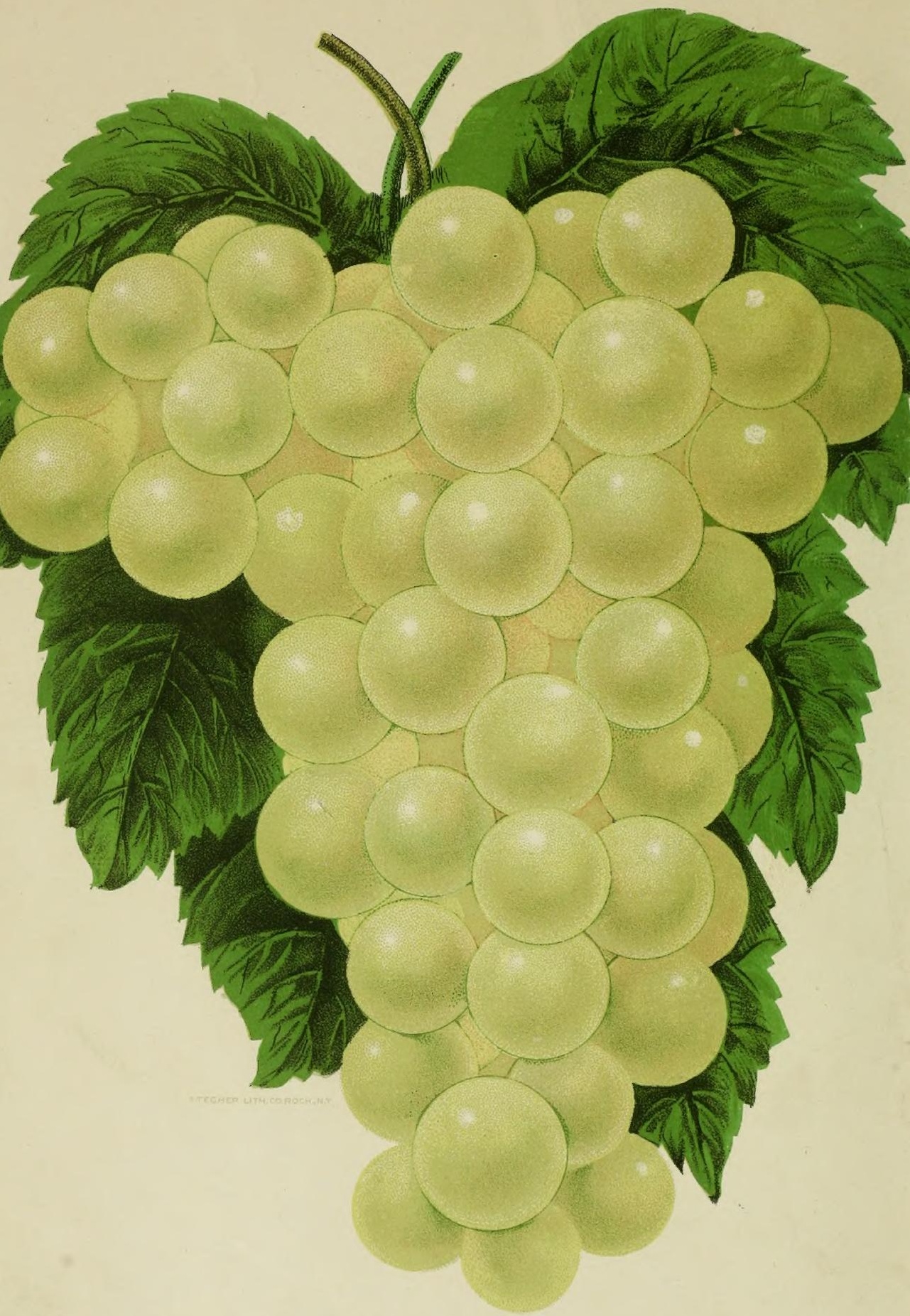

GREEN MOUNTAIN. 


\section{Our Native Grape.}

\section{Grapes and Their Culture}

A I_SO

DESCRIPTIVE LIST

OF

\section{OLD AND NEW VARIETIES,}

PUBLISHED BY

C. MITZKY \& CO.

I893.

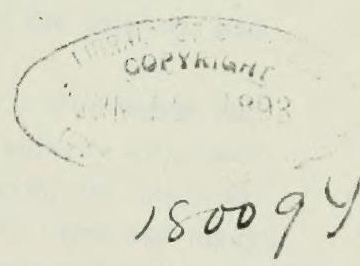

W. W. MORRISON, PRINTER, 95-99 EAST MAIN STREET ROCHESTER, N. Y. 


\section{$5 B 389$ .$M 68$}

Entered according to Act of Congress, in the year 1893, by C. MITZKY \& CO., ROCHESTER, N, Y.,

in the office of the Librarian of Congress, at Washington, D. C. ALL RIGHTS RESERVED.

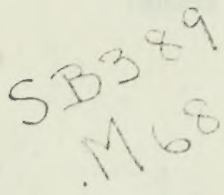




\section{INTR D DUCTION.}

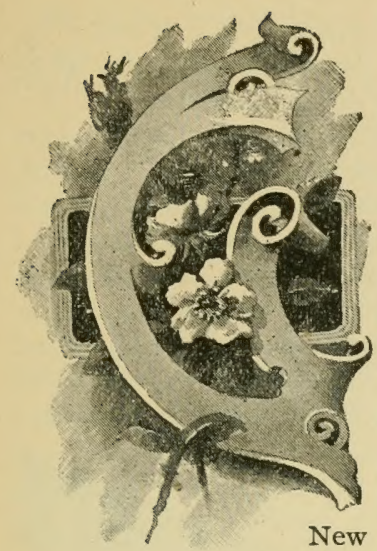

RAPE GROWING is fast becoming a great industry. Its importance is almost incalculable, and it should receive every reasonable encouragement. It is not our intention in this manual, "OUR NATIVE GRAPE," to make known new theories, but to improve on those already in practice. Since the publication of former works on this subject a great many changes have taken place; new destructive diseases have appeared, insects, so detrimental to Grapevines, have increased, making greater vigilance and study necessary.

Many labor-saving tools have been introduced, in fact, Grape culture of the present time is a vast improvement on the Grape culture of years ago. The material herein contained has been gathered by the assistance of friends all over the country in all parts of the United States, and compiled and arranged that not alone our own experience, but that of the best experts in the country, may serve as a guide to the advancement of Grape culture.

We have spared neither time or expense to make this work as complete as possible. With all our efforts, however, we feel compelled to ask forbearance for our shortcomings and mild judgment for our imperfections.

We beg to acknowledge our obligations to our numerous friends who came forward with such a willingness to assist, that with pleasure we pushed the task we had undertaken, being confident of its success.

We are under great obligations to the Agricultural Department at Washington, and to many of the Directors of our Experimental Stations who have aided us with valuable articles and engravings,--Prof. T. V. Munson, D. S. Marvin, Dr. Stayman, Luther Tucker of "The Cultivator and Country Gentleman :" To these and many others who have kindly furnished us information necessary for the completion of our work, we feel grateful and hope that many readers who have had more or less bitter disappointments in the cultivation of the most delicious of all our fruits, may profit from this work. 



\title{
History of the Grape.
}

\begin{abstract}
RAPE CULTURE is a matter of increasing interest. If we look back through
(5) the pages of history into the dark ages of the past we find that God in the very beginning gave us, in the garden of Eden this most delicious of all the choice fruits, and that in Noah's vineyard there were Grapes sweet and tempting. History tells us that as early as the year I630 there was in Palestine, Grapevines, the stems of which were nearly a foot and a half in diameter, thirty feet high with branches covering a space over fifty feet square, producing clusters of Grapes weighing from ten to twelve pounds, with berries, which might be compared to our plums of the present time. At Hebron Grapes grew so large that a single bunch was as much as two men could conveniently carry, and on the Jewish mountains the bunches of Grapes which grew wild, were each half an ell (27 inches) long and the berries two joints of a finger in length. These historical statements are worthy of credence,
\end{abstract}

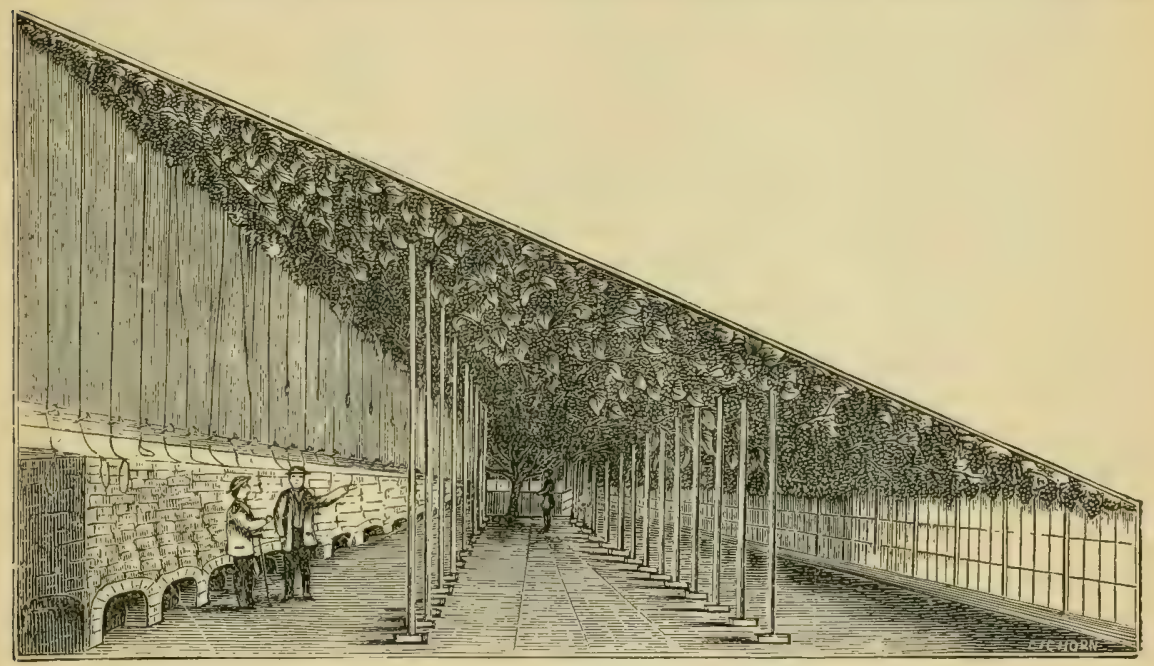

GRAPEVINE, AT HAMPTON COURT, ENGLAND.

but are, indeed, surpassed by the Grapes of Damascus, at the present day, which are often found to weigh twenty-five pounds to the single bunch. Vines in Crete and Chois produced clusters from ten to forty pounds each. A bunch of Syrian Grapes grown in a vineyard at Wetbeck. England, weighed nineteen pounds.

It was known to the Egyptians; representations of the culture of the vine, of the treading out of the juice and of the storing of the wine in jars, being all discovered in paintings within the tombs. Columus in Juno's Temple at Metapont, and a statue of Jupiter in the city of Apollonium were made from the wood of the vine. The 
great doors of the Cathedral of Ravenna are made of vine planks, some of which are twelve feet long and fifteeu inches broad. The Hampton Court vine is the most famous in England. It was planted in 1769 in a glass house seventy-two feet long and about thirty feet wide which is completely filled by this one vine. The trunk is nearly three feet in circumference at about three feet from the ground, or about as large as the trunk of a full-sized apple tree. It bears an annual crop of about a ton of Black Hamburg Grapes, and has produced 2,500 large bunches in a single season. As this vine was planted not many hundred feet from the Thames, it is thought that the roots extend to the river and thus have obtained nourishment for so many years. At Montecito, Cal., four miles from Santa Barbara, there is a Grapevine, probably the largest in the world. Its diameter and yield would be incredible, were it not that they were vouched for by met of veracity, speaking from personal observation. It is a single vine, planted by a Miexican woman about sixty years ago, and has a diameter of twelve inches, one foot from the ground. Its branches cover an area of 12,000 feet and produce annually from 10,000 to 12,000 pounds of Grapes of the Mission variety (many bunches weighing six and seven pounds), the crop being generally made into wine. The old lady who planted this one-vine vineyard died in IS65, at the age of 107. California also has the largest vineyard in the worid. It is in Tehama county. consisting of $3, S_{25}$ acres, to which a considerable number of acres are added every year.

Up to IS40, the only Grapes grown in this country in open air were the Catawba and Isabella, and these were confined almost wholly to the cliffs about Cincinnati. The Ires and Iona came later, and when Mr. Rogers commenced his work of crossing the foreign Grapes with the wild Fox Grape of Massachusetts, the result was the production of over forty varieties, some of which are still esteemed very highly. Soon after this, Mr. Rickett began his experiments of hybridizing or crossing, in which he was successful, producing many valuable varieties. From about this time on, the interest in such work began to develop and scores of experimenters have been lisy multiplying varieties until we now have a long list of valuable sorts of this excellent fruit.

Grape culture in the old world has always been considered one of the most important branches of industry and in our own favored land, especially in some sections, it is fast gaining importance. The acreage is constantly increasing, but not as rapidly as the consumption. A larger and larger amount of this delicious fruit is being consumed by all classes of people. It has been but a few years since our native Grapes have become an article of commerce in our large cities, yet the trade is enormous; single persons selling as many as a thousand tons in one season, and in our country villages, where a short time ago a few baskets would supply the demand, tons are now used. As compared with France and many parts of the old world the vineyard business in this country is only in its infancy.

In New York State, in what is known as the Lake Keuka district, a grower of Grapes shipped his first crop, amounting to fifty pounds, to the New York market, about 1845, by way of the New York and Erie canal. The Grapes were delivered in good condition and the commission houses handling them wrote encouragingly to the shipper, advising further shipments. The next year the grower was able to ship some two or three hundred pounds. He overdid the matter, however, and the New York market on Grapes broke under the pressure. It is estimated, that during the season of I 8 go, there have been shipped from the same district and carried by the different railroads and express companies to New York, Boston, Philadelphia and other markets about 20,000 tons or $40,000,000$ pounds of Grapes, and probably one-quarter of this amount was, in addition, sold to wine manufacturers. The Hudson River dis. 
trict is estimated to have shipped to New York and other markets, between $\mathrm{I}_{3}, 000$ and 15,000 tous of Grapes, whils the Chautauqua district of New York furnished abont I5,000 tons of Grapes for the different markets of the country, making a grand total of nearly 50,000 tons as the product of what is known as the New York district. This does not include over I5,000 tons of Grapes used in the districts for wine.

According to a bulletin sent out by the Census bureau at Washington, there are, to-day, over 300,000 acres planted to vines that are bearing Grapes, and nearly 100,000 to vines not yet arrived at that remunerative stage. The average yield of Grapes per acre is something over two tons, the commercial value of which is set down at fiftyseven dollars a ton; the total product is put at over 600,000 tons, of which over 267,000 tons are sold for table use, including what are eaten ripe from the vines and what are dried and disposed of as raisins. This leaves over 300,000 tons as the amount turned into wine in the year, yielding the enormous amount of $24.000,000$ gallons. This will probably surprise the average citizen, and none more than those whose highly cultured taste leads them to regard with contempt any wine that has not the foreign brand on the bottle or cork. Though some American made wine is openly sent abroad for foreign consumption, by far the greater part of the product is consumed here, some of it directly from the places of its manufacture, and some of it after a clouble sea voyage, in the course of which it passes through a French custom house and gets a French name before it comes through an American custom house and finally sparkles on an American table.

The average value of wine in this country is eighty-three cents a gallon, and inasmuch as the capital invested in Grape cuiture of all kinds for wines, raisins and fresh table use is about $\$ 156,000,000$, it indicates a very handsome return upon the investment, say $33^{\mathrm{I} / 3}$ per cent. on the wine Grape alone and not counting the profit on the table grape and raisin.

This does not represent the ultimate profit from the whole sum derived from the sale of the wine manufactured, because it is only the manufacturer's price, and to that must be added the retailer's profit on all the wines sold by the gallon, or bottle, say nothing at all about that sold by the glass. California, the state which produces the largest amount, has more than half the total acreage under cultivation. New York State is the next largest wine producer. Sixty thousand of its 75,000 tons of Grapes are sold for table use and only 15,000 tons are turned into wine. California sells 236,000 tons to wineries and nearly 39 a0o for table use, and produces $14,626,000$ gallons of wine, while New York produces over 2,500,000 gallons. The yield per acre of Grapes is just about the same in New York as in California, 1.75 tons to 1.77 tons. New York Grapes, however, yield about 160 gallons to the ton while those of California only about 60 .

Grape culture shows a more remarkable growth than any other agricultural industry. This is largely due to the development within the past ten years of new, better and ear.ier varieties than were before known. Yet so large is the demand for the best Grapes that there is yet less danger of this industry being overdone than there is of a surplus of any other kind of fruit. Millions of dollars are annually made by viticulturists in the United States. Judging the future by the past, we shall know a great deal more about the Grape and its best, most scientific and profitable cultivation, than we do now. The Grape grower's vocation properly, promptly and intelligently attended to is one of the pleasantest, most healthful, respectable and enjoyable in the whole range of human industries connected with the tilling of the soil, and therefore one in which it is entirely justifiahle to take an honest pride. 


\title{
Classifichtion.
}

HE Grape vines of America have been more or less judiciously divided into different classes, but all of the varieties now under cultivation belong to either of these four classes only, viz.:

\section{Vitis AEsTIVALIS, VITIS RIPARIA,}

\author{
VITIS LABRUSCA, \\ VITIS ROTUNDIFOLIA.
}

The varieties of one class have not always such distinct peculiarities as to be easily identified as belonging to that class, and sometimes the difference between varieties of the same class is so great, that it could not be ventured to give the general characteristics of each class, and be certain that they would apply to all its varieties. This explains why viticulturists do not always agree in the classification of the same species.

While it is not of primary importance for the practical vineyardist to know exactly to which class a special variety belongs, such knowledge, however, will enable him to determine at once for what soil and climate that Grape is better suited.

The Grapevines cultivated in the district east of the Rocky Mountains are natives of this country, which have either been picized up in the woods, improved by cultivation, or are a product of natural or artificial hybridization; but all the varieties which we cultivate under the name of American Grapes belong to one of the following classes :

\section{Vitis Aestivalis.}

Wild Aestivalis is found in different parts of the United States, on the road side, in the hedges of the plantations and climbing the trees in the woods. It is the wine Grape of the south and some of the best wines made in this country are produced from varieties of this family. They have not been planted extensively and their superior qualities are but little known. One of the characteristics of the Aestivalis is the manner in which its roots push down into the ground instead of spreading around near the surface of the soil, thereby withstanding the most severe drought without any effect detrimental to the continuous growth of the vines. This species requires a long season and productive climate to mature and therefore their culture has been limited. The berries are without pulp and contain a large percentage of sugar. The principal varieties of this species now cultivated are :

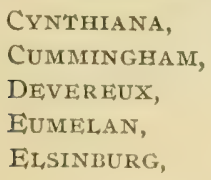

CYNTHIANA,

CUMMINGHAM,

DEVEREUX,

EUMELAN,

EILSINBURG,

HERMAN,

HERBEMONT,

LENOIR,

LOUISIANA,

NOR'ON'S VA. 
Norton's Va. and Cynthiana besides being the best wine Grapes of America, are also very fine table Grapes. All of these varieties are more or less subject to mildew and rot.

\section{Vitis Labrusca.}

To this species belongs the largest number of our cultivated varieties. Our most popular table Grapes are crosses of Labrusca with varieties of better classes. Its home is between the Atlantic ocean and the Alleghany mountains. The vine is strong and stocky, hardy and productive; the roots are fibrous, heavy branching and abundant. The fruit is of superior size with a foxy flavor, which, however, has mostly disappeared in some of the newly introduced varieties. It is easy to propagate from cuttings and also an excellent stock for grafting. Some of the varieties furnish the bulk of our most popular wines, though for wines of finer qualities the Aestivalis is far superior. For table use, Labrusca and its improved varieties will always have the preference.

\section{Vitis Riparia.}

This species is adapted to almost every kind of soil, except heavy clay. The roots are tough and grow rapidly. The flavor of the fruit is virious and pure. The fruit contains sufficient sugar for a good wine, but it requires age to develop their qualities. All the best Grapes for white wine such as Elvira, Missouri, Riessling, etc, belong to this class. It also includes a few varieties of black Grapes which produce a fine red wine. Clinton, which belongs to this class, is known to almost everybody.

\section{Vitis Rotundifolia.}

This is entirely confined to the Southern states and is very characteristic in its appearance. Its leaves are small, round and shining. The fruit is not formed in bunches, but grows in large, thick-skinned and pulpy berries. The Scuppernong, Flowers, Tender Pulp and Thomas are the varieties under cultivation. For a long time the first named has been considered the only valuable Grape for the south, but they never have proved profitable enough to plant on a large scale. The Scuppernong has no commercial value as it cannot bear transportation, while it makes a splendid wine, though deficient in sugar, it is very sweet having but little acid.

\section{Hybrids.}

A vine or plant produced by the mixture of two species is called a Hybrid. This operation can be performed artificially or by nature. This hydridizing by nature is mostly done by insects carrying pollen from one flower to another. A cross is the production of two varieties of the same species. For instance Diamond was produced by crossing-Concord with Iona. Concord is a Labrusca while Iona is a seedling of Catawba, which also belongs to the Labrusca species. The operation in hybridizing and crossing is the same, but the results obtained are different. The seed of a berry will never produce the same Grape from which it was taken as always more or less hybridization has been done by nature. Plants thus obtained are often called seedlings, though by right they are either hybrids or crosses. 


\section{Prophgation.}

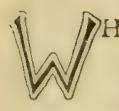

HEN propagating a Grapevine we simply make a new vine from a part of another and this new vine being apart of the parent vine is like it in all respects; the same habit and constitution, the same bark, foliage and fruit. The several methods of propagating, are by cuttings, grafting or by layering.

One of the cheapest and easiest methods by which to get a start in Grape culture, is propagating by cuttings. To have good results take cuttings from thrifty, wellripened, close-jointed wood, avoiding all spindling twigs or reedy-like canes. Grape cuttings should be made just as soon as possible after the wood is cut from the vines, for if it is left in the wind and snow for any length of time it will dry out more or less to its detriment. If not convenient to cut up at once, the wood should be gath ered into bundles and put into the cellar or some other convenient place out of the wind.

\section{Propagating from Short Cuttings.}

With new varieties, where wood is still scarce, the propagating can be done by using one eye cuttings. These should be cut about two or three inches long; one eye on the top is sufficient. It is not necessary to have an eye below as they will strike

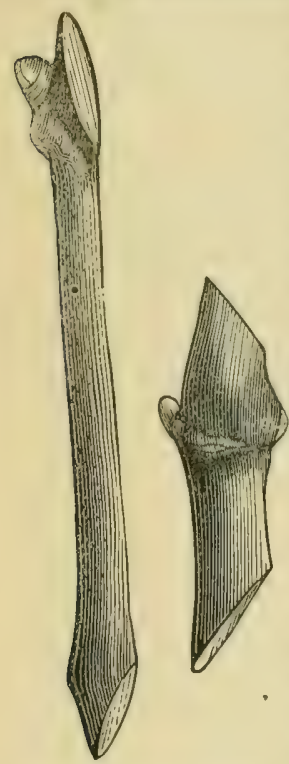
root just as well, if not better, with one, and this is true of all kinds of cuttings without any exception. These cuttings should be put in propagating beds in a green-house the middle of February. Set them upright in rather coarse, clean sand down to the top bud. The sand should be rather compact than loose. To drive out roots bottom heat is necessary and it should remain for a few days at 60 degrees, then raised to 75 or 80 degrees during the day time and not below 65 degrees at night. The top heat should be kept about ten or fifteen degrees lower than the bottom heat by ventilation and shade. If there is sufficient ventilation no mildew or damping off will occur. The cuttings must be kept always moist by frequent sprinkling. Some varieties will root in three weeks or less, while others may take twice as long. After the cuttings have rooted and the buds driven out the first leaves, the cuttings should be taken from the propagating bed and potted singly in a small pot (thumb pot.) An average heat of 70 degrees during day time and 55 degrees at night is sufficient for their growth. About three weeks later these small pots will be completely filled with roots and the young plants should be shifted into a larger pot, where they will increase in size. As soon as all danger from night frosts is over the vines should be planted out in open SHORT CUTTINGS. ground. Nothing is gained by setting out at an earlier period.

In planting choose a plot of rather sandy soil, heavy soil will not do; trench it deeply and mix it with thoroughly rotted manure. Plant the young vines in rows two and one-half feet apart and six inches apart in the rows. After shaking the plants from the pots, lay the vines in trenches made by the spade or plow, using the earth thrown out to fill in again where the young plants are placed. Always be care- 
ful to have the soil firm around the plants. In dry weather at planting time water the plants thoroughly before taking them from the pots. The vines will soon get established in the open ground. They make rapid growth and strong plants are obtained by fall in a favorable season. A thorough cultivation is necessary for success. These vines are then called yearlings. If intended to remain in the ground another season, the young growth should be cut back to two buds, the soil plowed up to them and a light covering of coarse manure for mulching given. In the following spring the manure will be raked off thus uncovering the plants. As soon as warm weather sets in, buds will begin to swell and soon throw out new shoots. Only two canes should be allowed to grow in order to strengthen both the roots and the tops. Cultivating and hoeing several times during the growing season will produce strong, thrifty and healthy plants by fall, which are then dug up and stored in a cool cellar during the winter.

\section{Long Cuttings.}

For out-door planting the cuttings should be made six or eight inches long; if short-jointed there may be three or four eyes to a cutting; if long-jointed there will be sometimes but two eyes. Cut close beluw the lower eye and slanting at right angles

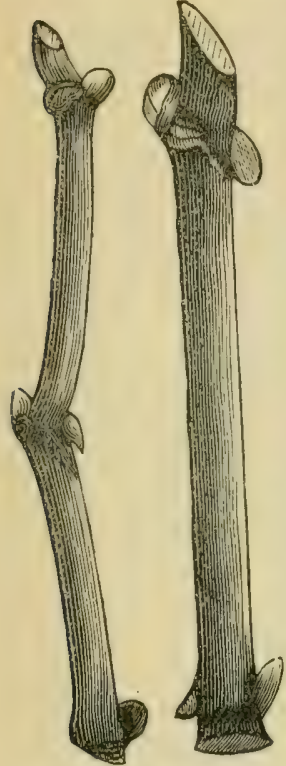

I,ONG CUTTINGS. with the bud, one half inch above the upper bud, in like manner, slanting so that the upper point is on the same side as the bud. The cuttings should be tied up in bundles of fifty and may then be preserved in a cool cellar, buried in moderately dry sand or laid on the floor and covered with damp sawdust or moss. Excessive dryness or dampness are equally to be avoided, keep the temperature low, but not low enough to freeze the liquids in the cuttings. As soon as the frost is out of the ground the cuttings intended for out-door propagation should be put in bundles in trenches in a warm sunny spot with the top ends down and about two inches of earth covering the top of the bundles. By the time the ground is ready for the cuttings, which should not be until the soil has become dry and warm, aly of the cut ends will be calloused and covered over with a nice growth of fine rootlets, which will give them a quick and vigorous start when put into the ground. A better and heavier root growth is then secured, than would be if the tops or branch ends of the cuttings are allowed to start first, as is the case when the cuttings go direct from the cellar to the open ground for planting. This also enables the propagator to throw out all the poor or dead wood, saving for planting only those which show life asd vigor.

For planting out follow the same directions as given for one eye cuttings only that the cuttings, when placed in the trench, should stand at an angle like one side of a letter V, and also have the end buds, which should be out of tine soil, uppermost. The end cut with the slant will throw the rain away from the bud, thus preventing rot.

\section{Propagation by Layering.}

Layering is a method of propagating plants by burying a cane while still attached to and sustained by the parent vine. For layering select a cane of well ripened wood that will bear being bent down to the earth without breaking Remove the earth to the depth of two or three inches, then carefully bend the cane into the earth, secure 
it in that position by a peg, and cover it over with only a very little earth. At every joint young roots will be driven out and the buds will develop into leaves. After the shoots have grown three or four inches in height, select the strongest ones to remain

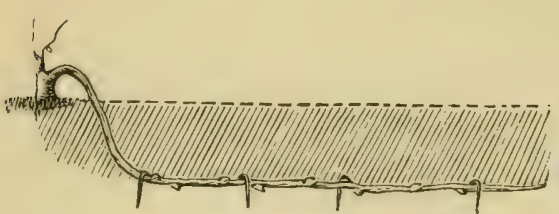

LAYERED CANE.

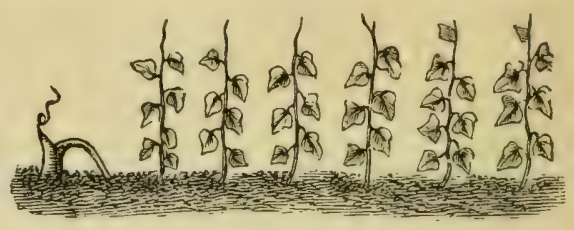

IAYYERED CANE WITH GROWING SHOOTS.

and break off all those of weaker growth, thus enabling the remaining shoots to obtain additional strength. Every bud on the cane will make a plant, but not of equal vigor, and the less number growing on the cane the better will be the result. The remaining plants should be supplied with stakes, as soon as sufficiently high to be tied up. More soil can now be drawn into the trench and every week, while hoeing, more soil can be added until the trench is filled up. Filling up too quickly will cause the cane below the ground to rot. Frequent cultivating and hoeing and also a light mulching will be found beneficial.

At the end of the first season these plants can be separated from the parent vine by commencing with the vines nearest the original one, and carefully digging up and storing away in a cool cellar for next season's planting.

\section{Root Grafting.}

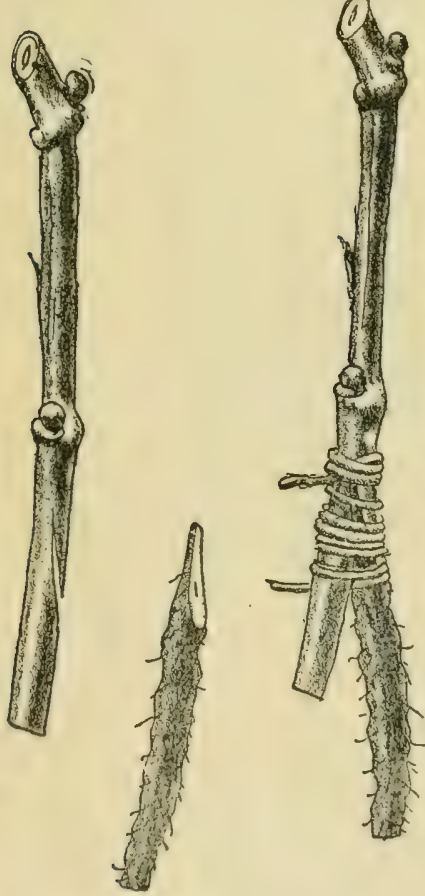

From AMrRICAN GARDENING: Copyrighted ROOT GRAFTING
This method of grafting will be interesting for experiment with varieties that are difficult to propagate from cuttings, which do not easily form their own roots. The junction is effected after the ordinary manner of whip-grafting, but the tongue is cut in the center of the graft instead of at its end. The grafts consist of pieces of root about a quarter of an inch in diameter, which can be obtained from young vines when taken up in the fall. These roots may be stored away in a cool celler in damp sand or moss until wanted for operation. If the cuttings of the Grape to be grafted are long-jointed only one eye to the cutting is necessary, while two eyes are needed for short-jointed wood. The root graft should be cut sufficiently long to permit of its entering the ground to the same depth as the stock, thus affording an independent source of nourishment to the graft until firmly united and enable it to make roots and also draw sap from the stock. After joining the graft with the cutting, tie firmly with waxed thread. These cuttings can be started at once in a propagating bed by placing them uprigh; in boxes with damp sand. If given a moderate heat they will begin to grow and when warm weather has arrived be in fine condition to transplant in the open ground. By fall many good strong plants are obtained by this method. 


\section{HYBRIDIZING.}

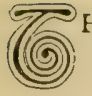

$\mathrm{HE}$ production of new varieties of fruits, etc., by crossing and hybridizing is a favorite line of work with many progressive horticulturists and altogether an interesting subject of study. But the path of the hybridizer is not always strewn with roses, especially such as are free from thorns, and the reward of brilliant results, or the pay financially, for the labor is frequently not forthcoming. The idea prevails, that only a few skillful horticulturists can do it, but really the operation is very simple. All the knowledge required is enough understanding of botany to know the difference between the stamen and pistil, and all the skill needed is a reasonably steady hand. The tools are few and plain. A small, soft, well-pointed camels hair brush, a pair of sharp, fine-pointed scissors, that cuts well at the extreme points, and fine, thin, light muslin or cheese cloth, or tissue paper to carry the pollen.

Hybridizing, or cross-ferti!izing to be successful, should be done when the vines are in full health and vigor and before they have become exhausted by blooming. No guess work should be allowed, but everything should be done thoroughly so that wheu a cross is made we may be absolutely certain as to the parentage. Furthermore, we should not expect that all our attempts will be successful, for we have to bear many disappointments and failures. In this work nature has yet many things hidden for us to bring to light.

The parts of a flower are in their order, beginning at the stem, calyx, coralla, stamen and pistil. The calyx is the outer envelope, usually green; the coralla is composed of several leaves called petals. These parts are simply ornamental; the useful and necessary parts, and those with which we have mostly to deal, are the stamens and pistils. The stamens are the parts which bear the fine dust known as pollen. Their form is a slender stem bearing a head, shaped something like a keruel which is called the anther, and which, when ripe, bursts and scatters the pollen. This latter is a fine granular dust, quite often yellow, but sometimes brown, white, \&c. The pistil is the part bearing the seed. At its base is a pod known as the ovary which when in proper condition to receive the pollen from the anther is usually slightly sticky. From this ovary the fruit is formed.

The operation is performed as follows: In the selection of varieties to hybridize select those which combine hardiness, quality, earliness, \&c. Choose flowers of these varieties which open nearly at the same time. As soon as the flowers are opened sufficiently cut off every stamen with the scissors and tie a small bag of gauze cloth carefully over the flowers to prevent meddling by insects. Cover also the other flowers which are to be fertilized, in the same way and for the same reason, but do not cut off the stamen. As soon as the latter flowers burst the pollen take off the gauze bags and with the aid of the camel's hair brush take some of the pollen and place it on the stigmas or extreme ends of the pistils in the flowers from which the stamen was cut, and replace the gauze bags after this operrtion. Flowers on Grapevines do not open all at one time; care should therefore be taken that all the flowers are fertilized. The operation should be repeated several times, as very often the stigma is not properly fertilized the first time. It is also a good plan to thin out some of the flowers to give the berries more room to grow larger and perfect. The fruit 
from these fertilized flowers will set as usual and should be allowed to ripen perfectly. As soon as the Grapes are gathered, the seeds should be separated from the pulp and placed in boxes with sand during the winter in the cellar. The seeds may be planted the following spring in the open ground as soon as the weather is warm. Plant in drills three feet apart and the young plant should be treated the same way as those raised from cuttings. By proper care fruit can be expected the fourth year after planting the seeds. All our best varieties of Grapes have been obtained by this operation, though some are chance seedlings which were produced from berries accidently dropped.

\section{The Production of New Seedling Grapes.}

\section{BY DR. J. STAYMAN, LEAVENWORTH, KANSAS.}

It is a well known fact that the selection of seeds from the best specimens is the only sure method of producing improved varieties. It then follows, as a corollary, that the only certain and successful way to grow those seeds is to fertilize their bloom with the pollen of congenial, characteristic, healthy, desirable varieties.

Many of our best Grapes are the result of "chance seedlings," as the Catawba, Isabella, Delaware and Norton Virginia. These Grapes, while good for certain purposes and locations, did not fully meet the requirements of our progressive age and refined tastes. We had become acquainted with the fine quality of European Grapes and. in our eager desire to possess those of such excellence, we sought hybridization as the only sure method of producing them. We never considered for a moment by what method and how long a time it took to originate them. It is very certain that we have no account of its being done by hybridization or forced crossing, as these methods were then unknown. It then must have been the result of domestication and natural congenial pollenization.

Hybridization is a violent, forced fertilization and is seldom, if ever, congenial; nature seldom, if ever, employs it, or there would be no distinctive species. We hope by these brief introductory remarks that we are fully understood.

There are two well known theories given for the production of improved fruits, one by Dr. Monz, of Belgium, the other by Thos. Andre Kuight, Esq., of Englaud. The former advocates the planting of the seeds of wild varieties that have been domesticated or cultivated, and then plant their seeds and continue that method through successive generations until you get what you desire. This method does not answer our advanced and progressive age, and at the best it is too slow and uncertain.

The latter method, by Mr. Knight, is by cross breeding and hybridization, which so far has been tolerably successful in the production of new flowers and plants. but we have few fruits produced by it of very great merit. The dificulty appears to be that we have no way to determine the congenial pollen for any flower. It is left entirely to the imagination of the operator. This is proven by the results, as well as by the fact that the pollen of a flower will not always fertilize its own bloom. This has been frequently observed in Staminate Strawberries that have sufficient pollen to fertilize other varieties, while it fails to pollenize its own bloom, showing clearly a want of congeniality. This being true, how can we know or determine the congenial pollen for any flower to produce a given result. Then we need not wonder that chance seedlings produce more blanks than prizes.

Having shown the difficulty in both of these methods, we will give what has proven to be successful and satisfactory with us, not only satisfactory, but the most remarkable and surprising in its results. 
If we had every species and every variety of Grapes at our command, and the selection of pollen from all, and the mother plant also, we cannot see how we could accomplish the same results with such a degree of certainty and in such a short time.

To produce hardy and productive seedling Grapes from our native varieties and species, of as high character as the European Grapes, appears impossible, yet it has been done. To show that this is the case, we will give the facts, and let the reader draw his own conclusion.

About fifty years ago, Mr. John Burr, then a resident of Columbus, Ohio, commenced the production of Seedling Strawberries, using selected seed from the few varieties then in existence. In this he was so successful that the Cinciunati Horticultural Society, of which he was a member, awarded him the honor of having produced the finest lot of seedlings, among which was "Burr's New Pine," which is to this day considered the highest standard of excellence. Having been so successful in the production of Strawberries from so few and indifferent varieties, it is no wonder that he should have been sanguine that he could produce similar results with Grapes. He planted on his lot the Catawba, Isabella, Bland, Delaware, Hartford, Prolific and Concord, and soon added the Salem and Gothe, with these few varieties he commenced, not even a neighbor vine was near to mar his operations.

He first tried the Concord, but soon found that it had no congeniality to other better kinds, and was not very susceptible to improvement, so he took the Delaware, a much weaker grower, but of much higher quality, and in his first effort he produced the "Early Victor," which is a strong grower, very productive, and of very good quality.

This showed that he had struck the key-note to success, namely, that weak varieties were very easily impressed by stronger varieties, but very strong and positive varieties very seldom, if ever, by very weak varieties.

From this fact and data, he soon discarded those that proved unworthy, until now he has but few on his list, except his own seedlings.

But the most remarkable fact connected with this is that he has produced so many lardy varieties, with such a high per cent. of fine qualities and so few indifferent. Out of some twenty or more growing on our grounds, nearly all are of high quality. We know the source of some of them, but how and from what his "Eclipse, Paragon, Matchless, Omega, Cochee" and "Primate" came we cannot even imagine, as he never had such Grapes upon his lot, and there is no other source from which they could possibly have come. This same improvement bids fair to continue as long as the same method is pursued.

We have dwelt more particularly upon Mr. Burr's success, as his method is the same as our own, and our first success was made with the same variety. Our grounds, however, are much larger, the vines planted much farther apart, the varieties more numerous, the type of many more positive and the results are a greater departure from the original types. We have the pure, wild Fistivalis, Labrusca and Riparia, as well as the best and most refined; the feeble grower and the most vigorous and rampant from the same variety of seed. While, in some other instances, the type is so exact that it is with difficulty that we can tell the one from the other, while others do not apper to be succeptible to our improvement. From these observations and results, we believe the time is not far distant when we will produce as fine and excellent Grapes as the European varieties.

In a great measure we have to acknowledge the perseverance of many of our professional propagators, who through proper, careful operations in hybridizing, have given to the public at large so many improved and superior varieties, which aimost every inhabitant of this Union now enjoys, and with which the name of the originator will be forever connected. 


\section{Proposition to Protect the Originators.}

All our originators of new varieties have not derived the benefit, compensation and protection by law for their long years of labor that is accorded an inventor who often obtained his invention by mere accident. A patent will protect him for years, securing for him pecuniary benefits as long as his patent holds good. What protection has the originator of new plants and fruits? Such originators have as much right to protection as inventors of anything else. It takes years and years for the originator of a new variety of Grapes to determine the fruits of his labor and he ought to be entitled to some pay for all the time and troulble spent to develop the Grape. This is an age of progress and improvement. In the horticultural world this progress has been marked and rapid and one need not go back to observe the advance which has been made, particularly in the originating from seed and the process of hybridization of new and superior varieties. Protection would he an incentive to extensive and systematic experimenting, which would, without rloubt, result in producing valuable additions to our fruits.

Many notorious swindles in horticulture have leen caused by the lack of exclusive rights to new productions. A favorite trick of unscrupulous parties in the trade is to substitute old sorts for some new, rare variety under the name of the latter. Of course several years will elapse before the purchasers can find out that they have not the product of nature they bought.

How can these evils be remedied? By a law making the trial of all new varieties at the Experiment Stations compulsory before allowing them to be introduced, in order to determine, if they are really new and have merit. If, after due investigation, the new plant or fruit is accepted, the originator should be granted a certificate, which wonld secure him the exclusive right to propagate and sell the same for a term of years, without the right to renewal. This would give him sufficient time to prepare stock for the market and an abundance of time in which to enjoy the privileges of exclusive sale, and he in turn would protect the people in its purchase in order to protect himself in its sale. Further, the law should guarantee to the originator that in case plants or cuttings of the variety are stolen from him or the Experiment Stations and disseminated in that way, the stock shall be confiscated wherever found. The principal inducement for stealing new varieties, so frequently practiced, would then no longer exist. The purchaser of a plant entered under this act should have the right to propagate it for his own use but not to sell or disseminate it except by special arrangement with the originator. At the time of the purchase he should be furnished with a certificate of purchase by the vendor, who should keep an accurate record of the same as a means of protection to himself and to the purchaser. At any or all times before the expiration of the propagation right the possessor of a plant may be required to show how he came into possession or hold himseif responsible for violation of the law. All accepted new plants or fruits being registered and numbered, very few plants or fruits could be sold which would not have the official name, number and description found upon the National register. There is reason to believe that the enactment of a law protecting originators would constitute one of the greatest benefits to horticulturists, and we hope that the time is not far off, when such steps will be taken as will protect and promote the origination of new fruit. 


\section{The Søil.}

$\mathrm{HE}$ soil is a complicated subject that varies greatly in its nature in different localities. Soils are classed for convenience as sandy, clayey, loamy and peaty soils.

A SANDY soil is one which has a larger part of sand than other substances. Such a soil is easily plowed and cultivated, but dries out rapidly unless underlaid with a clay subsoil, and soon loses the manure put into it to feed crops. Sandy soils are generally warmer, start things into growth earlier than others, and are therefore often sought for early crops.

A CLAYEY soil is one in which clay is the larger part. Clay soils retain moisture and are cold late in the spring. They also get very hard and difficult to cultivate in dry weather, and are generally the most difficult of all soils to improve.

A LOAMY soil is one in which clay and sand are found in such proper proportions that they are easily worked, retain moisture, do not bake hard in dry weather, and generally contain more of the various elements of plant foor than other soils. They are fitted for a greater range of crops than any other class of soils in the same region.

PEATY soils are made up of decayed vegetable matter. They are generally found in swamps and low lands, and when there is a sufficient mixture of mineral matter may be very productive when drained of the surplus water, but usually a peaty soil is unproductive. They are often of great value when made into a compost with lime or ashes, for dressing other classes of soil for the purpose of adding vegetable matter to them.

The SUBSOIL, or that part of the soil immediately under the cultivated soil, is of great importance to the grower. If the subsoil is such a hard clay that water cannot easily pass through it the upper soil may be kept wet and cold by it. If the subsoil is sand, water and manure put on the land soon break away out of the reach of the crops. It is desirable then that this subsoil should be open enough to let water through easily but compact enough to take and retain moisture and plant food. A mellow loam on such a subsoil is the best possible soil for ail farming operations.

Grapes will thrive both in sand and clay, in fact, in almost every mixture. The old idea that Grapes thrive best on light land is mainly due to the fact that such soils are naturally dry and warm. While a heavy clay is not best for the Grape, it is not an obstacle which must be overcome for success in vineyarding. but it should be thoroughly underdrained. Grape growing is possible under a wider range of conditions and soil than is the case with any other crop. The one thing that Grape roots cannot abide is stagnant water. No matter if it dries out in midsummer it is then past the power of the vine to regain lost time. Land thoroughly drained, to the depth of three feet, warm more quickly in the spring and makes a difference in temperature of five to ten degrees or more at the time when the vine most needs warmth.

Each individual grower should depend more on his own experience in the cultivation of fruits or on that of his neighbor, than an opinion obtained from a distance. Good corn land as a rule, is suitable for Grapes, provided the climate and location are right. 


\section{Vineytard Planting.}

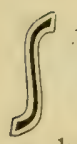

UCCESSFUL Grape growing always involves care, expense and above all well experienced management. Location, soil, climate and selection of varieties are all important. For garden culture we have but little choice to make, for we have to plant our Grapes where the gardens are or do without them. In planting a vineyard it is nccessary in the first place to make a selection of a location and soil.

\section{Location and Soil.}

It is true that some varieties of Grapes will grow and mature in almost every state of the Union, but to insure a crop one danger has to be guarded against, that is the late spring frosts, which will injure the young, tender shoots. With the freezing of these shoots the hope of any crop is destroyed. It is always best to locate vineyards where they can have a full and free circulation of air, not only as a protection from frosts, but also from the excessive humidity that in wet and warmer sections, develops the fungus diseases. The selection of a location near by some deep water, which, being unfrozen, will moderate the temperature several miles inland. Our best crops, and most Grapes for market, are grown along the shores of the small lakes.

A vineyard should not be planted in a low, damp location. Grapes succeed best. on high, dry, well-drained ground. It is a well established fact that the southern slope of a hill with a clay subsoil well drained, is the best location in which to grow Grapes. The best conditions are warm soil, dry, elevated, sunny hillsides in a temperate climate. It should be remembered that the grape requires a daily warm temperature of fifty-five degrees dnring the months of May and June and for the maturing months of July, August and September, an average of not less than sixtyfive degrees of temperature or tinere can be no success. Where the temperature for tive growing period averages sixty-five or seventy degrees and that of the maturing period seventy-five or eighty degrees fruit of the most excellent kind can be procured.

All the varieties, in the time of ripening, depend upon this and the amount of rain fall. The quality and richness of the Grape depends upon the amount of sugar the fruit contains and this again upon the high mean temperature under which the seeds are formed and the Grape matured.

Our native varieties of Grapes are found growing wild in a great variety of soil, thus showing their adaptation to a wide range. Soils containing more or less clay with a mixture of rotten shale, small stones, limestone, etc., are considered the best. gravelly and sandy soil, sandy loam are also well adapted. In fact any soil that can grow a good farm crop can successfully grow Grapes, if climate and exposure are favorable

As it is expected that a vineyard is to occupy the land for many years, the depth and thoroughness of the preparation of the soil cannot be too strongly emphasized. If the subsoil is clayey or of a tenacious character, the whole section to be planted should be deeply subsoiled and heavily fertilized with manures of the best quality, such as ashes and ground bones. Subsoiling does not bring the subsoil to the surface, 
but merely loosens it up so that the roots of the plants can penetrate it. The subsoil plow consists of a small plow not much larger than the tooth of a horse-hoe set upon a stout standard about two feet long, or even more in a large size. The furrow is turned with an ordinary plow and then another team attached to the subsoil plow follows after the first, and the plow is put down as deep as desired in the same furrow. Then upon this loosened subsoil the last furrow is thrown and each furrow is treated in the same way. It is of great value in a clay subsoil. for the loosening affords more opportunity for rain, frost and heat to penetrate the earth and under their influence the elements of fertility, that have soaked down in the subsoil, are made available to

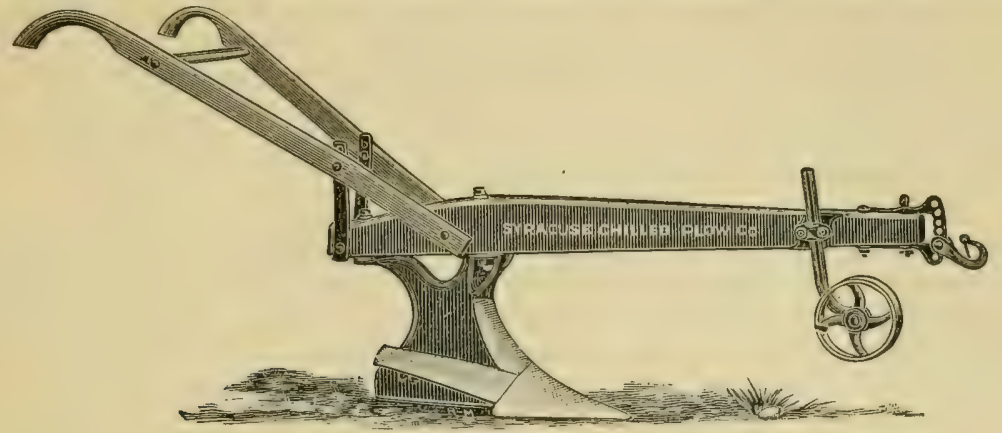

SUBSOIL, PLOW.

the plant roots, which can now find their way down there. The use of this plow is therefore very beneficial in land where there is a hard clay subsoil, but where the surface soil rests upon a layer of sand or gravel it is not needed. Deep plowing enables the surface soil to appropriate fertility and moisture, both from considerable depth in the soil and from the air. The preparation should be commenced a year, or at least the previous fall, before planting the vines. After plowing and subsoiling the whole area of the proposed vineyard, the ground should be thoroughly pulverized

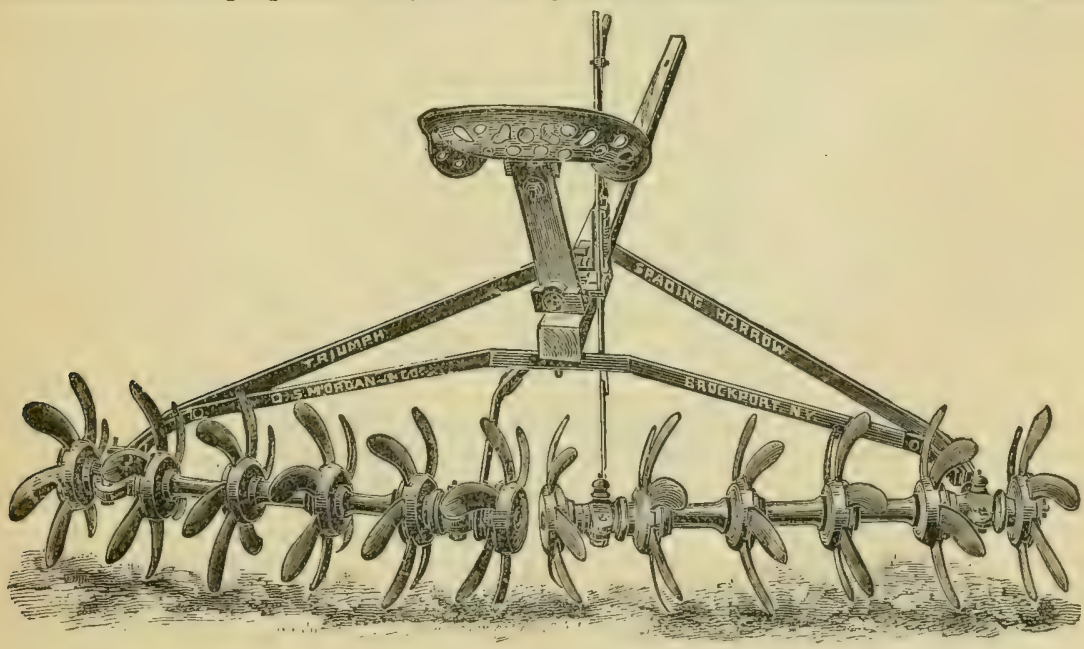

SPADING HARROW.

and harrowed over. It has been customary, on this class of work, to break up the lumps with heavy rollers and pulverize afterwards with a common drag. We have 
now, however, a spading harrow, and it is surprising with what rapidity this harrow will cut up and pulverize lumpy, hard ground. With the weight of the driver on it, it will soon pulverize any ordinary ground and it must be extremely hard ground if it does not penetrate at least six inches. The ground will be left as smooth as after a spike or spring-tooth harrow and not in ridges or furrows.

To facilitate planting the lands should be plowed just the width of the rows apart, which will bring the vines to be set out in the dead furrow. Then very little digging is required for the holes in which to plant the vines, which should be about twelve to fifteen inches deep, depending on the size of the rooted cuttings and should be at least that depth below the level surface of the ground in ordinary soil. The cultivation during the season will fill up the dead furrow. Holes should be dug large enough so the roots can spread naturally without one root crossing the other. In dry days it is better not to have many holes dug ahead of the planting, as the earth will be more moist if freshly dug. Put the finest and best earth at the bottom of the hole and among the roots and the coarsest and poorest on the top.

The next important step to be taken is the selection of roots. The planting of a vineyard is for a lifetime and therefore the difference of a few dollars on the thousand vines should not influence anybody to buy from unknown or irresponsible propagators. There are many good and reliable nurserymen all over the country, who make a specialty of growing Grapevines for vineyard planting. The most experienced

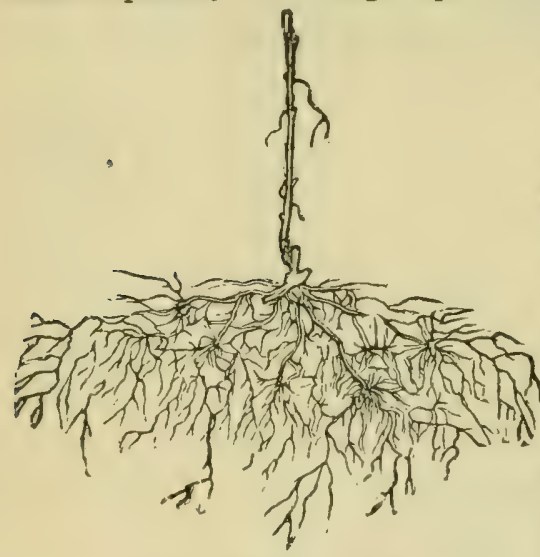

WEILL-ROOTED VINE. vineyardists prefer well rooted, strong, firstclass one year old vines from long cuttings, though some use vines two years old. These cuttings generally have from four to six good healthy roots with plenty of smaller fibrous roots attached to them. The tops of the cuttings should be from six to ten inches long according to the length of the joints and should have not more than three eyes. Before planting the roots should be pruned to about eight inches, which will give us a diameter of root surface of sixteen inches, also all bruised roots should be carefully cut smooth. The object of pruning the roots is to render them not alone more convenient for planting but also to incite the under roots to throw out new ones. To keep the roots from drying out they should be covered with moist moss and only taken out as fast as wanted for planting.

\section{Planting.}

Place some vines in a pail of water thus insuring that none shall get dry before planting. The holes having been dug large enough to completely take in the roots so the crown will come a trifle below the surface, when covered over. The roots must be carefully spread out, each one in place, and not in a heap or cramped up in a hole. A doubled-up root will not make a good healthy vine. Cover the roots with fresh surface soil, slightly raise and shake the vine so as to allow the fine soil to settle among the roots, and press it thoroughly down with the foot, put in a handful of good fertilizer, taking care not to have it too near the roots because it is liable to burn them. This mistake is often made. Fill the holes to within two 
only three or four buds. Plow up to the vines after being pruned, by using a gang plow. The object of this plowing is not to keep the frost from the vines, but rather to keep them frozen all winter. It is the alternate freezing and thawing, not the steady cold, that injures the vines. It is not necessary to cover deep. The roots also are thoroughly protected during the winter.

\section{Second Year.}

In the following spring, as soon as the frost is out of the ground and before the buds start, uncover the vines by gently lifting them with a flat-tined fork out of the earth that encases them. Sow broadcast some good fertilizer (about 600 pounds to the acre). Use again the gang plow, but plow from the vines, which will work the fertilizer in. For this work the spading-harrow is also used with great success, as reverse irons are furnished with the harrow, whereby the gangs can be easily reversed to throw the soil from the vines cultivating the ground thoroughly, whether throwing the soil to or from the roots of the vines. As soon as warm weather sets in the buds will begin to start and when the new shoots have grown a few inches rub off all but two, leaving the strongest to form canes for fruiting the next year. These two canes can be trained the same way as the single one was trained last season by tying to the small stake. No fruit ought to be allowed to grow this year. If the posts are set and the wires put up the second season one of these canes can be trained to lay on the right and the other on the left side from the cane extending vertically to the first wire,

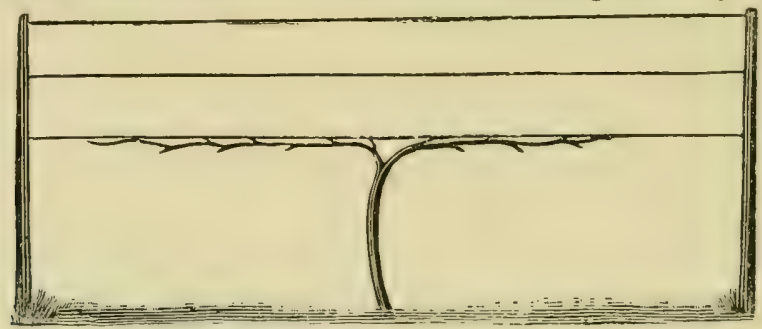

VINE TRAINED TO FIRST IVIRE.

Cultivate and harrow again as much as first year, each time in uniform depths. Do not cultivate shallow one time and deep the next, but keep up an even cultivation, on which the life of the vine depends. Vacancies should be filled as early as the weather will permit. It is found very often that some vines will show weakness in growing; the tops of these vines should be pruued closer, and by giving them some manure, the main strength will go to the roots. Attentiou must be paid to what is below the ground as well as on top. If the roots are strong, the tops will also be strong and thrifty. At the close of the season, after the leaves have fallen from the vines and before winter sets in, the vines shonld be pruned according to the strength of the vine, each cane to six or eight buds. Do not neglect to plow up to the vines.

\section{Trellises.}

It has been the practice with vineyardists in the Southern States, where the seasons are longer and the vines make a more rapid growth the first year, to put up trellises the second season, and posts are placed in position during the fall or winter of the first season; at the north, however, not until the following spring as soon as the frost is out of the ground. Posts made of either chestnut, oak, white or red 
cedar are the most preferable and should be at least eight feet long, six feet above ground after being set two or two and a half feet in the ground according to soil and location, and should be set in rows running north and south if possible. The end post should be the strongest and well braced to withstand the stretching of the wires tightly. After the posts have been sharpened on one end, they are ready for setting. The quickest and best way to dig a hole is with a bar made for the work. The holes should be twenty-four feet apart, thus having three vines between two posts, if the vines are eight feet apart in the row ; other distances in planting in proportion. The posts are dropped in the holes and afterwards settled down by sledges. Two men in a wagon driven between the rows can drive the posts on either side to the desired depth. The wires are fastened to the posts by one and three-fourths or two inch staples, which are driven only part way in to allow the wire to be stretched tight. The first or bottom wire is placed two and one-half feet from the ground. Stretch

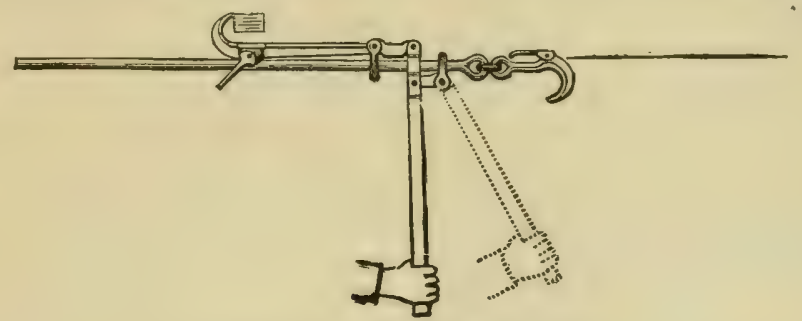

IMPROVED WIRE STRETCHER,

the wire with a contrivance made for this purpose. The second wire or top wire should be also two and one-half feet above the first wire, or where three wires are used, the second fifteen to eighteen inches above the first and the third the same distance from the second. The two wires will be found sufficient, although some prefer the third. The wires must be drawn as tightly as they will bear, so they cannot sag under the weight of the fruit. Number nine or eleven steel, annealed wire is generally used, which will stretch nineteen feet to the pound in the vineyard. The posts can be made to last much longer by painting the ends which go in the ground with Carbolineum Avenaris, a wood-preserving paint, which was invented by a prominent Grape grower on the Rhine and used with highly satisfactory results on vineyardposts, stakes, etc., and positively jrevents rot and decay below the ground or water. If the posts were set equally distant, beginning on the same line the vineyard will be divided into sections, and the space between the end posts in one section and the end posts in the adjoining section will leave a space for a roadway which will be convenient in gathering the crop. It is a part of every spring's work to drive the posts as soon as weather permits, to make the posts set firm. Tightening of the wires must be also seen to every spring.

\section{Third Year:}

The horizontal canes which have been cut back in the fall are tied to the lower wire. In tying vines to the wires, the string or whatever is used, should not be drawn tight but sufficient space given for the vines to grow. The tying up of Grapevines has been always an item of considerabie expense to the vineyardist. The enormous demand for tying material, and the fact that such material as is now in use is so perishable and expensive, makes it a point of consideration in saving a share of this outlay in Grape growing. Willows are used for the so-called first tying, which takes 
place in the spring before the vines begin to start. The prices of willows, however, have increased the past few years so enormously, on account of being used for other purposes to a greater extent, that other substitutes have been hunted up. Twine, wire, or trimmings of cotton goods have been tried to replace the willow, but the extra expense in the manipulation of tying has almost condemned these substitutes. The advisability of producing something better and cheaper than willows, and which could be more rapidly applied to the wire, has been introduced by the Rochester Radiator Company of Rochester, N. Y.

This holder is made from galvanized steel wire, which will hold vines ranging from one-fourth to five-eighths of an inch in diameter. When the vineyardist trains

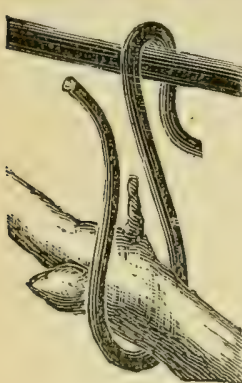

GRAPEVINE his vines, instead of leaving the remaining canes upon the ground to be tied up afterwards, can just as quickly loop the vine in to this device for holding it, taking but a moment to fasten the canes of a vine to the wire, thus saving an extra man to follow up the trimmer; an ordinary man can place the vines on the wire at the rate of five acres per day. Willows, as it is well known, can be used but once and a new lot has to be procured for another season's tying. These vineholders will save this expense, as once equipped they will last at least five years. The new canes at the next season's pruning can be easily placed on the wires. The cost of this labor, time and money saving device is less than the price of willows for one season, and taking into consideration that the HOLDER. holders will last for several years, they are much cheaper. Four of the devices are required for one vine, if pruned on the Renewal system, while eight will do for the Kuiffin system.

Fertilize and cultivate as directed for the second season. When the buds have well started train the shoots or laterals upright to the second wire, leaving only three

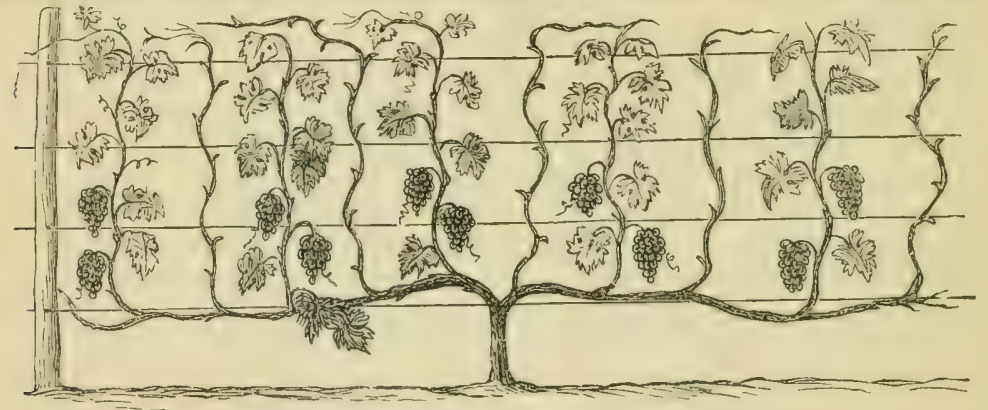

VINE BEARING FIRST CROP.

of the strongest on each cane to grow. Each of these shoots will bear three clusters, making eighteen clusters to the vine, about one-third of a full crop. The number of bunches which a vine will produce, may therefore be estimated with a considerable degree of accuracy in advance. The crop can be regulated to suit the capacity of each vine, as indicated by its vigor. If not vigorous the crop should be reduced by the entire removal of some of the laterals.

It is advisable to cut out some of the smaller clusters and let only the best ones remain this season, thus strengthening the vine and preventing injury by overbearing, which will insure a good crop the next year. Buds starting out from the vertical cane should all be rubbed off except the two strongest ones, which will be used for fruit canes This pruning just described is known as the "Renewal System," and 
mostly used in Western New York and Ohio. The different systems will be described in another chapter.

One of the greatest labor-saving tools ever invented for use in the culture of Grapes is the Morgan Grape hoe. After cultivating between the rows this hoe will

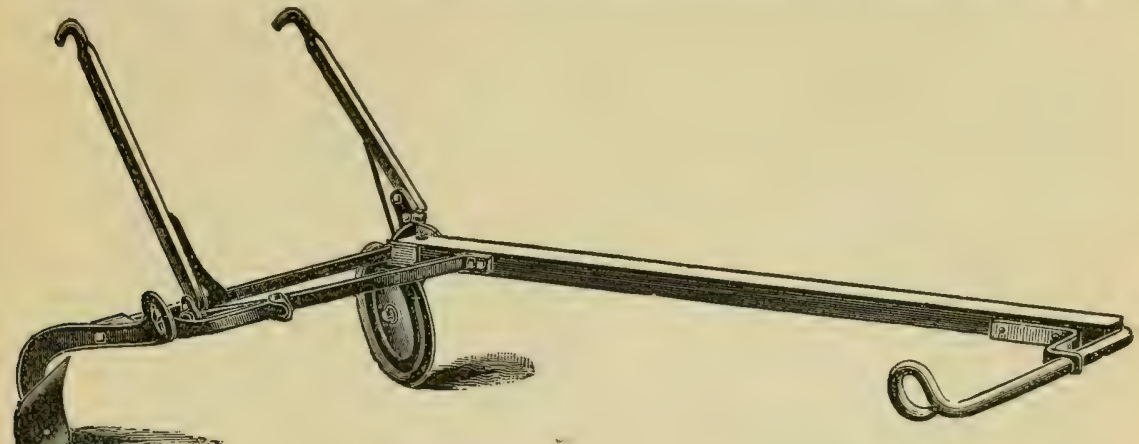

GRAPE HOE.

take out all grass and weeds that remain under the wires and around vines and posts and will stir the soil close to the vine. Without any careful attention to driving the hoe is guided in and out around post and vine by the disc castor wheel to which a handle is attached. The horse is hitched on one side of the pole, which gives plenty of room for the plow to work under the vines and without injury to them by horse or whiffletree. The saving of time and labor will soon pay the cost of this tool, for this work is usually done by hand-hoeing, a slow and expensive way.

\section{Fourth Year.}

If vines have strong and healthy growth the previous season an increased crop can be expected if everything is favorable. All the old bearing wood from last year should be cut out. The canes intended for fruiting can be allowed a larger number of buds, to increase the growth of laterals developing the clusters of Grapes. As soon as the laterals have attained sufficient growth, tie up carefully to the upper wire of the trellis, and pinch off the ends to throw the strength of the growth on the fruit. It will be well also to thin fruit by picking off the smallest and poorest bunches. Two tons per acre is expected to be a fair average crop and the less the number of clusters this weight can be put into, the more satisfactory will be the crop and the market returns for the same. The finest, best and largest fruit is produced upon the strongest shoots of the previous year's growth.

Cultivate and keep the vineyard clean from weeds and work into the soil during the season some wood ashes (about one-half ton per acre), which is very beneficial to Grapes, producing better quality.

At the end of this season we find that the vine is now fully established and consequently able to bear a full crop another season. The work to be done in the vineyard is precisely the same as last year, except that the fruit canes can be pruned now for a still larger crop.

\section{Selection of Varieties.}

Success in Grape culture requires that varieties should be selected which are especially adapted to the locality where they are grown, and that because a Grape does not succeed in one section, it is by no means certain that it may not be both 
successful and valuable in another to which it is fitted naturally. The area of adaptation is evidently much wider for some varieties than others. The matter of adaptation should be considered as one of the most important points by the practical Grape grower. Concord, Worden, Moore's Early, Diamond, Niagara, Lady Woodruff, Catawba, Delaware, U1ster and a few others are found more generally planted for vineyard use than any other variety. Catawba is for some sections too late, but if pleasant and sumny weather extends late into fall without unseasonable frosts or cold winds, the lighly flavored sweetness and refreshing sprightliness is obtained, which its origin and nature require. Grapes intended for wine making are not always goorl table or market Grapes. The planter must use his own judgment, based mostly on the success of varieties already growing in his vicinity.

The widely differing opinions which are expressed upon the character and value of our most popular Grapes seem almost unaccountable. Varieties have in some localities failed to justify the commendation which followed their introduction, while in other sections the same varieties are decidedly good and cannot, therefore be recommended for general culture.

\section{Imperfect Fertilization.}

Heavy rains at the time that Grapevines are in bloom are usually quite injurious. The nature of the injury is very strikingly exhibited by the cut of a cluster of Grapes made from nature. The juicy Grape berry encloses the seed, and its principal use in the economy of the plant is to protect the seed. The fertilization results in the growth of the pulp as well as the perfection and growth of the seeds which it surrounds. When heavy rains prevail at blooming time the pollen is in great part washed away and but a few ozules are fertilized; the bunches are straggling and loose, as here shown. Many of the berries however, grow to an unusally large size, since the vine has few of them to support. These large berries are shown in our engraving; the seeds in these, of which there are a full number, have been perfectly fertilized. Smaller berries in the cluster may be noticed, and these represent those that have but one or at most two seeds. The very small berries are entirely seedless. Brighton and Salem suffer most in this way, hecause their flowers are in the right condition if the anthers are ripe, and scatter the pollen at the time of a heavy rain. If for no other reason we should, on this account, have different varieties of Grapes that bloom at different times. 


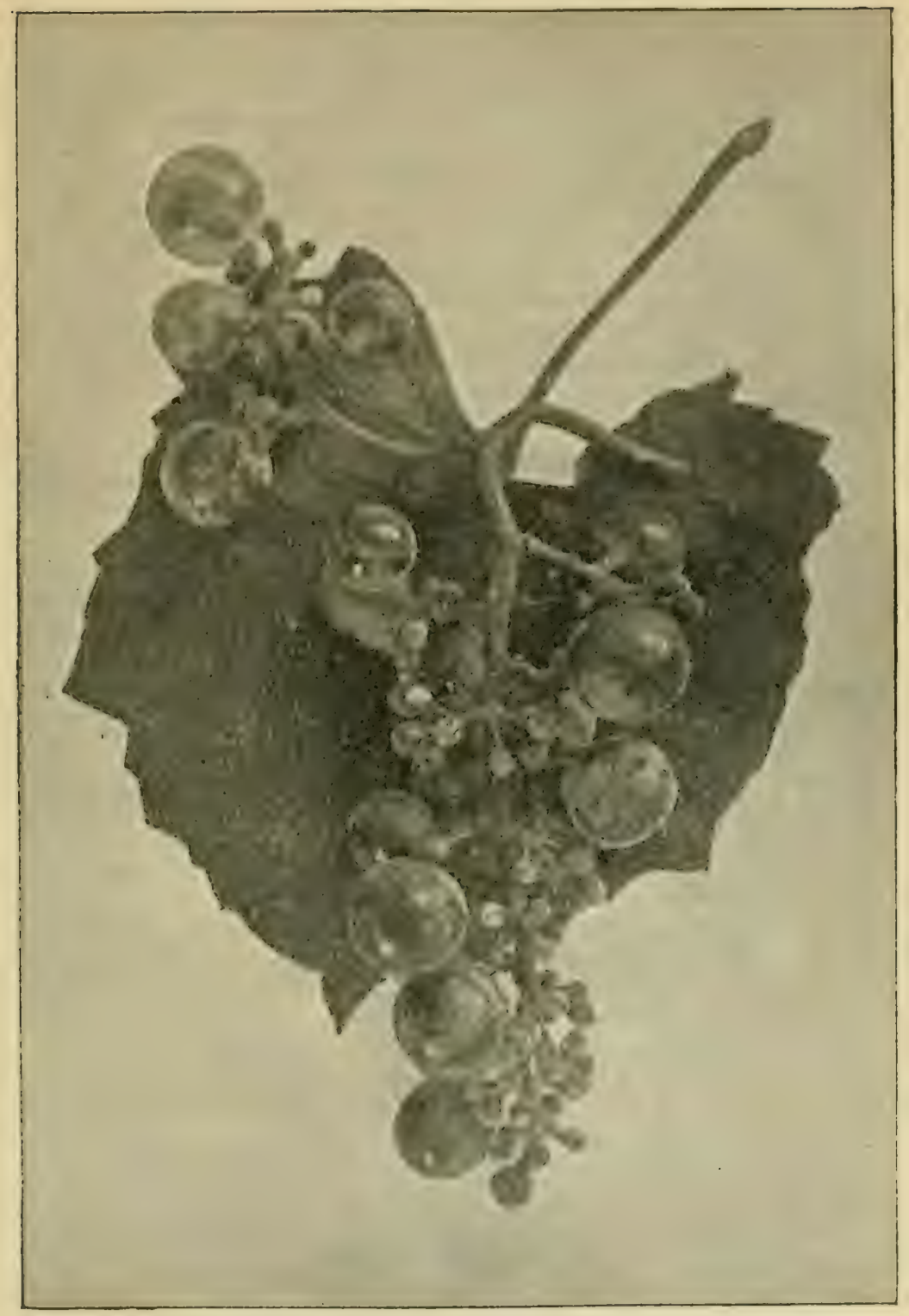

IMPERFECT FERTILIZED BUNCH OF GRAPES. 


\section{Grape Groming at Homme.}

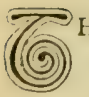

$\mathrm{HE}$ home garden furnishes a source of ever-increasing and uever-ending enjoyment. Good Grapes can be insured in the garden or elsewhere, in the near vicinity of the dwelling. This is a subject especially interesting to many residents in large towns and cities, where land is scarce and high, and the average tenant has a limited area of land at his disposel. Most garden soils are rich enough for Grapevines, but also should be dry and well drained; the location warm, sunny and airy. If near a building, choose the south and east sides; do not train on the building, but a few feet off, as t'sere is a better circulation of air. Plant in the spring and plant deep, not less than fifteen inches. Select vines graded as first-class, one or two years old, and, if possible, choose those having many fiberous roots. Cut the roots back to twelve or fifteen inches and the tops to eight inches. Cover the root with surface soil, not letting any fresh manure come in contact. After six or eight inches of soil has been put on the roots, a covering of unrotted manure will serve as a mulch, and, later on, as a fertilizer. Broken bones are excellent to put near the roots in planting, and after the vine is old enough to bear, pour round the roots the soapsuds from the kitchen.

The first two seasons after planting are given to growing new wood only, the first crop of fruit being horne the third season. The fruit of any one season comes from buds on the canes of the previons year's growth. This growth of the last season is the new wood, and all former growth is known as the old wood. Vines eight feet apart each way are pruned, so as to leave not more than five nor less than two canes of new wood for bearing, each cane two and one-half to three feet long. Two canes are sufficient for the first crop of fruit.

When planted, the vines should be cut back to two buds, both of which slould grow. After they are ahout a foot long, the most vigorons one should be tied up to a stake and the weaker one broken off. The next season the vine should be pruned back again to two buds. If hoth show great vigor, the two canes might safely be allowed to grow, but if not, grow only one cane during the second season. The third season the vine can be pruned back to about four buds, the two lower ones should be rubbed off, while the two upper buds, after starting to grow, will have more or less fruit.

A trellis is generally preferred to stakes for training the vines. When only two vines are grown, set a post seven feet long, two and one-half feet deep, two feet from this plant a vine, four feet from the vine set auother post, four feet from this another vine, and two feet from this the third post. To the post firmly nail three slats, each sixteen feet long by three inches wide, putting one slat at the top of the posts, one two fect from the ground, and the third between the others. When three or more rines are planted in each row, use No. 9 wire instead of slats, firmly bracing the end posts. A very simple summer house may be made by setting a post at each angle of an octagon, each sile of which is eight feet, and plant the vines midway between the posts. Vines can easily be trained to form an admirable screen, which, with proper annual pruning, will be for a life-time a thing of beauty and a source of profit.

For planting select early and hardy varieties, winter protection of the canes will not then he necessary. For black Grapes, Moore's Early, Worden, Concord; for red Grapes, Ulster, Wyoming, Deleware; and Diamond, Green Mountain and Duchess for white varieties. There are several fine later Grapes, but for the garden, try first the earliest sorts. If these succeed in all seasons, it is casy to add the later ones. 


\section{Pruning and Training.}

Q

INE PRUNING is a part of Grape culture that perhaps has a greater bearing upon its present and future success than any other portion of the work. It commences at the very time the vine is selected and before planting Vines when first received should be properly pruned, cutting the top back to one or two buds on the new wood, then all roots should be cut back short enough that each root will assume its natural downward position when planted, and not be bent up at the end or cramped. A vine may grow and look well for a time, if simply thrown down and partially covered, but a neglect to properly prune and place the roots when planting will be a failure in making a productive and lasting vineyard. The first pruning of a young vineyard should not be for fruit, but merely a shaping of the vines to form the future crown of the plant, leaving bnt one or two spears about the height fo form the crown.

The time to prune depends upon climate and location. In the far north, or where rines are laid down in the winter and covered, fall pruning is the best, for the wood is thus protected and ready for the early spring growth. In warmer climates, where vines are never injured by winter, pruning can be done any time before the vines show signs of life again, but it is more beneficial to the strength of the vine to prune as early as possible in the fall. Vines exposed to changes of climate and severe winters, spring pruning is the only safe policy, for the reason that vines cut in the fall are more liable to die back than when pruned in the spring, when the dead wood is easily detached.

There are several good systems of pruning and training, each of which has its merits and advocates. A simple method, and one largely practised, is known as the Renewal System, which has been described under vineyard planting.

\section{Kniffin System.}

At the close of the first year, after the leaves have fallen, cut the vine back to about three buds. The second year the vine will make a strong growth and the simplest and best form is to train the vine to one cane, the strongest always selected, until a little above the top wire and then pinch the end off, and to the many laterals

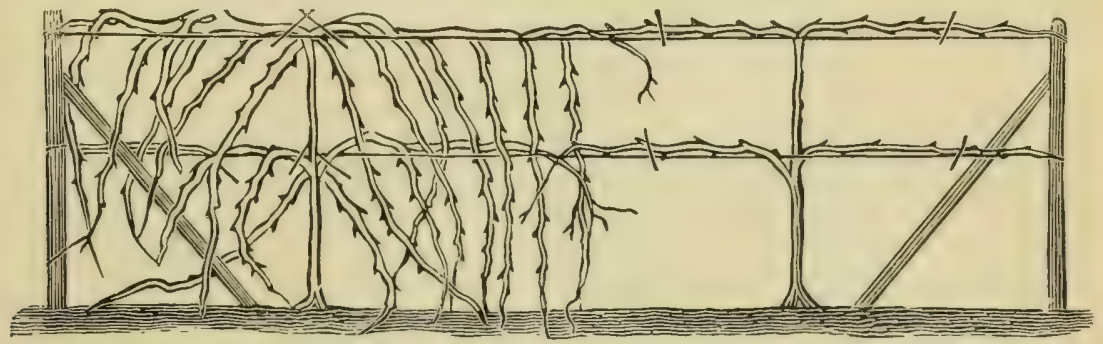

THE KNIFFIN SYSTEM SINGLE CANE.

or branches that will then put out on either side of the vine, save two, one on each side for the upper wire and the same for the lower wire and take off all the other laterals. At the close of the second year, when foliage has dropped, prune the hori- 
zontal canes on the two wires to three buds each for fruiting. The management at the end of the third year is a little different still.

The engraving shows the condition of the vine with its growth of wood from which has been taken a crop of fruit. The whole horizontal arms are pruned away each year after the third year, leaving a cane which comes out at the point, where the arm joins the main vine to replace the arm that is cut away and so on year after year, renewing the arm each year with the lateral allowed to grow for this purpose, tying it up in place to the old arm. Cut back to seven or eight buds according to the strength of the came. If the vine is extra strong two upright canes can be grown

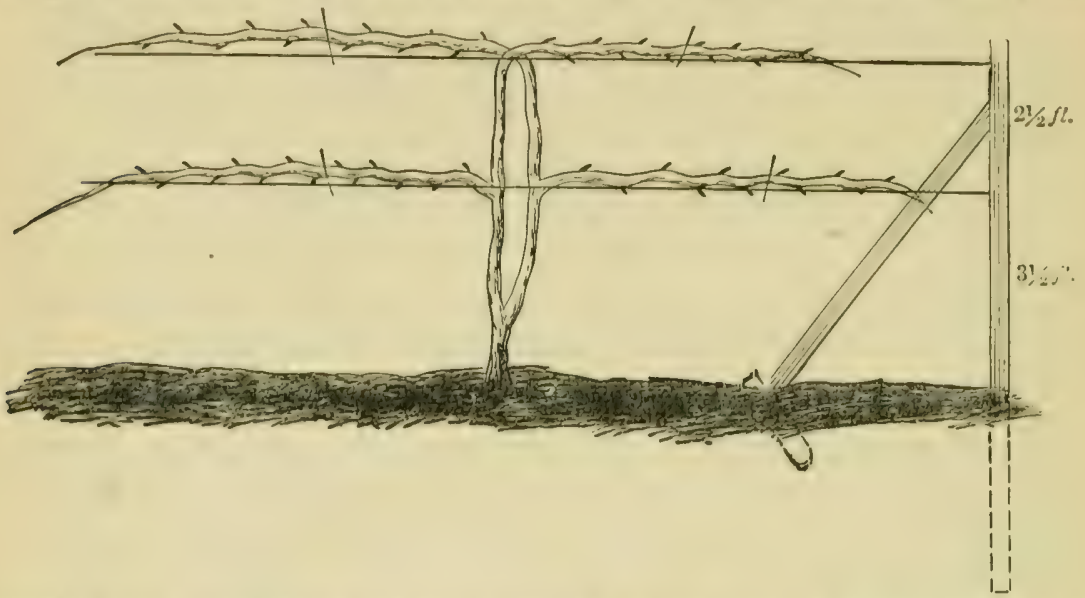

insteal of one. One having one arm to the left on the lower wire and one arm to the right on the lower wire and one arm to the left on the upper, both of which are on the Renewal plan.

I'requently will be seen two shoots come out of a fruit bud, one with two clusters and the other with three clusters. It is better to take out the one with the smallest clusters whether it be the one with two or the one with three clusters, and preserve the largest. The aim should be to grow nothing but prime clusters that will bring prime prices in market. It is better to destroy the poor clusters than offer them in market only to gain a bad reputation for both the Grape and the grower, which is sure to meet the following year.

\section{Fan System.}

This method of pruning and training vines is employed considerable in the Chautaugua region of Western New Vork. The first year, on planting the top is cut back to three or four buds. No other pruning is given this year. The second year cut back to five or six buds and when the new growth is about a foot long remove all but the three strongest sloots; these are to be grown for canes for fruit bearing the thirl year. The third year tic up two hest canes only, each three or four feet long. This year is the time for putting up the trellis on which three wires are nsed. The lower wire is fastencel two feet from the ground, the second wire three and one-half feet, and the third wire at the top of the post.

The fourth year from planting put up three or four canes, each three feet long. The fifth and each year thereafter, put up five canes of three feet each, or not to 
exceed forty-five buds, the canes being spread out like an opened fan. The position vill be somewhat as shown in the engraving, where the portion indicated by the letter 's" represents the permanent stock with three branches, and those parts markerl

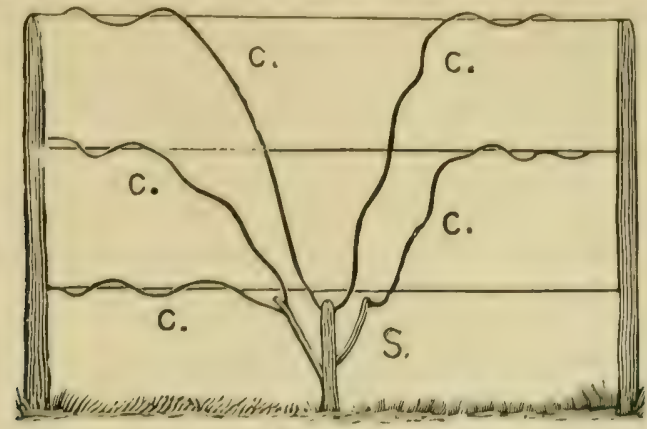

IAN SYSTEM.

" $C$ " the annual bearing canes. Only one or two canes are tied to the upper wire, the remainder heing tierl to the two lower wires. The olject is to get on all the sprace between the upper and lower wires, an even distribution of the new growth and of the fruit.

\section{Munson Alternate Renewal System.}

It is well demonstrated that American vines generally give best results when dhe bearing woorl is renewed alternately from one side of the vine to the other, and a few arms are foreserved wather than many short ones. This system is designed to accomplish this with the least expense as well as to form a slatling canopy for the roots, broly and fruit of the vine, and at the sane time put every thing in the most convenient shape and position for cultivation, pruning and harvesting.

Two No. I wires tightly stretched both at same height (five or six feet as preferred) from ground, parallel about two feet apart, supperted by and stapled on top of a pair of durable posts set in same hole, flaring apart at top, twenty-four feet, on three vines from the next pair of posts, make the best trellis for American vines. The illustration shows the arrangenent. For Delaware the vines should be eight feet apart; for Concorl, Niagara, etc., ten feet apart and the rows always cight feet apart. Cross pieces nailed to the single posts would be often knocked off in cultivation.

The trellis should be set as soon after the vincyarel is planted so that training may hegin with the first year's growth ( V I). When the plant is set tie a string (n) its tip) (which should be a stuh, the plant from the nursery having been cut back to four

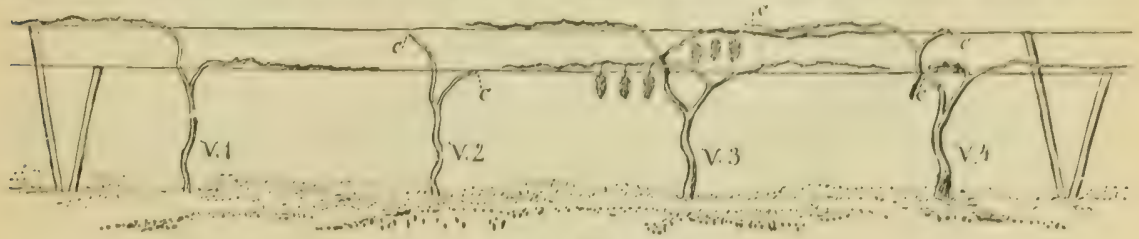

AI,TKRNATU, RUNLWAL。

or five eyes) and to the wires above. Train up this string. the only one strong cance that is to be allowerl to grow, to make the permanent borly of the vine for two or thre feet at least. When near the level of the wires pinch off the tip, and from the two 
upper buds shoots should be allowed to grow, one to be trained along one wire in one direction, the other along the other wire in the opposite direction. At the end of the first year when the viue is fully at rest and leaves off, prune as shown at V 2, C. C. The following spring allow each prong of the fork to push two arms only, occupying both wires in both directions and if strong the plant could be allowed to retain a few clusters on each of two prongs as shown in $\mathrm{V}_{3}$, as the first partial crop.

The two year old vine should be pruned in the fall, as shown at $\mathrm{V} 4, \mathrm{c}$, c, cutting back the alternate arm which bore the few clusters to one or two eyes each, and the other two arms to four, sis, eight or ten eyes, according to strength of plant to throw out and easily carry to maturity bearing arms which represents the first profitable crop at three years old. This three year old should be pruned in full, as shown at

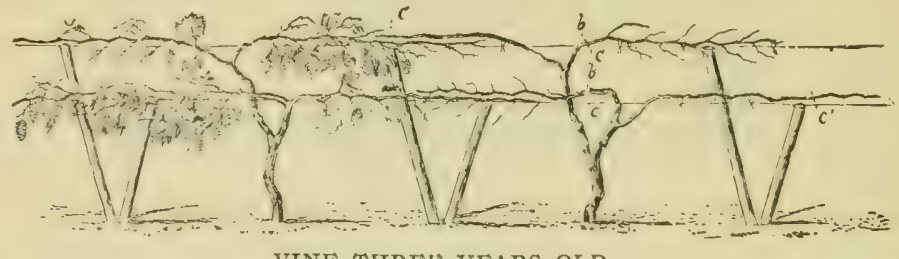

VINE THREE YEARS OLD.

e, e, d, d. The third year's process will be repeated annually, simply alternating the bearing arms, so as to maintain the balance of the vine, and to secure wood for bearing each successive year, that has not been produced by the sap passing through the wood which is bearing the crop.

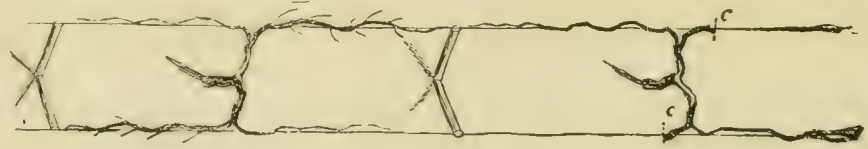

TOP VIEW OF THE TRELLIS AS SEEN FROM ABOVE.

There are many advantages to this system of pruning of which the most important ones are the following :

It presents less resistance to storms than vines trained one above another and hence less liable to be blown out of place; a perfect canopy of foliage is secured above the fruit, body and roots, preventing sun scald.

The work of pruning, tying, spraying for mildew, rot, \&c., harvesting, and of passing from row to row is rendered easiest and most convenient possible.

A free passing of air beneath the vine is allowed, thus preventing dampness and is almost an absolute preventive of black rot; as the vines stand erect free from contact with posts, there is no place for lodgment of winter spores about the bearing head of vine. When the wind blows there is a current of air under the vines which will catch the spores and develop most readily near the ground and in the shade and carry them along to drop on the ground or go on through the vineyard without reaching the fruit above, protected by the foliage from currents.

When it is desired to cultivate both ways, the posts should rise to six or seven feet. The system is easy to manage. Even a novice can prune after a minute's showing, and the prunings can be easily removed.

\section{Single Post System of Training.}

Grape culture simplified. While many professional and amateur Grape growers will condemn this single stake system of raising Grapes, yet they can be produced abundantly, cheaply and in a manner practical for farmers and others who may be 
somewhat horticulturally inclined. The vineyards on the Rhine are enormous, and are all laid out on the single post system. That being the great crop, it dare not fail, and every bit of labor pays.

Set a seven foot post two feet in the ground at planting time. Train the vine to this, cutting back at the end of the season to two buds. For the first couple of years do not expect fruit, but aim to get not less than four canes to start close to the ground. Train these to the post, cutting back each fall. Canes thus pruned after a year or two will bear some fruit, but later the fruit will come from buds borne on spurs (side shoots) on these.

Aim to have never less than four canes on each vine, each of which has thiee buds to five spurs which carry about three buds each when pruned. When the canes attain considerable size cut one out each season, allowing a new shoot from near the ground to take its place. Under this system the fruit will, much of it, be borne near the ground, an essential point, as such fruit ripens earlier and richer in flavor than that borne higher up.

Prune after leaf fall. At first there will only be four straight canes; later there will be spurs which trim back to two or three buds. By fall pruning the vine is so reduced in size that it is easily buried, if necessary. The tallest of the pruned canes should be no longer than the posts. In the summer, when all the canes have been confined to the posts, new rapidly growing shoots will spread out in all directions forming somewhat an umbrella-shaped top. Cut these new shoots off about four leaves below the last fruit cluster, keeping the vine in a compact mass near the post.

\section{The Caywood Overhead System.}

Posts eight feet high are set in the usual manner, the tops being spotted on one side upon which boards, five or six inches wide and three feet long are nailed, representing a cross. On the tops of these boards are stretched three wires, one on either end and one in the center. Plaut the vines close to posts and tie those planted between the posts directly to the wire. In this way the whole space between the vines is unobstructed for the passage of a team.

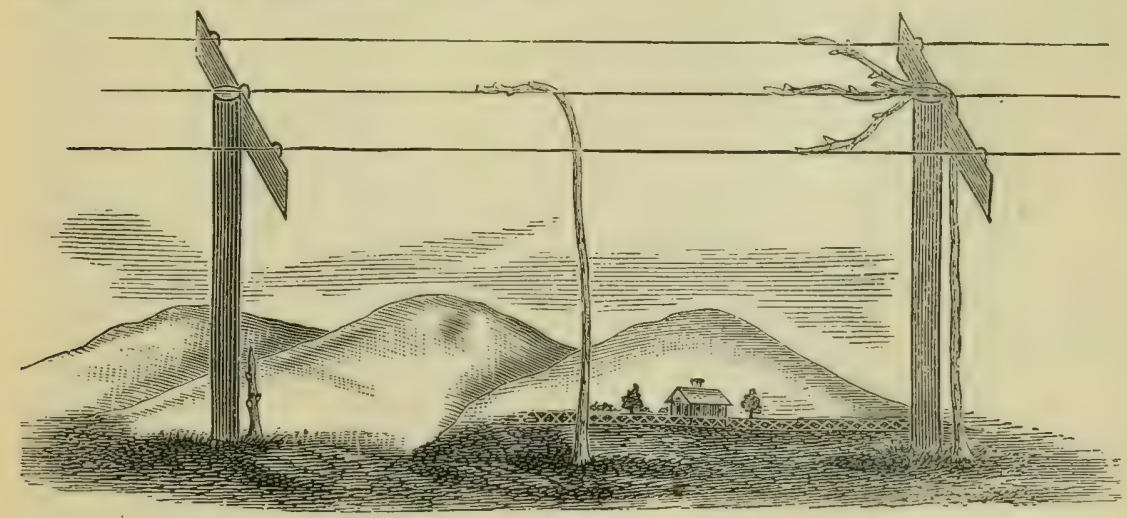

OVERHEAD SYSTEM-VINE PRUNED.

A long string can be used for the middle vine when small. Branches are trained off from the top of the main trunk, one over the upper side of each wire. These may be pruned in the fall to any desired length. The vines should all run in one direction to avoid tangling. But few branches will get off or hang from the sides of 


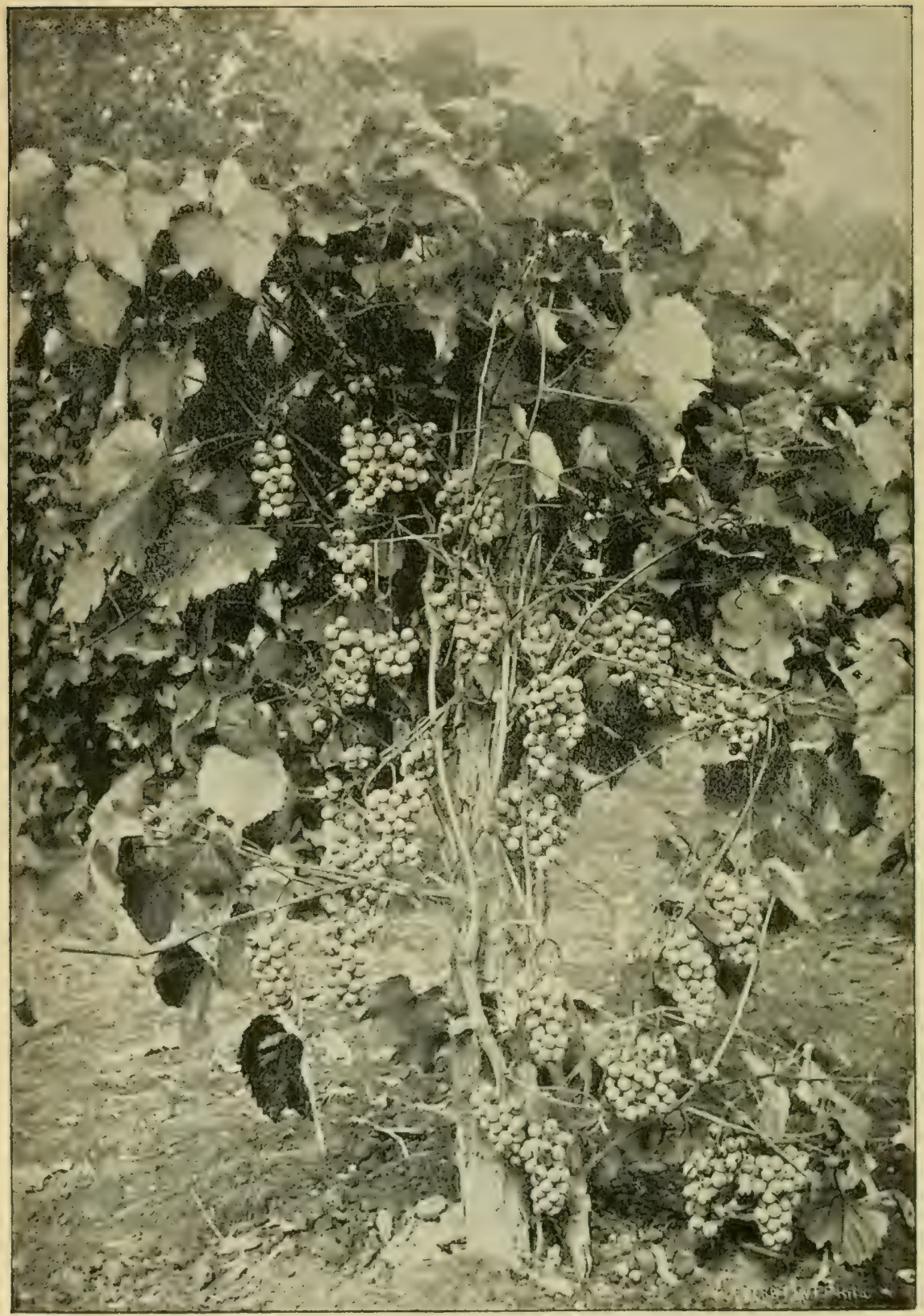

WORDEN ON SINGLE POST SYSTEM. 
this trellis, as the vines will cling to the nearest object and, if desired, these can he thrown over the top:

The clusters hang below the wire, not tangled with the wood and foliage, and in a free circulation of air, and dry off quickly in the morning, which protects the bloom and prevents rot.

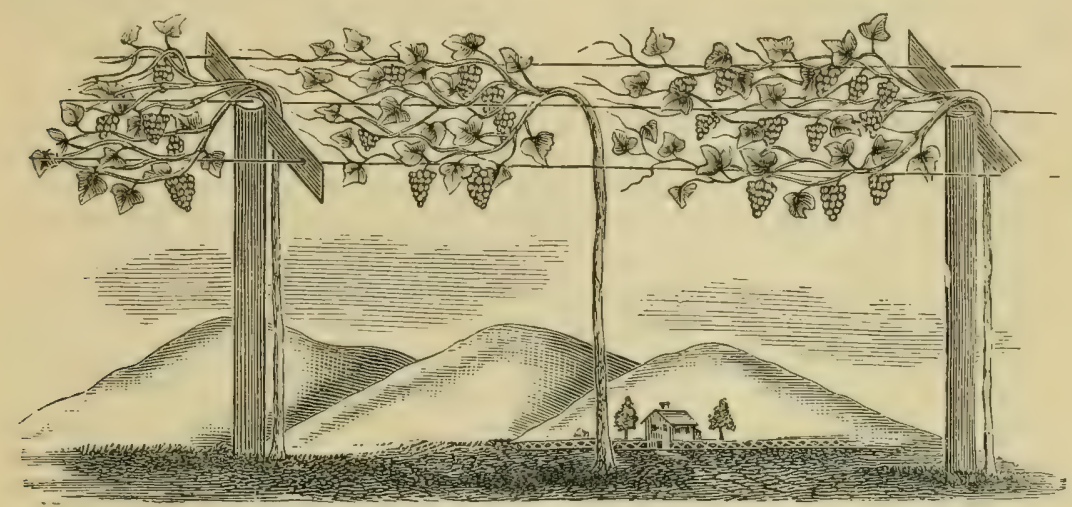

OVERHEAD SYSTEM-VINE IN FULI, BARING.

Birds seldom creep through the foliage to injure the Grapes. If the Grapes are not cut until after frost the foliage protects the stems from becoming weakened by it.

Either of the above mentioned systems of pruning have been used by Grape growers for many years, although the system of training the vine varies in some localities. In fact, it appears that there are as many different methods of training in practice as there are vineyardists. We will mention here the Spur system, Single Arm, Bow, Upright Canes with side spurs, Horizontal Branch system, etc.

Pruning, if possible, should be done in the fall and a new argument in favor of fall pruning comes from Wm. Saunders, the experienced experimental horticulturist of the National Department of Agriculture in Washington. The best time for winter pruning of Grapes is soon after the fall of the leaves and the sooner the better, for the reason that the buds will push with more vigor in the spring, will bear better fruit and will ripen somewhat earlier. This arises from the circumstances that the plant during winter continues to absorb more or less nutriment by its roots, which is distributed in the branches of wood. If, therefore, pruning is delayed until approach of spring this winter accumulation is largely destroyed and lost. When, however, the vine is pruned in the fall, the winter accumulation of increase will be deposited in the buds and parts left after pruning, and such buds will start vigorously, and in consequence of their better development, the fruit they show will be increased and the shoots will advance rapidly in growth and attain maturity sooner than those from weaker buds, as may be tested by comparative trials and close observation of results. This is certaiuly a very philosophical reason for pruning and will hold particularly good in mild winters, when there will naturally be more activity in the vine than in long and steady cold winters. It probably holds good in the Southern States, where the winters are far less severe than in the North.

\section{Summer Pruning.}

METHOD BY D S. MARVIN.

The manner of summer pruning, as usually performed, is to thin out all the shoots not needed as they start, then wait until after the vines have blossomed and the fruit set. As the canes are tied to the trellis, cut off the canes some two or thres 
inches above the last cluster of Grapes. This is the most important operation of the vineyard, and it has become so firmly fixed in the minds of the average vinedresser, that to question the value and correctness of the practice is treason, to be frowned down by the vast majority of vineyardists. This operation is, in fact, a crude and ruthless practice, that does not study or meet the conditions and wants of the plant. The object of pruning, is to grow fruit and preserve intact the health and energies of the vine, but neither of these objects is promoted by the old practice. More fruit may be grown by a different system of summer pruning, and higher health of the vine be conserved. The greatest danger that threatens this industry, is the insiduous attacks of the various sporadic diseases diuring the season of growth. This system of cutting and slashing the vine just at the most critical period of its annual development is mainly the cause of, and invites the attack of the several vine diseases known as black rot, anthracnose, etc. The vine, under natural conditions, is never summer pruned or its growth checked, but under cultivation it must be controlled, and this control must. therefore, come as much as possible, not at the critical season, but when the vine is dormant in fall and winter, and it follows that what summer prun ing must be done, should not be done in a rude way, but to prevent the least possible interference with the vine's natural growth and development. In doing this pruning, we must study the several organs of the viue and its economies, so as not to do violence to its vital functions. All the enormous activities of the vine are, and must be carried on through and by its leaves, or the foliage. There, then, is the vital point of the whole matter. Never rudely sever the canes or cut off the developed leaves or foliage of the vine, for the moment this is done, the vine's nervous energies and functions are disturbed, its health in danger, debility follows, and disease is invited, and if the weather be at all unpropitious, disaster comes on apace. The manner of pruning is the question. Pinch in only a half, or at most, an inch of the tips of the canes, and do this continuously until growth ceases, or the canes cease to lengthen. The time to begin pruning is before and vot after blossoming. Pinch off an inch of the end of the canes as soon as they have grown to either three, four, or five buds, and bear little clusters of Grapes, according to the strength of the vine, or the species, or variety operated upon. One species may develop but two clusters to a cane, another may grow five. A very weak vine should not be summer prumed at all. By this system of early pinching, the canes cease to lengthen and the energies of the vines are turned to the development of fruit instead of wood. The leaves are also enlarged at the point where large, vigorous leaves are needed to support and develop the fruit. and not alone are the leaves upon the main canes $\left.s^{\prime}\right)$ enlarged, but the laterals are forced out and their leaves enlarged, until there results abundance of well developed leaves, just at the proper places upon the vines, to insure the growth and maturity of the increased amount of fruit to be grown. Leaves at the end of long canes, instead of supporting the development of fruit, detract from it, and impoverish the supply of nutriment for the fruit. But if we wait and cut off a foot or two of the ends of the canes after blossoming is over, this supreme moment is forever lost, and the more we cut off the smaller the leaves at the important point of development near the fruit clusters. Then there is this further advantage by this system of early pruning. There is but a minute portion of the vine sacriticed and thrown away-an inch or two instead of a foot or two. No developed leaves sacrificed; all the strength and energies of the vine are thus maintained and turned to good account, and but little shock or check to future growth is given. and consequent weakening of health avoided. The vines are maintained in full and high health, ready to meet unpropitious after-conditions, surmount them and go into the autumn season to ripen an earlier and better developed crop of fruit. This system of clipping 
the ends of the canes is to be continued during the whole season, or until growth mainly ceases. Another important after-consideration, is the development of large fruit buds for the next season's operations, there being no waste, no shock, full sized and well developed canes, and fruit buds result as a matter of course. Furthermorc. the canes are always kept short, and at the fall or winter pruning season there are no immense piles of brush, in the shape of wasted energies, to be carried away from the vineyard and burned.

No other way of summer pruning the vine is at once so effectual, conserves health and brings out the force, energy and high development of bud and fruit as this pinching at the right time, and its continuance during active growth. The important idea always to be remembered, is to commence the nip and go process at the right moment, so as to throw the energies of the vine into fruit instead of wood production.

\section{Thinning Grapes.}

After a vine has been carefuily pruned, it will often be found profitable to thin out the fruit according to the strength and natural habits of the variety. Some kinds habitually produce more clusters than the vines can mature, and if all are left, many imperfect bunches, many small, unripe berries with much immatured wood and feeble vines will be found at the end of the season. The present crop is poor, and with the same treatment, the next one will be poorer still. A continuance of this treatment with some varieties will kill the vines, or render them worthless. From one-third to one-half of the fruit may, with advantage, be taken from very productive varieties by thinning, and the earlier it is done, after the Grapes are out of bloom and clusters are formed, the better. First, all the small and imperfect clusters should be cut out; then those which are crowded should be partly removed, and all weak shoots, leaving but one bud to mature. This is especially advisable when the Grapes are bagged, to protect them from rot or the depredation of birds. By this treatment, leaving only the largest and funest clusters evenly distributed upon the vine, the Grapes will ripen perfectly with their highest flavor; the vines will mature their wood for next season's bearing, and the crop will, in most cases, be worth twice as much as if all had been left without thinning. In picking Grapes for market, all the unthinned fruit has to be picked and handlerl. It is cheaper to thin and drop it, than it is to gather it all and then to cull and handle all over again. It is less labor to thin fruit than it is not to thin it, and it is not lalf the labor that you may imagine.

\section{Grafting the Grape.}

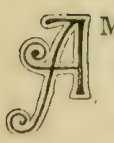

MONG the general advantages of grafting the Grape is the facility of increasing new and rare sorts by grafting on old stock; the short time required to test the fruit of new sorts, vines so worked bearing a full crop the second year; the ease with which sorts not readily reproduced by cuttings are made to grow when grafted; the ability to retop a worthless stock with a valuable variety, and to bring about increased fruitfulness by grafting on appropriate stocks those sorts that are shy bearers on their own roots. More or less grafting is resorted to every year caused in all probability by the unreliability and worthlessness of so many 
varieties of Grapes that have been recommended and planted. People do not wish to lose all their time, money and labor, if there is any successful way of changing them to better sorts. This can be done with little loss of time, money or labor, compared with the alternative of destroying them and setting out a new vineyard.

The modes or methods of grafting are various both above and below the surface of the ground, and are known by the name of "cleft," "whip," or "splice," etc.

To do grafting successfully the following important conditions must be considered :

THE STOCK INTENDED TO BE GRAFTED ON. It is not necessary that the stock and scion belong to the same class, but it is important that the stock be perfectly healthy and vigorous.

THE SCION. Considerable depends upon the selection of good grafting wood. The wood must be as fresh and green as when taken off the vines, and should not be less than the size of a lead pencil and well matured. The scion must be cut at least six or eight inches long, and it is better to have two buds, for if one does not grow the other may. The best time to select grafting wood is when pruning ; the wood can be cut in lengths of two, three or four grafts; tie in small bundles and store away in damp moss.

THE TIME WHEN TO GRAFT. The time depends upon location, but as a general rule should be done before the sap begins to flow, or vines bleed. Whenever the mean temperature is fifty-two degrees and remains at that for ten days or so, the vines will begin to bleed and as soon as it falls again for a week to forty-two degrees or below, they stop bleeding. This condition takes place every spring and it is about the best time to do the work.

The tools required for grafting are a good sharp shoemaker's knife, a light mallet, fine saw, pruning shears and a ball of grocer's wrapping twine. These are generally put in a basket with the scions.

\section{Grape Layer Grafting.}

This is another way of grafting an old vineyard over with better varieties, which may be more successful with those of little experience in root grafting. If it is desired to change all or a part of a vineyard at one time the vines should be pruned very short, or if the vineyard is entirely worthless it is much better to take an axe and cut the vines off close to the groudd. The object of this short pruning or in cutting off the vines is to get new strong canes for both layering and grafting, as both are done at the same time. The layering of the cane is done as soon as it is grafted. If the right kind of canes for layering and grafting are to be had readily it is not necessary to prune short or cut off, but to go to work at once grafting and lavering. The time or season to do this grafting is the same as in other grafting. Select two good strong canes from each vine and dig a trench, exactly the same as for layering. on each side of the vine for a distance of three or four feet from it each way. If the vines are six or eight feet apart and one cane layered each way half the distance there would be two in the same place. This makes no difference for it would be better to graft two vines and have too many than not to have enough, for some will not grow however expert one may be, and if too many, one may be taken up and planted somewhere else.

When commencing to graft, lay the cane down in the trench and bring it up within about eight inches of the surface of the ground and work it there so that it may be known exactly where to insert the graft. Be particular and have the bend in the cane where it is brought up below the graft, or the graft may be misplaced in bending it too close to where it is inserted. This is a very important matter to insure 
success. 'To graft the cane cut it off just where marked (G); slope off oue side about an inch and a half long to a thin edge and cut a tongue in it about one inch and a quarter deep, as done in whip grafting. Then strip off the outside bark of the cane from the end about six or eight inches, so the bend of the cane will be where the

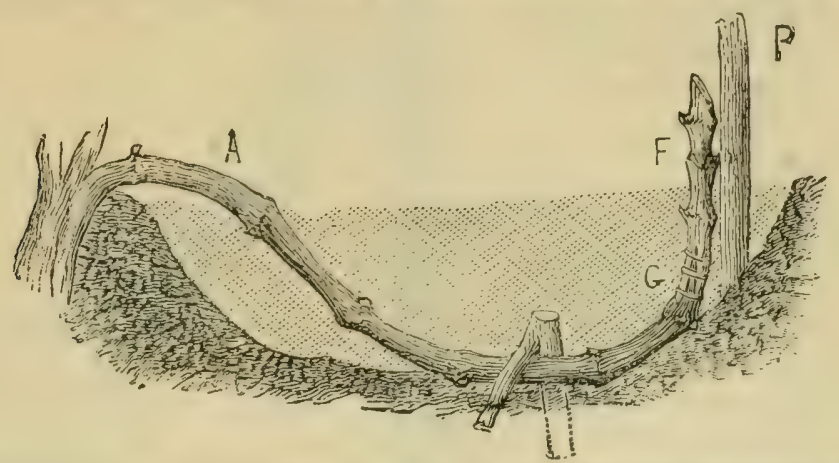

bark is taken off. This is for the purpose of making the graft take soon as well as to make the cane or layer strike roots quicker and better. Then take a good strong graft with no less than two eyes (F), about eight inches long, slope and tongue it exactly like the cane, take the bark off up as high as where inserted. Match and place the tongues within each other firmly so that they match exactly on one side at least, or both as the case may be, then wrap with waxed threads or grocer's twine to keep the grafts in place until put in the trench or until united. This grafting is done befure the cane is layered down to its place at once, for the sooner it is done the better. In layering it down press the ground firmly at the bend and around the graft. The upper bud should be about level with the surface and marked with a stake (P), to tie it to when growing. Whenever the work is fiuished. or before, cut away all other canes that are left and as often as they start out from the old vine to throw all the strength of growth into the grafts. After the layers are well rooted, which will be after the second year, the old vine may be dug out and a new and better vineyard is established.

\section{Whip Grafting.}

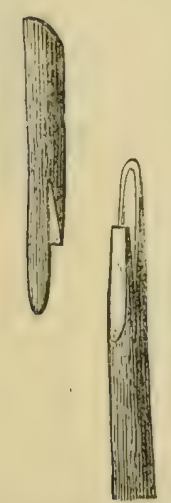

SCION AND

This operation is not at all difficult, but in order to perform it easily, it requires a very sharp kuife, ground to a fine edge. The grafts or scions should be about six inches long. By the same method any surplus stock of vines may be changed into other and more desirable varieties. This is often a great advantage, for if they could not be sold or planted they would have to be destroyed. This method of grafting may be done upon young seedling Grapes, one or two years old. It can be performed in the house from February until time to set them out in the spring, provided there are stocks and grafts on hand to do it. The grafts when put together should be wrapped with waxed cotton warp and when finished packed away in a cool cellar until time of setting out. They will make good strong plants the first year, GRAFT. much better than can be grown from cuttings and layers.

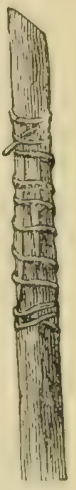

JOINTTED GRAFTS. 
The grafts should be as nearly as possible corresponding in size or thickness with the stock and with two eyes. In preparing split and cut precisely the grafts in the same manner as the stock, except only that the cleft and level will be at the lower extremity instead of at the upper.

The scion as well as the stock should be cut as shown in the engraving, by means of a very sharp knife and also sit in to the depth of one inch and a half to three inches, according to the size of the stock to be grafted. The joining of the graft and stock is an easy matter, but care should be taken that the union is perfect at least on one side. After this tie the new made graft with string or with Raffia, which lately has been used considerable by nurserymen for budding and grafting. Take off the outside bark in whip grafting, the same as should be done in all other Grape grafting.

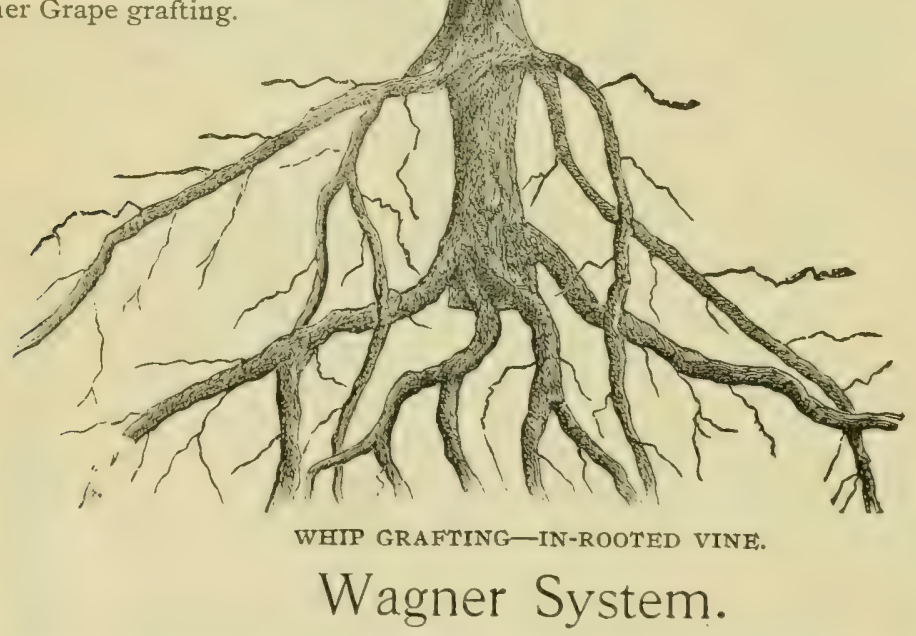

A very successful method on cld or good sized vines which have been productive of sure and best results, is performed considerable in some sections of New York and involves the use of the Wagner grafting saw. This grafting consists of sawing a 
notch or slot for the scion in the stock after it has been smoothly taken off several

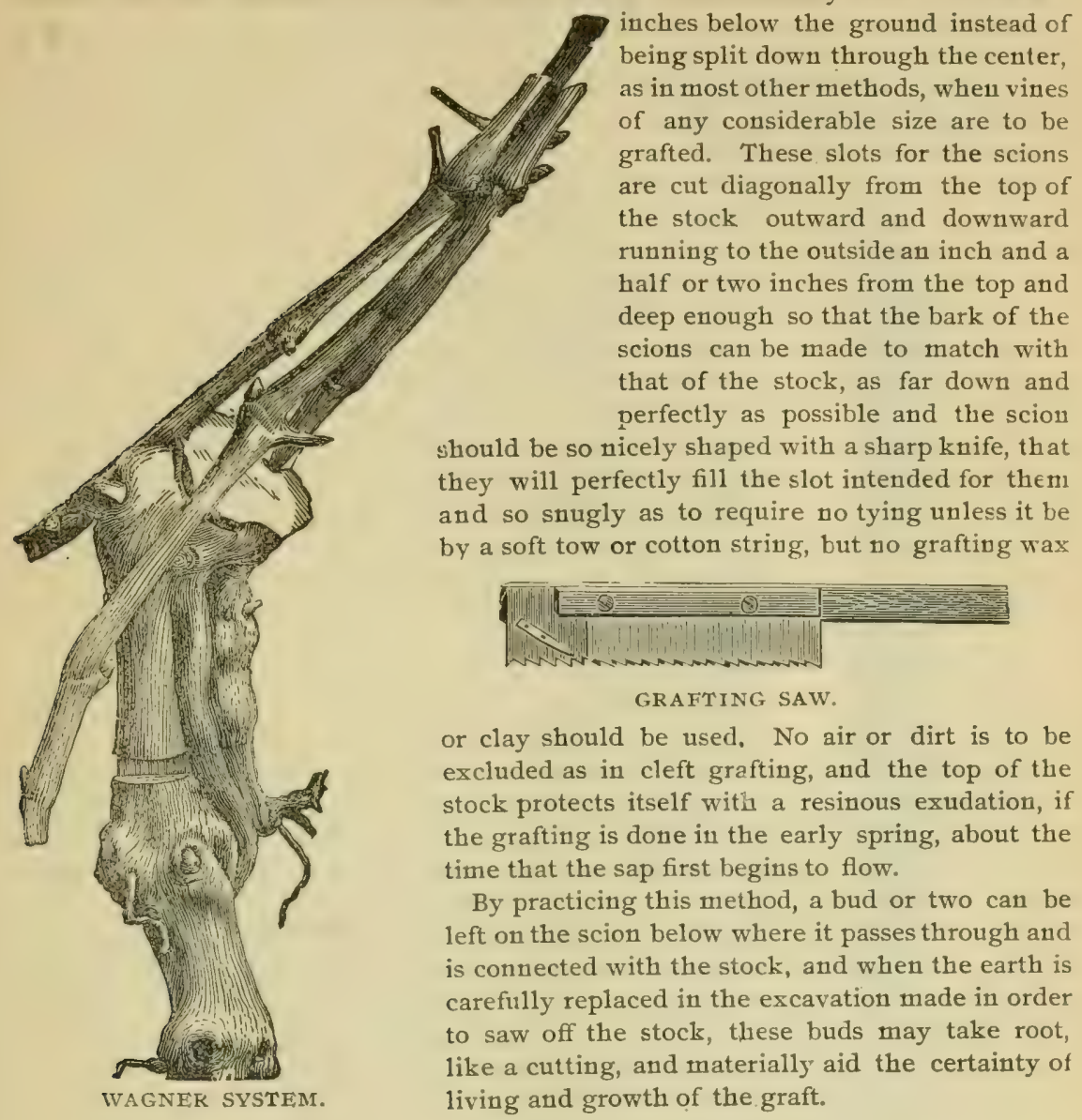




\section{Cleft Grafting.}

Dig out with a spade the ground all around the vines down to a point below the first tier of roots, about eight inches deep. In spading down no attention is neces. sary to be paicl to the surface roots as they must be all cut away to get down to a clean

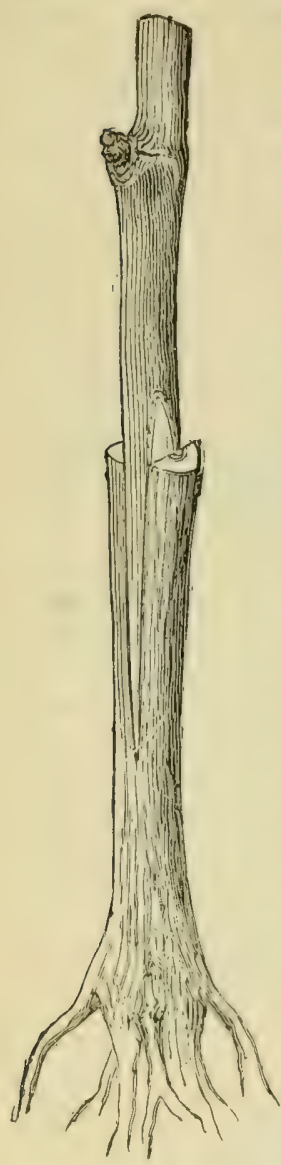

VINE WITH SINGLE GRAFT. spot to graft. The helper should not go too far ahead of the grafter, as the stocks should not be exposed too long to the sun in the open condition. If the stock is not more than half or three-quarters of an inch through, cut it off with the pruning shears, but if larger saw it off about six or seven inches below the surface. Take off the outside bark, select the most favorable side and cut a slope on the side about one inch and a hall long, and about one fourth of an inch deep at the top. The length and depth of this slope depends to some extent upon the size of the stock. Set the knife about one-eighth of an inch from the top of the slope and drive it down with the mallet about one inch and a quarter or more deep to form a tongue in the stock. The knife must be set exactly, or it will cut too shallow or too deep, but a little practice will soon determine the matter. If it is cut too deep the tongue will be stiff and unyielding, and if too shallow it will be too flimsy to hold the graft. If the stock is three-quarters of an inch or more in diameter, insert two grafts, one on each side. but if less, one stout graft will be sufficient. Cut the scions long enough that the upper bud will be just about above the level of the ground or a little above, but never under the surface. Slope the grafts on one side only, about one inch and a half long, to a thin edge below. Take the outside bark off from the grafts up as high as the slope. The bark is taken off the stock in grafting, not only for the purpose of seeing that the grafts fit and are properly adjusted, but also that the damp soil may come in contact with the inner bark so that callus may soon form as well as keep the graft alive until united or roots are thrown out to support it. Then cut a tongue in the graft about an inch and a quarter deep, the outside of which should be a little larger than the inside to make a neat fit. When inserting the grafts they cannot be made to match the stock at every part of the slope, in fact, pay no attention to that, but find the place where they do and push them down tight and firm. Then as precaution against moving, wrap a string around to keep the grafts in place, while working about them.

Fill in first a little good soil below, and pack it down firmly around the graft with the hands. Then add sufficient soil to about half fill the hole and tramp carefully around the graft to make it firm. Finally, level it with the surface and put a stake to mark the place as well as to tie the grafts to when they grow. A union will generally be made in the course of three or four weeks, which will be further consolidated during the following month.

The grafts should be carefully examined the first summer about once a month. It frequently happens that the buds of the grafts swell rapidly within a few days after the operation, and then, after having given great promise for a week or two, 
they turn brown, and apparently die off. Do not let this discourage you too quickly, and above all, make no rash examinations of the cause of this seeming failure, by pulling out the scion or otherwise loosening it. A graft will often remain in this state for a period of five or six weeks, and then start up all at once with a vigor that

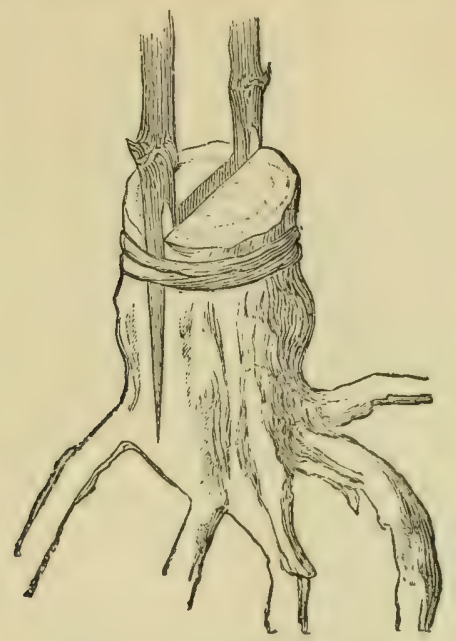

VINE WITH TWO GRAFTS,

will push young wood to the length of ten or more feet the same season. Keep the young growt. 1 well tied up, and carefully remove all suckers from the parent stock as soon as they appear. It is also well to protect the grafted joint the first winter by a slight covering of straw or coarse manure, to keep the frost from splitting it apart.

\section{A New Method of Grafting}

has been successfully operated in Kansas on stock one-half and three-quarter inch in diameter. A slit is cut upwards (b), and a similar one downwards (a), in the stock at

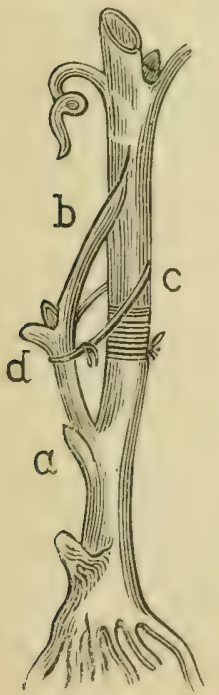
any convenient height above the ground between two well-formed joints ; wrap a string tightly around the cane at this joint. This tieing will, as in girdling, prevent the return sap. Select from the graft one with a bow like bent (d), which keeps it tightly in place, and cut it wedged shaped on both ends. Insert the grafts carefully so that the bark of both is in contact and secure it with a string bound around the scion and stock (c), sufficiently tight to force and keep the ends of the scion in the cuts. The bud will begin to grow in a short time and all the growing shoots not belonging to the graft should be removed. During the summex all the wood above the upper insertion can be cut off and in the fall or when winter pruning is done, all the wood above the lower cut should be removed, thus leaving only the wood grown from the scion.

There are several other ways of grafting the Grapevine, but few are of any use to the grape grower. The above described methods are the best and the most practiced.

It is also unnecessary to speak of the many machives and tools lately introduced for grafting. A good pruning knife is the tool most in use, and quite satisfactory in skilled hands. 


\section{Girding.}

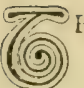

HE practice of girdling the Grapevine to hasten the time of ripening of late varieties, has attracted much attention during the past few years, and has led to the statement by some prominent Grape growers that the increased size of the fruit was at the expense of quality.

Nearly one hundred and fifty years ago experiments were made in France in girdling of Grapevines for the purpose of its influence on the fruit. Girdling consists in removing below the lowest fruit bud a ring of bark a half inch in width, using as a tool the small blade of a jack- $\mathrm{knife}$. By this removal of the bark the downward or return flow of sap after it has been assimilated by the leaves, is checked at the point of bark-denuded wood. This operation should be performed as soon as the clusters have formed and the berries get to be the size of buckshot. Instead or removing the bark two copper wires can be fastened on the cane, placing them from one-half to three-quarters of an inch apart. Careful experiments in girdling have been made and it was found that the fertility of the size of the berries and bunches was considerably increased. The quantity of the juice in the fruit was also of larger percentage, and for wine-making purposes it adds to the saccharene properties of the must and therefore improves the quality of the wine. There is no doubt that it causes the fruit to ripen earlier and helps late varieties to mature before frosts will be injurious.

In ripening later varieties earlier it gives us more scope. The drawbacks are in a wet season, that a loss of from twenty to forty per cent. of the berries by cracking open will occur, and also the production of berries too soft to bear shipping. Both of these drawbacks would be lessened in a dry season. A gain of ten days in the ripening would make a great differeuce in the market price of Grapes, the increased size of the fruit would make it very attractive and more than make up for the softness of the berry.

Dr. J. Fisher of Fitchburg, Mass, has made several experiments in the girdling of the Grapevine. In a vineyard he girdled sixty Concord Grapevines, one arm of each, leaving the other in natural condition. He girdled the same on July 5 , by taking out a ring of bark half an inch long, near the trunk of the vine. It was curious to look at the row the midule of September; on the girdled half the Grapes were in fit condition to pick for market, the single Grapes being almost as large as the Hamburgs in a cold grapery. The others were just beginning to turn and not picked until the first of October.

The two important elements in the Grape are sugar and water. In the girdled vines the portion of water was a little over seventy-six per cent., while in the ungirdled vines it was eighty-one and a fraction per cent. An increase of nearly two per cent. in sugar took place between the girdled and ungirdled vines. It is not advisable to girdle the same vines every year as it seems impossible to long continue the operation without injury to the riperring of the vine. After one season's girdling the vines should be allowed a year in which to recover through generous feeding and entire ahstivence from fruit. Girdling is a complete draft upon the future without prospect of means to pay it through the gains of the present. After several years of experimenting it is still a question whether in the end it will not serionsly affect the vigo: of the vine. 


\section{Fertilizers.}

( $T$ is true, that nothing pays worse than poor crops upon large areas, of which the cultivation cost just as much as if it were yielding large returns. Whether fertilizing will pay or not, depends entirely upon the particular requirement of the soil. Vineyards which are expected to last from twenty to forty years, require special attention, in order to keep up the fertility of the soil. To fertilize properly, it is necessary to know first of all what ingredients are chiefly drawn upon by the crop sold off the land; secondly, which of these ingredients are so abundantly present in the soil to render their replacement unnecessary for the present, at least. The three most valuable materials in fertilizers, are Potash, Phosphoric Acid and available Nitrogen, the elements of plant food.

Plants receive their food first from the atmosphere, and second from the soil. The atmosphere supplies by far the greater quantity. This supply is always furnished to the plants in abundance, and, therefore, we need not concern ourselves about it when studying how to supply plant food. The food, however, furnished by the soil has received a great deal of attention. It is well known that plants do not thrive on all soils, sometimes because the soil is incapable of giving to the plant the quantity of food it requires for full development, or the kind of food it needs, or both. Generally speaking, a worn soil is deficient in Potash, Nitrogen or Phosphoric Acid, or any two or all three of these ingredients. A plant cannot be made to grow and develop if any one of these is absent. For this reason commercial fertilizers are manufactured and sold for the porpose of supplying Potash, Phosphoric Acid and Nitrogen

COMMERCIAL FERTILIZERS have become a necessity. The value of these depends mostly upon the fertilizing elements. So extensive is the use of these articles, and so important the testing of their composition, that a large number of states have laws requiring the official inspection of commercial fertilizers. The inspection and analysis are made, in some states, by the Experimental Stations, and in others by State Officers appointed for the purpose. In some cases the Stations simply make the analysis called for by the law, while in others the Stations collect the samples of fertilizers, make the analysis, publish the results, and if necessary, prosecute the parties who violate the laws, by either selling fertilizers without statement of composition, or selling articles which do not come up to the composition stated. The official inspection, publication of analysis, prosecutions where called for, are included in what is commonly called "Fertilizer Control." Inferior goods have been sold in the past, and purchasers have not known how to distinguish between the good and the bad. Some of the fertilizers in the market were absolutely fraudulent; others were of the best quality and sold at very reasonahle prices. Buyers should make use of the information offered them by this law, know what they buy, and be able to judge of its commercial value. In making fertilizers, various substances are used to furnish the ingredients.

NJTROGEN is supplied either in form of Nitrate of Soda, which contains about sixteen per cent. of Nitrogen, or

SULPHATE OF AMMONIA, which contains some twenty per cent. of Nitrogen ; or 
ORGANIC NITROGEN, from dried blood, bones, fish, fish scrap, cotton seed meal or other vegetable products rich in Nitrogen. These organic substances contain from seven to sixteen per cent. of Nitrogen.

Nitrogen is the most expensive element in fertilizers, and also the element soonest exhausted in soil. If the Nitrogen, which is found in nature in large quantities, could he appropriated by plants as food, there would be no need in seeking this element in commercial fertilizers, but most plants are incapable of taking up free Nitrogen of the atmosphere as a food.

PHOSPHORIC ACID is next in importance, as a plant food. All cultivated soils contain more or less Phosphoric Acid, but it is generally more deficient than most other forms of plant food. There are many sources from which the Phosphoric Acid is obtained for fertilizers, such as Bone Meal, which also contains Nitrogen, Bone Black.

When bones are heated in iron cylinders, into which air is not allowed to enter, gas, water, oily matters and other products are driven off, while bone charcoal is left in the cylinders. This product is used to take the coloring out of raw sugars. After a time it becomes worthless for this purpose, when it is sold to the manufacturers of fertilizers, as all the Lime-Phosphate still remains. The decomposition of Bone black in the soil goes on slowly, and therefore it is not generally applied as such, except after a treatment with Sulphuric Acid. The chief sources of Phosphate of Lime are the Phosphate rocks, which are found in large beds in North and South Carolina, Florida and Alabama. The South Carolina Rock is pulverized and sold under the name of Floats. This becomes more quickly of use than ground bone, but a still greater solubility is attained by dissolving it in Sulphuric Acid, called Super-Phosphate, or known in the markets as Acid Phosphate.

POTASH rauks next to Phosphorous as a valuable food for plants. Plants consume this element in comparatively large quantities, and some soils are unable to supply the demand. especially is this the case with light, sandy soils. Potash is found largely in the ashes of plants, and constitutes one of the chief sources of food supplied by wood ashes. Potash in ashes in very easily dissolved in water. Other sources of Potash, as generally found in fertilizers, are Sulphate of Potash, Muriate of Potash, Kainit and Sylvauite, Cotton Seed hull ashes made at the oil mills. The first named are imported from Germany, where they are mined in great abundance.

The cost of fertilizers are estimated from the essential ingredients contained therein, or in other words, the commercial value, at which the fertilizers can be put on the market. In all manufactured fertilizers there is a certain percentage of inert matter, but only the plant food elements Potash, Phosphoric Acid and Nitrogen are guaranteed by the manufacturer of fertilizers.

Grapevines differ from ordinary farm crops and have to withstand the storms, ice and snow of winter as well as the heat of summer. The Grape likes a soil very rich in nutritious substances. The lealthy growth and capacity for production of the vine appears to be promoted by the lower layers of the vineyard soil. If made particularly rich in soluble nutriment, that the rootsmay reach down to these layers, they will be well nourished and more powerfully developed. A large quantity of nutritious substances will, however, only penetrate to the lower layers, and a superabundant amount of such substances must be used, if the vineyard is to be brought to a healthy condition, and yield large proceeds. The condition and quality of soil differ largely in different localities, but it may be safely observed and relierl upon, that the lower and damper the situation of the rineyard is, the more must the use of Nitrogen be diminished; while the higher and drier it lies, the more the Phosphoric Acid and Potash must be supported by Nitrogen. A healthy and vigorous development should 
be promoted in young vines to encourage them to attain maturity early in the season, that the wood may ripen thoroughiy and bear the winter well. For this object Nitrogen may be administered in the form of Soda, which acts speedily, adding also some Phosphoric Acid.

An analysis of the ash of Grapewood shows a very large percentage of Potash and Phosphoric Acid, and therefore it is necessary to apply a large amount of these two elements. The effect of these is to produce a rapid, early growth and with the addition of Nitrogen mature and ripen the fruit.

\section{Manure.}

It is a stated fact, that even the richest soil, after a while decreases steadily in fertility ; the ground becomes worn out, exhausted, unable to respond to the demands made upon it. To raise paying crops, without artificial fertilization, is possible only where stable manure of the best quality can be offered in abundant quantities. In our common language, manure usually refers to the droppings of domestic animals united with a greater or less proportion of straw or other litter. It is exceedingly variable in its composition and nature, depending upon the kind of animal from which obtained, the nature of food, the protection of weather, etc.

Of the food consumed by animals, but a very small proportion of these parts is retained, which are the most valuable in manures, namely, the Nitrogen, Phosphoric Acid and Potash. They use Phosphoric Acid in the shape of Phosphate of Lime to make their bones and Nitrogen in making flesh. Of the most important part, the Nitrogen, a considerable amount generally is found in the Urine. It is, therefore, advisable to save the Urine, which is the soluble part of manure and the most valuable, so that when exposed to rains it is readily washed away. It is almost needless to say, that it is poor economy to allow such waste to occur, when it may be prevented by a little thought and care.

It is practically impossible to determine the worth of manure. Complicated as the manure question is, it is of vital importance to the Grape grower. Upon the right management depends success or failure. The wide awake vineyardist does not hesitate to apply all the fertilizers necessary to the production of a large and fully developed crop. Grapevines require food, like animals and human beings, and it is only natural that plants cannot thrive luxuriously unless they are properly and well fed. If the Grape grower has not enough farm manure he can supply plant food with a well formulated commercial fertilizer, by choosing those brands rich in Potash and Phosphoric Acid. The manure will help the land mechanically, and the fertilizer will furnish the food for the prouluction of vigorous, perfect plants and, consequently, prime fruit.

\section{Wood Ashes.}

The composition of wood ashes varies greatly with the kind of wood from which they are formed and the amount of impurities, such as sand, charcoal and moisture which they contain. Unbleached hardwood ashes, when free from dirt, often contain a much larger per cent. of Phospheric Acid and Potash. Aside from these substances, ashes contain Calcium Carbonate sufficient to amount to half their weight or more. This article here serves the same purpose as in marl or chalk, while the highly alkaline nature of the Potassium Carbonate, which unbleached ashes contain, make their action upon the soil very similar to that of caustic lime. One difference in the 
action, however, seems to be that there is much more danger of applying an excess of ashes than of lime. On certain heavy soils, which even very large quantities of lime make more easy to work, the application of ashes in large quantities cause the land to become hard and difficult of cultivation. This result is believed to be brought about by a chemical action of the Potassium Carbonate upon the soil whereby it is in a measure connected together. Because such soils are more likely to be benefitterl hy an application of Potash, and partly because they are apt to be improved by the mechanical action, shortly to be described, ashes are most suitable for sandy or gravelly soil.

In considering the capillary power of soils, it was noted, that the fewer the particles and consequently the fewer the pores between them, the greater will be the capillary power of the soil. Wood ashes are generally in a very finely divided condition, and are found to be very retentive of moisture, either when by themselves or when mixed with earth. When applied in considerable quantities, they are found to increase to a marked extent the capacity of the soil, not only for retaining moisture, but for bringing it from the depth below.

$\Lambda$ shes are especialy useful for small fruits and orchards. The amount to be used varies somewhat with the quality of the ashes, the nature of the soil, and the purpose for which applied. Ashes may serve a useful purpose for composting with bones and also tend to correct "sonrness" of the soil. In most cases this is not due to free acid, but to the presence of soluble iron salts, which in undue quantity are poisonous to plants, and in smaller quantities show that the soil is stagnant and neers aration. Ashes precipitate these salts and open the soil, that contains them, to the air, by making it lower in'texture. In Southern States cottonseed hull ashes are used considerable. These serve as a valuable source of Potash. On an average of several analysis made, they contain over twenty per cent. of Potash soluble in water, and about eight per cent. of total Phosphoric Acid. Of the Phosphoric Acid per cent., more than seven-eights was found to be in a available condition. As in woor ashes, the greater part of the Potash here exists as a Carbonate. Little Chlorine is present and, as compared with woor ashes, contain but little lime.

\section{Disethes of the Grape.}

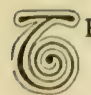

HE Grape, like all other fruits, is subject to diseases, which have been so troublesome and destructive to the vineyards in all sections of our country. It shows us the necessity of using every remedy that we know of for the destruction of these diseases, and through patient and persistent industry of our scientific workers, we are enabled, by efficient remedies, to keep these diseases in check and are no longer the dreaded foes they once were.

All fungii are plants and not insects, which may be divided into two groups, those growing upon living matter, and those upon dead matter; the former ones (parasitic) are most interesting to the Grape grower.

Few of our cultivated plants are attacked by more fungous diseases, or more injurer by them, than is the Grape. It seems as if, whatever be the nature of the sea- 
son, there is some destructive Grape disease, which almost forbids us to grow these delicious species of fruit.

Every fungus is produced from a spore or seed, which will develop rapidly when exposed to proper condition of heat and moisture. These spores are very small, minute germs, generally colorless, orange or black, however, so powerful and rapid in its growth and spreading, that Grape growing in some localities has almost been rendered impracticable by different varieties of fungii, were it not for the valuable experiences we receive every year through science, to aid us in a successful effort fighting these injurious fungous diseases. In order to make an intelligent use of remedies for checking or preventing these ravages, it is essential to gain a complete knowledge of their nature and habits. Every Grape grower, therefore, should first familarize himself where the fungus lives from year to year, how it gains access to the tissues of the leaves and fruit, thus causing blighting of the leaf and decay of the fruit. There are a considerable number of fungii, which attack the Grape, the most important ones we will now explain.

\section{Black Rot---Laestadia Bidwellii.}

This disease is familiar to all Grape growers and especially dreaded by growers of the Southern States, where all the conditions are favorable to nourish the rapid growth of this fungus and has caused the total destruction of the Grape crop. Black Rot is the most serious and important disease of the Grapevines in the United States. There is no disease yet known that causes in a few days such great losses, and our vineyardists rightly consider Black Rot as the worst of the scourges. It demands a

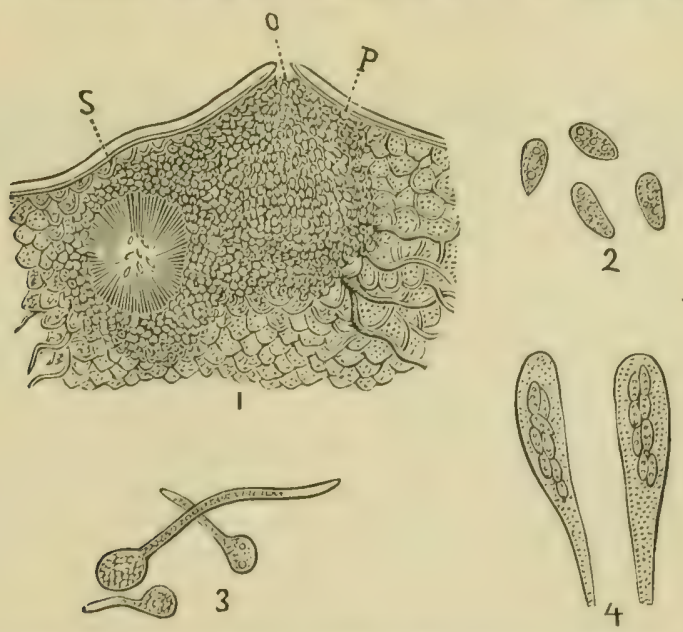

1. A section through a bit of the berry including an immature pyenidiman (P) and spermagonium

(S). At $\mathrm{O}$ is the osteolum, through which the spores escape at maturity.

2. Four of the sporidia, that have escaped trom an ascus.

3. Three styles spores germinating.

4. Two separate asci, showing the eight sporidia in each.

high temperature combined with sufficieut and frequent humidity to develop inost actively. This fungus is undoubtedly of American origin and has lived for many years previous to its discovery upon the wild Grapevines of the United States. 
The first manifestation of Black Rot is the appearance of a livid brown spot on some part of the berry, which gradually increases in size until the entire Grape is uniformly discolored, so that it appears to be rotten, althongh its original contour and firmness are retained. It usually happens that before the completion of this change the part first effected becomes darker in color and small black pimples are developed over the surface. The berries begin to lose their fullness, which soon ends with a withering of the berry, and become hard, dry, shrivelled to one-half its natural size, the skin pressed closely upon its seeds. The destruction of the berry is now complete. These little pimples which are easily seen with the naked eye are characteristic of this form of rot. The rotted berries remain firmly attached to the supports for a long time sometimes even to the following spring. These berries, which are generally allowed to drop to the ground, since unfit for use, conceal through the winter months thousands of minute sacks within each of which are a number of resting spores, awaiting the copious spring rains to be loosened from the rotten mass of Grape and tissue, and blown upon the green foliage which has made its appearance. The fungus can be seen very distinct on the shining deep green leaves of the Grapevines by small round or oval brown spots not more than one-quarter of an inch in diameter. In these spots are little pimples, which discharge through the pores in jelly-like masses, myriads of little round spores, which are washed down the stems or drip from the edge of the leaf upon the young Grape cluster beneath. Having gained a favorable resting place upon the berries, they grow and send their threads into the soft pulp of the berry. These spores develop on the berry in a similar way as upon the leaf. As soon as Black Rot appears on the leaves steps should be taken to check the spread of the disease which shows itself from two to three weeks ahead of attacking the berries. In wet seasons the leaves will always show the fungus first, while there have been some cases in dry seasons when only the berries have been attacked.

\section{The Downy Mildew, Peronospora viticola.}

The Downy Mildew is common to both the wild and cultivated Grapes of this country, and was doubtless conveyed from the former to our cultivated Grapevines. This disease is also called grey rot in its early stage upon the berry, and brown rot in its later, and stands to-day as one of the best understood fungous diseases. It attacks all the green parts of the vine, including the young shoots as well as the leaves and berries, and reproduces, by means of spores, minute bodies corresponding in function, seeds of flowering plants. It works in the interior of the leaves and gives the upper side a yellowish appearance, like down or frosty patches. In a short time the spores are produced on the extremity of minute, thread-like stems, that pro. trude through on the under side of the leaves. The spores, which are contained in small, spherical sacks, are blown by the wind upon the soft green surface of the leaves, where in warm, moist atmosphere of spring, they germinate with great rapidity. The contents swell, become segmented, and finally burst forth as ciliated swarm-spores. They move about for the time and then, having come to rest, drop off their cilia and soon throw out more thread-like stems, which develop into a new fnugus, if the conditions are favorable. In this way the Downy Mildews reproduce themselves during the summer, generation following generation in quick succession. These spores, which are produced in countless thousands, are blown from this one leaf, perhaps, in a single day, over the entire vineyard, infesting leaves upon almost every vine. This sprearling or fruiting of the spores continues until late in the autumn, when within the leaves are formed in small sacks with tough, leathery coats 
the hardy winter spores, which will live through the winter and infesting new vineyards again the following spring. The disease is particularly favored in its development by cold, wet weather, although any weakness of the vines, caused by overbearing, soil-exhaustion or similar causes, may induce the development of the disease, and increase its injurious effects.

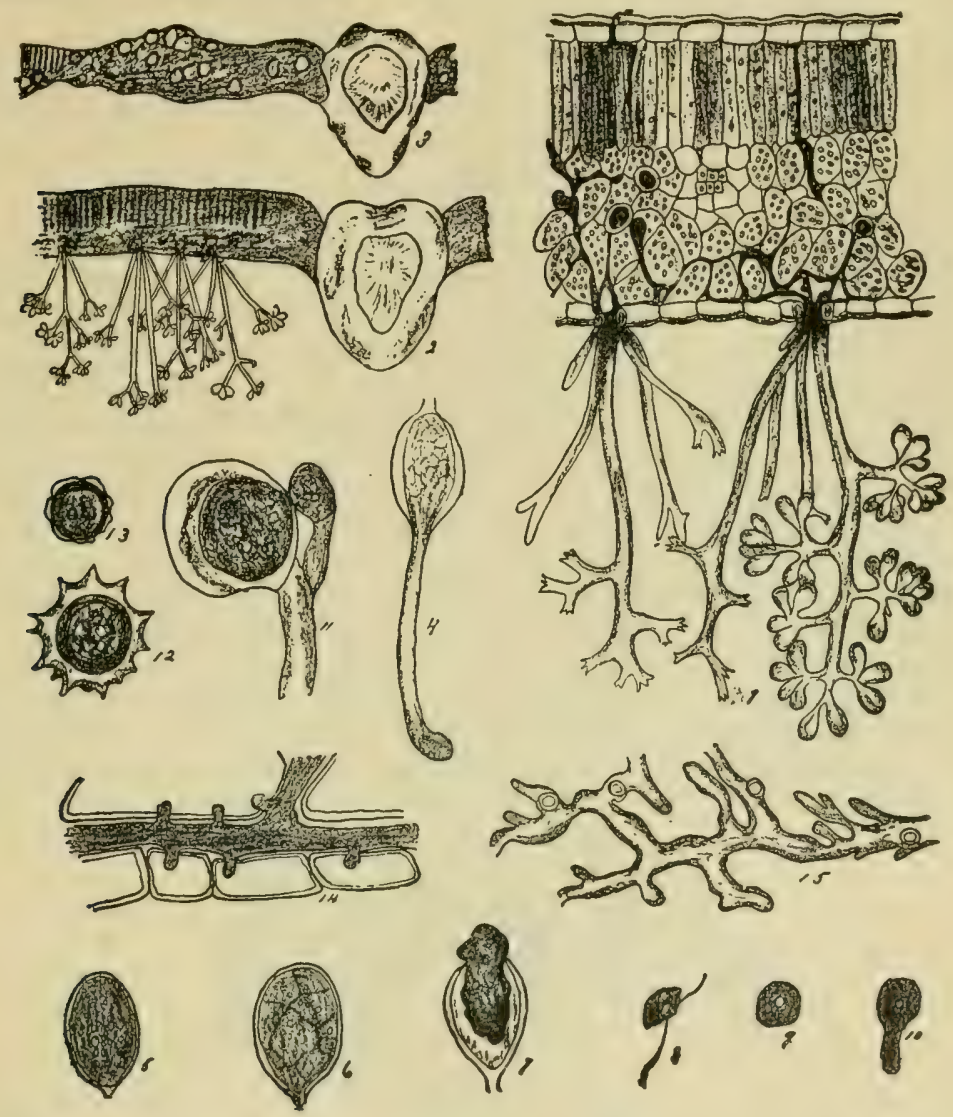

. Section of leaf (greatly magnified) showing conidial stage.

2. Showing the same less magnified.

3. The same, showing the effect of the fungus, the leaf brown and shrivelled.

4. Germinating conidia.

5-8, Development of conidia through zoo spores and swarm-spore stages

9. Spore.

ro. Germinating spore.

II-I3. Fertilization of organism and development of the spore.

14. Section of leaf (greatly magnified) showing mycelial thread passing between the cells and sending its haustoria into them.

15. Branching mycelium, the spots representing haustoria.

Berries, when attacked by Downy Mildew, rarely attain more than one-fourth their full size, often remaining not larger than small peas. The fungus upon them is of a grayish color, which soon turns brown, thus producing a kind of brown or gray rot. 
From the study of the above outlined life history, it would be evident to an intelligent observer, that all diseased leaves and berries should be burmed in the fall in order to kill the winter spores, and it would also be evident that any mixture applied to the young leaves in the spring, before they become diseased, would prevent the spread of the Downy Mildew as well as of other fungous diseases.

\section{The Powdery Mildew---Uncinula Spitalis.}

In many respects the Powdery Mildew is quite the reverse of the Donwy form. It flourishes in hot, dry weather ; it is not found within the tissues, but obtain its food by means of suckers piercing the outside skin of the leaves or epidermis and always occasions most injury during seasons of protracted drought. In the average season, however, little injury is done comparatively in the open vineyard, at least the injury is slight in comparison with that by the Downy Mildew. It is living wholly upou the outside of the leaves and fruit of the Grape, causing the dirty white coatings so well known to all Grape growers, which makes so many clusters unfit for market purposes.

If this fungus is examined early in the season short branches will be seen arising from the threads at right angles (a). These branches are divided into several oblong cells by cross walls. The one on the tip, which is slightly larger than that immediately below, soon falls off and the others follow. If they fall on good soil they at once germinate. Dampness or a moderate amount of humidity is sufficient for their germination. One of these oblong cells falling upon a Grape leaf will under favorable condition of temperature and humidity, push forth one or more germ-tubes, which sends suckers into the epidermal cells. Through these small suckers, which are the only part of the fungus entering the Grape leaf, the sap is drawn upon which and without which the leaf dies. The spores are formed much in the same manner as those of the Downy Mildew, but their structure is far more complex. From the exterior, appendages of various forms are develuped. In some cases they are straight,

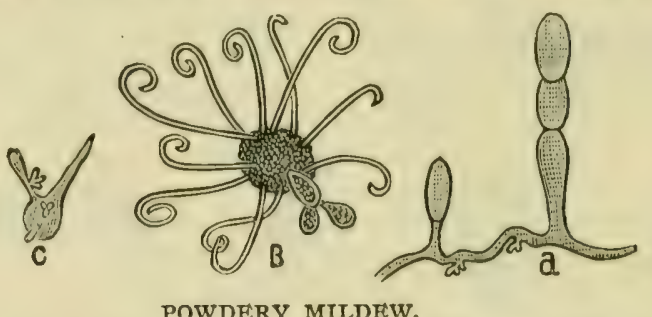

in others forked at the extremities, and yet in others they are coiled (B and C). By their multitude these threads now become visible to the unaided eye and we have what has been familiarly termed "Mildew." In the fall again, after these summer spores have been produced for many weeks, the small baskets of winter spores are formed, which remain in their cases on the fallen leaves or berries until spring, when the spores burst the walls of the cells and escape; they soon germinate and begin their life cycle anew.

The Powdery Mildew makes its appearance during the early days of June and continues its development late into the autumn. It appears in dull grayish-white patches, most conspicuous on the upper surface of the leaves. It never has the bright, lustrous or frosty appearance that characterizes the Downy Mildew, and the livid brown or seemingly scorched blotches on the leaves are wanting. Upon the young and tender shoots the fungus is often particularly abundant, its action being to check their growth. Sometimes it appears during the season of bloom and coming 
on the newly expanded flowers prevents them ripening to maturity. Attacking young berries their growth is permaneutly checked. Upon older berries the presence of this Mildew is made evident by small brownish spots produced by the action of the suckers on the epidermal cells.

Oftentimes the fungus spreads over only a small portion or the berry; this part fails to grow and a much distorted or imperfectly formed fruit is the result, sometimes causing the berries to crack open exposing the seerls. If completely overgrown the berries become dry, shrivelled and finally drop off.

\section{Anthracnose.}

This disease, like the Black Rot, is caused by a minute fungus, which is also propagated from plant to plant by spores, that are blown by the wind and require moisture in order to germinate. It inhabits both stems, leaves and fruit. All the green parts of the vine are subject to its attacks from the beginning of the season until the close of vegetation. Anthracnose appears on the shoots as early as June and attacks the terries, when nearly full grown. The spots on the latter are very - characteristic, gray in the middle, and then a ring of orange or reddish color and finally a dark ring outside. From this appearance the disease is known sometimes as the Birds-eye-rot. After a period the skin of the berries will burst exposing the seeds, the berries begin to wither and dry up, leaving nothing but the skin and the seeds. A berry may be attacked upon one side when it is not more than half grown ; it then becomes irregular in shape, the diseased part making no development, and it sometimes happens that this side cracks open exposing the seeds, which are gradually forced out by the unequal growth. On the green shoots first appear irrregular, small brown patches, a little depressed in the center with a slightly raised dark colored horder. These spots increase in size, drawing out in length with the grain of the bark ; the central portion becomes more destroyed, sometimes appearing as if burned
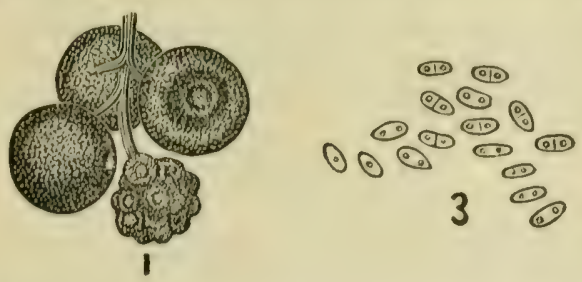

I. Berries destroyed by Antliracncse.

3. Mature spores, much magnified, usually thin-walled and transparent, with ouc or more bright spots.

and reaching in as far as the marrow. The action on the leaves is similar to that upon the stems and it is very evident that, where the diseased spots are numerous and the development of the fungus proceeds without interruption, both shoots and leaves. must succumb to the parasite. The intensity of the disease upon the shoots may cause the destruction of the young leaves even when the latter are not attacked.

Anthracnose, which in some parts has been bitterly complained of, is not in other sections nearly so destructive as other diseases, but from the fact that it has proved a difficult one to deal with, should be looked after with scrutiny. This fungus seems to affect white or light colored varieties more than the black, especially on rich ground, which is very moist, badly or not underdrained. Precaution should be taken at once, on the appearance of this disease, by cutting out the afferterl wood and destroying the same by burning. It is also advisable to give the Grapevine a dry 
application of powdered Sulphur and air-slacked Lime in equal proportion. We have found that "Fostile," lately introduced from France, has checked the Anthracnose on its start. More attention ought to be paid to this disease, as, once taken a firm bold on the vises, it is very hard to battle against.

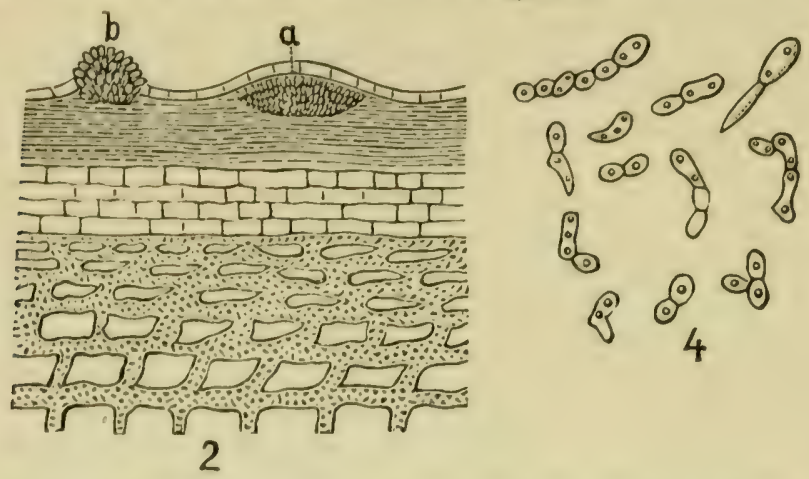

2. Vertical section (enlarged) of diseased berry, showing large numbers of spores laying beneath the epidermis (a) and finally rupture the latter and escape (b).

4. Spores germinating.

The foregoing are the principal fungus diseases against which our Grape growers have to fight, though occasionally cases of Bitter Rot and White Rot have been found in some vineyards.

\section{Bitter Rot.}

Bitter Rot derives its name from the flavor it imparts to the fruit, which is attacked generally about the time the berries attain full size. At first a brownish circle or spot appears on the herry, which rapidly enlarges and soon the entire berry turns brown, but still retains its usual shape. Finally, little purplish black pimples appear thickly dotting the surface and soon the berry shrivels and falls to the ground.

\section{White Rot.}

White Rot attacks the fruit, pedicles or stalks which support the latter but seldom the branches. The pedicles, if attacked, turn brown and the berries which they support dry up and appear as if scorched. Berries affected with this disease first become very juicy and soon minute gray or brownish postules appear on the surface. Finally the herries dries up assuming at the same time a greyish white color, easily distin. guished from that produced by the Black Rot fungus.

\section{Rougeot.}

A new Grape disease first complained of in 1890 , has been found in numerous localities through Western New York. The attacks of this disease seem to be con. fined to bearing vines three or more years from the planting. Small irregular blotehes of a dark color appear between the veins, which enlarge rapidly, darken to a dull purplish or redlish brown and unite so as to fill up the space between the veins, which remain green or yellow. These changes occur so rapidly that the foliage seems to change color suldenly. The contrast between the green or light yellow veins and 
dark purplish brown of the intervening tissues gives a peculiarly streaked appearance to the leaves. In the most serious cases they curl up, became dry and brittle, and finally drop from the vine, leaving it nearly bare.

The berries borne upon diseased vines, almost without exception, have a flat insipid, and often intensely sour taste, due to the fact that they are only partially ripened. When the attack is severe the berries drop off and the ground beneath a diseased vine is often seen to be covered with haî ripe Grapes. The berry is found to part from its pedical taking with it the fibers, which enter the material of the pulp and are normally withdrawn from it when the berry is pulled off. After the crop has been harvested aiso, bunches are found to shell badly, ruining them for the market.

The worst attacks of the disease occur upon cold, heavy soils containing a large percentage of clay and rich in uitrogeuous matters. There seems to be no connection whatever between the fertilizers and the trouble. Diseased plants being found upon land unmanured, heavily manured, fertilized with phosphate, wood ashes and bone dust. In cases where the soil is at all inclined to retain more moisture than necessary, thorough underdraining will probably be the surest means of preventing a second attack. Examinations of the roots of many diseased and healthy plants have shown no parasite of a nature adequate to cause the injury. Should the vines show no mature wood available for the next year the better plan will be to prune close to the ground and raise an entirely new growth. The diseased vines should not be allowed to bear heavily the coming season, as the necessary strain may favor a second attack of the disease.

\section{Ripe Rot of Grapes--Glorosforium Fruct- tigranon.}

This peculiar disease has received particularly no attention until lately. This fungus seems to be slowly gaining a foothold on the Grape and in some parts of the country causes the Grape to rot after they are carried to the packing houses. It is closely related to the Black Rot in general appearance, causes the berries to soften and turn a dark shiny color after showing red pimples on the surface. It attacks the berries when they have begun to ripen. Unlike any other of the dis. eases of the Grape, this one will be likely to spread after the Grapes are crated and await the attention of the packers. One diseased berry under favorable circumstances being able to affect a whole crate and render it unfit for market. The young fungous threads penetrate the soft Grape-pulp, aud after living within the delicate substance for about seven days forms spore postules under the skin which finally break open and allow myriads of minute pink spores to escape, which, when washed upon healthy berries. grow and produce similar diseased spots and similar postules. This new disease, unless guarded against, may prove to the Northern States what the Black Rot has been to the Southern, and demands attention from all Grape growers. Experiments have shown that it can be controlled by fungicides; any of the copper remedies will doubtless check it.

This disease is closely connected with one of the apple, known as the Bitter Rot of the apple, and it is a fact that spores from the Grape would produce Bitter Rot on the apple and vice versa. In the Grape, however, the rotting Grapes do not have the bitter taste characteristic in the apple. There is great danger in the fact that it is already widespread on the apple, and wherever it is present on this fruit the Grape is not secure from it.

Probably in no other country of the world is spraying for fungous diseases of 
fruits practiced to the same extent as in the United States. Five years ago practically nothing was known of this subject; in fact, the number actively engaged in spraying their trees, vines, etc., for such diseases as apple scab, black rot, Downy Mildew, and other diseases of the Grape did not exceed half a hundred, all told. Now, as a fair estimate, probably no less than 50,000 fruit growers are engaged in this work. From the Atlantic to the Pacific and from the Great Lakes to the Gulf the methods recommended by the Department are practiced every year.

DOES IT PAY TO SPRAY? No work that did not carry merit with it could have had such a phenomenal growth. To give a direct answer, however, it may be stated that two hundred and fifty Grape growers in different parts of the country made a series of observations with a view of obtaining some definite information as to the value in dullars and cents of the recommendations made by the Department in the ireatment of Grape diseases. The facts reported by these men show conclusively that the actual profit to them over all expenses resulting from the treatment of black rot and Downy Mildew was in round numbers $\$ 37,000$. Thirteen thousand dollars of this sum was reported from the State of New York alone.

Other examples equally as striking could be given, but this is sufficient for our purpose. Of course, every one is not successful, but where failure is reported it is usually easy to locate and remedy the trouble.

\section{Treatments.}

Attention may be called to the oft-repeated statement that practically all efforts to treat diseases of the Grapevine must be preventive, not remedial in purpose, as nothing can restore the fruit to health after it is once diseased. There is no cure for these diseases and the treatment therefore must be altogether preventive and the following methods cannot fail to bring favorable results :

I. In the fall at pruning time remove from the vineyard every particle of diseased canes, leaves or dried berries and either burn them, which is preferable, or bury them deeply in the earth. By all means avoid leaving them exposed where the wind can scatter the leaves back toward the vineyard.

2. Wash the canes before the buds are exposed in the spring with a solution of Iron (Copperas). This wash will destroy the spores it comes in contact with, and thereby lessen the amount of infective material ; it has especially a good effect upon vines affected with Anthracnose.

3. Spray the vines thoroughly by means of the well known force pumps, with one of the copper mixtures.

Numerous preparations have been recommended and used for the work. For all practical purposes, however, there are but four which properly may be called remedies. They are Bordeaux Mixture, Ammonical Solution of Copper Carbonate, Eau Celeste, Modified Eau Celeste.

The latest experiments indicate that the best results will follow the use of these preparations when made as follows :

\section{I --Bordeaux Mixture.}

In a barrel that will hold forty-five gallons dissolve six pounds of copper sulphate, using eight or ten gallons of water or as much as may be necessary for the purpose. In a tub or half barrel slack four pounds of fresh lime. When coupletely slacked add enough water to make it creamy whitewash. Pour this slowly into the barrel containing the copper sulphate solution, using a coarse gunny sack stretched over the 
head of the barrel for a strainer. Finally fill the barrel with water, stir thoroughly, and the mixture is ready for use. Prepared in this way the cost of one gallon of the mixture will not exceed one cent, the price of copper sulphate being seven cents per pound and lime thirty cents per bushel. In all cases it is desirable to use powdered copper sulphate, as it costs but Jittle more and dissolves much more readily. It is highly important also that fresh lime be used.

It will be seen by those familiar with former suggestions made by the Department that the strength of this mixture has been diminished one-half. It was found as the result of experiments made in I89I, that a mixture of this strength, and even much weaker, gave practically as good results as the old formula, which required six pounds of copper sulphate and four pounds of lime to twenty-two gallons of water.

In mixing Bordeaux the trouble of weighing the lime may be obviated by use of the following simple test, and a tub of slacked lime can for convenience be kept on hand. Add milk of lime to the solution of copper sulphate and test it with two or three drops of Potassium Ferro-cyanide in solution. If enough lime has been added, the Potassium Ferro-cyanide will not change color, but if not sufficient lime has been added the Potassium Ferro-cyanide will turn to a dark reddish-brown color. By adding more lime and repeating the test, it is easy to discover when there is enough lime in the mixture. As an excess of lime does not harm there is no danger of adding too much.

Bordeaux must be kept constantly agitated when spraying in order to prevent clogging the nozzle and to insure uniform strength of the application.

\section{2.--Ammonical Solution of Copper Carbonate.}

In an ordinary water pail mix five ounces of copper carbonate with enough water to make a thick paste. Dissolve this paste in three pints of strong aqua ammonia; then dilute to forty-five gallons. If three pints of ammonia are not sufficient to dissolve all the paste add enough to bring about this result. Copper carbonate occurs in the market in the form of a fine greenish powder. The retail price is usually sixty cents a pound. Aqua ammonia having a strength of twenty-six degrees retails at eight cents per pound. Upon this basis one gallon of ammoniacal solution of copper carbonate will cost one cent.

In view of this fact that copper carbonate is sometimes difficult to obtain, the following directions for manufacturing it are given :

In a half barrel or some similar vessel, dissolve three pounds of copper sulphate in two gallons of hot water. In another vessel dissolve three and one-half pounds of common washing soda or salsoda in one gallon of hot water. When cool pour the second solution slowly into the first; then as soon as all action has ceased add enough water to bring the whole up to eight or ten gallous and stir thoroughly. In twentyfour hours pour off the clear liquid, taking care not to disturb the sediment. Add fresh water and stir again. Again allow the solution to stand tw snty-four hours, pour off the clear liquid as before ; then remove the sediment, which is a copper carbonate. Prepared in this way there is formed one and one-half pounds of copper carbonate at an expense of materials of approximately eighteen cents per pound. The copper carbonate paste may be immediately dissolved in aqua ammonia, using two gallons of the latter, or as much as may be necessary for the purpose. This concentrated fluid should be kept in well-corked jugs and when ready for use should be diluted at the rate of one pint to twelve gallons of water. 


\section{3.--Eau Celeste.}

Dissolve two pounds of copper sulphate in eight gallons of water. When completely dissolved add three pints of strong ammunia and dilute to forty-five gallons. When prepared in this way the solution will cost about two-thirds of a cent per gallon.

\section{4.--Modified Eau Celeste.}

Dissolve four pounds of copper sulphate in ten or twelve gallons of water and stir in five pounds of washing or sal-soda; then add three pints of strong aqua ammonia, dilute to forty-five gallons. The cost will be one and one-half cents per gallon.

The regular application of any of the above formulæ should be made as soon as the young shoots are six to eight inches long. Little material is required at this time; however, the canes as well as the young foliage should be treated. The second spraying should be made at about ten days later as much foliage is being formed which should be protected from infection. This treatment comes about or just before the period of full bloom. After this the Grape grower will have to use his own judgment in regard to the number of sprayings and the proper time to discontinue them, and should be governed by the condition of his vines, as serious results may follow by the residue left upon the fruit when mature. There is on the part of consumers an ever-present fear concerning such matters; and their lack of correct information tends to make them peculiarly liable to a panic when uniutentionally or otherwise, a scare concerning so-called poisoned fruit is started. In the case of the Grape scare in New York city some time ago, Grape growers all over the country were made to suffer, partly through the folly of a few over-zealous individuals who upon their own responsibility made more applications than were necessary and partly through the action of a somewhat hasty Board of Health. No other positive stand on this question have been taken so far, though many misleading statements have from time to time appeared in our horticultural and agricultural papers. We take the ground that fruit sprayed with the copper compounds in accordance with the direction of the Department at Washington is harmless.

\section{Treatment of Black Rot.}

METHOD A.-After pruning the vineyard and putting the ground in thorough order spray the vines first, as the buds begin to swell, with Bordeaux mixture. When the leaves are one-third grown make a second application of the same fungicide, following with a third when the vines are in full bloom. After this, applications should be contiuned at intervals of ten or twelve days until the first signs of ripening are noticed. This will usually be three weeks or a month before the Grapes are ready to pick. In no case should the treatment be contiuued up to the time of harvest, as this is entirely unnecessary; moreover, it is sure to render the fruit unsightly. It is important to bear in mind that in case of dry weather the sprayings should cease.

IIETHOD B.-Following the direction laid down under Method A, with the exception that the ammonical solution be used instead of Bordeaux mixture.

METHOD C.-For the first three sprayings use the Bordeaux mixture, then substitute the ammoniacal solution for the rest of the season.

The cost of the treatment as laid down in Method A need not exceed two and 

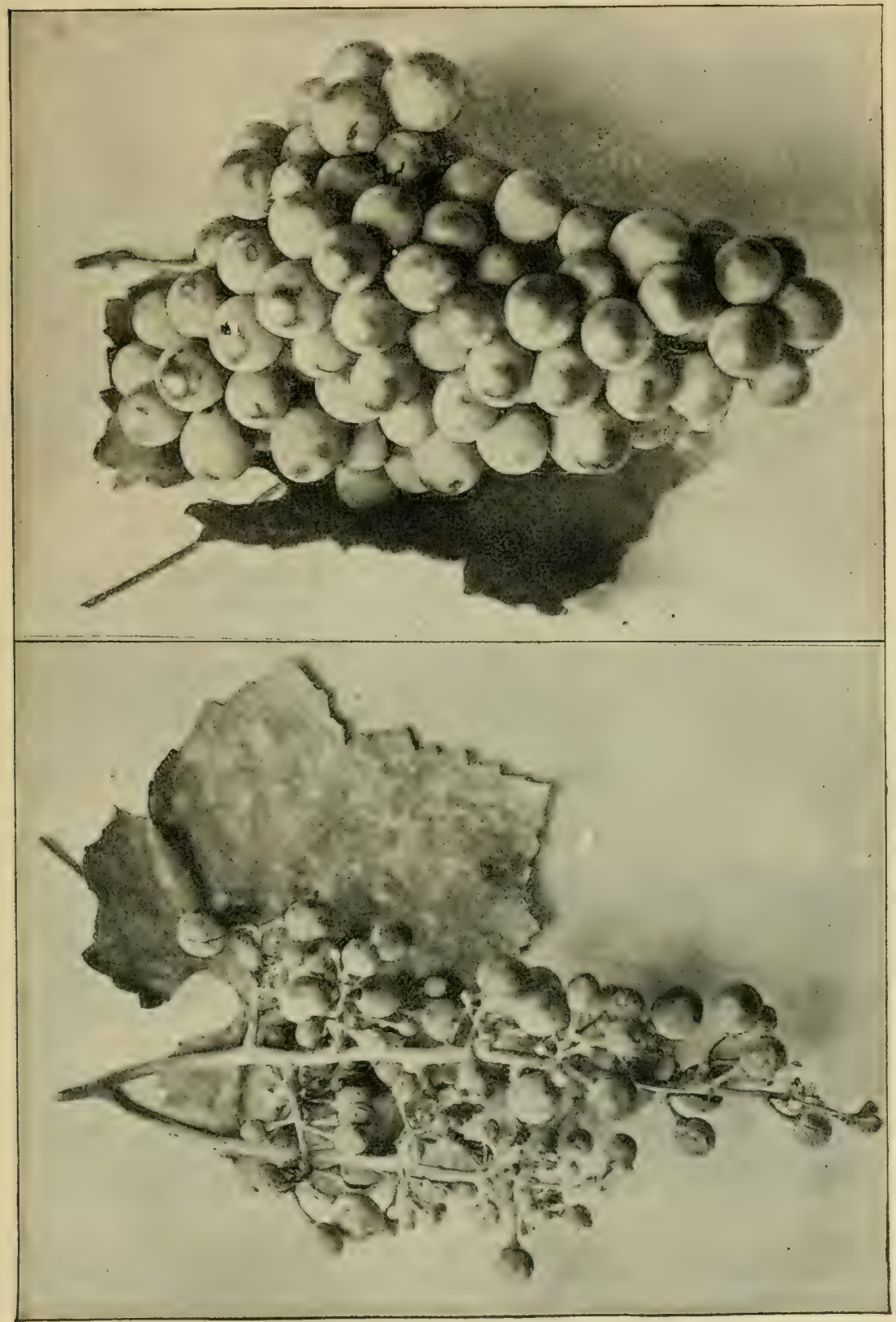

UNTREATED.

BLACK ROT.

TREATED.

The above illustrations show two bunches of Grapes, one without auy treatment whatever, while the other cluster was three times sprayed with the Bordeaux mixture and twice with the ammoniacal solution of copper carbonate. 
one-half cents per vine. Method B will cost two cents and Method C the same.

So far as efficacy is concerned there is little choice. All things considered, however, Method A will doubtless prove the most satisfactory.

\section{Downy Mildew.}

When this disease occurs alone ammoniacal solution or modified eau celeste may be used. The first spraying should be made when the fruit is well formed, the others at intervals of ten or twelve days as recommended for black rot. What is known as brown rot is caused by the fungus of Downy Mildew. It is seldom that brown rot occurs in the berries without the leaves being also affected. In regions where this happens the treatment recommended for black rot should be followed.

In some sections eau celeste has been more effective against these diseases than any of the other fungicides. This is notably the case in Northern Ohio and Western New York. Eau celeste, however, sometimes injures the foliage, and we do not advise its extended use.

\section{Anthracnose.}

Use Bordeaux mixture the same as recommended for black rot under Method A.

It is important to the vineyardist to use preventive remedies which protect their crops from all diseases, and within a year or two a powder, what is known as Sulfosteatite or Fostite, has been introduced from France, where it has given gratifying results for several years as a preventive for Grape diseases. It consists of copper sulphates, soapstone powder, which is exceedingly fine and adheres well. The powder is put on the vines by means of bellows; is cheaper and more easily distributed than Bordeaux mixture or any other remedies usually applied. By the means of the bellow the Fostite forms a cloud which moves with the least air current and covers the objects in its path with a slight coat of dust. This success

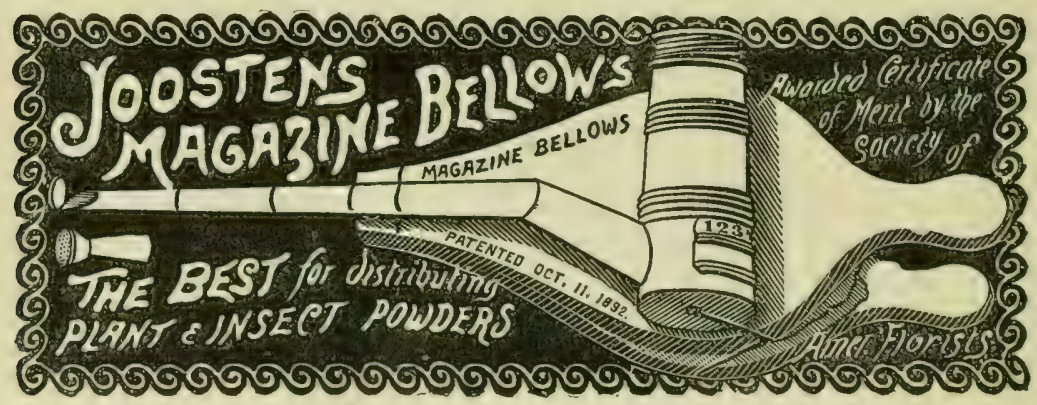

is obtained by the very composition of the powder. Owing to a very ingenious process the sulphate of copper is converted, and the salts resulting therefrom adheres to all the particles of the vine with a wonderful adhesiveness and fineness, allowing the preserving salts to reach all the points of the plant. Consequently no spores, whether of mildew, anthracnose or black rot can eacape, if the application is made during calm and damp weather, which allows the powder to adhere. Fostite is entirely haruless to men, animals and plants and can be handled with safety. 


\section{Spraying Outfits.}

The use of fungicides necessitates the possession of proper spraying pumps. These should be carefully selected according to the amount of work to be performed. There is no question that the Knapsack sprayer fills every requirement. In no other machine is the work so absolutely at all times under control, it being possible to place nearly every drop of liquid exactly where it is wanted. Knapsack pumps are now used in many vineyards, also in places where the larger or horse power machines, owing to the nature of the land cannot be utilized.

The improved Galloway Knapsack Sprayer manufactured by the Deming Company of Salem, Ohio, is one of the best of this kind made. It consists of a copper

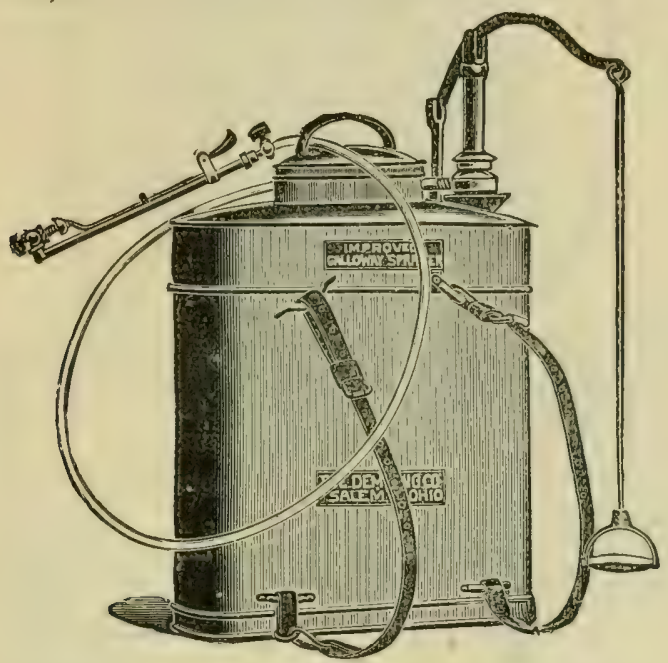

GALLOWAY'S IMPROVED KNAPSACK SPRAYER.

tank arranged to strap on the back, and a brass pump, which is operated by a rod attached to the lever. The pump is so constructed that all leakage from the stuffing box will drip back into the tank. If it become necessary the valves can be taken out for repairs without removing the pump from the tank. Quite a number of acres can be sprayed with one of these outfits. Knapsack sprayers are now manufactured all over the country.

Next in importance is a nozzle, that will throw a mist-like spray and will not clog when thick fluids are used.

The Vermorel nozzle is the best. It is economical of material, produces the finest kind of a spray, and if the aperture is clogged, the needle-like degorger easily removes the obstruction. Every sprayer is provided with one of these nozzles.

A cheap, and most practical and efficient sprayer is found in a strong, light, double acting, double discharge force pump mounted on a barrel. It may be said here at the same time, that while they cannot do the work as rapidly as the horsepower automatic machines. they are more effective, much cheaper and far less wasteful of the liquid used.

The Double Empire Spraying Pump made by the Field Force Pump Company, Lockport, N. Y., cannot be too highly recommended. It will spray two rows of vines at the same time, supplying two spraying nozzles, and stirs the liquid automatically. This pump is equipped with the Vermorel nozzles besides the return pipe for stirring 
the liquid. The suction pipe has a fine strainer and the pump is furnished with a

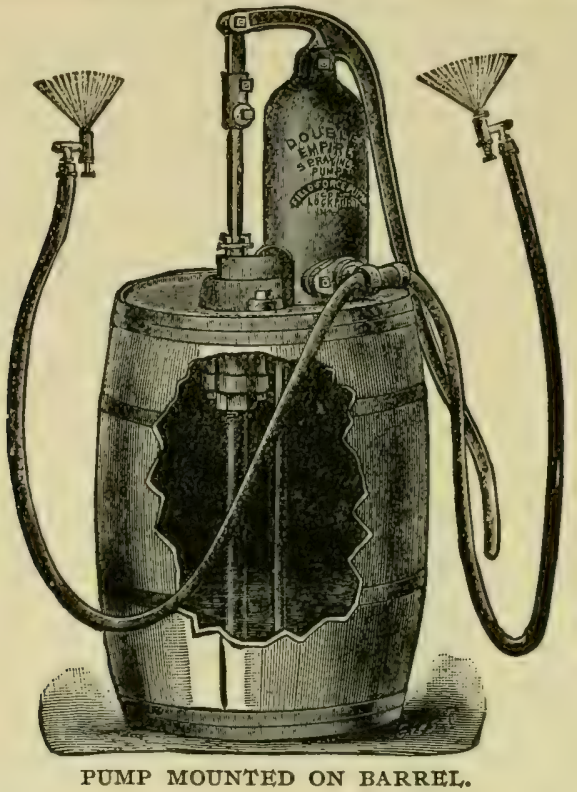

long lever. The nnusually large air chamber will continue to discharge the spray for over a minute after the operator stops pumping.

These spraying machines are worked by gearing taking its power from the wagon

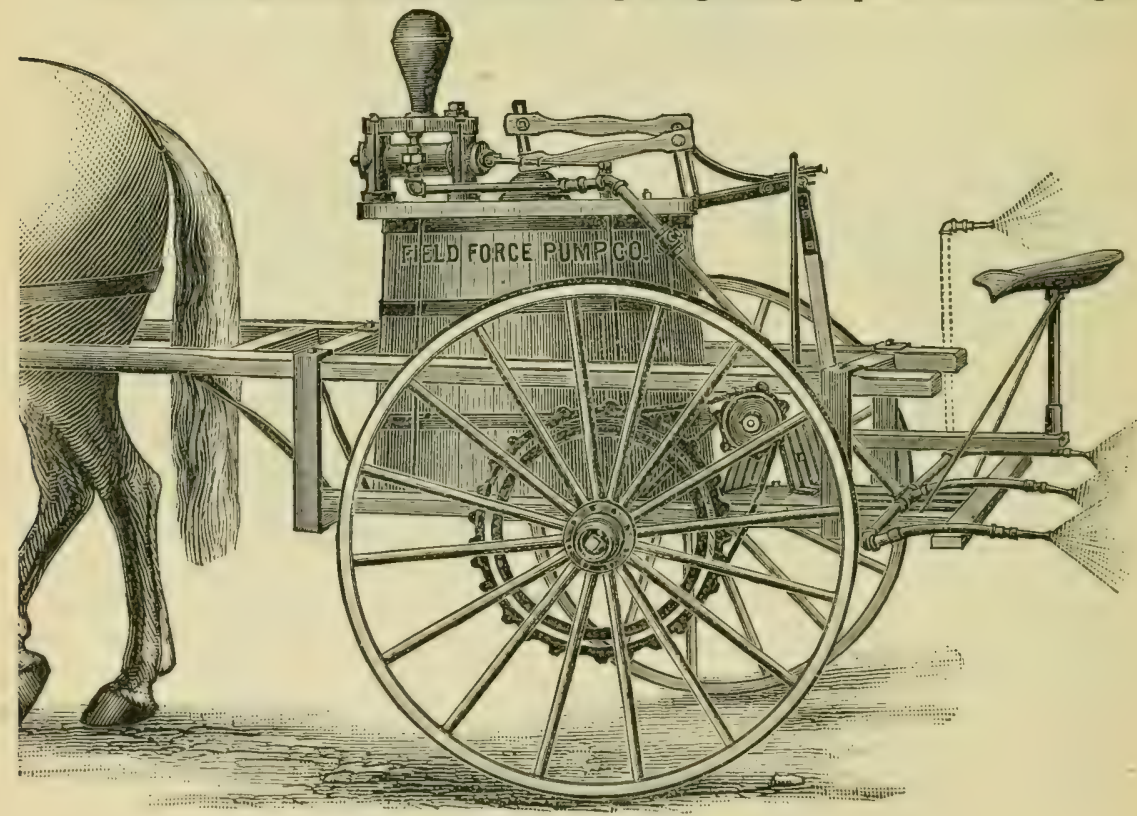

FIELD'S EMPIRE, SPRAYING MACHINE. 
wheels. It is a double acting force pump, the working parts that come in contact with the chemical liquids are made of brass and very durable. The pressure of the pump is controlled by an automatic valve, thus preventing too great strain upon the hose while at work. There are four nozzles with stationary pipes so arranged, that one row on each side of the machine, as well as the higher and lower foliage on those vines can be sprayed at the same time; by means of elbows and fittings furnished the nozzles can be set at any angle desired. The spray may be also shut off on one side of the machine while it is in use on the other side. This machine is complete and perfect in every respect. Fully twice the work can be done with a horse power machine, than can be done when pumping by hand and with much less labor.

Another, but less expensive automatic machine, is the Red Jacket Sprayer, suitable especially for small vineyards. It is a single wheel contrivance with tubular iron frame and a wooden tank holding about ten gallons, fitted with an endless

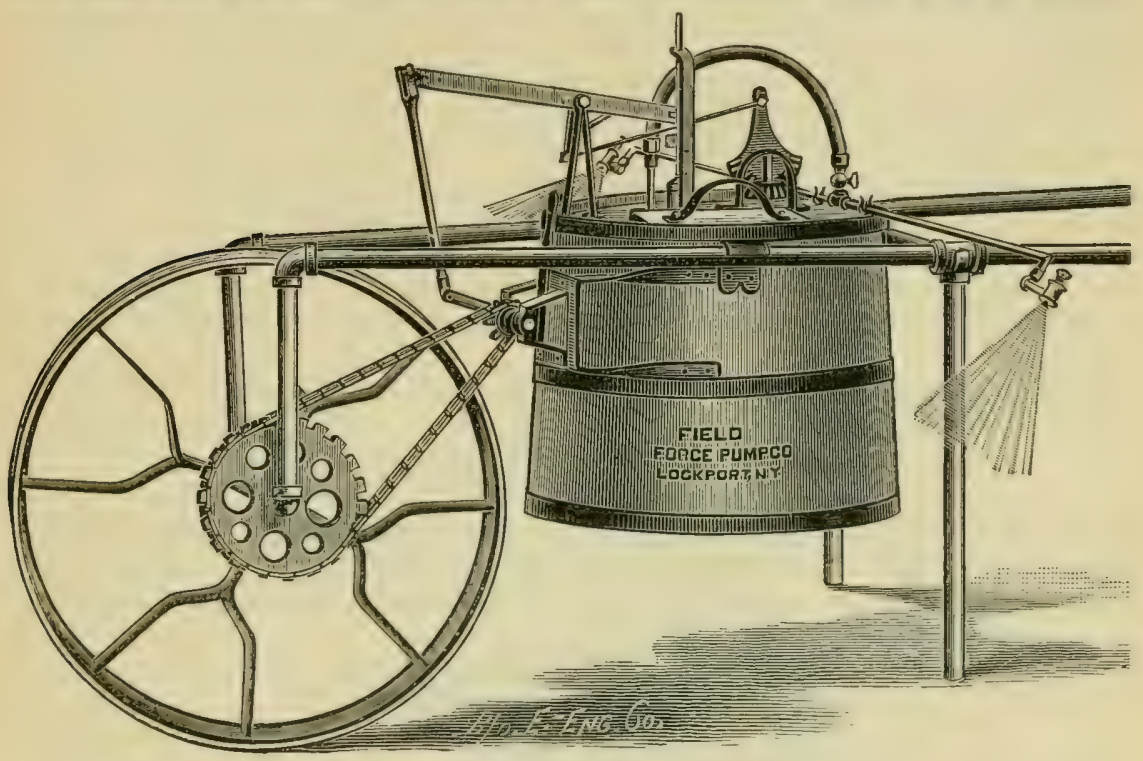

RED JACKE'T SPRAYER.

sprocket chain gearing, and has a mechanical automatic agitator which travels in a semi-circle in bottom of tank and keeps the mixture from settling. The pump and air chamber are brass, and the valves are metal. It has double tube sprayers for two rows of potatoes, and has two Vermorel Nozzies. The tubes are so arranged that they can be set in a perpendicular position for spraying Grapevines, and can also be used for spraying currants, berries and other small fruits. It is pushed the same as any wheel barrow, the revolution of the wheel doing the work.

By spraying with the copper remedies we are living in hope that we may so far overcome the difficuities as to permit the successful growing of all our valuable market varieties. We regard as the greatest importance the use of these recently discovered preventives against the various diseases which have been so prevalent and so discouraging to the Grape growers. We believe that their general adoption and general use will not only greatly enlarge the area of successful Grape growing, but also enable us to grow with profit many of the finer varieties in sections where it would be impossible without them. 


\section{Chemicals.}

The retail price charged by druggists for the chemicals required for making these mixtures, has prevented many persons from using them. The increasing demand however, has induced several firms to arrange for supplying them to Grape growers at wholesale rates, and that they may save to the consumer the expense of freight or express charges, on small quantities for long distances, distributing depots will be provided in different parts of the country.

Among the firms making a specialty of this business are the Nichols Chemical Co., New York, and the W. S. Powell \& Co., Baltimore, Md. The latter firm also manufactures liquid and dry copperdines, prepared Bordeaux, and other ready mixed fungicides. The chrystal sulphate of copper can be obtained in five pound packages at five cents per pound, but in barrel lots the price is only three and one-half cents per pound. The copper carbonate costs sixty cents per pound, or fifty cents in larger quantities. Ammonia having a strength of twenty-six degrees retails at eighteen cents per pound (one pint) and considerable less by the carboy. Soda carbonate, salsoda, or washing soda can be bought for less than one cent per pound in barrel lots. Good fresh lime is worth thirty cents per bushel. The commercial mixtures are for sale by several of the largest seedsmen, and when one has only a few vines to spray, although the prices charged for them seems unnecessarily high, they will be nearly as cheap as the chemicals at drug store prices. Where any number of vines are to be sprayed, the chemicals at wholesale rates will be considerably cheaper. The question of the cost of material is of less importance, than the power to produce the effect intended.

Next to spraying and almost as essential in Grape growing is the

\section{Bagging of Grapes}

as a preventive of Grape rot. The time to put them on, where the main object is to protect the fruit from rot or mildew, is just as soon as they have passed out of bloom, as the Grapes grow and increase in size very rapidly after that, and the spores floating

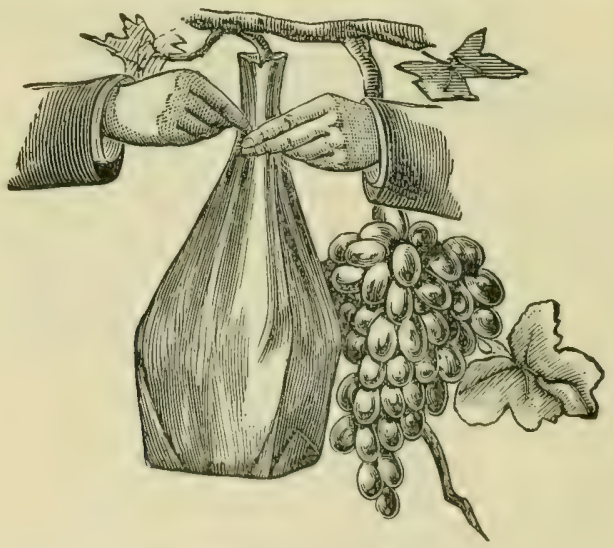

BAGGING OF GRAPES.

in the atmosphere may come in contact with the fruit and infect it before the bag is put on, only to develop later inside the bag. As soon as the clusters have set, the work should hegin and he pushed as fast as possible until completed, for the sooner 
the bunches are covered the less danger will there be of loss by mildew and rot. The best bags to use are the common manilla one and one-half or two pound paper bags, which can be bought at less than one dollar per thousand. These bags are slipped over the bunch, gathered on top and fastened by a small piece of needle wire around the stem which holds the cluster. Before the bags are put on the Grapes the Doth corners in the bottom of the bag should be cut off, thus allowing any water that may get into the bag to drain out. A man rapidly puts on over one thousand a day. Wet weather very seldom injures the bags, as they are protected by the foliage from the direct effects of storms. Injuries by birds are also avoided.

The improvement in the appearance of the fruit where the paper bags are used is astonishing. The fruit comes out in the most perfect condition. Clusters appear larger, quality excellent and no imperfect berries. Whether it would pay on a large scale for market must depend upon the demand for fancy table fruit at prices above the average for Grapes in baskets as commonly shipped. Where a market can be found for this grade of fruit at corresponding prices, the outlay would be doubly repaid.

\section{INJURIOUS INSECTS.}

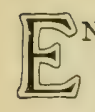

NTOMOLOGY as a science and horticulture, as an art or industry, meet in many places, and it is next to impossible for the fruit grower to progress far in his branch without finding some of these places of meeting. He recognizes the effect of insects on his crops by the production of fruit filled by these in fertilization, while on the other side the decrease in fruit by the ravages of noxious species, requires the fruit grower to keep a watchful eye on the intruder. From the economic standpoint, we have little to do with the species of value to the horticulturist. Nature minds her own business, and these minute allies of the husbandman perform their duties unasked, though not unrewarded. Their importance will be conceded by all. The case, however, is far different with insects detrimental to the fruit grower.

Along the elementary requirements necessary to the intelligent application of the methods to the prevention and killing off of these pests, we should study at first their peculiar habits. The class of creatures to which this name is applied, is very different from all other kinds of animal life. The life of all insects begins with an embryo contained in an egg, differing from all others in the first active form emerging from the egg and the subsequent changes which take place before their lives are complete. The first form is usually entirely different, both in appearance and habits, from the parent which deposited the egg, and it is in this first active stage of their lives, that they do their growing and principal feeding. At this stage they are properly known as larva. After a time, varying from a few days to several years, according to the species, they change into another form different from the first. In this second stage, certain kinds remain inactive without food until the perfect form develops within the shell, from which they emerge in due time to deposit eggs for another generation. This inactive form is called pupa.

Injurious insects are divided into two divisions, according to their manner of feeding : 
Ist. Biting or chewing insects, include all of those in the perfect or imperfect form, which bite and consume the substance upon which they feed.

2nd. Sucking or piercing insects, include all of those perfect or imperfect forms which pierce their food substance with a beak and suck out the sap or juice from beneath the surface.

If a strange insect makes its appearance, threatening the destruction of some plant or crop, before selecting a method to repel or destroy it, it is necessary to ascertain how it feeds. If it belongs to the first division and eats the leaves, it may be easily destroyed by Paris Green applied to its food substance, either in a powder or liquid, as the poison will be eaten by them with their food.

On the other hand, if belonging to the second division, that suck the sap from the plant, causing it to wither and die, poison will have no effect on them, because we cannot apply it to the inside of the plant where they get their food. Most of this class of insects may, however, be easily destroyed with remedies like insect powder, kerosene emulsion, etc., which kill by contact, where it is applied to the insects themselves.

DR. LINTNER, State Entomologist of New York, advances the theory that insects are attracted to plants, not by the sense of sight, but by that of smell, and that substances giving off a strong odor like lamp oil, coal tar, carbolic acid, gasoline and the remedies applied to or near the plants to be protected, prevent egg deposit by giving out an odor overpowering that of the plant or animal itself, thereby preventing its recognition by the insect. If this theory is correct, the importance of the measure is evident, for as DR. LINTNER argues, "if no eggs are deposited, we have no artificially concealed eggs to seek for; no larvæ whose rapacity and destructiveness we must arrest; no pupæ whose retreat is to be discovered and no perfect forms to be captured or entrapped."

If everyone were thoroughly acquainted with all insects, their habits, and methods of dealing with each, and would be persistent in the thorough and prompt application of preventive measures it would seem, that we should have no use for remedies. It is safe to say, however, that such a condition will never exist; and that after all, certain kinds of insects will appear, which will destroy certain crops, if they are not killed by the prompt application of poisonous and other substances. These remedies we will describe later on.

The Grape like all other fruit, has enemies among the insects, which, if allowed to increase, would soon become a burden on our hands. We will briefly mention these insects, which have been the most injurious in our vineyards.

\section{Phylloxera.}

This insect has undoubtedly attracted the most attention among the Grape growers. It is impossible to give, in this manual, a history of this insect, the extent of its injuries, and the experiments made to prevent the same. We will, therefore, mention only a few facts, which will show the importance to recognize this insect. It was known many years ago on our native vines, as the Leaf-gall-louse, which was found to be identical with the Phylloxera of the Old World. It has been the most ruinous in our country among the European varieties planted in California. The destruction of vineyards in France by the Phylloxera has amounted to nearly a million acres. In 1874 , a sum of 300,000 francs was alloted as a premium for the invention of some efficacious way of dealing with this pest, but up to last year this had not been claimed. Here is a little gauze-winged fly, which can be crused with the finger, defying all the science and intelligence of the world to extricate it. Various 
experiments have been tried, but they have not been of very real use, and nothing but destroying the vines and not cultivating them as vineyards for a number of years has been generally adopted. There is in this country, for the most part east of the Rocky Mountains, very little to be feared from the Phylloxera, at least so far as our native vines are concerned. Most of the American varieties of Grapes are resistent to the root form of this insect, and, hence, suffer little injury. The Leafgall form is not particularly serious in its effects on the vine, except in a few thinleaved varieties. The damage done by the Phylloxera in France and other parts of Europe, where it has obtained a foothold, is due to the root form exclusively.

The danger in this country then, is confined to those localities, chiefly in California, where European varieties are grown. Within the last fifteen years, hundreds of acres have been destroyed in California by this pest, and grafting of foreign varieties on the roots of our native vines has been resorted to, thus rendering the vineyards proof against the attacks of the Phylloxera. The true criterion resistant is, that the vine and its roots will not only outlive the attacks, but flourish and bear remunerative crops, under the same conditions under which the most sensitive foreign vine will succumb. There are undoubtedly two distinct forms of the Phylloxera.

The root-inhabiting type, which attacks the roots of European varieties, mostly found in California, and the leaf-inhabiting type, which flourishes mostly on the Riparia Class.

A study of the life history of the Phylloxera shows that the larvæe and small proportion of the wingless mother insects pass the winter in a dull, lifeless condition, but are easily brought to life and activity by a proper change in temperature. The middle of April finds the adult mother beginning to lay, and soon after young larvæ are produced and scattered to all parts of the roots. The increase is slow until

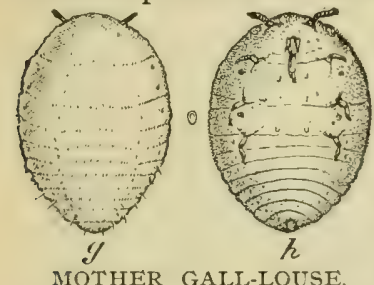

ventral and dorsal views. 'about the middle of June. Shortly after the larval form with rudimentary wings appears, and by the first of July the winged formed is found fully developed. The eggs of the mother-louse are most abundant at the end of the same month, and at the same time a decrease in the number of adult mothers becomes apparent; the maximum number of larvæ is also reached. Only a few eggs are usually found after October, and very little action is noticeable after November. The time of these changes, however, will vary greatly with the season. It was found, that a single insect can produce seventy-five eggs, laid frequently at the rate of five per day ; some days none at all were produced. Thirteen days are required to hatch them, and seventeen more for development into egg-laying mothers. The detection of these pests is very difficult, on account of their dull brown color being very often the same as the roots of the vine.

There are no outward manifestations of the attack of this insect the first season. The work of destruction begins on the fibrous roots, and, when these have disappeared, the insects not only prevent the formation of new fibres, but also spread themselves on the large roots. As the increase of the louse is so enormous, the roots will finally succumb, the leaves have a yellowish appearance, the growth of the vine is feeble and it finally dies. The vigorous, busy, fibrous growth, or network of roots around the taproot, evidently caused by manuring and moisture, seemed best to fulfill the necessary conditions for the development of this insect.

The leaf inhabiting form of Phylloxera shows itself by galls on the leaf, which often cover the whole under side. By opening one of these galls with great care, the mother-louse can be found surrounding herself with very small, pale yellow eggs. 
The eggs began to hatch when six or eight days old. The young lice, which are of bright yellow color, escape from the galls, spreading themselves all over the vine, selecting the most tender part of the leaf to begin their operations by piercing the

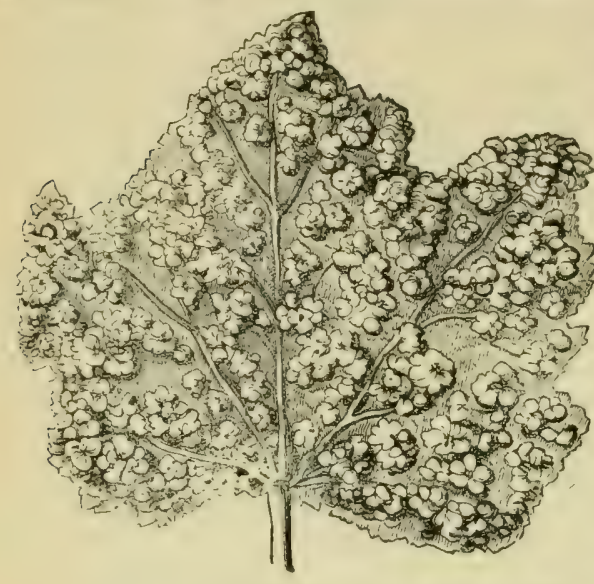

Under side of Leaf covered with Galls, nat. size.

leaf, appropriating the sap, forming galls and depositing eggs, as their parents had done before. This process continues during the summer, until the fifth or sixth generation. Every egg brings forth a fertile female, which soon becomes wonderfully prolific.

By the end of September the galls are mostly deserted, and those which are left appear as if infested with mildew and, finally, turn brown and decay. The young lice attach themselves to the roots and there pass the winter in a dormant state. It is an important fact, that the gall inhabiting insect occurs only as an agamie and wing. less female form. It is but a transient summer state and does, compared with the other root-inhabiting type, but trifling damage. In some seasons it is even difficult to find a few galls on the very vines on which they were very abundant the previous year.

The problem of repression, and if possible extirpation of the Phylloxera, still contiuues to form a subject of reflection to many persons for the discovery of an available remedy. Some of these remedies are still under trial, but nothing thus far brought forward has seemed to give any reasonable promise of success in curing vines once infected.

\section{Grape Leaf-Hopper--Erythroneura Vitis.}

Frequent complaints are made against a small species of Leaf-hopper that often seriously injures the Grapevines. They appear in swarms in certain localities very unexpectedly, and often disappear just as suddenly. Their presence in the vineyard is readily known by one, who happens to disturb them by moving the vine, or often by even approaching it as they leap from leaf to leaf ahead of him, like grasshoppers in a clover field.

There are several species of Leaf-hoppers that live upon the Grape, but their habits are so much alike, that practically all may be considered together. The most common one, and generally the most injurious, is known scientifically as ERYTHRONEURA VITIS.

This beautiful little species is about one-tenth of an inch long, and clad in a robe of pale yellow, or straw color, and trimmed with two narrow red lines on the head and two bright scarlet bands crossing the thorax and wing covers. Along in June, their first appearance on the Grapevine leaves is made. They are at this time in the larval state, which with these insects differs from the mature form only in being smaller and having no wings They cast their skins from time
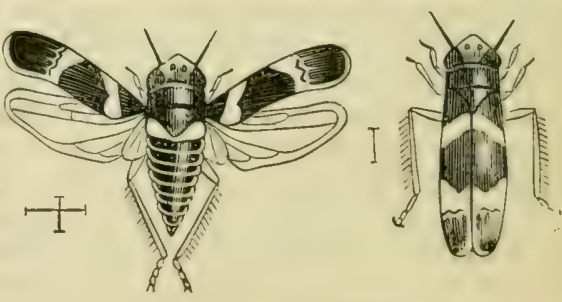

GRAPE LEAF HOPPER. 
to time, as they grow larger, and these white cases may often be found attached to the under side of the foliage just as its occupant left it. In July they assume the pupa state, in which they have little wing pads that indicate what may cone in the future, but which do not come till nearly a month later, and then they not only can hop, for they are wonderful jumpers, but can fly as well. Their injury to the leaves is caused by puncturing them with their long needle-like mouth or beak, and then drawing the sap, on which they live, from the puncture by means of this tubular beak. This work is most generally done on the under side of the leaf. At first only little discolored specks show on the leaves, but these rapidly grow more numerous, and increase in size till later they become brown blotches. If the attack be severe enough, the leaf will prematurely wither away and fall from the vine, appearing as if scorched by fire. In consequence of this interrupted growth, the canes cannot mature the wood as they should, and the fruit is stunted and its ripening interfered with. When this continues the death of the vine may follow.

While these Leaf-hoppers are in the larval state, they can be killed very easily, probably soapsuds, sprayed on the under side of the leaves, at this time, will be the most convenient, and at the same time, an effectual remedy. With the more mature insect, perhaps, no remedy is equal to the Kerosene emulsion. This has proved very effectual.

These hoppers live through the winter in the mature state, and seek sheiter under the fallen leaves and rubbish over the ground. If they cannot protect themselves from the cold, wet storms of autumn they have to succumb to its fatal influences, for they cannot endure much moisture at a low temperature.

\section{The Grapevine Flea-Beetle--Haltica Chalybea.}

The Grapevine Flea-beetle is apparently on the increase in Western New York, and

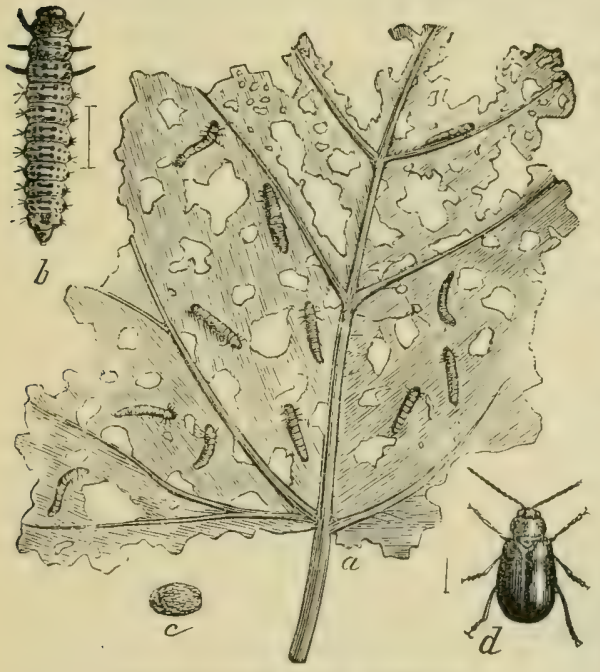

GRAPEVINE FLEA BEETLE.

a. Larva, natural size. b. Larva magnified. c. Cocoon.

d. Beetle enlarged. is becoming a pest of the Grape grower. Its multiplication should not be permitted, but should be persistently fought by breaking up or removing in the autumn its usual place of hibernation, as loose bark and the refuse material of the vineyard, and by preventing the beetle eating out the heart of the buds in the early spring. When they first make their attack on the buds, to which they are so destruc. tive, they should be knocked off daily into a pan of water and kerosene, or this form of injury can be prevented by spraying with a mixture of limewash made with brine, to which is added some London purple. In the accompanying illustration, the larvæ are represented in their natural size, feeding upon a leaf. A hemipterous insect has been detected preying upon the larva by sucking its juices.

It belongs to the plant bugs, so many of which have aided us in the destruction of our insect foes. 


\section{Rose Chafer---Macrodactylus Subspinosus.}

This insect is more commonly known by the name of Rosebug. Its body is about one-third of an inch long. It tapers before and behind, and is entirely covered with very short and close ashen-yellow down; the thorax is long and narrow, angularly, widened in the middle of each side. The legs are slender and of a pale red color, and the joints of the feet are tipped with black and are very long. The larve

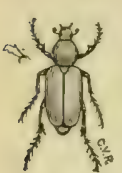
attain their full size in the autumn, being then nearly three-quarters of an inch long and about an eighth of an inch in diameter. They are of a yellowish white color, with a tinge of blue toward their hind extremity, which is thick and obtuse or rounded; a few short hairs are scattered on the surface of the body; there are six short legs, a pair to each of the

ROSE first three rings behind the head, and the latter is covered with a horny CHAFER. shell of a pale rust color. In general appearance this larva closely resembles the white grub of the May beetle, which is a much larger form.

It makes its appearance in the greatest numbers just as the Grape blossoms begin to open. The female Rosebug deposits her eggs generally directly beneath where she feeds, thus many more of the larve are found right under the Grape row than in the middle space between the rows. If, before these insects are ready to oviposit, they have consumed all their fuod in a given district, they will generally emigrate to ancther place where they can obtain food, and this will be their breeding place. For example, on many sorts of Grapevines they prefer the blossoms to the leaves. Of the Riparias they eat the leaves also. If there be a vineyard of Riparias accessible to the bugs, they will, towards the close of their dispensation, mostly abandon other vines and congregate on the Riparias. The eggs hatch in about twenty days and the young larva produced from them feed on such tender roots as are accessible to them. They attain maturity in the fall. Late in the autumn they descend beyond the reach of frosts, where they remain through the winter in a torpid state, and in the spring burrow upward near the surface, and mould an oval cell by the pressure of their body, within which, in the month of May, they transform to the pupa state. During the early part of June the thin pupa skin is rent, and the perfect insect digs its way out of the ground.

As with most of the beetles which are concealed beneath the ground, very little can be done to destroy this species in these stages, and it is scarcely vulnerable except in its last and perfect stage. The most efficient means to control its depredations is collecting by hand and killing. Mr. L. LYMAN of Virginia, claims that the ammoniacal solution of copper carbonate is the only one of the copper solutions which checks the Rosebug.

\section{Grape Berry Moth--Eudemis Botrana.}

The infected Grapes are usually perceived late in July by a'discolored spot where
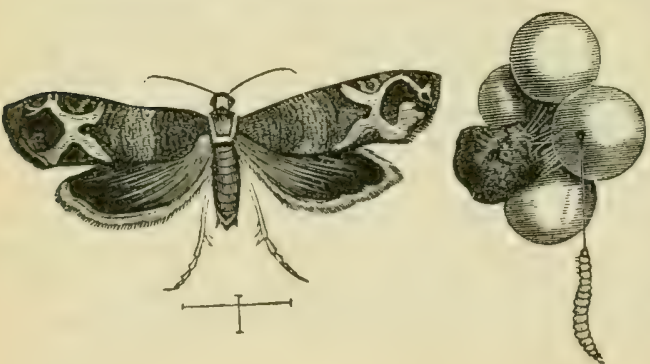

GRAPE BERRY MOTH. the worm has entered. The larva is of a whitish green color ; if the contents of one berry are not sufficient to satisfy it, it draws two or three berries together by means of silk threads or web, and then passes from one to another. As it approaches maturity it becomes darker in color, with a black head, and a body of yellowish green, and is then about one-fourth of an inch in length. When the larva is full 
grown it cuts an oval flap from the leaf and turns it back and fastens it over itself, forming an enclosure, which it lines with silk, where it remains until it has passed the chrysalis state. The perfect insect is here shown enlarged, the diagram underneath indicates the full size. The body is greenish brown, the fore wings a dull bluish shade with dark brown bands and spots, and the hind wings a dull brown. It is said there are two broods in one season.

As it is possible that some of the last brood pass the winter attached to the leaves, if these were gathered and burned, a large number of insects would perish and the infested Grape might also be gathered and destroyed. The insect is attacked by a small parasite, which doubtless does its part toward keeping the enemy in subjection. According to Professor Riley, this insect is an imported species from Europe, where it is known as LOPESIA Botrana.

\section{Grapevine Scale Insect--Pulvinaria Innumerabilis.}

This scale insect is so conspicuous from the white, cottony mass which it secretes, that it often comes under observation and arouses interest in its character and habits. It possesses remarkable power of multiplication and eventually, if left to themselves, increasing until they nearly or quite cover the surface of the plant. When they have become so numerous as this they cause the death of the plant. as their nourishment is drawn from the juices by means of a proboscis inserted through the bark. The milk-white cotton-like mass, that protrudes from one end and the sides of the brown
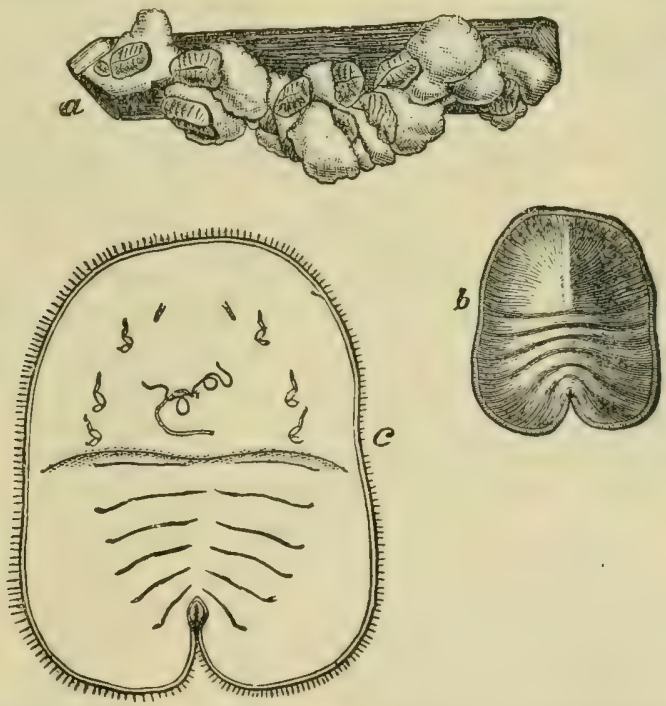

(a) Cttony Scales on stem.

(b) Back view of Scale, magnified.

(c) Ventral view of Scale, maguified,

sub-oval scale, present three or four times the surface of the scale. Within it are contained the numerous eggs of the mother scale insect. The young lice are developed from these masses about July, appearing as myriads of minute ochreous-yellow atoms too small to disclose any structure to the unaided eye. These distribute themselves over the vine and soon become stationary by attaching themselves to the bark by their proboscis, gradually increasing in size until the following summer, when the females will present the appearance of these large scales raised at one end by the 
cotton-like substance thrown out from beneath. This insect is so great a pest, that every pains should be taken to eradicate it as soon as its presence is detected. The leaves infested by it should be plucked and destroyed, and all the scales scraped from the vines whenever they are observed. In the very young stage of the insect the greater part of the brood can be killed by going over the infested portion of the vines with a stiff, thickly set, bristle brush, as in their early state they are quite tender and can be easily crushed. Spraying with a weak solution of carbolic acid before the young are protected by their scales would also destroy them. A strong soap solution is often sufficient for killing them at this stage. Later when the scale has become fully formed and fastened to the vine, it would be necessary to use kerosene emulsion or a strong alkaline wash.

\section{Grape Leaf Galis--Lasiaptera Vitis.}

These galls have been noticed as somewhat numerous in some of the vineyards. They are formed at the nodes of the young shoots and on the flower buds before blooming. They form a mass of irregular, succulent swellings on the stem and leaf stalks of the Grapevine, very variable in size and shape, from the single round, cranberry-like swelling to the irregular, bulbous protuberances, which look like a group of diminutive tomatoes. The galls are very variable in size and form, from less than a quarter of an inch in diameter to some nearly an inch in length, often several galls running together, forming a long compound one. The galls on the

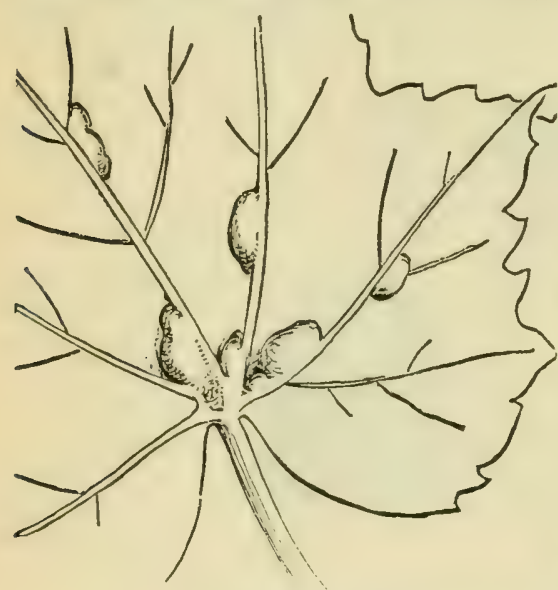

GALIS ON THE LEAF.

leaves are smaller than those on the stems They, in most cases, rest on the veins, but few only touch them on one side; rarely, they are entirely disconnected. They have a yellowish green exterior, with rosy cheeks, and sometimes are entirely red; the interior is soft, juicy and acid. Each gall has several cells, and in each cell there is an orange yellow larva, which, before the gall has entirely decayed, enters the ground, where it changes to a chrysalis, and finally emerges as a pale reddish gnat, with black head and

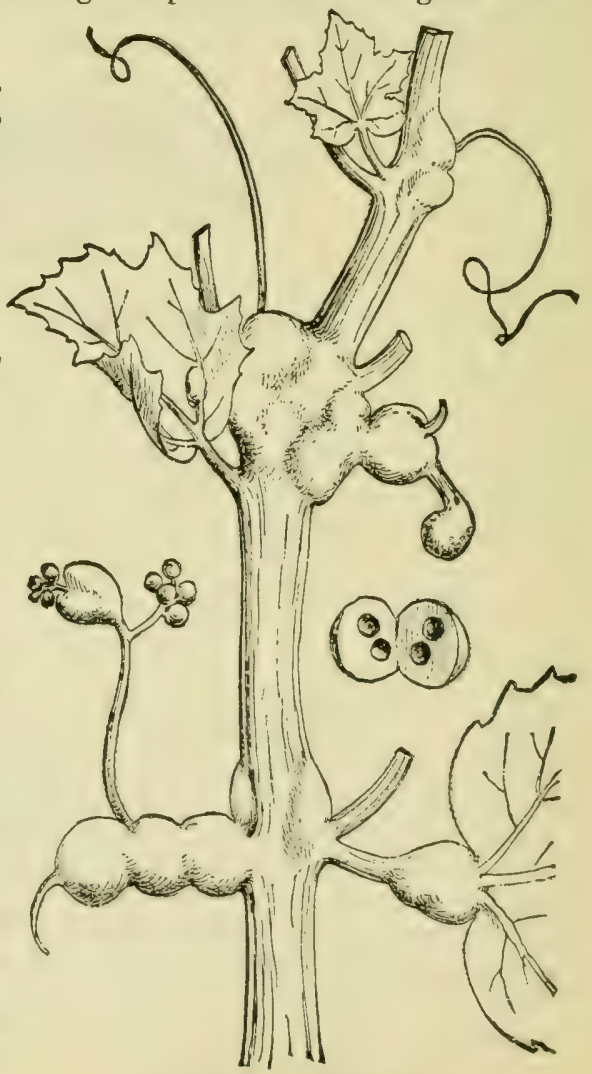

GALIS ON THE STEA:. 
antennae, and gray wings. The larvae are liable to be attacked by a parasite, and also by a species of thrips, which invade the cells and destroy the inmates. As the insect is native and can always have the wild vines to breed on, however closely it may be stampeded from our vineyards, we shall probably never be entirely free from it. On the other hand, as it has never appeared in much force, it is not probable that it will, but it is not best to encourage its increase by neglect. It has been reported from various parts of the Northern States, and is, without doubt, wide spread.

The best preventive known of this attack is to remove and burn the infested leaves aud tips during early June, before the larvæ leave them for their further development in the ground.

Beside those insect pests described in this chapter mention should be made of the following :

The GRAPESEED MIDGE (Isosoma Vitis), a small insect, which lays its eggs upon the Grape during the month of July, the larva from which burrows into the fruit to feed upon the seed, and causes the Grape to shrivel and dry.

The GRAPE CURCUlio (Craponius Inæqualis), a small snout-beetle which punct. ures the fruit for the deposit of its eggs, causing its premature ripening and dropping to the ground. This Curculio is of a black color with a grayish tint.

The GRAPELEAF FOLDER (Desmia Maculatis), a worm of grass green color, which, by means of its silken threads, folds the leaf. The moth appears in the early spring;

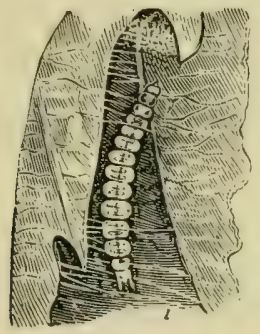

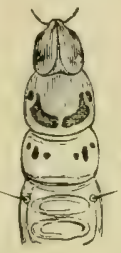

2

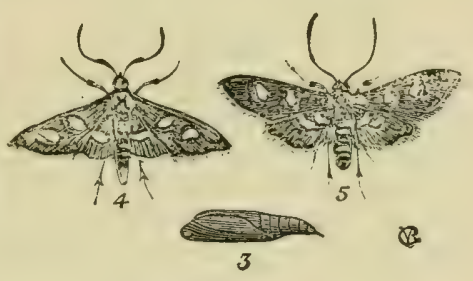

GRAPE I.EAF-FOLDER.

1. Larva. 2. Head and thoracic joints, enlarged. 3. Chrysalis. 4, 5. Male and female moths.

the worms, however, are not noticed until midsummer when they can be crushed with the hands within the leaves.

The LADY BIRD (Hippodamia Convergens) is a small beetle of a broadly oval form, having the wing-covers of a dull red color, marked conspicuously with black spots; the thorax is of a cream color with an inverted W shaped black mark. It is also one of our insect friends being especially fond of plant lice and feeding considerable on the eggs and the young larvæ of insects.

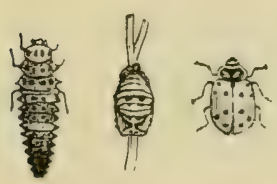

IAADYBIRD.

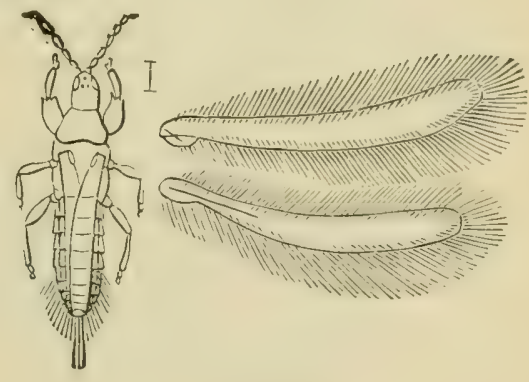

THRIP.

Larva. Pupa. Beetle. 
THRIPS (Thrips Phylloxeræ). This is one of the most useful enemies of the Crape Phylloxeræ, as this insect makes its home within the leaf-galls caused by Plyylloxera. Thrips are very small black insects scarcely a sixteenth of an inch in length; wings are of a creamy-white color. They live on the under side of leaves and the discoloring upon the upper side shows their presence. By holding a lighted torch at night on one side of the row in the vineyard and shaking the vines on the other side their numbers can be greatly diminished, as they will fly towards the blaze and burn up.

\section{Birds Injuring Grapes.}

Birds sometimes injure Grapes quite seriously. There can be no doubt about it ; and in their defense we have always claimed that they were entitled to a great deal of indulgence on account of the good they do in destroying noxious insects. But the question is by no means settled in how far the various species of birds are responsible for damage done to Grapes.

PROF. LAUTz, of the Kansas Experiment Station, has recently made efforts to get at the truth of this matter. Having always been a most ardent advocate of bird protection, he says : I have been especially anxious to discover whether this injury to the Grapes can be traced to any particular species of birds, or whether many species puncture them. I have sought the information from many Grape growers, but the testimony received has been of such a contradictory character, mingled with so much of conjecture by the observers, that it has been entirely insufficient to establish the guilt of a single species of birds. When I have asked whether the persons actually saw a bird puncture the Grapes, they have usually admitted that the blame was attached to the species because it was seen in the vineyard, but they themselves did not see the damage inflicted.

Some are positive that the oriole does the mischief; others think that it is the English Sparrow, and thus through the list of our most common birds; while not a few insist that the injury is due to the stinging of bees and wasps, and not to the birds at all. These last would not be very trustworthy observers to establish the identity of the real marauder.

There can be no possible question but that the injury is done by birds. It may be done by many, a few, or even by a single kind of bird. If but one or two species are responsible for the damage it would be of advantage to know it, especially if, as some suspect, the Euglish Sparrow is the principal thief. There is some color to the claim that this species is mainly responsible for the damage, from the fact that the injury is greatest near our cities and villages. Observations seem to point to the fact that the most injury is done very early in the morning. The birds puncture the Grapes to obtain the cool juice laying under the skin, and they are excellent judges of the flavor of the different varieties and of the ripeness of any kind. It is doubtful however, whether such investigations will change the present opinion as to the usefulness of a single species of birds,

\section{Insecticides.}

Remedies proper differ from preventives, (which are sometimes called remedies) in the fact that preventive measures are used to avert an attack and remedies after the attack is made. The best remedies in general use are: Paris Green, London Purple, Kerosene Emulsion, Pyrethrum (Insect Powder), White Hellebore, and Tobacco in various forms.

PARIS GREEN is a combination of Arsenic and Copper, and is the most widely known iusecticide and more generally used than any other. It will kill most of the 
biting insects, provided it is pure and applied in the proper proportion and at the right time.

LONDON PURPLE is a refuse material obtained in the manufacture of analine dyes, and its principal constituents are arsenic acid and lime. It is cheaper and better in most cases than Paris Green except that it is more liable to injure the foliage.

KEROSENE EMULSION is probably the best known remedy for insects. This emulsion consists of one-half pound of hard soap, two gallons of Kerosene oil and one gallon of water. Boil the soap in the water until all is dissolved, remove from the fire and add the oil, then churn for ten minutes until it is thoroughly mixed and will form a substance like butter when cold. Dilute with nine parts of water to one of emulsion, and apply with a spraying pump.

INSEC'T POWDER (PYRETHRUM) is manufactured from a plant largely grown in California. It can be used diluted with flour and applied with a bellows or powder gun.

IVHITE HELLEBORE is a vegetable substance. This, like insect powder, may be also used with a bellows.

TOBACCO DUST is made from tobacco stems, large quantities of which are found at cigar factories. This material may be used without grinding into powder, and is valuable both as an insecticide and as a fertilizer. A strong tea made from it will kill insects by contact. Take five pounds of tobacco stems, steep them in three gallons of water for three hours; strain the concoction and add sufficient water to make seven gallons. One or two applications are generally sufficient to clear the vines from the insects, such as lice, etc. Use a fine spraying nozzle.

The only insecticides which are at all dangerous to use are the arsenic compounds. Paris Green and London Purple have for many years been extensively used in this country as insecticides and great precautions in the handing and application of these remedies should be exercised. The question as to whether arsenic may be absorbed by the growing plant in any degree was long ago settled in the negative by the best chemists in this country.

These poisons are of the greatest service against all masticating insects, as larvae and beetles, and they furnish the most satisfactory means of controlling most leaffeeders, and the best wholesale remedy against the codling-moth. Caution must be used in applying them, on account of the liability of burning or scalding the foliage.

The poisons should be thoroughly mixed with water at the rate of from one pound to one hundred to two hundred and fifty gallons of water, and applied with a force pump and spray nozzle. In preparing the wash, it will be best to first mix the poison with a small quantity of water, making a thick batter, and then dilute the latter and add to the reservoir or spray tank, mixing the whoie thoroughly.

Bagging Grapes also offers a means of outside protection, if the fruit is liable to insect injury.

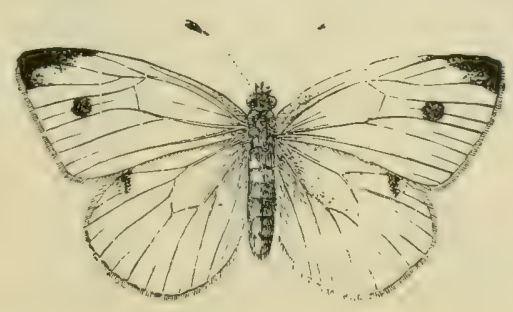




\section{Harvesting of Grapes.}

DHE scene from the solitude of a vineyard changes with the ripening of the

(9) Grapes and therefore let us follow the Grapes from the vine until they reach the table of some home. Grapes should be allowed to hang until fully ripe. It is not enough that they hang until fully colored; they should hang until

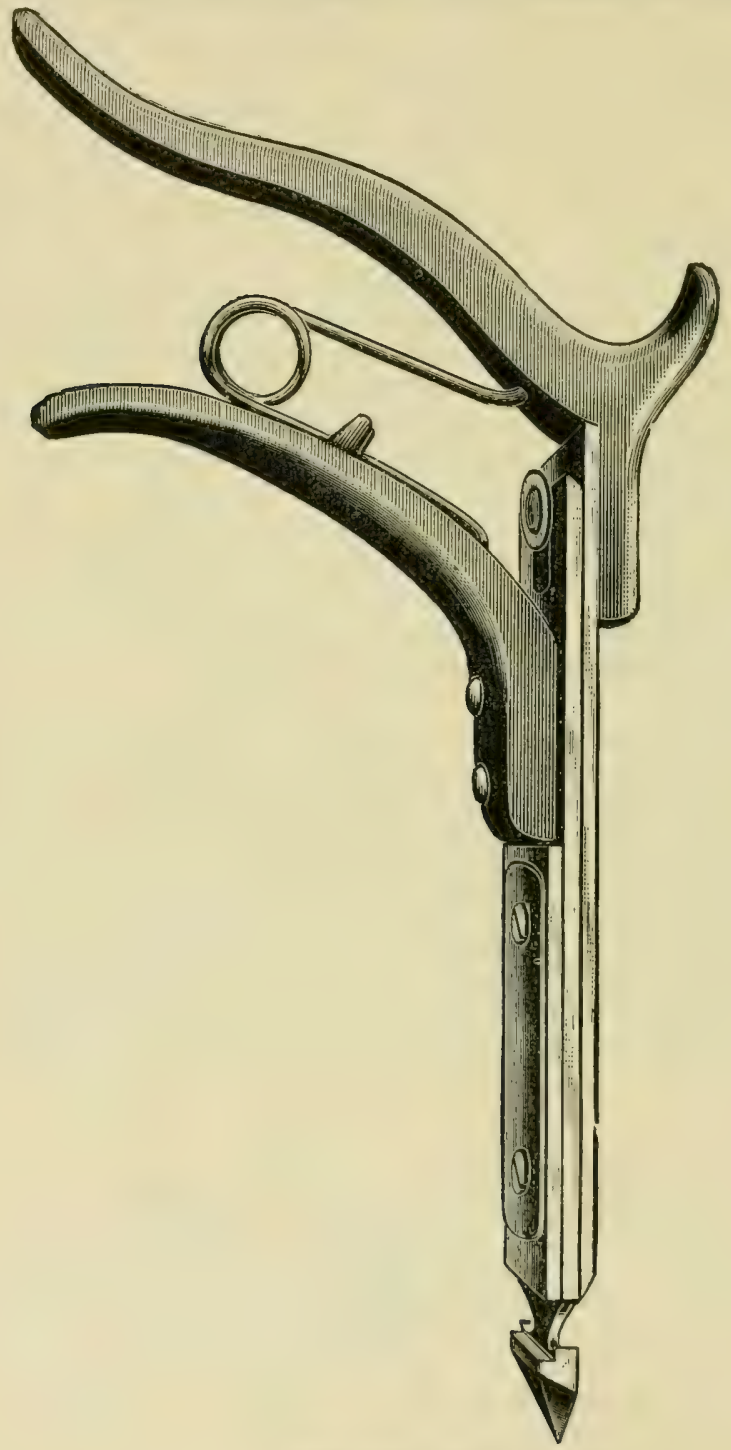

AUTOMATIC FRUI'T PICKER. 
translucent. The experienced picker can tell when that is the case without spending much time examining a bunch. With a sharp knife or scissors in hand we find him busy cutting of all the clusters of well-ripened Grapes and laying them in a tray or open box generally about two feet long by a foot wide and a foot high.

An automatic fruit picker has been lately introduced, which is designed to take the place of knife or shears. It cuts the fruit clear from the twig and holds it at the same time. It can be used with either hand. The picker need not touch the fruit, thus preserving the delicate bloom on the Grapes, and this device cuts and holds the buuch; every injury resulting from the handling is avoided until placed in the tray. This cutter is made of the best tool steel, simple in construction and neat in finish and warranted to stand hard usage far better than a knife or shears.

The empiy trays or picking boxes are placed at a certain distance in the rows to avoid carrying the same very far when partly filled. As soon as a good load is picked these trays are taken to the fruit house. As there is generally very little room at the end of the rows a new style of Grape wagon has been constructed which can turn in

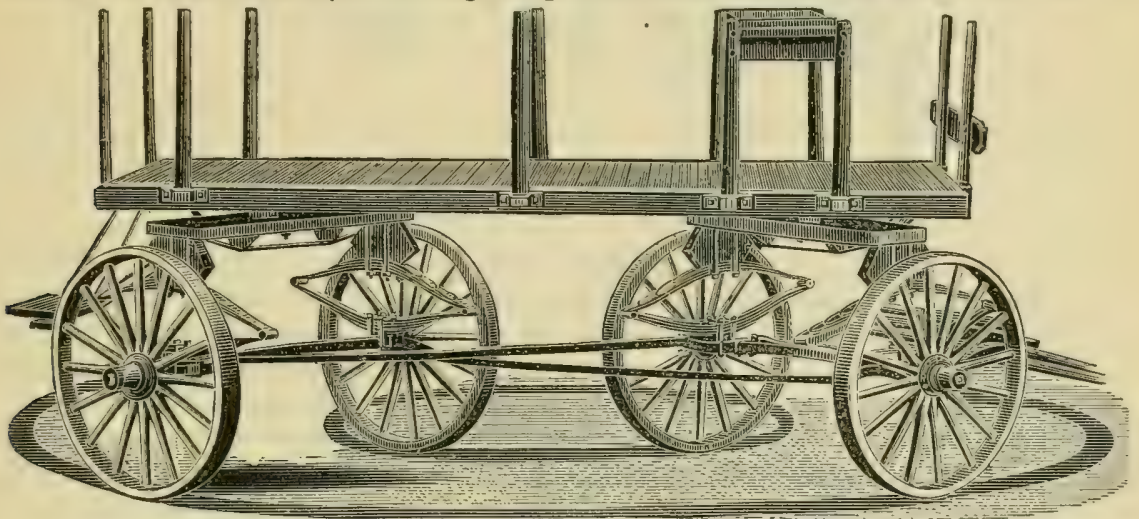

GRAPE WAGON.

a very small and narrow place, as the wheels always track. They are capable of carrying from 2,000 to 3000 pounds. This wagon cannot be excelled for vineyards. When not used for transporting fruit, manure can be hauled with it, also for driving the posts or stakes, in fact one has but to see the working of it to be satisfied what it will do. This wagon is manufactured in several styles, by the DUNkIRK WAGoN Co., Dunkirk, N. Y.

After the trays have been put in the fruit house, girls take bunch after bunch of the Grapes from the trays and with scissors made for this purpose all green and

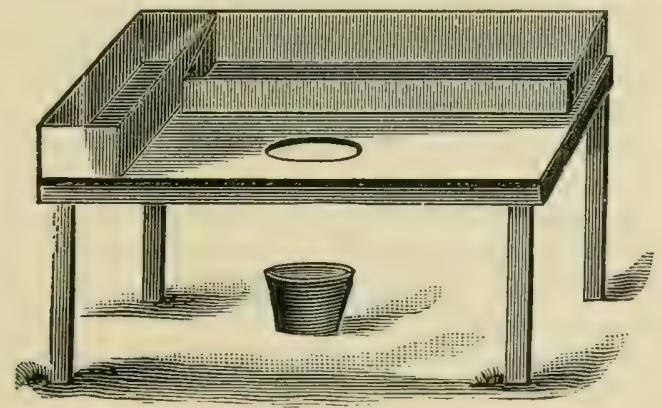

TABLE FOR PICKING OVER GRAPES. 
imperfect fruit is cut out and the trimmed Grapes are laid upon a table from which the packers fill the basket. Nothing but good fruit should be put up.

A very convenient table for picking over Grapes is shown in the illustration. The trimmer sitting at the table has in front a tray filled with Grapes from the vine-

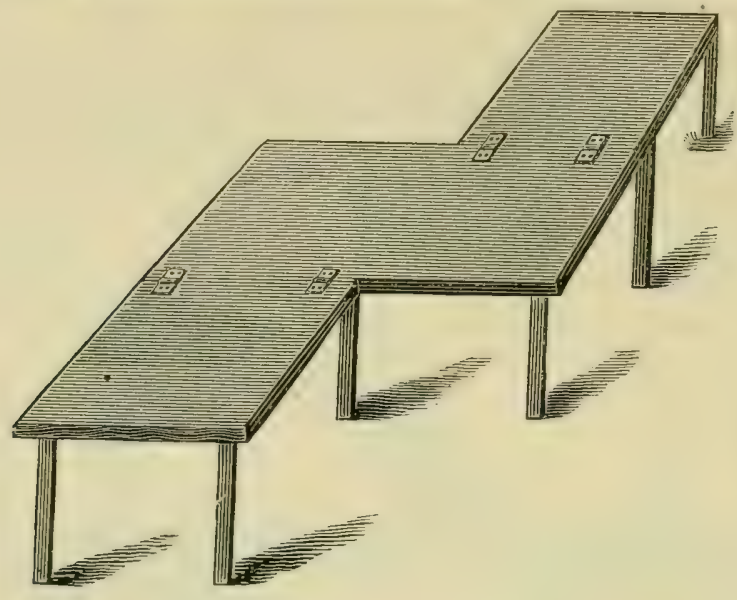

PACKING TABLE.

yard. All imperfect berries are cut out and fall through an opening in the table into a receptacle below, while the trimmed clusters are laid with care into a tray beside the trimmer. These trays are removed then to the packing tables, from which the Grapes are packed in baskets, which work is generally done by girls. This table is fixed in such a manner that two packers sitting opposite of each other can use the same tray for filling the baskets, which are placed on an extension of the table beside the packer. Both of these tables are made with hinges, in such a way, that after the packing season is over they can be stored away without occupying much room.

Poor fruit is one of the prolific causes of gluts and will lower the standard of any locality. Grapes are packed with much skill in baskets of five and ten pounds sizes. The package must be solid and of good weight; the top layer smooth and must project just enough above the top of the basket, that when the cover is pressed down even and fastened on, the Grapes will have no chance to be shaken up. It does not increase consumption for the consumer to find, that what he purchased for a five or ten pound basket holds but little more than four or eight pounds of fruit. Consumers resent all such petty deceptions more than they do high prices. Too much care cannot be taken in sorting Grapes. Some make three grades, the first and second for market, and a third to be disposed of at home, while the most careful fruit growers make but two grades, the first and best only goes to the market. Topping off, putting on top all the good Grapes is a mistake and its injustice must be apparent to the most indifferent. The surface should represent a good average of the contents, but no effort should be taken to practice a deception. The name of the grower or his stencil number is on the packages and the consumer commits to memory very readily the brand which deceived him. Some of the crooked brands are so well known in the markets, that it is difficult to find a buyer for them, even at a big reduction. Every dealer is trying to secure the best trade which can only be accomplished by having nice, uniform fruits. Packing is the most important part of the business and cannot be studied too closely. The consumption of Grapes is increasing wonderfully, 
but it is also natural that more regard should be paid to the quality of Grapes and the manner in which they are placed in the market. It is the poor fruit that kills the market and demoralizes the industry.

After the Grapes leave the hands of the packer, the packages are marked, weighed and finally taken to the dock, or freight depot. Sufficient time should be taken when loading up, to handle them carefully, both at home and at the place of shipping. With these precautions properly observed, the prospects are that Grapes will reach the consignee in good order. The average shipper has no idea how often the Grapes are handled and moved about before they reach the consumer and therefore the importance of the most careful packing cannot be lost sight of. Considerable time in rehandling is saved by using crates for the package.

\section{Marketing of Grapes.}

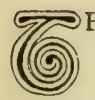

HE success of the Grape business depends greatly upon the ability of the commission-man to promptly place all ehipments at the best prices. Don't select the man who makes the greatest promises, but the one who has the best reputation for fair dealing and promptness. Large cities do not always prove the best markets for Grapes. The best market is often passed by, and Grapes sent to New York, Boston and other large Eastern markets are sold at a less price than they would have brought nearer home. It is always advisable to look well to the question of markets before Grapes are ready.

Much complaint is heard about the unsatisfactory service aud the rates charged by the express companies and other carriers. There is no doubt that our systems of transportation are defective and have been a cause for low prices and profits for the grower by reason of unjust discrimination and defective regulations for interstate commerce. Local rates are too high; in some cases it costs more to ship short distances than longer ones and the short-distance shipper has consequently to pay some portion of the longer-distance shipper's freight bill, or an undue portion of the freight profits. Such obstructions and hindrances should be removed. The large quantities of Grapes and other fruit shipped yearly give to the transportation companies a vast amount of businese and a large income, and they ought to co-operate with the growers to their mutual advantage. Their charges on Grapes, even when prices are away down, are in many cases about all that shipments sell for. The margin between actual expenses and selling price goes almost entirely into the pockets of the transportation companies. Trausportation is a question of profound interest to the Grape grower. Freight rates are difficult to make satisfactory to all. A large portion of our growers must depend upon facilities for reaching distant markets. We hope that the time is not far off when important changes in the Interstate Commerce Law will take place and reward the labors of the fruit grower.

Grape growers should unitedly and forcibly protest against careless handling of baskets by railroad, steamboat employes, draymen and all others employed to handle them. Consumers in many instances find the berries near the bottom of the basket mashed and decaying from the effects of dropping the baskets or letting them down too heavily. Everyone should be interested in getting their Grapes to market fresh and unbruised and the baskets as full and nice-looking as when first packed. This is undoubtedly money in the pocket of the grower. From its perfect condition the 
jobber as well as the retailer will receive more benefit, as he can sell to the best trade, who will buy regular. Such Grapes can be sold with less work and expense at largely increased prices.

The question of packages is an important one, yet so wide in its scope and so dependent upon the grower and shipper as well as on the receiver and retailer, that reform is most needed on this subject. Grapes receive the best treatment both in regard to uniformity of packages and the manner of packing. Dealers, who are familiar with all sorts of packing, claim that they have great difficulty in inducing growers to use proper packages. The style of packages for Grapes has changed considerable within the last few years, and the introduction of new packages has always met opposition in our markets. Years ago, Grapes were all pucked in little round boxes and when they changed to the square boxes, it was just as hard to sell the square as it was later to sell the baskets when they came, and the same is now true of the crate with the favor amongst the sellers of fruit in most cases and the merit there is in the crate. It will come by degrees, and is already here to stay with many growers and becoming more universal. A cheap, light crate that will stand a shipment from a distance is sufficient. It is a well known fact that by far the larger proportion of Grapes shipped to our markets come from a distance and often arrive in bad condition, more or less damaged by rough handling. Growers and shippers of Grapes cannot realize how it injures the sale and depreciates the value of their goods to find damaged fruit mixed in. There is no prejudice against crates in the most of our large markets, simply an inability to displace immediately, a standard style of package, and it requires constant pushing to convince all those interested in fruits of the advantages.

The introduction of the Perfect Spring Fruit Crate, manufactured by ATwATER, ARMSTRONG \& CLARKE, Rochester, N. Y., has facilitated the shipping of our most tender fruit even from long distances. We are perfectly satisfied that the inevitable jarring and jolting in freight cars, express wagons and drays have contributed largely to the destroying of fruit shipped in this country. This has now been almost abso-

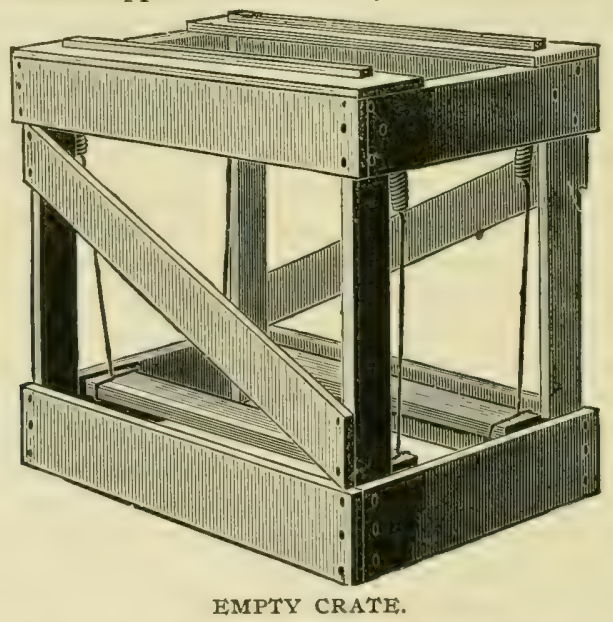

lutely counterbalanced by the Spring Fruit Crate, which is by all means the safest package for our markets. The employment of spring is a necessity to the shipping of tender fruit to have them arrive in good selling condition, Many practical tests have been made the past season. Its simplicity, cheapness, strength, utility, com- 
pactness, and above all its efficiency commend it at once. An important feature of this crate is the peculiar application of the springs, which are attached to the top of the crate and support the trays on which the baskets rest. Its working can be seen on accompanging cuts. It is the only fruit crate in the market having springs attached to the crate itself Defective devices in fruit packages have often been the cause of low prices for Grapes. It is an accepted truth, that fresh Grapes are now shipped 3,000 miles to eastern markets in these spring crates successfully, even competing

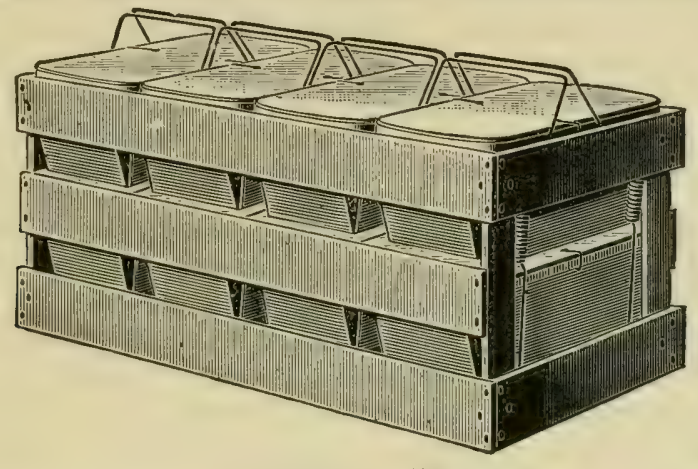

IOADED CRATE.

with the products of eastern sections. Too much care cannot be shown to the packing and shipping of Grapes. If Grapes, in fact all kinds of fruit, are put up in such a way that they must reach the market in prime condition, the grower will build up for himself a reputation and a demand for years to come. The consumer will be always ready and can afford to pay an extra price for good Grapes. Any one who expects to do business will find that the best returns by far will be secured by growing and shipping only first-class Grapes put up in first-class packages. The time is surely coming and the start has been made when nothing but crates will be used for shipping. Clean white packages are the best for marketing fruit. Nothing can so quickly tempt the eye and palate of prospective customers as Grapes having the appearance of being freshly picked, and offered for sale in clean, white baskets and crates. A practical test will very soon show that fruit put up in such packages almost invariably brings better prices than that standing alongside in unclean and mouldy crates and baskets. It is false economy to use old crates and baskets when new and better ones will so quickly pay for themselves.

Climax Grape baskets are the strongest, most solid and compact basket made. Grape growers appreciate their many good points and they have the greatest sale of all

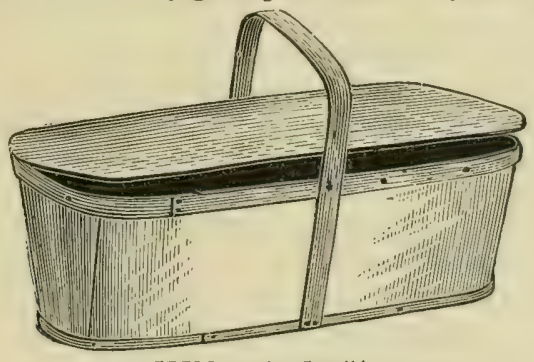

CLIMAX BASKET.

styles made. It is the only basket that will not crush down and mash the fruit more or less when packed one on top of another to the car roof. Their strength and the 
absence of openings between slats in the sides and ends give them more of a character of a box than a basket. It is now almost impossible to sell in the Grape growing regions any other style of package. These baskets were invented by Mr. C. N. Longstreet, late of Onondoga Valley, N. Y.

The Grape interest of our country has become quite extensive. The production of Grapes has been increasing for many years, yet the demand still continues. Our American people are learning to appreciate Grapes more and more every year. Their consumption has been enormous of late years and yet there is many a country town where they are usually scarce. Local markets should be hunted up and supplied. There is little fear of over-production in this direction if only good fruit is marketed and neighboring inland towns chosen rather than the large city markets. Good, ripe Grapes of several of our better varieties are second to no other species in deliciousness.

Vineyardists in Grape growing sections should unite and form some association for marketing their Grapes. This combine saves the grower all the anxiety, labor and expense of finding his own markets, which is necessary if he markets his own fruits. A competent manager will look up markets, solicit orders, seek freight rates, and make sales of fruit that may be put into his hands for sale or shipment. Good fruit will always sell and we have none too much of it, but there should be a resfonsible head, to whom dealers all through the country could send and order what they wanted witho:at fear of being disappointed in quality. The growers at the same time must agree to select and pack the Grapes to a given standard and have a certificate on every package, which means choice fruit honestly packed. The consumer will always remember this brand and demand it on account of its value. This will secure better prices as the good, certified quality and reliability of the Grapes will secure the reputation with the consumer.

To attain the best results aside from thoroughness in culture, care in picking, etc., that as the acreage increases and more engage in this business our first care should be by associating on terms of absolute equity to all, and forming a union for the marketing of the product of our vineyards. Only by such union can prices be maintained at anything like uniformity or make Grape raising more than a speculative enterprise. It must be formed in good faith and lived up to in like good faith. The grower with one acre, must get as much for his Grapes per basket as the grower with one hundred acres. Thus is the expense to the individual brought down to the lowest possible point. Founded on this solid foundation of equal rights it becomes a matter of common interest to maintain the integrity of the union. The larger producer is benefitted by having prices kept from being demoralized and cut below the point of profit, by keeping the large number of small dealers out of the open market in which they are governed by no fixed standard of price, but each individual making such prices as seems to suit his individual needs. Through the association all this becomes unnecessary as all receive the same price and it relieves the Grape grower of becoming a salesman, as under the old plan a grower finds himself away from home with his frapes, and as there is no means of determining what market is full and what one is not, he takes his chances, often finding perhaps a dozen more have been a few hours ahead of him. It is expensive to wait and so he lowers the price, closes out, and returns disappointed, sometimes chagrined, and wonders secretly to himself if the Grape business is after all what it is cracked up to be. This is not overdrawn as many a one will make personal answer to its correctness. With an association of the Grape growers of the different sections good results can be attained. 


\section{Compuission Men.}

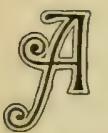

COMMISSION MAN has a hard name, because growers will ship to unreliable, unprincipled men, who induce shipment by false high tips, that a $\cdot \mathrm{e}$ simply a bid to a shipper to rob him. There are rogues in every calling and honest men in most. In every market there is unfortunately a class of commission men who spring up every season, run a career of sharp practice for a brief period, take a header from public view, to bob up serenely in some other locality. They call themselves hustlers, wideawakes, etc., promising impossible prices. The grower is beguiled into making shipments and the result is what any sensible man would expect. Bitter denunciations and vindictive slanderings of commission men as a class fill our agricultural papers. It can readily be seen that houses lacking experience, who receive such consignments only occasionally, are not prepared to do justice to shippers, or as well as those making a specialty of Grapes. A firm not regularly in this line of business sometimes receives a shipment when the market is weak and easily broken, and having no regular trade are compelled to sell under the market value, thus precipitating a general decline, which could be avoided had the fruit been held by some house having an established trade. There is probably no line of business involving such a great amount of work, worry and responsibility as a commission business. The work of the commission man begins at the early hours of morning and lasts till late at night, having in view the interests of the grower. A good, honest commission man not only pleases but also surprises his shippers. We have no doubt there are many among the Grape growers who can tell stories about losses they have suffered with commission men, listened to the smoothtongued voice of new-comers with great promises. Our large markets are well supplied with responsible, honest commission men of good financial standing. Ship to these and you will not be robbed or cheated and every grower and shipper should stick to them as to their best treasure.

In dealing with our commission men there are a few things which we should not expect of him, yet which are too often asked. He stands between two fires, one from the grower and the other from the buyer, we must not ask him to protect us from our own shortcomings in any form. Lovers of good fruit are looking forward to the Grape crop to partially supply the deficiencies in other fruit and partially satisfy the natural hunger for Grapes.

Selling Grapes at auction has been tried in various places and only partly gives satisfaction, though we have no doubt that ultimately Grapes will be sold as much at auction as other fruit. Foreign fruit shippers adopted this system long ago. If in the hands of good, reliable men Grapes will have a quick sale from the highest bidder. The aggregation of the best buyers will be present, if promptly advertised, and if the gathering is large enough to induce spirited bidding, the results are usually far better than by the old methods. Consignments will be promptly cleaned up each day, thereby enabling the auctioneer to make prompt returns. With this system the nicest and best put up fruit will bring the highest prices, as baskets of Grapes when opened up, showing ripe, aromatic and sweet fruit, will be always in demand; shippers of snide packages must not expect as good prices as those that put up standard ones.

The capacity of our people to consume Grapes is only just beginning to be tested. What we want is to improve their quality, to cheapen and quicken transportation 
and to extend the season. Every northern market should be supplied with Grapes from June until January, and in abundance. Our people have only been eating Grapes for two months; they ought to be supplied for six.

\title{
Keeping Grapes.
}

HE Grape is like the apple, a fruit that should be on the table several months in the year. The varieties that are good keepers have usually a thick, tough skin that does not crack. Preparation begins by producing fruit worth keeping, by good cultivation, thinning out the crop, prompt treatment of mildew, \&c. The fruit should be thoroughly ripe, then the stems of the clusters lose their rigidity, and the clusters hang directly downward from the vine. Grapes that are badly ripened, poor and watery, will not keep under any circumstances. A dry day should be selected for picking the Grapes. In picking handle by the stem only and avoid removing the bloom. Lay the clusters in shallow trays in a single layer only. The trays are taken in a spring wagon to the fruit house cellar, which is provided with racks to allow the trays to be placed one above another, but far enough apart to allow of ventilation. The fruit house should be provided with means to control the admission and the exclusion of light, air, temperature, moisture, \&c. The Grapes may remain in a honse of this kind for months and when wanted will be found to be cured. While the berries retain their plumpness their skins have acquired toughness; they will cling to their stems. With a favorable location and a due regard for ventilation, \&c., a fruit house may keep Grapes in good condition as long as the market lasts.

\section{Fruit Houses and Fruit Rooms.}

\author{
BY LUTHER TUCKER ALBANY, N. Y.
}

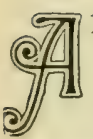

FTER a year of much scarcity, a number of fruit growers are inquiring for a good plan for the construction of fruit houses for a family supply, to furnish fresh fruit through the entire year. Such houses may be constructed at moderate expense, which, with properly selected varieties, will afford fruit through nearly the whole year, if the circle is completed by early cherries and early strawberries. It is not necessary to employ ice for maintaining a low temperature in hot weather, such houses being adapted to large establishments, and requiring constant care and much skill in their management. For the smaller and cheaper structures th essential requisites are non-conducting walls and ventilating windows, provision being made for the cool air on cool nights, to maintain a temperature slightly above freezing, and thus preventing decay during warm seasons. With such a provision, we have found no difficulty in keeping such apples as the Baldwin and Newtown Pippin through winter and into the middle of June, and such winter pears as Nelis, Lawrence and Malines into February and March.

The fruit room may be a separate building, or an apartment connected with the dwelling, and separated from all other parts by means of a non-conducting wall. A 
building fifteen by twenty feet, or any similar or equivalent dimensions, will furnish ample room for all the fruit required by a common fanily. It may be wholly above ground, or partly sunk in the earth. The advantage of excavating for a part of the space, is to obtain more warmth from the earth at the sides, and to expose the structure to less of the sweep of winter winds.

A common practice is to erect a frame of six-inch studs, and cover both sides of these with boards, filling the space between the boards with sawdust; but a better way is to nail on the studs building-paper before the boards are applied, the studs being placed just far enough apart to give a slight lap to the paper as the rolls are successively applied. The sawdust is omitted, as it is liable to cause crevices by settling, and to be attacked by rats and mice. If this air space and the two covers with boards and building-paper are not sufficient to make a good non-conductiug wall, nail vertical strips on each lath and add another covering of paper and another boarding. The roof is to be made non-conducting in a similar way, and the room is to be protected with double doors and double windows. The natural heat from the earth floor, with these protecting walls, will prevent the room from freezing.

But the most important requisite in preserving the fruit from decay, is to main tain a low temperature,-only a few degrees above freezing, -through all warm weather. Two thermometers should therefore be provided, and the temperature frequently examined. By admitting cold air during nights and keeping the room closely shut in the day time, the fruit may be kept cool. Windows should be placed on opposite sides, so that by opening them a free current of cold air may be admitted in the night. This result will be facilitated by means of a Mott or Espy ventilator on a vertical ventilator, as these always produce an upward current when there is any breeze outside.

Instead of an earth floor, there may be a slatted floor, the copious openings through which will admit the warmth from the earth below, and prevent freezing,

If the fruit room occupies a part of the basement of the dwelling, it should be entirely separated from the rest of the basement by a double brick wall, and opposite windows provided as already explained. The windows in both kinds of fruit rooms should be coristructed so as to open or swing open to any desired degree, to admit cold air slowly or freely as the thermometers may indicate.

When entering the fruit room after the fruit has been stored within it, the door at the side should be promptly closed against warm air without. Larger and more perfect rooms, with a half-story above, may be entered by means of a flight of stairs, and thus not allow the heavy cold air of the room to escape.

The accompanying figures will assist in rendering these explanations plainer.

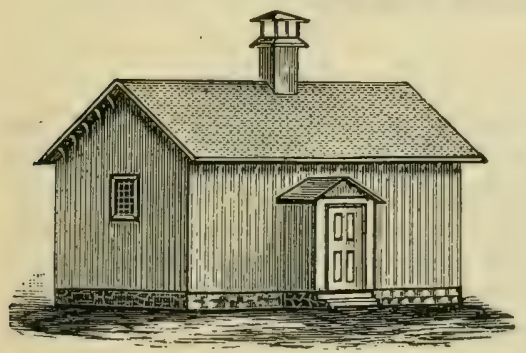

Fig. 1.

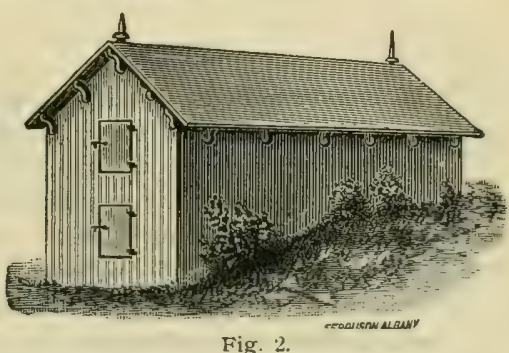

Fig. 2.

Fig. I represents the exterior of a small fruit house, with the double entry at the side. A single window at each end gives ventilation in connection with the vertical wooden pipe surmounted with an Espy ventilator. 
Fig. 2 is a larger fruit house built on a billside, with an upper half-story, from which the main room is entered by stairs. The windows at the end are closed as soon as the apartment is filled.

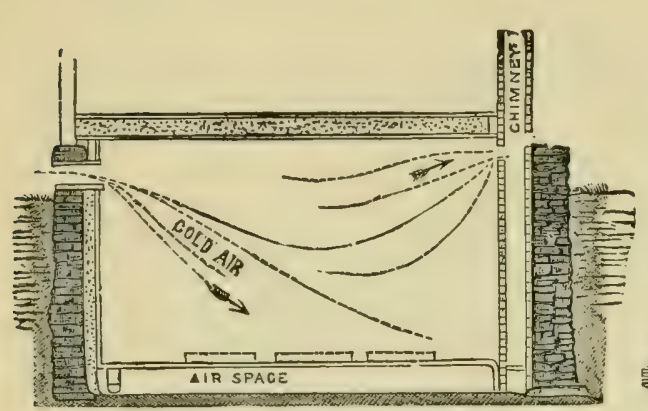

Fig. 3.

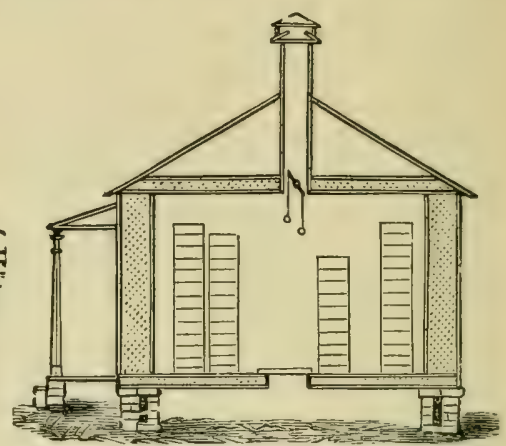

Fig. 4.

Fig. 3 represents the cross section of a fruit room, and showing the ventilation. The dotted lines and arrows show the entrance of the cold air at a side window, and the escape of the warmer air into a vertical chimney in which some upward current is kept up by a stove above, or by the ventilator at the top. This window is closed as soon as enough air is admitted. The space between the slatted floor receives the warmth of the earth during cold weather in winter. Instead of the stone wall represented in the figure, the upper part may be constructed with the air space already described. This figure more particularly represents a fruit room in a dwelling; the floor is double to prevent the passage of heat.

Fig. 4 is the cross section of a fruit house built wholly above ground, the exterior of which is represented by fig. I. The underpinning is double, with an air space as a non-conductor of heat, and with a free connection with the earth below through inoard registers or through slatted work. The ventilator is readily controlled by the 11.ngıng buttons. The piles of fruit boxes are filled with fruit, and being placed one above another operate as separate covers for each other, and whenever assorting is necessary for removing decayed specimens, they are successively lifted off and new piles thus formed.

\section{Cold Storage.}

CHE latest methods of keeping fruit is done by refrigeration. The use of ice

(a) has been familiar for a long time, but it is inefficient and will not reduce the temperature below its own. Its melting is rapid and fills the air with moisture. The refrigeration by ice machines has become universal. The process is very simple. Ammonia, sulphuric ether, sulphurous oxide, are driven into a coil by a powerful forcing pump and condensed into a liquid form. The operation throws out a vast amount of concealed heat, which is carried away by a constant stream of cold water which flows or trickles over the coil. The liquidized vapor is then allowed to escape into large pipes, where its sudden change to gaseous form absorbs the heat of everything in its neighborhood, and reduces the temperature to any desired point. At this point the cold pipes pass into vats of brine, which is immediately chilled to 
about zero. The cold brine is then pumped through coils or lines of pipe. This cools the air of any room in which the pipes are located, the extent of refrigeration depending upon the number and size of the pipes in any particular case. To those who are accustomed to see huge blocks of ice in refrigerators, the power of these pipes is simply wonderful. A half dozen pipes suspended from the ceiling around the sides of a well built room lowers the temperature close towards the freezing point. As the cold increases, curious results occur. The atmospheric moisture slowly precipitates in the form of snow and the pipes will soon be covered to a depth of six or eight inches.

It next forms upon the ceiling and walls. Some of the particles are snow, others are frost crystals, such as are produced upon the window-panes in long winter nights, while still others are of an ice, so brittle as to break at the lightest touch of the hand. As this moisture is frozen the air grows strangely dry. The cold and dryness together are destructive to all living organisms. Flies, moths and gnats entering these rooms, are benumbed in a few moments and in a half-hour are dead. No spider ever spins a web and no mould or fungus is ever formed upon wall or ceiling.

The dryness and low temperature of the air prevent all decay and preserve to a remarkable extent the flavor of the goods stored in these rooms. The season for berries, fresh fruit, etc., will be prolonged from weeks into months. This temperature can be regulated for rooms, in which fruit is stored, to forty degrees, where it will keep indefinitely if the tissues of the fruit are not frozen, otherwise it will not keep well when taken out.

Cold storage has already become a special busicess and is likely to become a very large industry, but improvements have to be made yet to save our tender fruit from decaying.

\section{Preservative Fluids.}

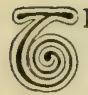

$\mathrm{HE}$ preserving of the different kinds of fruit in their natural state for exhibition. $\& c$. is a very delicate matter, as a good many points have to be taken into consideration, some of which are not easily overcome. The preservations must prevent all fermentations, moulding or other fungus attacks. This means that the outside of the fruit, and the air or the liquid around it, shall be sterilized in some way consistent with the preservation of the form at least, of the fruit. This excludes any considerable heating, such as is necessary in putting up fruit for eating purposes. The use of antiseptics or substances which resist putrefaction, acting at the ordinary temperature, must be relied upon. We have to choose between gas and liquids, but as the manipulation of gases does not come within practicable condition of every one, we are confined to the use of liquids. This liquid should not exert any solvent or softening action upon the skin of the fruit. One of the most difficult conditions to fulfill and yet one of the most essential is, that the liquid should not extract or change the color of the fruit. The preservative fluid should neither cause the fruit to swell, so as to increase its size and sometimes burst it, nor should it have the opposite effect of causing it to shrink. This implies that in the exchange that will unavoidably occur between the juice inside and the fluid outside, the two shall pass through the skin with about equal rapidity, which means that both liquids shall be of the same density. If not, the fruit will either shrink or swell, at least at first. In thick-skinued fruits the change is more or less permanent. 
Sugar may be used, but being easily fermentable and liable to change tint when not very pure, it is preferable to use glycerine. Commercial pure glycerine will act very satisfactorily when used per cent. for per cent. by weight in place of sugar. To do this by liquid measure, use four-fifths per cent. of glycerine as equal to one per cent. of sugar. According to the statement of Prof. E. W. Hilgard of California, who made the subject a special study, it is not always easy to ascertain the density of the juice of fruits, but may rest content with the following approximations to the soluble matters of fruit juices for ripe fruit:

Apples and Pears, about.............. I2 per cent.

Plums, Prunes, Apricots and Peaches, about . . . . . . . Io per cent.

Cherries, about.. ............. I2 per cent.

Most Berries, about............... 8 per cent.

Currants..................... Io per cent.

Grapes, average. . . . . . . . . . 24 per cent.

It is only in very tender skinned fruit that a per cent. or two, more or less, will make a difference in the result.

The following are the most available antiseptics. Salicylic acid, boracic acid, sulphurous acid and its compound, bisulphate of soda (and lime), and last but not least, bichloride of mercury or corrosive sublimate.

SYLICYLIC ACID, or its compound, is one of the best and most energetic preservators, a solution of one ounce of salicylic acid to five gallons of water, to which as much glycerine has been added as corresponds to the density of the fruit juice, constitutes a preservative fluid, which has been used with very satisfactory results. The acid will dissolve readily in water heated a little.

BORACIC ACID is not well adapted to long conservation of samples in their natural aspect, but will do well for a few weeks with most fruits, as it is liable to soften the skin and alter the color of the fruit. Use about five ounces to a gallon of water.

SUlPHURIC ACID, which is used so much in fruit drying, can also be employed in solution for the preservation of fruit. This solution may be made directly from the gas of burning sulphur in the following manner: "Put thirty gallons of water into a forty-gallon barrel; float on top of the water a tin pan, in which put a portion of twenty-five cents worth of sulphur. Set the sulphur on fire and cover tightly uutil the fire goes out; renew the sulphur until the whole is consumed, opening the barrel for renewal of air between the doses. This mode of proceeding is so simple and sulphur so cheap, that it may well be recommended for use.

Lately the use of BICHLORIDE OF MERCURY for this purpose has been brought forward. Grapes can be best preserved for collectious by keeping them immersed in a solution of corrosive sublimate, taking care to wash the clusters thoroughly beforehand with water. They will remain perfect in color, form and size and the berries firmly attached to their stems. The strength of the solution should be half an ounce of corrosive sublimate to a gallon of water. About the end of the second year the solution may be renewed, thus assuring the preservation for a number of years at a trifling expense. This fluid is of a poisonous nature. It should properly be made with distilled water; if not available other water may be used by first boiling and allowing to clear by settling, before dissolving the sublimate. The proper addition of glycerine prevents the shrinking or bursting of the fruit. No metal must come in contact with the sublimate solution, as it would be quickly decomposed ; only glass stoppered jars should be used.

To keep air from access, tight-sealed jars must be used. Experience also suggests that inasmuch as all fruits, when they are to be preserved, are gathered before fully matured, that they may not be too soft for handling, therefore the full amount of 
sugar given by the analysis quoted in above table is not yet present. It would seem advisable to reduce the above figures to two-thirds or even to one-half, taking into consideration the ripeness when the fruit has been gathered and add the glycerine accordingly

Many preparations are offered for sale, of which the California Fruit Salt and the Liverpool Salt are the best. While these methods will for a long time perfectly preserve the bloom and color of the fruit, they will make it, of course unfit for eating. Twigs, with the foliage attached, when preserved in this way, are exceedingly attractive for exhibition purposes.

\section{W Ine $M$ Taking.}

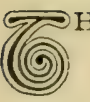

HERE are in the manufacture of wine, general rules, which apply to all countries, but the vintner has to take into consideration the climate conditions of the country in which he is to operate and the kind of Grapes he has to deal with. The art of wine making is very simple and not as complicated as generally believed. Wine properly is the pure fermented juice of Grapes ; its composition is very variable; and the difference in the varieties of grapes used admit almost endless modifications of the product obtained from them. Many other conditions affect more or less the manufacture of wine, as the nature of the soil, the climate, the method of cultivation pursued, the weather during the season when the Grapes were ripened, etc. The same varieties of Grapes when grown under different conditions of soil, climate, etc., produce different wines. Grapes in the different states ripen at various times and therefore have to contend in some sections with difficulties attending the fermentation due mainly to the hot climate and early season, in which Grapes ripen and have to be fermented. In sections where the vintage takes place in October, regular and steady fermentation results, converting all the sugar into alcohol. In warmer climates like Florida, where Grapes mature in July, the hottest part of the season, greatly agitated fermentation occurs at first, causing the heating of the mash and the stopping of all fermentation, when there is still several per cent. of sugar unconverted. The different kinds of wines sold can be numbered by the hundreds. They refer usually either to the country where it is produced or of whose product it is an imitation, as Port, Sherry, Hochheimer, Madeira, etc., or to the variety of Grapes from which it is made, as Catawba, Riesling, Delaware, etc. No generally recognized classification is made, except into white or red wines according to their color, and into dry or sweet wines according to their contents of sugar, Champagne or sparkling wine. Champagne is simply the result of a peculiar way of fermenting the wine in closed bottles, which will be described later on.

In order to operate rationally and mathematically, it is necesary to have one of Twitchell's Acidimeter, an instrument for ascertaining the strength of acids contained in the must. Oechsle's Must Scale or Saccharometer is another important instrument with which to determine the amount of sugar in the must. Must is called the wine pressed from the Grape but not fermented. No good wine can be made from any Grape that does not contain two pounds of sugar to the gallon of must. For this reason we must have some guide or means of ascertaining this fact. The best method of doing this is with the must scale. Press a sufficient quantity of Grapes to make enough juice to fill up the glass cylinder of the must scale, and strain the must 
through a fine sieve or piece of cotton cloth. If this fresh pressed out must, which should not have had time to ferment at all, should indicate eighty degrees on the scale, it contains then two pounds of sugar and will make a wine containing eight per cent. of alcohol. No lower standard of wine will keep in a common cellar. Concords, when well grown will reach this. Norton and Cynthiana will run as high as one hundred and one hundred and twenty degrees.

When the acidimeter is used for the test of must intended to make claret, it is better to have the necessary quantity of Grapes for the test crushed the day before

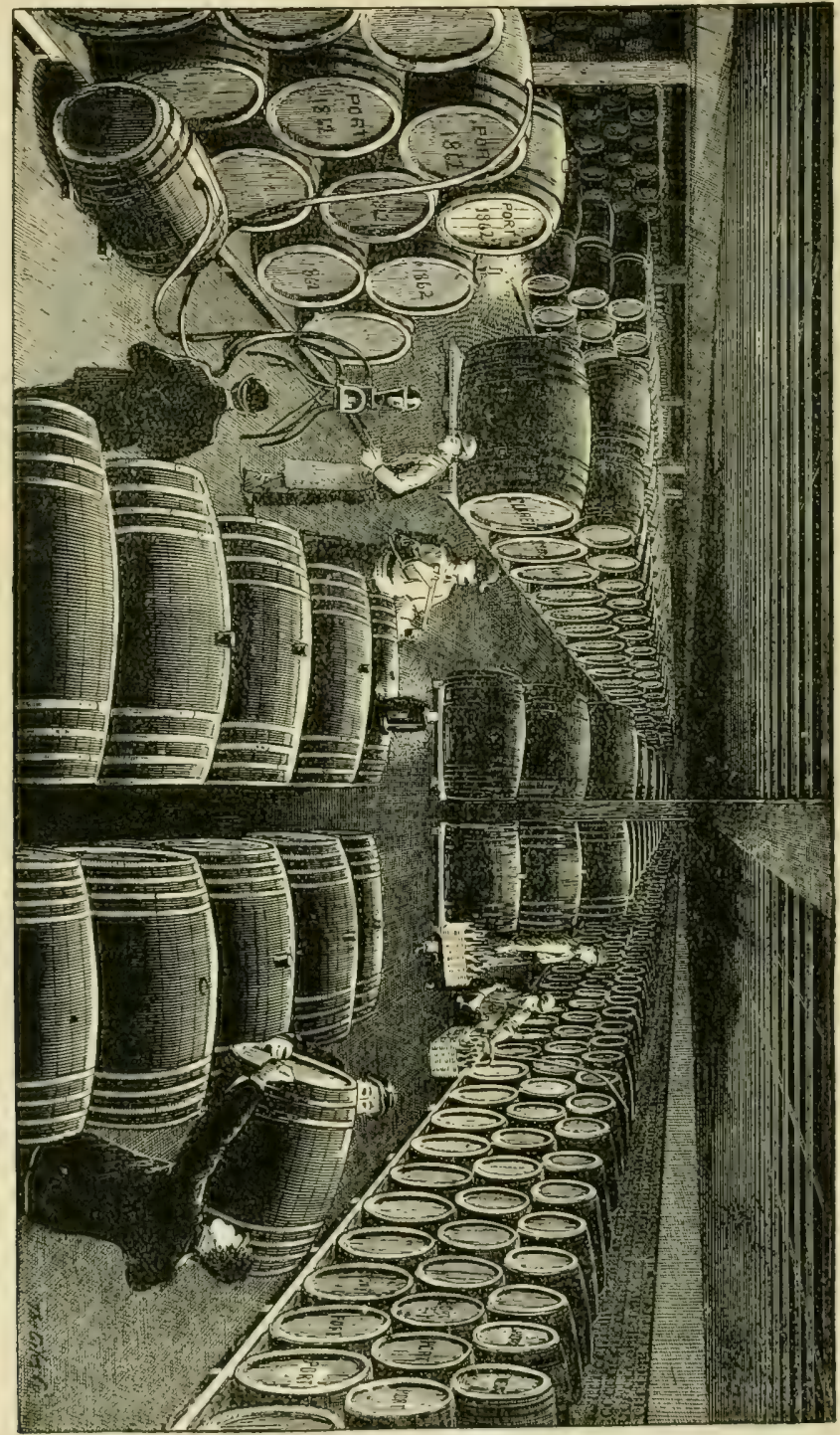


and allow juice and husk to ferment together, as most of our Grapes contain their acidity in the skin and fermentation only can draw it out.

Whenever any Grapes mark below eighty degrees that deficiency should be made up with granulated sugar, and for every ten degrees of deficiency in the must add one-third water to dilute the excess of acid found in the Grapes when in that condition. It should be distinctly understood that the more acid the Grape is, the greater should be the addition of water. The adding of sugar and water is especially resorted to in unfavorable seasons, when the want of sufficient sun prevents the

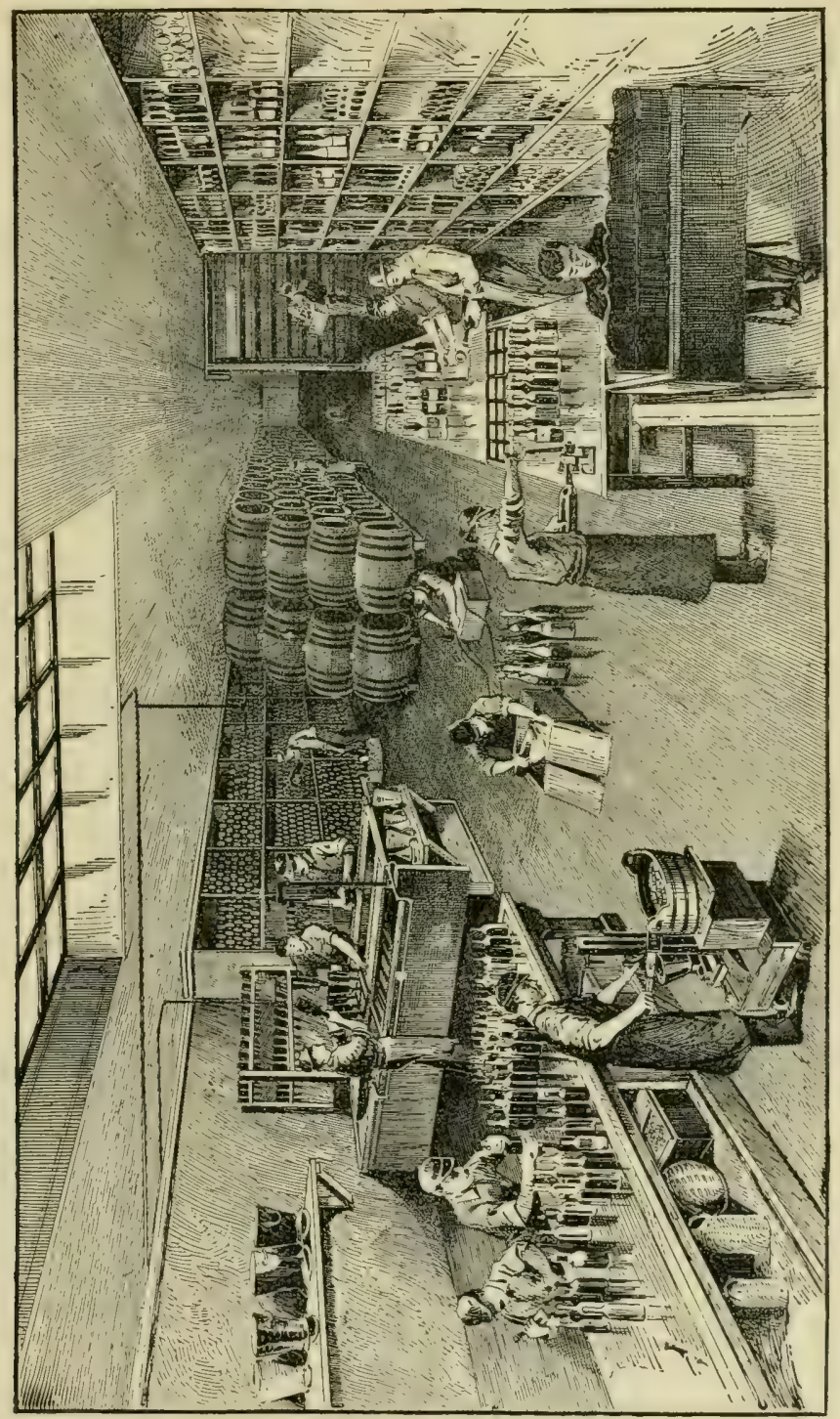


formation of enough sugar in the Grapes, and the proportion of acid is high. This method for improving wines is but very little used in this country as American Grapes are generally up to the standard in the contents of sugar. The more sugar Grapes contain the more alcohol will be developed in the wine, and will keep so much better.

The first step in wine making is the production of must. Grapes should be perfectly ripe, carefully looked over, that all rotten, green or other imperfect berries are removed. In some sections it is necessary to resort to the stemming, or separating the berries from the stem. Such is specially the case when rot or mildew have destroyed half of each bunch. For some very fine wines the stems are also removed. The Grapes are then put through a grinder or machine that will simply break the skins, and then subjected to pressure to obtain the juice or must. The amount of must varies with the means employed, the kind of Grapes, etc., but may be stated at about sixty to seventy per cent. of the weight of the Grapes. For red wine the must is allowed to stand in contact with the skins a variable length of time until it has acquired from them the desired depth of color, and in this case fermentation commences before the juice is expressed. The must is fermented in suitable vats or tanks made generally of oak. The best approved dimensions for fermenting vats are four feet high by five feet in width. Before filling the tanks, fasten a small wire screen over the faucet hole to keep the berries out of the faucet, when racking off the wine. The tank should not be filled higher than ten or twelve inches from the top. Stir the mass four times a day at even intervals, with a kind of pestle made like a churn dasher. By twisting and downward motion of this contrivance the pomace is pressed down, disintegrate and immerge the whole mass, thus preventing the over-heating of the mass, causing cessation of fermentation before all the sugar has been converted into alcohol. It may happen, that notwithstanding the frequent stirring, the temperature will be higher and the fermentation more active at the top than at the bottom of the vat. After having ascertained this fact by testing the must, some can be drawn out by the faucet and poured on top, repeating the operation until the must in all parts of the vat has the same temperature and about the same amount of sugar. The fermentation is produced spontaneously, that is, by germs accidentally introduced into it from the air or on the surface of the Grapes themselves. If the fermentation does not take place promptly it is started up by introducing into it a supply of yeastcells from some must which is already in a state of fermentation. The temperature at which the fermentation is carried on has a very decided influence upon the character of its product and the practice differs in different sections. The duration of fermentation also varies with the temperature, the amount of sugar to be transformed, etc. After fermentation is complete and all the sugar has been converted into alcohol, which can be ascertained by testing the wine with the saccharometer, the wine is drawn off into casks or barrels, where a second slow fermentation takes place, continuing sometimes several months. When it is over the wine is racked off into fresh casks, which are closely bunged up. The operation of racking off may have to be repeated several times and it is necessary sometimes to add isinglass or other gelatinous materials, which serves to clarify the liquid, acting on the tanin which it contains. This operation is called fining. Wines made from thoroughly sound, ripe grapes, will under proper care become clear and remain sound without any addition of finings. The neglect of the proper management of the temperature is the cause of by far the greater proportion of faults in commercial wines and elaborate and costly precautions are taken in wine making countries to secure its control.

The most important constituent in the Grape is its sugar, and the principal change in the chemical constitution produced by fermentation is the conversion of the sugar into alcohol and carbolic acid. 


\section{Red Wine.}

The manufacture of red wine is more complicated on account of the numerous accidents aud influences to which the must is liable during its long contact with the solid parts of the Grape in tank fermentation. The first fermentation reqnires con. stant and intelligent care and judgment on the part of the maker, if the best results are to be obtained. The rejection of unsound Grapes from the red wine tank is of the utmost importance to exclude the germs of improper fermentations carried by them The sorting out of mouldy or otherwise faulty bunches must be much more vigorous than in the case of white wines. In red wine fermentation, the yeast of the pomace remains more largely in contact with the fermentable liquid; hence the fermentation progresses and passes more quickly, and is therefore more liable to raise the temperature to an objectionable degree, resulting in the partial or complete arrest of fermentation. The greatest source of difficulty is the cap formed on top of the mash by the carrying up of the pomace by the escaping gas. The often repeated stirring in as described previously is considered one of the best methods for preventing fermentation by bringing all the yeast into action and for fully extracting the pomace, while at the same time it serves to equalize and if necessary to lower the temperature of the tank charge. Unless faithfully and carefully done, it exposes the wine more or less to the evils resulting from the formation of the cap. If claret has been thoroughly fermented in the vat, it will but slightly ferment in the casks ; the bungs should not be driven in tight, but simply pressed in a little with the hand. When the wine is perfectly still the bung must be tightened.

\section{White Wine.}

In the manufacture of white wine white Grapes are generally used, although some red Grapes, such as Delaware, Iona, \&c., are also very often employed for the same purpose. The Grapes are pressed as soon as they have been crushed and the juice is not allowed to ferment on the husk. The juice, which runs out of the vessel in which the Grapes are crushed is put in clean casks or barrels and room enough must be left in each barrel to divide equally the juice coming off from the press. The cask or barrel should be filled only to within about an inch from the bung and a sand bag laid over the bung hole to prevent any escape of gas during fermentation, and at the same time prevent air from coming in contact with the wine. Some use perforated bungs in which one end of a rubber tube is inserted, the other end being submérged in a glass jar full of water.

Casks or barrels should be filled up with the same kind of wine put aside for that purpose at least twice a week during the first mouth, and once a week afterwards until they are no more subject to fermentation. When the fermentation is over the cask should be filled up with the same kind of wine and bunged up tightly.

\section{Sweet Wine.}

In sweet wines sugar has to be added. The quantity depends entirely upon the sort of wine to be made and also upon the kind of Grapes as well as their degree of ripeness. If Grapes are allowed to remain on the vines, as long as the weather permits, and get over ripe, they will improve in sweetness. Crush the Grapes and put them into a vat to ferment for about thirty-six hours, stirring the mash several times a day. Draw off the wine as done before with the red wine, and add to each gallon of wine one pound of granulated sugar and one pint of Cologne spirits. The wine obtained from the press should be treated in the same way. As soon as the wine 
is clear, rack it off into perfectly clean barrels or casks; the smaller the cask the quicker the wine will get age.

Coloring matters are frequently added to brighten and improve the color obtained from the Grapes. These colors may be of vegetable origin, obtained from the various vegetable dyes, or by mixing the juice of other highly colored berries or fruit with the wine.

\section{Unfermented Grape Juice.}

The Grapes are pulled when fully ripened, the juice extracted by press and bottled as soon as possible afterwards. The bottles are filled brim full and placed up to their necks in hot water, within ten degrees of boiling point. When the must is as hot as the water the cork is forced into the bottle expelling a portion of the liquid. If the least portion of air is left between the cork and the liquid, fermentation will ensue. When the cork is forced into the bottle the liquid is in a state of expansion from the heat. As it cools it contracts, leaving a vacancy between the cork and the liquid, but the vacancy must not be an atmospheric chamber. The cork must, of course, be thoroughly air tight. If fermentation does set in, it may be driven off by re-heating the wine.

The bottles are then laid on their sides in a cool place, to become clear and sufficient time should be given. At the end of the settling period it should again be filled into bottles the sediment being left behind. These bottles must be brim full and should again be set in vats of hot water, heated up to the same degree, and corked in precisely the same manner as at first, using sealing wax to exclude the air. The wine is then left to cool in the ordinary way and put away where the temperature is even and cool. It is now ready for use and will keep just as long as it is kept from contact with the atmosphere. This makes a very delightful beverage which is entirely free from alcohol.

\section{Home Made Grape Juice.}

A very simple method and at the same time a concentrated, unfermented Grape juice is made as follows: After the Grapes have been stemmed and the juice pressed out by any convenient means, the liquid is reduced to one-quarter of its bulk by boiling slowly in an earthen jar. Bottle the resulting liquid when cool, cork tightly and keep the bottle in a cool, dark place. By using two or three teaspoonfuls of this stirred in a glass of water, a delightfully, cooling, invigorating and refreshing drink is made for the invalid or the work-weary body. No sugar or other addition is required at any stage, and by reason of the boiling down process, comparatively little space and few bottles are required to preserve the product.

\section{Chatupagne Making.}

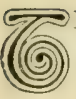

E art of Champagne making was discovered in 1688 by Dom Perignon, a monk in the French Province of Champagne, hence the name. Only the best Grapes are always able to produce the finest brands

The newly expressed juice, after the first fermentation in casks, is conveyed to the cellars and after a brief period it is racked and ready for blending or mixing the wines from different Grapes together in such proportions as to produce a perfect 
wine. As the result depends upon the skill, art, experience and judgment of the taster, the Champagnes of the several manufacturers differ accordingly. In order to insure the greatest uniformity the mixing is done in gigantic vats, containing several thousand bottles. The wine is then returned into casks, and at the proper time in May and June, bott'ed and securely corked. Shortly after bottling, the second fermentation takes place, which produces the effervescence and forms a sediment, which is deposited during fermentation.

Then another test of skill is required. Should there be too much saccharine matter left in the wine, the fermentation will be so strong that the bottles will break and the whole be a loss; should there not be enough there will be too little fermentation so that the wine will have very little effervescence, and be flat and insipid. But should this critical period be successfully passed and the fermentation be just right, it is then put down into deep vaults where it remains from two to three years, until the wine has become thoroughly ripened. It is then placed upon racks, where

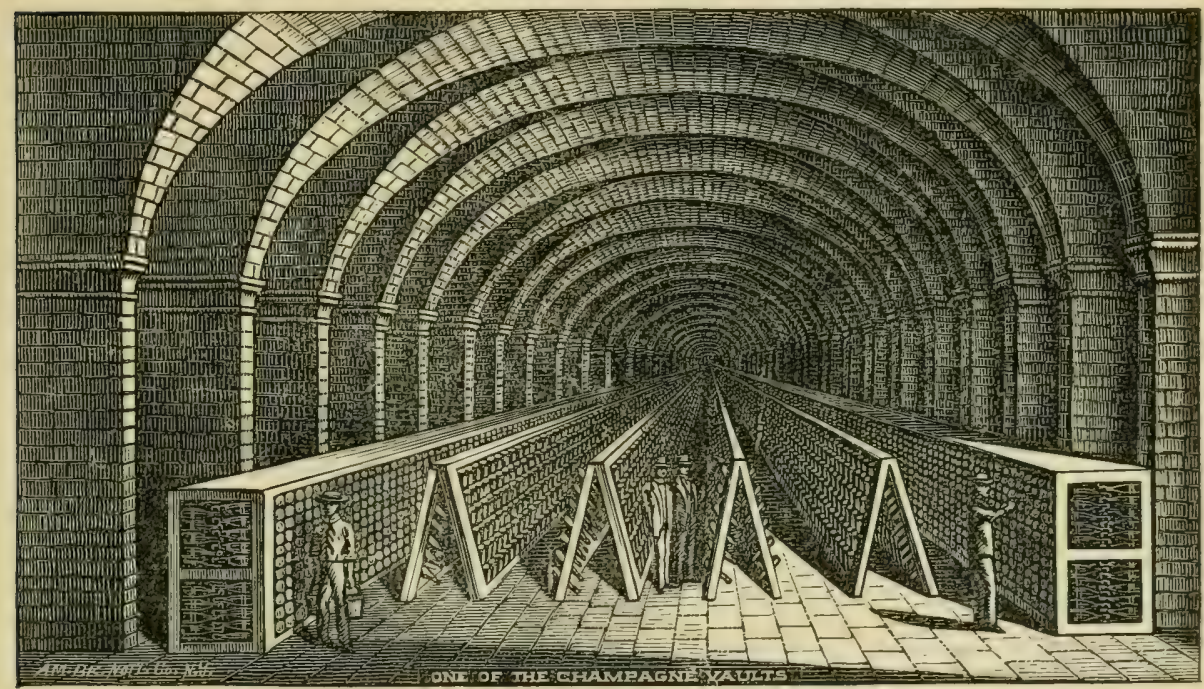

it is shaken several times daily, from three to five weeks by skilled workmen in order to detach the sediment and get it to rest on the cork, the bottles being in racks with necks downward. Then comes the work of the disgorger, who carefully loosens the cork, which flies out together with the sediment and a small quantity of wine. Then is added the "dosage," a preparation made of pure sugar crystals dissolved in old wine. The use of brandies or spirits renders it heady and heavy. Champagne with the least quantity of alcohol is by far the wholesomest and possesses remarkable enlivening power. It is then recorked with as fine a cork as can be found and after it has been tied down, wired, capped, labeled, \&c., it is ready for market. During this process each bottle is separately handled from two to three hundred times, and as much of the handling must be done by especially skilled workmen, one may see some reason for the high values set upon the best Champagnes. The making of Champagne is so complicated that it really needs the services of an expert for those that engage in this business.

Champagne should never be served otherwise than very cold. It should never be poured upon ice, as it will destroy the fine aroma and bouquet. The object in 
using it cold is that all the gas shall be received by the stomach and the wine when cold absorbs and retains its gas, liberating it slowly.

\section{Useful Information.}

NUMBER OF VINES REQUIRED PER ACRE.

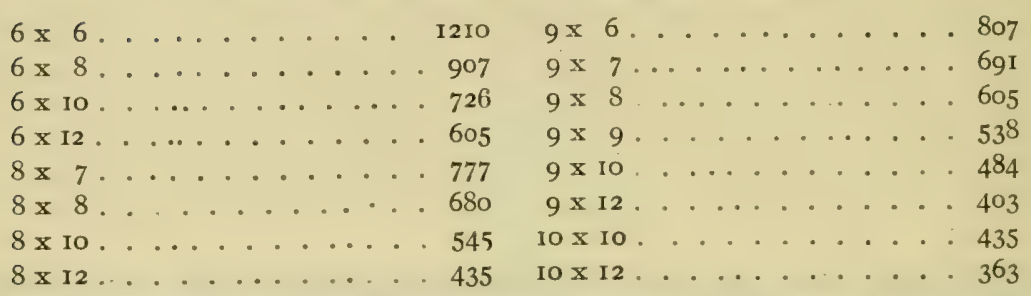

With rows eight feet apart and posts twenty-four feet apart about 250 posts per acre are required; also eight pounds of staples to fasten wires to intermediate posts. With rows eight feet apart and three wires per row $65^{\circ}$ pounds of No. II, 800 pounas of No. Io, and 900 pounds of No. 9 wire are required per acre. This can generally be purchased in quantity at two and one-quarter to two and one-half cents per pound. The wires may be secured to the end posts by boring a $1 / 4$ inch hole through one end post at the proper distance from the ground and fastening the wire around the other end post, and stretching it along the row, put it through the hole and fasten it by drawing into the hole from the outside of the post, using a hard wood pin and then twisting the wire securely around the pin. The wires should be drawn tight but each fall these pins may be driven out and the wires left with sufficient slack to admit contraction during cold weather, and again tightened in the spring.

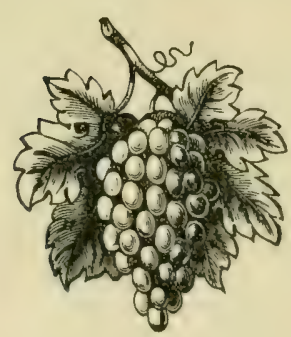




\section{Descriptive List.}

]$^{\top}$

Thas been our aim in compiling this list to make it the most complete ever published. All the different varieties, old as well as new, are brought up to date and though the descriptions are the best we could give with the resources at our command, we have no doubt that the experience of some of our professional growers with new varieties will differ from that given in this list. Many of these varieties have originated only within a year or two and were not sufficiently tested We were therefore obliged to take the description as received from the originators, and cannot recommend these novelties for general cultivation. The number of varieties now under culture is altogether too large and many of little merit should be dropped, while none but such which have good quality and points should be retained for general culture.

Quite a number of seedlings have been grown from our standard varieties. of which some are actually the same as the parent and only pretended seedlings to sell under a new name; others are so identical as not to require description. All these are referred to in our list as synonyms of some other variety, giving the name of the parent from which they originated, as far as known or supposed.

In the description all the names of Grapes are given in FULL-FACE type, arranged as near alphabetically as possible. The species are in italics abbreviated as follows : Est. for Estivalis, Labr. for Labrusca, Rip. for Riparia, Hyb. for Hybrids, which contain more or less foreign blood, Rotun. for Rotundifolia, Vin. for Vinifera, and those whose parentage is unknown, called chance seedlings, are marked with (?).

ADELAIDE. $(H y b$. $)$ Originated by Jas. H. Ricketts. A hybrid between Concord and Muscat Hamburg ; bunch medium size ; berry oval, black with light blue bloom ; sweet but sprightly ; subject to mildew.

ADELINE. (Labr.) Produced by the late T. B. Miner, of Linden, N. J. Probably a Concord seedling; white ; has been but very little disseminated; a good amateur Grape.

ADIRONDAC. (Labr.) Originated at Port Henry, Essex Co., N. Y. Probably a seedling of Isabella ; black ; early as Hartford; bunch long and compact; quality of the best, but the vine is neither healthy nor strong and is not recommended.

ADVANCE. $(H \cdot y b$.) One of Rickett's seedlings. A cross between Clinton and Black Hamburg; berry is black with blue bloom ; medium, roundish oval, thin skin ; bunch large, moderately compact and shouldered; scarcely any pulp; sweet and very sprightly; vine healthy, vigorous and productive; inclined to mildew and fruit rots badly ; ripens early.

AGAWAM. (Hyb.) (Rogers No. I5). Raised by S. Rogers, of Salem, Mass. Is considered by many to be one of the best Grapes in his collection. Produced by hybridizing the Mammoth, one of the best and earliest wild species of New England, with Black Hamburg. Red or amber color; bunch usually loose, shouldered; ber. ries large, skin thick, flesh pulpy, meaty, juicy, of a rich, peculiar aromatic flavor; ripens about with Concord; vine a strong, rank grower, hardy, productive and moderately healthy in most good Grape regions. On rich, low ground it is sometimes subject to mildew and rot in unfavorable seasons. A good keeper; should be pruned long. 


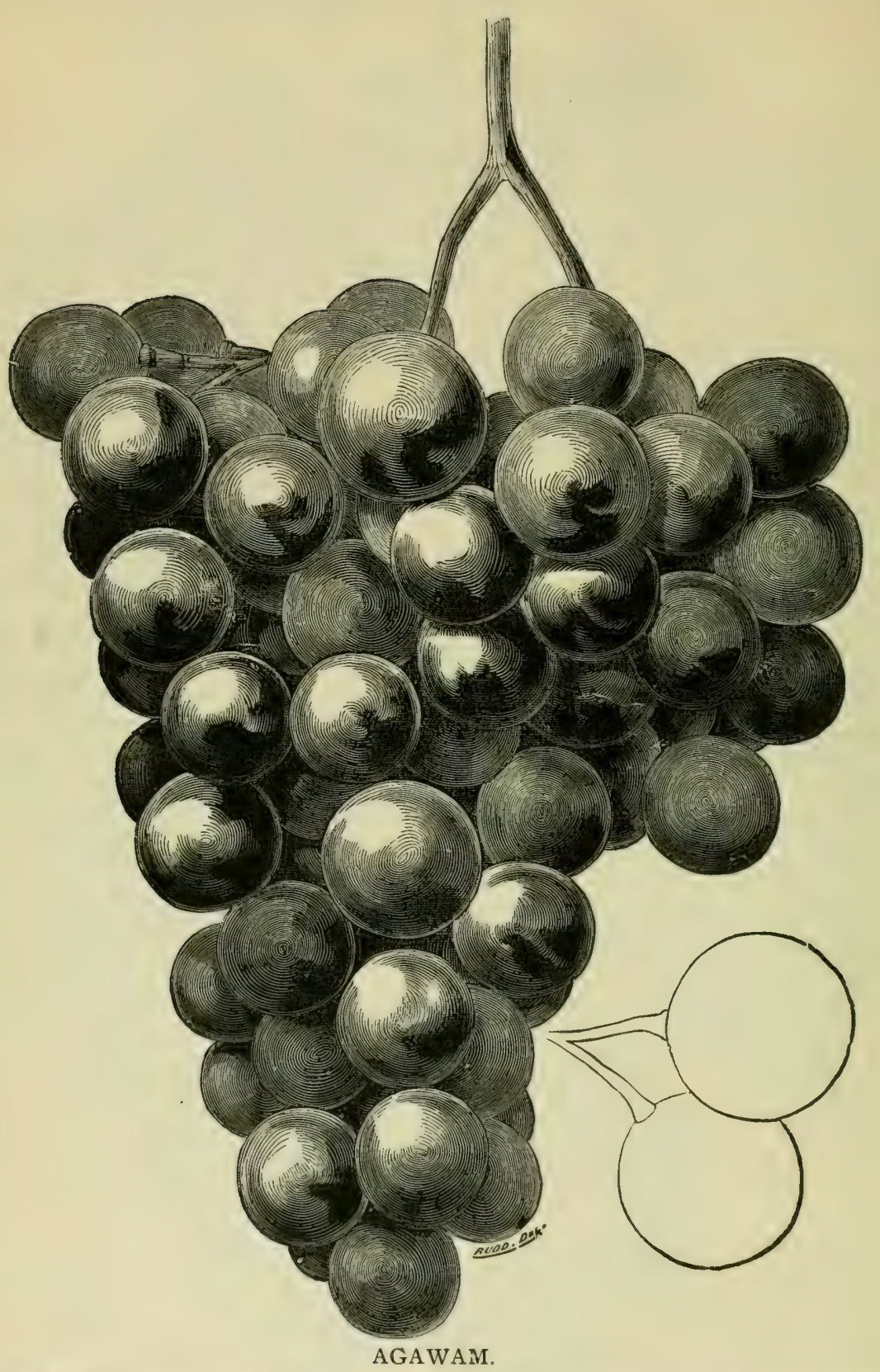

AIKIN. (Labr.) A seedling of the Isabella, differing very little in form, size or quality of fruit, or in growth and productiveness.

ALBERT. (Labr.) A Concord seedling grown by T. Huber, Illinois City, Ill. Bunch and berry Concord size; black. 
ALBINO. ( $\mathrm{Labr}$.) Seedling of Isabella, raised by J. B. Garber, Columbia, Pa. Bunch small; berries large, oval; yellowish or amber in color; flesh acid, tough but foxy; not valuable.

ALEDO. (?) Introduced by B. F. Stringer, Charlotteville, Ind. Bunch medium, compact; berry medium to large; green tinged with yellow; nearly round but flattened at base; pulp tender, moderately juicy; quality not very good.

ALETHA. (Labr.) Seedling of Catawba, originated in Ottawa, I11. Very early; bunch medium and loose; skin thick; dark purple; flesh pulpy and very foxy ; was never disseminated.

ALEXANDER. (Labr.) This Grape was found many years ago by the gardever of Gov. Penn, on the banks of the Schuylkill river. Supposed to be a natural seedling of the wild Fox Grape. Bunch rather compact, more or less shouldered; berries medium, oval, black; skin thick ; flesh very firm, juicy ; rather foxy ; of no value.

ALICE. (Hyb.) Raised from seed of Lady Washington by W. H. Lightfoot, Springfield, Ill. Vigorous in growth ; cane long jointed ; berry, large, round; golden yellow without bloom and glossy; cluster medium to large, moderately compact; leaf large, thick and healthy; very promising.

ALICE. (Labr.) A seedling of Martha, originated by J. A. Putnam, Fredonia, N. Y. Bunches about the same size as those of Martha, but more tapering; berries medium, round; greenish white; good bearer; a few days earlier than Martha.

ALICE. (Labr.) A chance seedling grown by W. D. Gunn, Clintondale, N. Y. Bunch medium to large, moderately compact; berries medium, round; amber inclining to a claret color; sweeter than Catawba with less stringency and somewhat less pulp; skin very thick; berries hang firmly to the stem; strong grower and healthy; ripens before Catawba.

ALLAIR. (?). Bunch small, loose; berry medium, red; flesh pulpy; quality poor; of no value.

ALLEN'S HYBRID. $(H y b$.$) A hybrid of Isabella and Chasselas, originated by$ the late John Fisk Allen, of Salem, Mass. Bunch large, shouldered, compact; berries medium, round; skin thin; color nearly white to pale amber when fully ripe; flesh tender without pulp, sprightly and vinous ; quality good ; ripens early; apt to mildew and rot.

ALMA. $(H y b$.$) Originated by J. H. Ricketts, N. Y. A seedling of Bacchus$ fertilized with a hardy hybrid seedling. Bunch medium, compact, seldom shouldered; berry medium; black with blue bloom; spicy and very sweet; vigorous and bealthy; ripens with Hartford.

ALPHONSO. (Labr.) Produced by T. Huber, Illinois City, Ill. A seedling from Concord; bunch and berries larger than Concord; white; sweet but drop the berries.

ALSTON. (?). A Grape of no value.

ALVEY. $(H y b$.$) A Southern Grape introduced by Dr. Harvey, of Hagerstown,$ Md. It is quite hardy in a protected situation; bunch medium, loose, shouldered ; berries too small for a table Grape; round, skin thin; black covered with a blue bloom ; sweet, juicy and vinous without pulp; not much grown.

AMANDA. (Labr.) Origin unknown, probably a black Fox Grape; bunch medium, compact; berries large; black; thick skin; hard pulp, vinous; said to make a good red wine. 
AMBER. (Rip.) A Riparia cross, originated by J. Rommel, Morrison, Mo. Bunch large, shouldered; berry oval; pale amber; thin skin; pulp tender; sweet, juicy and of good flavor; ripens after Concord.

AMBER MEDINA. (Rip.) Of no value and never disseminated.

AMBER QUEEN. (Hyb.) Originated by N. B. White, Norwood, Mass. Bunch large, shouldered; large berry of dark, amber color; flesh tender, rich; quality fine ; seeds small; a strong grower with thick leaves, somewhat downy on the underside; ripens early; good long keeper.

AMBROSIA. (Hyb.) Originated by Albert Rose, Penn Yan, N. Y. A seedling of Salem. Bunch large compact, often slightly shouldered; berry roundish, flattened, quite large; white, delicate bloom; skin medium thick; pulp not melting, juicy; flavor pleasant, sweet; vigorous, productive; berries shell off; ripens with Delaware.

AMERICA. $(H y b$.$) One of T. V. Munson's new Grapes, Post Oak crossed by$ Rupestris. Bunch large, conical, shouldered; berries large; black; skin thin ; melting pulp; flavor very good; productive and very vigorous grower; said to be a good shipper and keeper.

AMINIA. (Hyb.) (Rogers No. 39.) Hybrid of Mammoth and Black Hamburg. Productive; ripens early; bunches large and compact; berries medium to large; black with a fine bloom; flesh melting, with little pulp; sweet and of fine flavor; healthy, very desirable for market and home use.

AMOUREUX. See Rulander.

ANDOVER. (Labr.) A black Fox Grape of no value.

ANNA. (Labr.) Seedling of Catawba, raised by Eli Hasbrouck, of Newburgh, N. Y. Hardy and healthy, but a moderate grower; bunch large, rather loose and shouldered; berries large; light amber with a white bloom ; pulpy, juicy, rich and excellent; ripens with Catawba.

ANNIE M. (Lajr.) A chance seedling grown by Dr. L. C. Chisholm, near Nashville, Tenn.; was found growing in a flower bed and transplanted by him. Vine healthy, thrifty and hardy; foliage resembling Concord; bunch medium, compact ; berry medium; whitish green; sweet and sprightly ; ripens its fruit well and is rather attractive ; fine table Grape ; ripens several days ahead of Concord.

ANTOINETTE. (Labr.) Produced by the late T. B. Miner, of Linden, N. J. Bunch medium; berries white, large, similar to Lady in quality ; early ; vine vigorous, hardy and healthy.

ARCHER. (?). Originated near Philadelphia. Bunch large; berries medium, roundish; greenish white; flesh juicy, sweet and pleasant; ripens too late for the north.

ARIADNE. (Rip.) Grown by Jas. H. Ricketts, N. Y. Seedling of Clinton and Vinifera ; bunch and berry small; black; only recommended as a wine Grape.

ARKANSAS., (Est.) See Cynthiana.

ARKANSAW. (Labr.) Introduced and grown by Jas. Hart, Thompson, Ark. Vine strong grower, short jointed; lively green leaf which remains in perfection long after the crop is gone; hardy as Concord ; very productive and healthy ; bunch large, compact; berries larger than Concord and very even in size; white turuing pinkish when fully ripe, transparent; skin thin, tough, clear with a delicate bloom; pulp melting and juicy; flavor very high, similar to southern Muccadine and very fragrant; ripens a week ahead of Concord. 


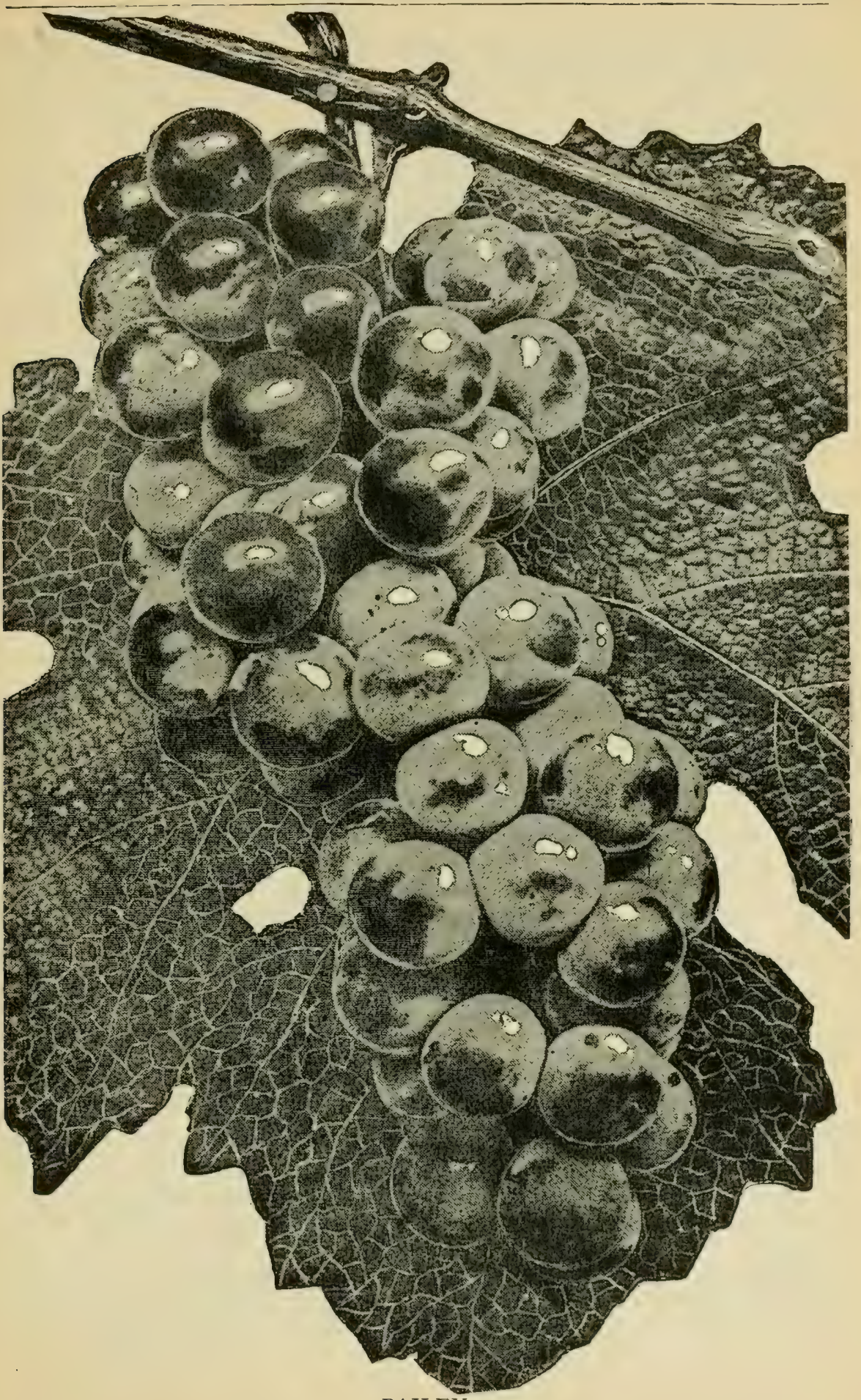

BAILEY. 
ARNOLD'S HYBRIDS. The late Chas. Arnold of Paris, Ont., has originated several well known varieties by hybridizing the Clinton with the Chasselas. Those still in existence are Othello (No. I), Cornucopia (No. 2), Autuchon (No. 5), Brant (No. 8), and Canada (No. I6). Descriptions of these will be found in their proper places.

ARROT. (Labr.) Originated near Philadelphia ; resembles the Cassidy. Bunch and berries medium; white; sweet with a thick skin; good grower, but liable to cast its foliage.

ATAVITE. $(H y b$.$) One of T. V. Munson's productions. Still under trial$

AUGHWICK. (Rip.) A variety having originated with Wm. A. Fraker, shirleysburgh, $\mathrm{Pa}$. Bunches and berries similar to Clinton, in size, form and color, though not as good and less productive; flesh dark red and juicy.

AUGUSTA. (Labr.) Produced by the late T. B. Miner, of Linden, N. J. Bunch and berries medium; white; quality fair; early; vine vigorous and hardy but unproductive.

AUGUST CORAL. Had never sufficient merit in it to warrant its dissemination.

AUGUST GIANT. $(H y b$.$) Originated by N. B. White, Norwood, Mass., and$ introduced by the late George A. Stone. A cross between Marion and Black Hamburg. Bunch large; berries large, oval, purple ; fruit of the Hamburg flavor; quite tender to the center, very rich and fine; vine strong grower and perfectly hardy; liable to mildew ; ripens early.

AUGUST PIONEER. (Labr.) Origin unknown. A black Fox Grape, one of the coarsest of native sorts, large, black, with a firm, hard, pulpy flesh; early.

AUTUCHON. (Hyb.) Originated by the late Charles Arnold, of Paris, Ont. Bunch quite large, moderately compact, often shouldered; berries medium; round; greenish white with a golden tint when fully ripe; skin thin ; no pulp; ripens with Delaware; too tender and unreliable.

AVILLA. (Labr.) Víne weak, nnhealthy grower; lacks constitution.

BACCHUS. (Rip.) An improvement upon the old and popular Clinton, from which it was produced by J. H. Ricketts of Newburgh, N. Y. Bunch medium, compact, shouldered; berry medium, round, juicy and sprightly; black; strong grower and very productive; has proven generally satisfactory ; perfectly healthy and hardy, and increasing in favor for wine making.

BAILEY. $(H y b$.$) Originated by T. V. Munson. Post Oak Grape crossed by$ Triumph. Bunch large, cylindrical, with large, black berries; thin skin but tough; pulp meaty ; red juice; quality very good; prolific. This is a grape of great promise, particularly for wine.

BAKER. (Labr.) A seedling of the Isabella with hardly noticeable difference.

BALDWIN'S LENOIR. (Est.) Originated at Westchester, Pa.; seedling of Lenoir. Bunch small, rather loose; berries small; nearly black; flesh somewhat pulpy; rough, acid; valuable for wine but not for table use.

BARNES. (Labr.) Originated by Parker Barnes, Boston, Mass. Bunch medium, shouldered; berries medium, oval ; black; sweet and good ; ripens nearly as early as Hartford.

BARONESS. (Labr.) Originated by Dr. H. Schroeder, Bloomington, Ill.; prohably a twin sister of Moore's Early, which it resembles in growth and fruit; more productive. 


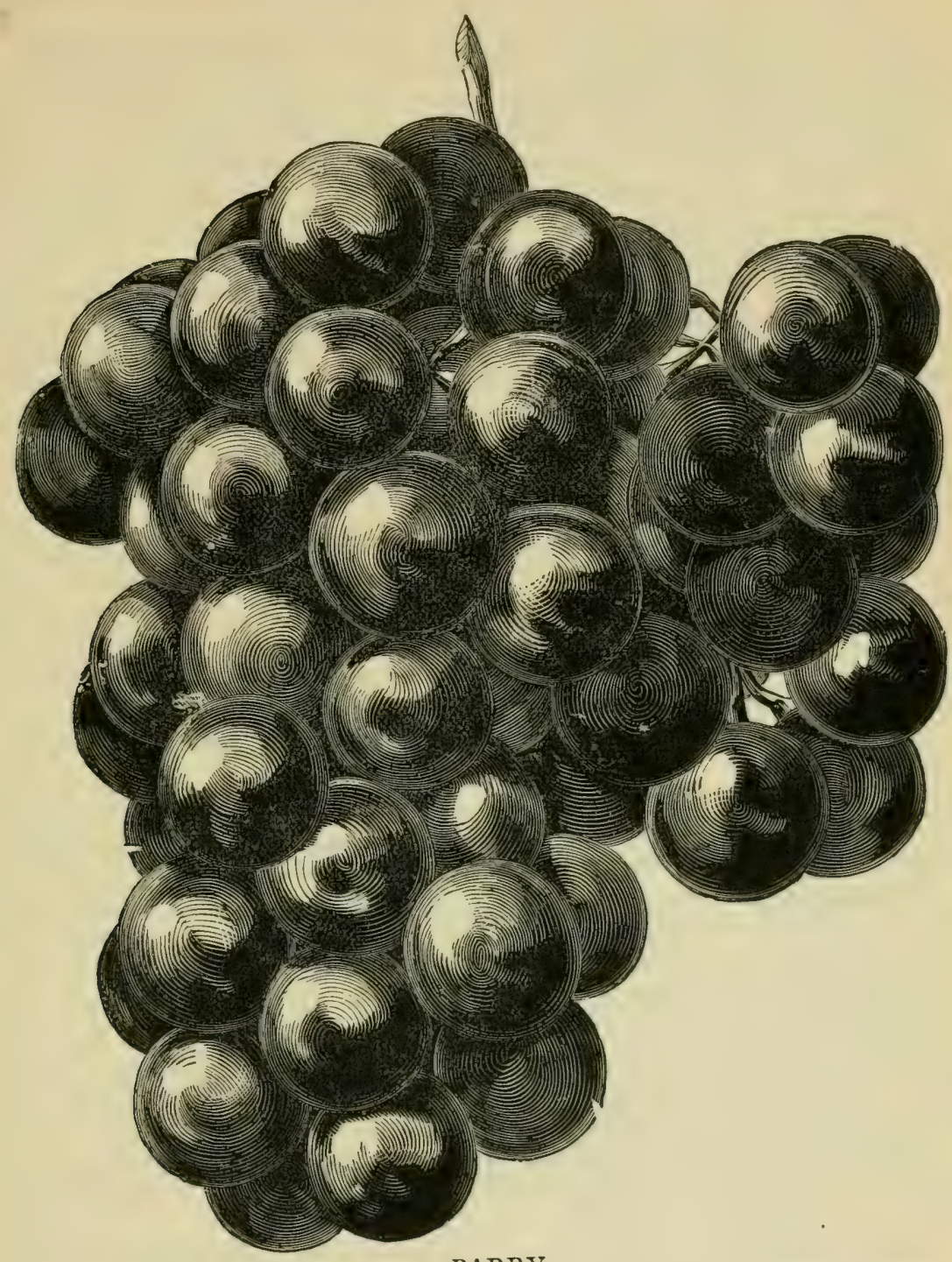

\section{BARRY.}

BARRY. (Hyb.) (Rogers 43) One of the largest and finest of Rogers' Hybrids. Bunch rather large, short, broad, compact, often shouldered; berries large, round, much like Hamburg; black ; delicate, sweet and tender; ripens with Concord; vine vigorous and productive; keeps well.

BAXTER. (Est.) A late ripening Grape from the South. Bunch long, loose ; berries medium; black; juicy; acid; not fit for table use.

BEACON. $(H y b$.$) T. V. Munson, originator. Post Oak crossed with Concord.$ Bunch very large, conical; berries black, very large; skin thin and tough; red, tender pulp ; quality very good, productive. 
BAY STATE. $(H y b$.$) Originated in Massachusetts, and now being grown by$ Wagener \& Co., Pulteney, N. Y. It is a seedling of the Black Hamburg crossed by Marion. Vine vigorous and hardy; foliage large and well retained; bunch medium to large, well shouldered and handsome shape; berry red; slightly oblong: holds well to the stem; pulp tender, juicy, rich, sprightly and sweet; free from mildew; season early, but a good keeper; has every indication of being the coming red Grape for table use.

BEACONSFIELD. See Champion.

BEAGLE. $(H y b$.) Produced by T. V. Munson. Cluster medium, quite short and compact; berries nearly round, medium to small; black; skin thick, reddish purple on inside; very sweet, heavy bloom; flesh firm, pinkish; pulp inclined to meaty; pleasant, sub-acid flavor.

BEAUTY. (Labr.) Seedling of Jacob Rommel, Morrison, Mo. A cross between Delaware, Catawba and Maxatawney; vigorous, healthy and productive. Bunch and berries size and color of Catawba; thick skinned, and will carry well; fine quality; ripens a little later than Concord.

BEAUTY OF MINNESOTA. (Labr.) Introduced by J. C. Kramer, of La Crescent, Minn. An abundant cropper, but too late and rather drops its leaves too soon; not disseminated.

BELINDA. (Labr.) One of T. B. Miner's seedlings. Strong grower and very hardy; large bunch and berry; in fruit it resembles the Pocklington, but ripens a week or more sooner; Concord foliage.

BELL. $(H y b$.$) Originated by T. V. Munson, but not sufficiently tested to give a$ fair description.

BELVIDERE. (Labr.) Originated by Dr. Lake of Belvidere, I11. Vine very vigorous, hardy and healthy; large size and fine appearance, much like Hartford Prolific; drops the berries when over ripe; very early and productive.

BENJAMIN. (Rotun.) Raised from the seed of the Muscadine by W. H. Lightfoot, Springfield, Ill. Bunch large, compact, rarely shouldered; berry very large, round; black with a thick blue bloom; flesh pulpy, slightly musky, sweet, juicy; very vigorous in growth; ripens with Concord.

BERCKMANS. (Hyb.) A cross between Clinton and Delaware, originated by the late Dr. A. P. Wylie, Chester, S. C., the vine resembling that of the former and the fruit that of the latter. A little larger than Delaware, but not as prolific; pale red color and of fine quality : ripens early.

BERKS. (Labr.) Introduced from Berks Co., Pa., resembling the Catawba, of which it is a seedling. Bunch large, compact, shouldered; berries large, round, red ; little pulp; fine quality ; liable to rot; also known as Lehigh.

BERTRAND. Originated with Hon. J. B. Jones of Henderson, Ga. T. J. Berkmans of Augusta, Ga., says in regard to this new Grape, that " it belongs to the type Cordifolium of which the Clinton is the best known variety, but is in every respect far superior in quality to any of that section. The skin is very thin ; pulp dissolving; vinous yet sweet and of delicate aroma ; in point of quality it ranks best." Bunch medium, loose; berries medium, round; blue-black; pulp dissolving; exceedingly juicy, vinous and of delicate aroma; skin thin; quality best; vine healthy and vigorous.

BERTHA. $\left(H_{y}, b.\right)$ A seedling of Roenbeck and originated by Fred Roenbeck, Bayonne, N. J. Bunch and berries not as large as the parent; white; sweet and of fair quality. 
BERLIN. (Labr.) A seedling from Concord, grown by George Hosford, Ionia, Mich. Bunch, large, compact, often shouldered; berries resemble the Niagara; greenish white with moderate bloom; clear; flesh translucent; texture fine, quite solid ; moderately juicy ; shipping quality good, except tendency to drop from stem ; flavor sweet, pleasant, slightly foxy; quality good, medium; vigorous, very productive, hardy and healthy ; season about with Concord.

BERTHA. (Labr.) Originated by T. Huber, I11. Bunch large, moderately compact, shouldered; berry small to medium; white; pulp tender and sweet; ripens a few days after Concord.

BETA. (Rip.) Produced by L. Suelter, Carver, Minn., by crossing Carver with Concord. Good quality and very hardy, enduring unprotected $50^{\circ}$ below zero in Minnesota, bearing good crops; not much disseminated.

BIG EXTRA. $(H y b$.$) By T. V. Munson; Oak Post crossed by Triumph. Vig-$ orous, prolific grower; large clusters with large, black berries; tough skin; tender, red pulp; very good quality.

BIG HOPE, $(H y b$.$) Originated by T. V. Munson, from Oak Post and Triumph.$ Vigorous, prolific; double, large cluster; medium berries; dark red; thin skin but tough; tender pulp, pale red.

BIRD'S EGG. (Labr.) Origin unknown, probably a seedling of Catawba, similar to Anna. Bunch long, pointed; berry oval ; whitish with brown specks; flesh pulpy ; only good for an amateur Grape.

BISMARK. (?). A chance seedling produced by Fred Roenbeck, Bayonne, N. J. Large bunch; black, large berries of excellent aroma; healthy, vigorous and prolific grower; new, very little disseminated.

BLACK CAP. See Alexander.

BLACK DEFIANCE. $(H y b$.) A hybrid of Labrusca and Vinifera, produced by S. W. Underhill, Croton, N. Y. A large and handsome black Grape. Clusters very large ; berries above medium ; good foliage and productive ; ripens late and is suited only to localities where the Catawba ripens perfectly.

BLACK DELAWARE. ( $D e !$. $S d l$.) A seedling of Delaware produced by Jacob Rommel, Mo. Vine very healthy, strong grower, very productive; bunch compact, shouldered; berry medium, black; skin firm; sweet; not subject to rot; ripens early with Hartford.

BLACK EAGLE. $(H y b$.$) Originated by S. W. Underhill, N. Y. Hybrid of$ Labrusca and Vinifera. Cluster long, sometimes shouldered, quite large; berries longish, elongated, medium to large, black; skin thin with blue bloom; flesh greenish, separating easily from the seeds; flavor pleasant, quite acid and free from foxiness.

BLACK GERMAN. See York Madeira.

BLACK HAWK. (Labr.) Originated at Avon, Lebanon Co., Pa. Seedling from the Concord. Strong, vigorous and hardy; foliage very dark green; bunch medium to large; berries large, black, nearly round, juicy, sweet; pulp tender; ripens as early as Concord.

BLACK IMPERIAL. (Hyb.) A black Grape; bunch large, shouldered, compact; berry above medium, tender, juicy, rich, sprightly, vinous, of a peculiar, fine flavor, pure as an European Grape; vigorous, hardy, healthy and very productive; wore or less subject to rot. If this can be controlled it would be a valuable market Grape. Originated by Dr. J. Stayman from Duchess.

BLACK JULY. See Devereux. 
BLACK HERBEMONT. $(H y b$.$) Seedling of Herbemont, grown by T. V, Mun-$ son. Very vigorous; large clusters; small, black berries; thin skin but tough; melting pulp, red juice; best quality; very productive.

BLACK MADEIRA. See Alexander.

BLACK MUSCADINE. See Flowers.

BLACK PEARL. (Rip.) Probably a seedling of Isabella, originated by Caspar Schraidt, Put-in-Bay, Ohio. Vigorous and healthy; in appearance much like Elvira and Noah; makes an excellent dark red wine; ripens before Concord.

BLACK SPANISH. See Lenoir.

BLACKSTONE. (Labr.) An early black Fox Grape of poor quality.

BLACK TAYLOR. (Rip.) Produced by Jacob Rommel. Black ; bunch medium, long, loose; berry medium, quality good; vine vigorous and healthy; ripens with Concord ; similar to Montefiore.

BLAND. ( $L a b r$.) It is said to have been found in Virginia by Col. Bland, of that state. Bunches rather long, loose and often with small, imperfect berries; round, on long stalks, hanging rather thinly; skin thin, pale green turning into pale red when fully ripe ; flesh slightly pulpy, of a pleasant, delicate flavor ; ripens late.

BLAND'S MADEIRA. See Bland.

BLAND'S PALE RED. See Bland.

BLAND'S VIRGINIA. See Bland.

BLAND'S BLACK. (Labr.) A native black Fox Grape; healthy, hardy and productive. Bunch short, compact, shouldered; berry round; worthless.

BLOOM. See Creveling.

BLUE DYER. (Rip.) Bunch medium; berries small, black, very dark juice : wine Grape. Origin unknown.

BLUE FAVORITE. (Est.) A southern Grape that does not ripen well in the north; vine vigorous, productive; bunch above medium; berries medium, round, blue black, sweet, vinous, with much coloring matter; good for wine making.

BLUE GRAPE. See Devereux.

BLUE IMPERIAL. (Labr.) Origin uncertain; vine vigorous, free from mildew, not productive. Bunches medium, short; berry large, round, black; flesh with a hard, acid center or pulp; ripens with Hartford ; inferior.

BOADICEA. $(H y b$.$) Produced by C. J. Copley, Stapleton, N. Y. Telegraph$ crossed with Black Hamburg. Rather a weak grower; bunch and berry medium large, very closely set, not shouldered; berries oval, black, no pulp, quite fleshy, splendid flavor, best in quality; a good keeper; ripens with Isabella.

BOADICEA. $\left(H y b_{0}\right)$ Originated by the late T. B. Miner, of New Jersey. White; bunch and berry small; vine vigorous but unproductive.

BOGUE'S EUREKA. See Isabella.

BOTTSI. (Est.) Was found growing in Natchez, Miss., and claimed to be the true Herbemont, from which however, it differs in color, being a dark pink in the sun; excellent in quality, and vigorous in growth ; prolific ; too tender for the north.

BOULEVARD. (Labr.) Originated by A. Koeth, Charlotte, N. Y., from Concord and Brighton. Bunch large, compact, shouldered; berries medium to large, round, greenish white with fine bloom, sweet, juicy, vinous without any foxiness; skin thin but tough, translucent; vigorous grower, healthy and productive; ripens early. 
BRIGHTON. (Labr.) This handsome and fine Grape was raised by Jacob Moore, formerly of Brighton, N. Y., and is a cross of the Concord and Diana Hamburg. One of the best early red Grapes and largely planted in vineyards. The flowers have

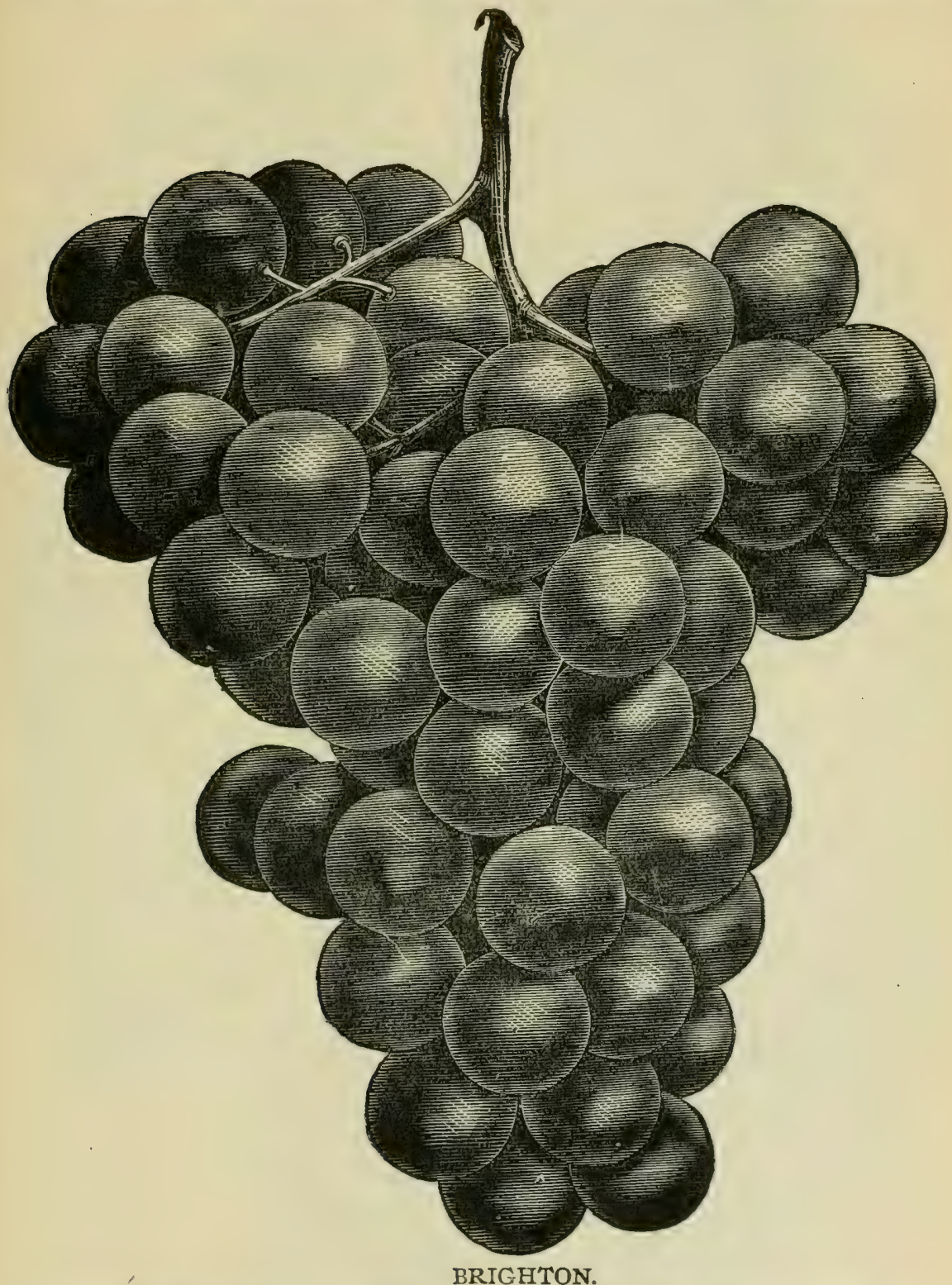

reflexed stamens, and do not always fertilize unless planted with other varieties having upright stamens. Clusters medium to large, compact, shouldered; berries nearly round, size of Concord, reddish purple; skin of medium thickness; bloom 
quite abundant; flesh tender, whitish, sweet, with scarcely any pulp, separates readily from the seeds, flavor pleasant; the bunches keep well, giving choice table fruit long past their actual season ; vine a vigorous grower, comparatively healthy, hardy and productive; in unfavorable seasons and localities sometimes mildews. It is worthy of extensive planting.

BRACKETT'S SEEDLING. (Labr.) A seedling from Isabella. Was never disseminated, as it proved to be unproductive.

BRANDYWINE. (I $i m$.) A seedling of Vinifera. Origin Wilmington, Del. Bunch large, shouldered, rather compact; berry oval, greenish white ; flesh tender.

BRANT. $(H y b$.$) Introduced by Charles Arnold, Paris, Ont., crossing Clinton$ with Black St. Peter. Vine a strong, healthy grower, with foliage of a dark reddish green, deeply lobed, smooth on both sides. Bunch and berry resembling the Clinton in appearance, but far superior in flavor when perfectly ripe; flesh free from pulp, very juicy and sweet, rich and aromatic; ripens early; makes a wine of excellent quality.

BRILLIANT. $(H y b$.$) This is a seedling originated by T. V. Munson, of Denison,$ Texas. It is the result of a carefully made cross between Lindley and Delaware, very handsome and promises to be valuable over a large territory, especially where Delaware succeeds. It has been tested by a few of the best Grape growers in this country and proves perfectly hardy in vine. The growth is quite vigorous and bears abundantly; it is undoubtedly worthy of extensive planting. The canes are of medium growth, light yellowish red, showing more of the character of the Lindley than of Delaware. The cluster is about the size and shape of the Concord, compact and slightly shouldered. Rerries of medium to large size, round, pale coppery red with thin lilac bloom and hangs well to the stem. The skin is rather thin yet tough enough to handle and ship well. The pulp is tender, rich and sweet. Ripens with Delaware, making it a splendid early market Grape, suitable for long shipment. Its beauty and excellence will command a profitable market.

BRINKLE. (Vin.) Raised by Peter Raabe, near Philadelphia, Pa. A seedling of Vinifera. Bunch large, compact, sometimes shouldered; berries round, black; flesh pulpy, vinous, saccharine ; early, vine too tender for the north.

BROWN'S SEEDLING. (Labr.) A seedling from Isabella, grown by W. B. Brown, Newburgh, N. Y. The vine is hardy, a vigorous grower with good foliage ; cluster is about the size of the Concord; berries not quite as large and color blacker; ripens as early as the Champion, but of very fine quality.

BULLACE. See Scuppernong.

BULLITT. See Taylor.

BUNDY'S SEEDLING. (Labr.) Originated by David Bundy, Colerain, O., who also introduced the Colerain. This seedling is a black Grape, (a full sister to Colerain) grown from seed of the Concord. Ripens its fruit with or a little before Moore's Eariy, and will hang on the vines until frost comes. They shrivel up like a raisin Grape and still lose but little of their good quality. Bunch and berry resemble very much its parent (Concord), and fully as good as that noted variety in quality. The vines are perfectly healthy, a very strong grower, abundant bearer and very hardy. It will take its place among the early black Grapes.

BURNET. $(H y b$.$) Seedling from Hartford fertilized with Black Hamburg,$ raised by P. C. Dempsey, Albany, Ont. Bunch large, nearly compact, shouldered; large, oval berries, purplish black, flavor almost like Hamburg. The vine is vigorous and healthy, hardy and productive, ripening before Concord. 


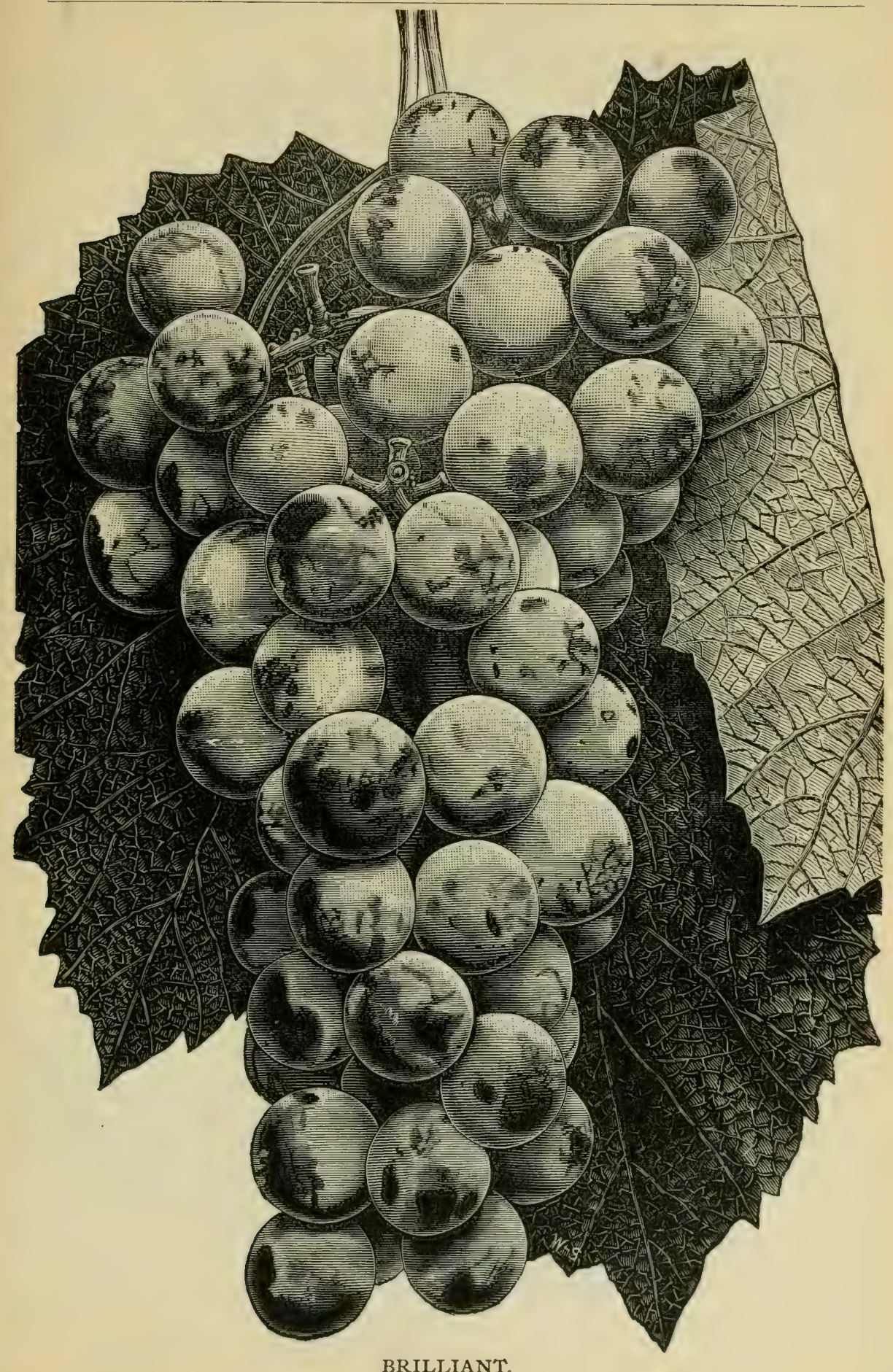


BURGUNDY. See Lenoir.

BURGUNDY OF GEORGIA. See Pauline.

BURRoUGHS. (Rip.) From Vermont. Vine allied to the Clinton. Bunch small ; berry round, black, heavy bloom; flesh harsh and acid; ripens a little earlier than Isabella.

BURTON'S EARLY. (Labr.) A large, early, poor Fox Grape, unworthy of culture.

CALYPSO. $(H y b$.$) A seedling of Lady crossed with Secretary, originated by$ C. J. Copley, Stapleton, N. Y. Bunches very large, much shouldered like a double bunch, uniform in size; berries large to very large, hanging firm to the peduncles, round, no pulp, juicy, sweet and vinous, aromatic flavor; medium to strong in growth, perfectly hardy and healthy ; excellent keeper ; ripens with Concord.

CAMBRIDGE. (Labr.) Originated in Cambridge, Mass, and was introduced by Hovey \& Co., in Boston. Black ; so nearly resembling Concord in every respect as to be considered identical with it.

CAMDEN. (Labr.) Of the Fox class; bunch medium; berry large, greenish white; flesh with a hard center, acid, poor.

CAMPBELL. $(H y b$.$) Originated by T. V. Munson, Texas. A seedling of$ Triumph. Vine vigorous and healthy, much resembling its parent. It appears to be as hardy as any of the Rogers Hybrids. Very prolific ; bunch large, long and compact; berry medium, very persisteut, beautiful golden yellow; skin thin, tough, melting without pulp, pure, rich, vinous, of the highest quality, excelling even the Triumph. It ripens with or a little before Deleware, and is slightly subject to rot or other diseases. Named in honor of Geo. W. Campbell.

CANADA. $(H y b$.$) Raised from seed of Clinton crossed with Black St. Peter,$ by Chas. Arnold of Paris, Ont. Vine and foliage somewhat like the Clinton, also the bunch, but larger berry, black with a fine bloom ; skin thin and free from acid common to other native Grapes ; flesh free from pulp, juicy with a distinct foreign flavor, and aromatic. It proves too tender and unreliable for the north.

CANANICUS. (Labr.) Originated by D. S. Marvin, Watertown, N. Y., by crossing Eumelan with Worden. Bunch medium or above, rather loose; berry medium, pale green with white bloom, round, translucent; skin thin, juicy, sprightly, sweet; vigorous, productive ; ripens with Concord.

CANBY'S AUGUST. See York Madeira.

CAPE. See Alexander.

CARLOTTA. $(H y, b$.$) Originated by the late T. B. Miner of New Jersey. White;$ bunch and berry large; vine moderately vigorous, healthy, hardy.

CARMAN. $(H y b$.) This Grape was produced by T. V. Munson, in 1885 , by hybridizing one of the best Post-Oak Grapes ( $V$. Lincecumii, Buckley), found by him wild in Grayson county, Texas, with Herbemont. It has borne four successive years. The vine is very vigorous, free from disease, and begins bearing in the second year, producing immeuse crops of medium to large clusters of medium to large berries, of very dark purple, almost black-when fully ripe. The quality is excellent; skin thin and tough; pulp tender, very juicy, rich and sprightly, similar to that of Herbemont, but ripening earlier than that variety, though later than Concord-about with Catawba, or perhaps a few days earlier. Berry very persistent to cluster; flavor pure, rich, sprightly and sound to the center. A Grape of high character, good keeper and shipper. 


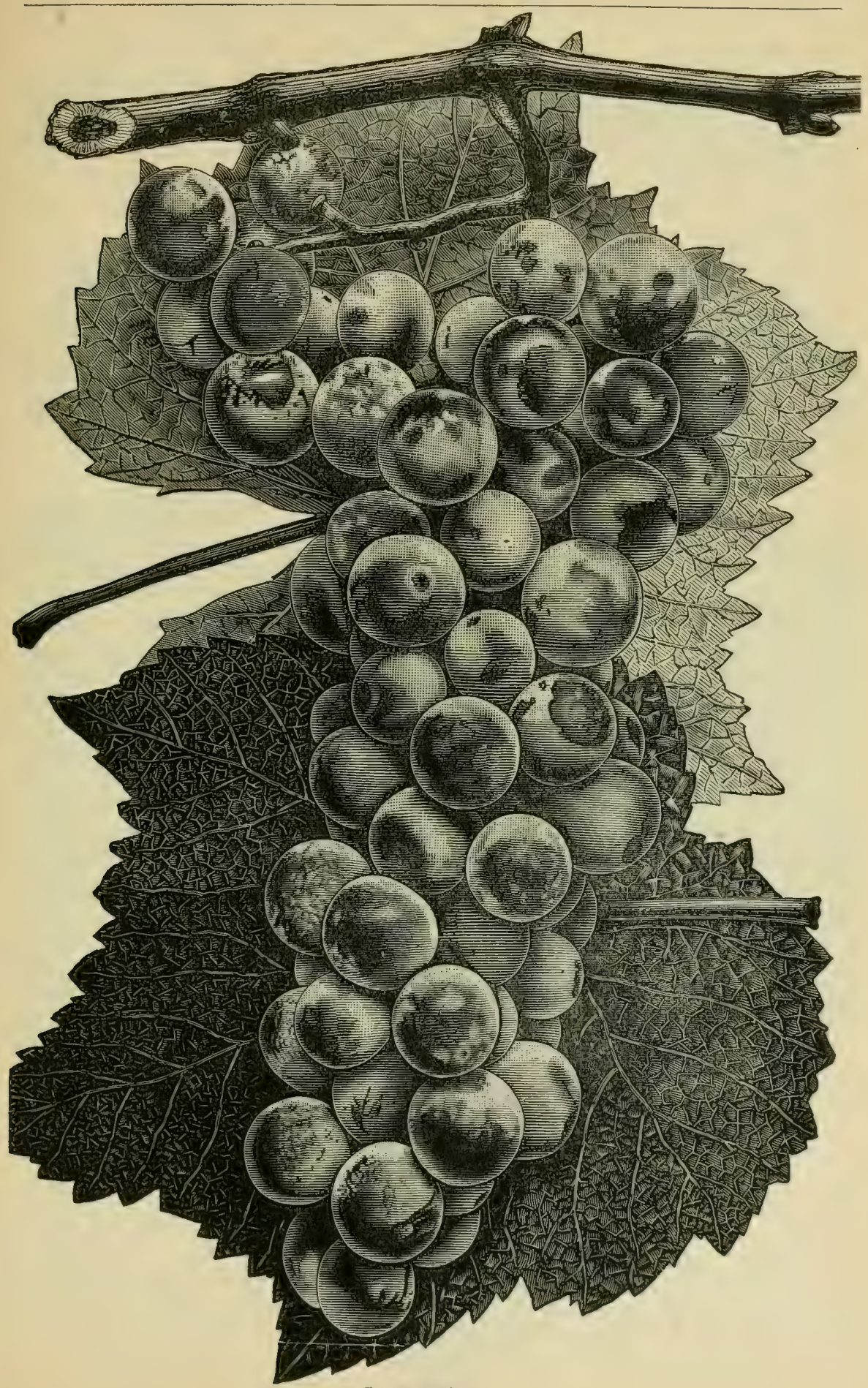

CAMPBELL. 
CARTER. (Labr.) Of a foxy character. Berries round, large, almost black ; ripens with Isabella; inferior.

CASPAR. See Louisiana.

CASSADY. (Labr.) A chance seedling found in the garden of P. H. Cassady, in Philadelphia Bunch medium size, nearly compact and sometimes shouldered; berries medium, round, pale green, covered with a white bloom; flesh juicy, little pulp, pleasant, peculiar honey sweet; strong and vigorous grower; ripens with Catawba.

CATAWBA. (Labr.) Derives its name from the Catawba river in North Carolina, where it was found growing many years ago and transplanted. Major John Adlum of Georgetown, D. C. introduced it. A popular and desirable wine Grape of this country ; thousands of acres have been planted with it. Dark red when fully ripe; bunch large, sometimes loose, shouldered; berries medium to large; skin thin, tough ; flesh somewhat pulpy, with rich, vinous flavor, of best quality for both table and wine; vine a good grower, hardy, with healthy foliage. In unfavorable 10 alities and seasons is subject to rot, but very productive and profitable where it succeeds and matures well.

CATTAWISSA. See Creveling.

CAYUGA. (Labr.) Originated by D. S. Marvin, New York. A cross between Eumelan and Adirondack with more habit and appearance of the latter, but its vinous flavor and considerable amount of sugar must be traced more or less to its Eumelan parentage. It is rather more the shape of Isabella than round, black with a beautiful bloom; cluster good size ; berry clings well to the stem ; a good keeper ; excellent quality; as early as Champion.

CENTENNIAL. (Est.) Originated by D. S. Marvin of Watertown, N. Y., a seedling of the Eumelan by some Labrusca Grape, probably Iona or Delaware. Vine a vigorous grower with heavy foliage; bunches small, rather oblong in form, compact, slightly or not at all shouldered; berry small, yellowish green at first, becoming amber when fully ripe; skin rather thick, quite tough, berry adhering firmly to the stalk ; flesh juicy, melting, with but little pulp, sweet and pleasant ; it ripens with Concord and is an excellent keeper. This is a valuable Grape for table and wine.

CHALLENGE. (Labr.) Raised by Rev. Asher Moore, New Jersey, from a cross between Concord and Royal Muscadine. Vine hardy and thrifty; bunch short, compact, shouldered; berries rather large, round, pale red; flesh slightly pulpy,

CHAMPION. (Labr.) Origin unknown. The earliest of all black Grapes, and although of very poor quality yet it is exceedingly profitable. Black; bunch medium to large, compact; berries large and adhere to stem better than Hartford which it closely resembles; skin thick ; flesh sweet, juicy, somewhat pulpy, with foxy flavor ; vine a very rank, vigorous grower, hardy, very healthy and productive ; ripens about with or a little before Moores Early; quality rather poor but desirable for early market, generally bringing a good price.

CHARLES DOWNING. See Downing.

CHARLOTTE. Labr.) A variety raised at Kelly's Island, N. Y. It resembles the Diana, but earlier.

CHAUTAUQUA. (Labr.) A seedling from Concord, originated in the vineyard of T. H, Barhite, Portland, N. Y. Very hardy and as strong grower as Concord Buuches large with extra large berries, holding firmly to the stem; blue black per. haps a little lighter than Concord; excelleut flavor, sprightly; flesh tender and melting; skin thin but firm; a good shipping and market Grape. Its mammoth size makes it very attractive; ripens with Concord. 


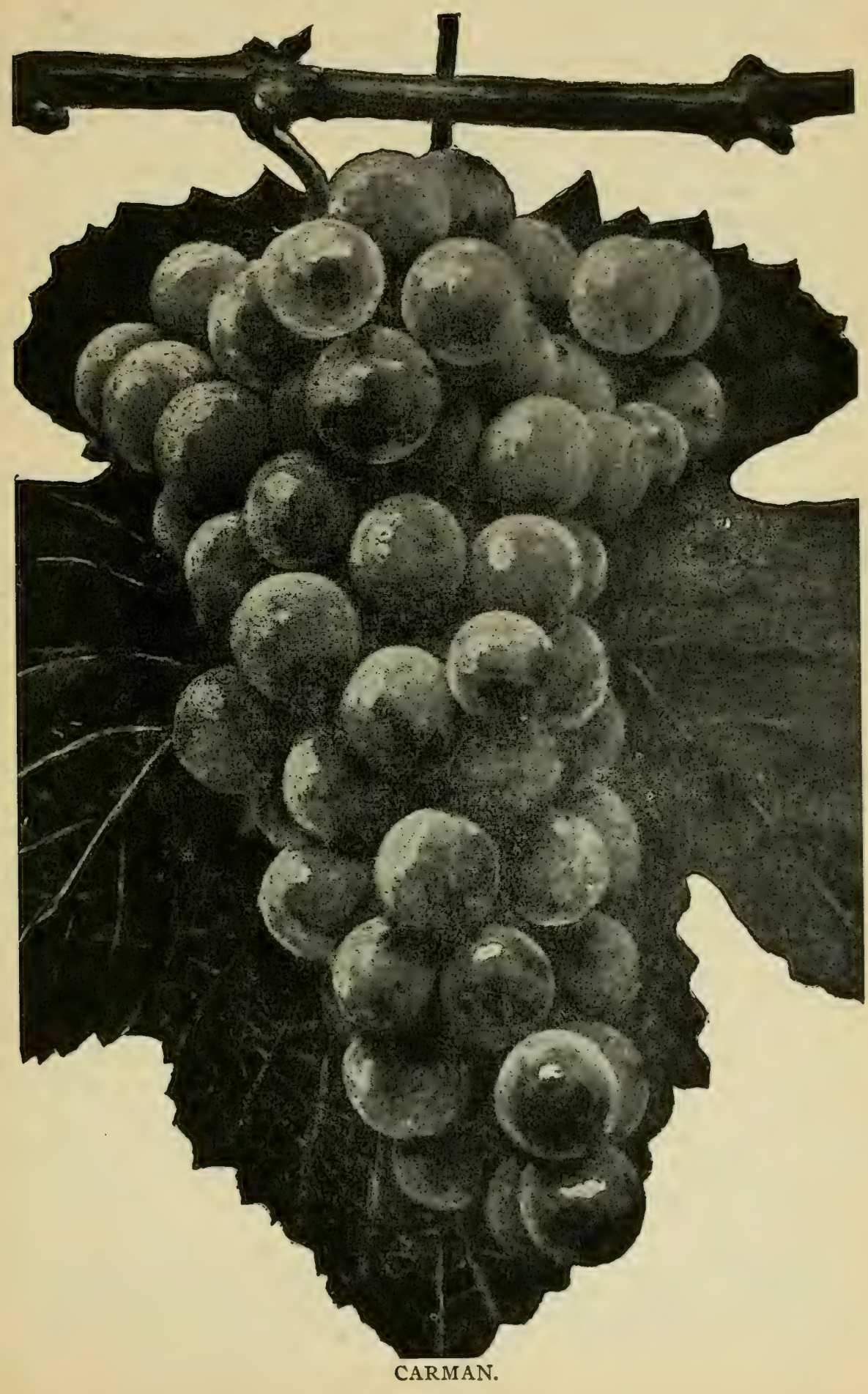


CHARTER OAK. (Labr.) A very large, coarse, native Fox Grape, quite worthless, except for size, which makes its appearance as attractive as its musky flavor is repulsive.

CHEROKEE. $(H y b$.$) A black Grape; bunch large, shouldered, compact ; berry$ above medium, tender, juicy, sprightly; vigorous, hardy, healthy and productive; free from rot and mildew; only good for wine. Originated from the same seed as the Ozark, by Dr. J. Stayman.

CHIDESTER SEEDLINGS. (Labr.) Produced by C. P. Chidester, Battle Creek, Mich., from Concord seed:

No. I. Is a purple Grape, clusters resembling Concord, only a little smaller, good quality; strong growing vine, hardy; ripening one week earlier than Moore's Early.

No. 2. Is a brownish purple Grape with clusters about the size of Concord, best quality; growth and hardiness equal to Concord; ripens at the same time as Worden or a little earlier; berries hang firmly to the stem; will keep for several weeks ; prolific and constant bearer.

No. 3. A purple Grape, clusters resembling the Moore's Early, except not shouldered, and berries considerably larger; excelleut quality; strong growing, healthy and hardy vine; ripens with Concord; keeps well until January without dropping the berries.

UNNAMED. Color the same as Niagara, clusters not quite so compact; berries considerably larger, better quality; very strong and hardy vine ; ripens the same time as Niagara.

CHIPPEWA. (Labr.) A variety found growing on the banks of Chippewa Creek and described in "Country Gent!eman" by Wm. H. Read. Bunches good size, compact, heavily shouldered; berries medium, black covered with bloom; flesh tender, melting, sweet and excellent ; was never disseminated.

CHISHOLM'S SEEDLINGS, No. 3. (Hyb.) A seedling of Delaware produced by Dr. L C. Chisholm, Spring Hill, Tenn. Fine grower, prolific bearer ; fruit medium in bunch and berry dark red or nearly black; handsome and fine flavor; ripens a few days before Concord.

No. 4. $(H y b$.$) Seedling of Delaware; good grower; medium in size; pure$ white; sprightly, vinous flavor; ripens with Delaware.

No. 5. $(H y b$.$) Seedling of Delaware; moderate grower like parent ; fruit$ light pink or red, of delicate flavor; ripens a few days before Concord.

No. 6. $(H y b$.$) Seedling of Delaware; good grower; larger than Delaware in$ bunch and berry; deep red and finely flavored ; ripens with Concord.

No. 8. $(H y b$. $)$ Delaware seedling; a fine grower, hardy, prolific, very early and ripens up well at once; medium in bunch and berry; jet black with white bloom, very attractive in market; best quality ; very promising; ripens with Moore's Early.

No. 9. (?) Parentage unknown; hardy, thrifty grower; bunch and berry above medium, finely shouldered, of good flavor; color of Perkins but much finer quality ; ripens with Concord.

CHRISTIE'S IMPROVED. See Isabella.

CHRISTINE. See Telegraph.

CIGAR BOX. See Ohio.

CLARET. (?) A seedling of Chas. Carpenter, Kelly's Island, O. Bunch and berry medium; claret red, acid ; vine vigorous ; not valuable. 


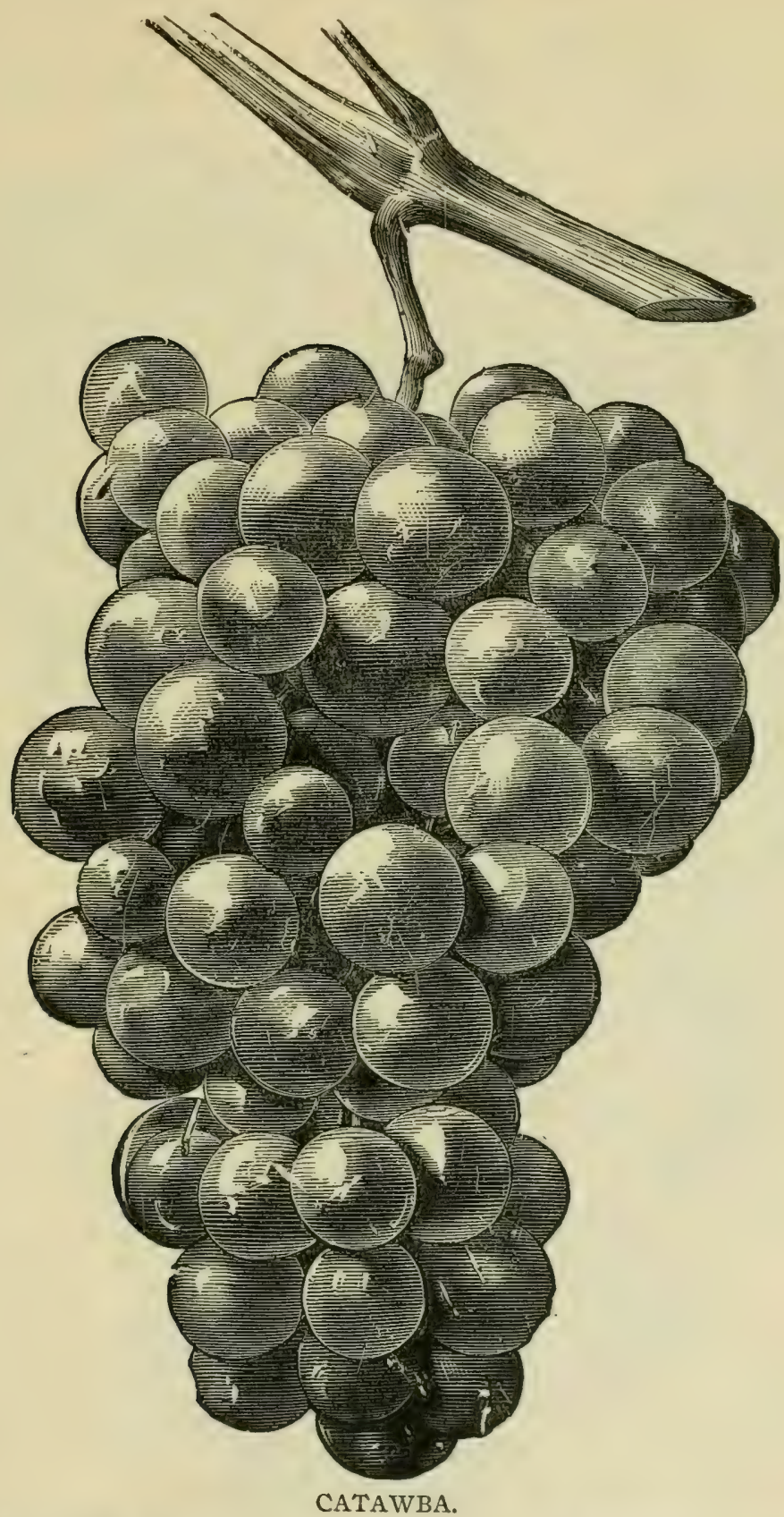

CLARA. ( in.) A chance seedling grown on the grounds of Peter Raabe, Philadelphia. Vine rather tender; bunch medium, loose, shouldered; berry medium. roundish, pale yellow, translucent ; flesh tender, juicy, sweet; ripens with Catawba. 
CLARKE. (Labr.) Introduced by T. S. Phelps, of Washington, D. C. Cluster moderately long, sometimes shouldered, moderately compact; berry medium to large, oval; skin dark, dull red with heavy bloom, tough, medium thick; pulp rather tough, slightly stringy, sweet, quite foxy.

CLEVENER. (Rip.) Introduced by J. S. Baruhart, Denton, Md. Vine not very productive, hardy and healthy; cluster medium, sometimes shouldered; berries small, nearly round; skin firm, colors the hands when broken, quite thin, bloom reddish purple; flesh firm, meaty ; fair quality, black ; wine Grape.

CLIFTON. $(H y b$.) Telegraph crossed with White Frontignon, originated by $\mathrm{C}$. J. Copley, Stapleton, N. Y. A good, strong grower, hardy, healthy and productive ; bunch very large and solid, compact; berries white, very large; skin firm, never cracks ; very productive, requires thinning out; ripens in September.

\section{CLIFTON'S CONSTANTIA. See Alexander.}

CLINTON. (Rip.) Origin uncertain, said to have originated at Hamilton College, N. Y., from a seedling. Black; bunch small to medium, compact, long, not usually shouldered; berries small; skin thin but tough ; flesh juicy, spicy, with little pulp, quite acid. Is used principally for wine; vine very vigorous, healthy, hardy, productive; requires long pruning.

CLOANTHE. (Labr.) A seedling from Kentucky. A strong grower; fruit black, resembling the Isabella, but more foxy.

CLOVERSTREET BLACK. (Hyb.) A hybrid raised by Jacob Moore, from Diana crossed by Black Hamburg. Bunches large, compact, shouldered; berries large, roundish, black with dark violet bloom ; flesh tender, sweet; vine moderately vigorous, not very hardy; ripens with Concord.

CLOVERSTREET RED, $(H y b$. $)$ Same origin as the preceding. Bunches larger than the Diana, loose, occasionally with a similar long stalk or shoulder appended to the top; berries large, roundish, oval, crimson when fully ripe, with a slight Diana flavor; vine a strong grower, needs protection in winter; ripens with Diana.

COCHEE. (?) A red Grape; bunch medium to large; berry above medium, very tender, juicy, sweet, of the best quality ; very vigorous, hardy, healthy and productive ; free from rot and mildew ; ripens before Concord ; originated by John Burr, from unknown seed.

COE. (Labr.) This variety originated in Iowa, and is considered valuable for northern climate. Bunch small, compact, rarely shouldered; berries small to medium, black, fleshy, juicy; vine a strong and free grower with bealthy foliage; ripens a week earlier than Concord.

COLERAIN. ( $\mathrm{Labr}$ ) A seedling of the Concord, originated by D. Bundy, of Colerain, $O$. This Grape is with reference to early ripening, prolificacy and quality, hardiness and vigor of vine, an exceedingly promising variety. Vine a strong, healthy grower, of marked Labrusca type, perfectly hardy and free from disease, slowing no tendency to rot or mildew wherever tested. An abundant bearer, very early, ripening from the $5^{\text {th }}$ to the 3 oth of August, and hanging a long time on the vine; bunches and berries medium size; bunches shouldered, color light green, with a delicate white bloom ; skin very thin and tender; flesh very juicy and remarkably sweet, fairly vinous, generally but one small seed to a berry.

COLUMBIA. (Rip.) Said to have been found in Georgetown, D. C. A vigorous grower, productive; bunch small, compact; berry small, black with a thin bloom; very little hardness or acidity in its pulp; not high flavored, but pleasant and vinous ; ripens late in September. 


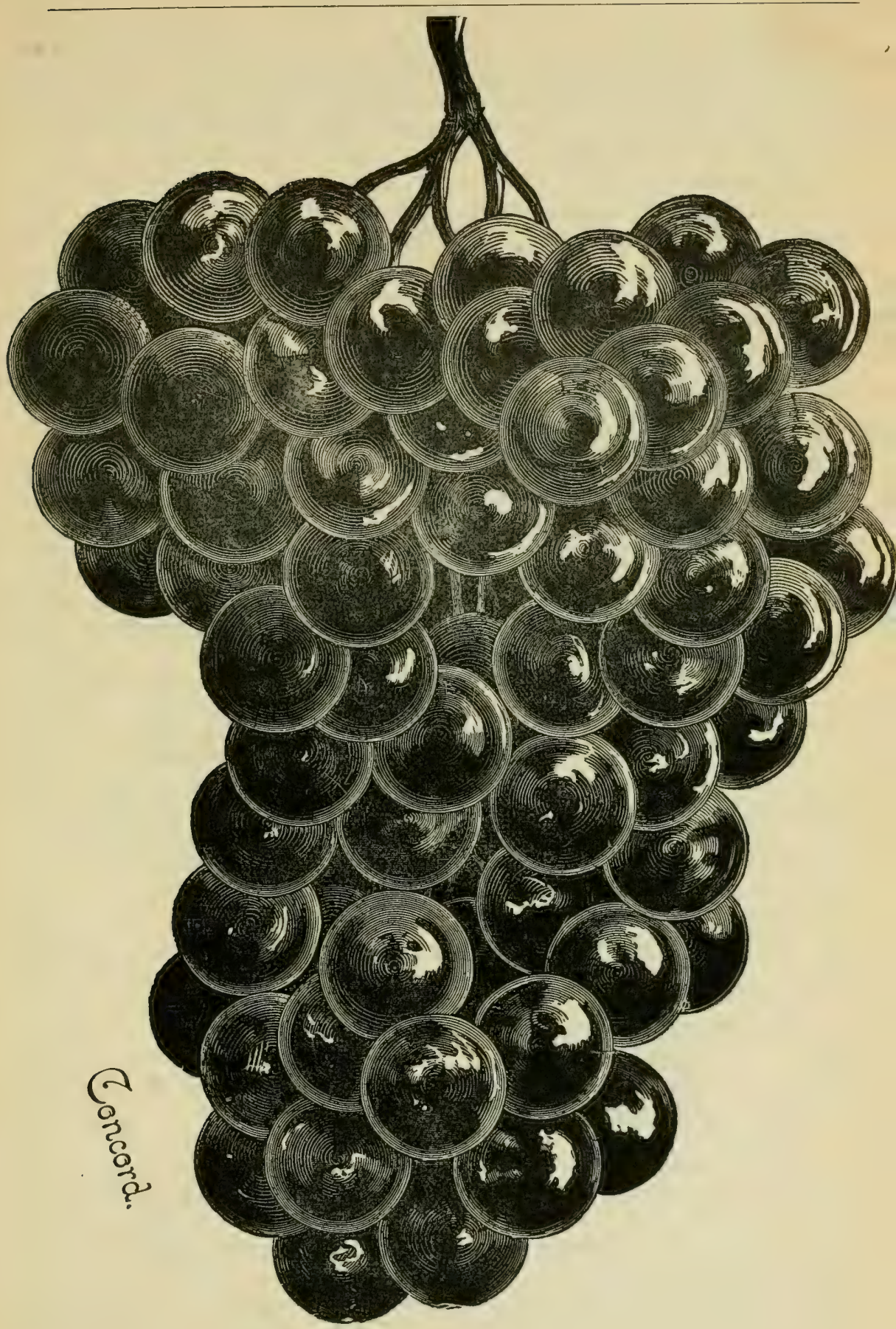


COLORADO. $(H y b$.$) Grown by John Gravestock, Canon City, Col. Similar to$ Brighton in foliage and growth. Probably a seedling of this variety fertilized with Chasselas. Bunches medium, rather long, often shouldered; berries crowded, larger than Delaware, sweet, no trace of acidity; pulp tender and melting; skin thin yet very firm ; hardy and vigorous ; late.

COLUMBIAN. $(H y b$.) Identical with Goethe (Rogers No. I).

COLUMBUS. (?) A chance seedling grown by John Hertlein, Spielerville, Ark., probably a cross between Delaware and Norton's Virginia. A good grower with foliage like Delaware, very prolific. Bunches medium to large, nearly compact; berries medium, black with a blue bloom; sweet, juicy with pleasant flavor; ripens with Delaware.

CONCORD. (Labr.) Perhaps no variety has yielded so quickly to the attention of the vineyardist as the Concord. It is to-day the most popular, and the leading commercial representative of our American Grapes. Originated with E. W. Bull, Concord, Mass., and for the first time exhibited in I853. Black; early ; bunch large, shouldered, compact; berries large, covered with a rich bloom; skin tender but sufficiently firm to carry well to distant markets if properly packed; flesh juicy, sweet, pulpy; vine a strong grower, very hardy, healthy and productive. In unfavorable sections and seasons is subject to rot, but all things considered, for general cultivation has been the most reliable and profitable variety grown and fully tested. The Concord makes a light red wine, which is very palatable and has a peculiar, refreshing effect upon the system. As a parent in hybrids, Concord has also played a prominent part and most of the products are of excellent quality and grand appearance.

CONCORD CHASSELAS. $(H y b$.) A hybrid grown from Concord seed by Geo. W. Campbell, Delaware, O. Bunch rather long, usually shouldered, compact; berries large, round, light amber color with white bloom; skin thin, transparent, but tenacious; flesh tender and melting; fine quality. Ripens with Concord.

CONCORD MUSCAT. $(H y b$.) Same origin as the preceding. Bunch long, moderately compact, somewhat shouldered; berries very large, oval, greenish white with a delicate bloom; skin thin ; flesh tender and melting; flavor rich, sugary, with the peculiar high flavor of the foreign Muscats; vine very vigorous, liable to mildew in unfavorable seasons and locations. Ripens same time as the Concord.

CONCORDIA. $(H y b$.$) A black Grape; bunch medium, compact, berry large,$ tender, juicy, sprightly, sweet, vinous, of pure quality ; vigorous, hardy, healthy and productive free from rot and mildew; ripens about with Concord and will hang on the vines long after ripe; originated by Dr. J. Stayman from Delaware.

CONQUEROR. $(H y b$.$) A seedling grown by Rev. Asher Moore, New Jersey,$ from a cross between Concord and Royal Muscadine. Vine thrifty, hardy and productive; bunch long. loose, shouldered; berries medium to large, glossy black with a fine bloom; flesh slightly pulpy, juicy, sweet; ripens with Concord.

CONSTANTIA. See Alexander.

CORNUCOPIA. (Hyb.) Raised by Chas. Arnold, Ont., from seed of Clinton crossed with St. Peter. Vine healthy and vigorous; leaves large, dark green, strongly marked with dark veins; bunch large, compact, shouldered; berries above medium, black with a fine bloom; skin thin ; flesh juicy, no pulp; ripens with Concord; very productive and good keeper.

CORPORAL. $(H y b$.$) A seedling originated by D. S. Marvin, New York, from$ Eumelan and Worden. Black, good-sized bunch and berry; healthy and heavy bearer; free from rot thus far ; excellent for shipping. 
CORTLAND. (Labr.) Introduced and grown by E. C. Pierson, Waterloo, N. Y. Clusters fair size, compact; berries medium large, black, sweet; thin skin and very little pulp, good quality ; vigorous, hardy, healthy; about two weeks before Concord.

COTOCTIN. (?) A chance seedling from Pennsylvania. Bunch large, often shouldered; berries medium to large, white, very little pulp, fine quality ; very late; liable to mildew.

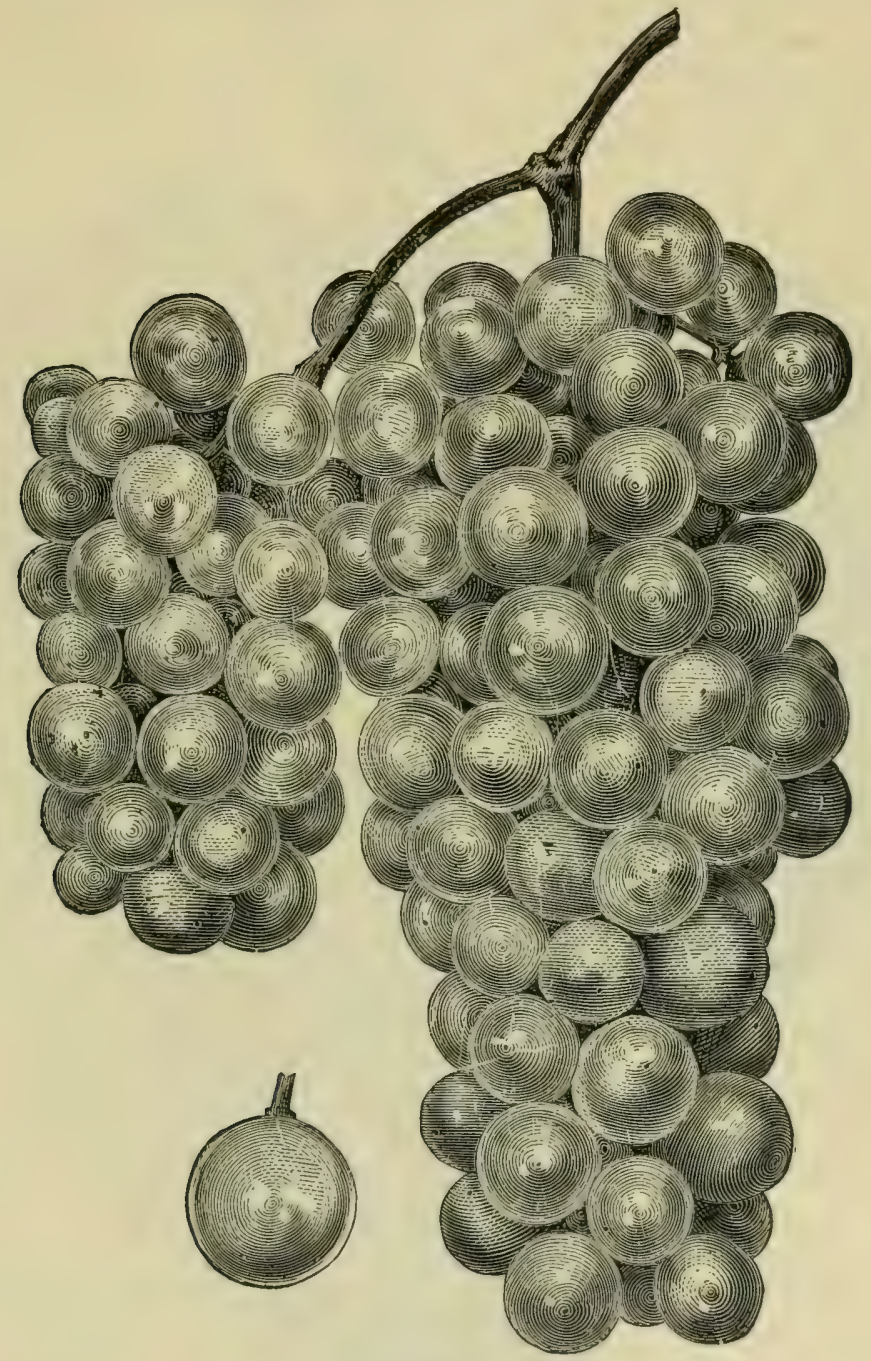

CROTON.

COTTAGE. (Labr.) Seedling of the Concord raised by E W. Bull. A strong, vigorous grower with healthy, large foliage; clusters quite large. shouldered; berries nearly round, large, larger than Concord, black ; skin thick with very heavy bloom; flesh pinkish, tough but not stringy, flavor very pleasant; sub-acid when pulp is broken; should be better known. 
COVERT. (Labr.) Introduced by N. B. Covert, Ann Arbor, Mich. Chance seedling. Bunches good size, moderately compact; berries medium to large. greenish white, slightly dotted with crimson, deliciously sweet. firm pulp and medium thickness of skin ; ripens with Concord.

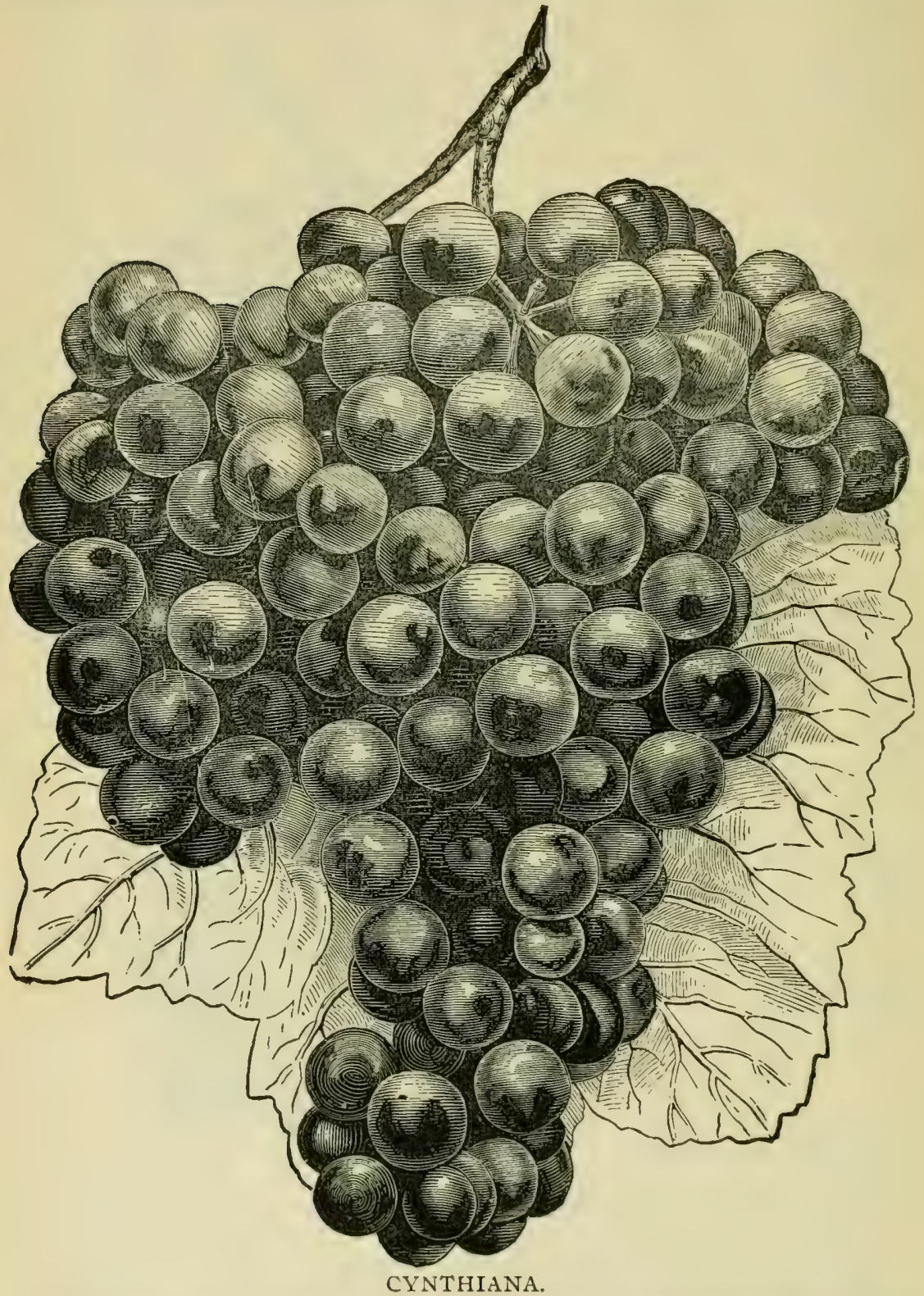

COWAN. (Rip.) Origin unknown, was grown to some extent along Lake Champlain. Bunch and berries medium, black, handsome, but very harsh and sour. 
CREVELING. (Labr.) A variety originated in Columbia Co., Pa. Vine hardy and vigorous, productive. It has imperfect blooms, but improves by growing it side by side with Concord. Black; bunch loose, straggling; berries medium to large, sweet and juicy; quality good; not very valuable on account of very imperfect clusters.

CRITIC. (Labr.) A seedling from Jefferson, originated by J. S. Breece, Fayetteville, N. C. Bunch fairly good size, color of a fully ripe Delaware, clings firmly to the stem, remaining plump and sound for a long time ; quality most mildly agreeable, not vinous but rich and delicious ; pulp melting ; vine only moderately vigorous but healthy ; foliage nearly the color of Delaware but coarser and larger; ripens with Delaware.

CROTON. $(H y b$.$) Cross between Delaware and Chasselas, produced by S. W.$ Underhill, New York. Cluster long, shouldered, quite large size ; berries medium, light yellowish green; skin very thin, light bloom; flesh tender, melting and separates readily from the seed; flavor very pleasant, vinous; has a tendency to mildew and rot.

CROWN. $(H y b$.) Produced by T. V. Munson, from the Post Oak crossed with Triumph. Very vigorous grower; bunch large, with medium sized berries, dark red; thin skin but tough, juicy, tender pulp, best quality;, will thrive best in southern states.

\section{CULINARY. See White's Northern Muscat.}

CUNNINGHAM. (Est.) Originated in the garden of Jacob Cunningham, Virginia, a southern Grape of the Herbemont class. Vine vigorous, healthy ; Llack ; buuch medium long, compact; berries small, juicy, vinous ; very late; wine Grape.

CUYAHOGA. (Labr.) An accidental seedling found growing and introduced by Mr. Wemple of Collamer, Cuyohoga Co., Ohio, Vine a strong grower, requiring a warm, sandy soil. Bunch medium, compact; berries medium, greenish amber; flesh tender, juicy, rich, vinous, sweet, fine quality ; late.

CYNTHIANA. (EEst.) Found growing wild in Arkansas. A black wine Grape ; bunch medium long, shouldered, compact; berries small; vine a very vigorous grower and healthy ; fruit ripens late. Highly esteemed in the South and Southwest where it is considered one of the best red wine Grapes ; strongly resembles Norton.

DAISY. $(H y b$.$) Uriginated by Dr. Stayman, Leavenworth, Kan. Cluster$ small, inclined to be loose; berries medium, red; skin medium thick, flesh whitish green, tough ; flavor slightly foxy ; healthy and vigorous.

DANA. (Labr?) A seedling produced by Francis Dana, Roxbury, Mass. Strong grower, perfectly hardy; bunch medium, compact, shouldered with red stems; berries large, round, red, with a rich bloom; almost free from pulp, sprightly ; ripens with Concord.

DAPHNE. $(H y b$.$) A seedling of Telegraph, crossed with White Frontignan,$ originated by C. J. Copley, Stapleton, N. Y. Bunch medium to large, long, rarely shouldered; berries medium to large, light yellow, transparent, very little if any pulp, aromatic; skin rather thick; a strong healthy grower, very productive, and perfectly hardy; ripens about with the Concord.

DELAWARE. $(H y b$. $)$ This variety must be accorded one of the highest places among American Grapes, for hardiness, productiveness, and unsurpassed flavor and quality. As to the specific blood composing Delaware, it has been long a puzzle to Grape students. Some suppose it to be Aistivalis, but most think it to be a hybrid embodying Labrusca and Estivalis, or Labrusca and Vinifera; that it possesses 
a part at least Labrusca blood is quite generally conceded, as so many of its seedlings show Labrusca marks. To produce its best results, the Delaware requires a rich soil and good cultivation. It seems more free from rot than any other variety, and if not permitted to overbear, is among the most reliable Grapes for a certain and profitable

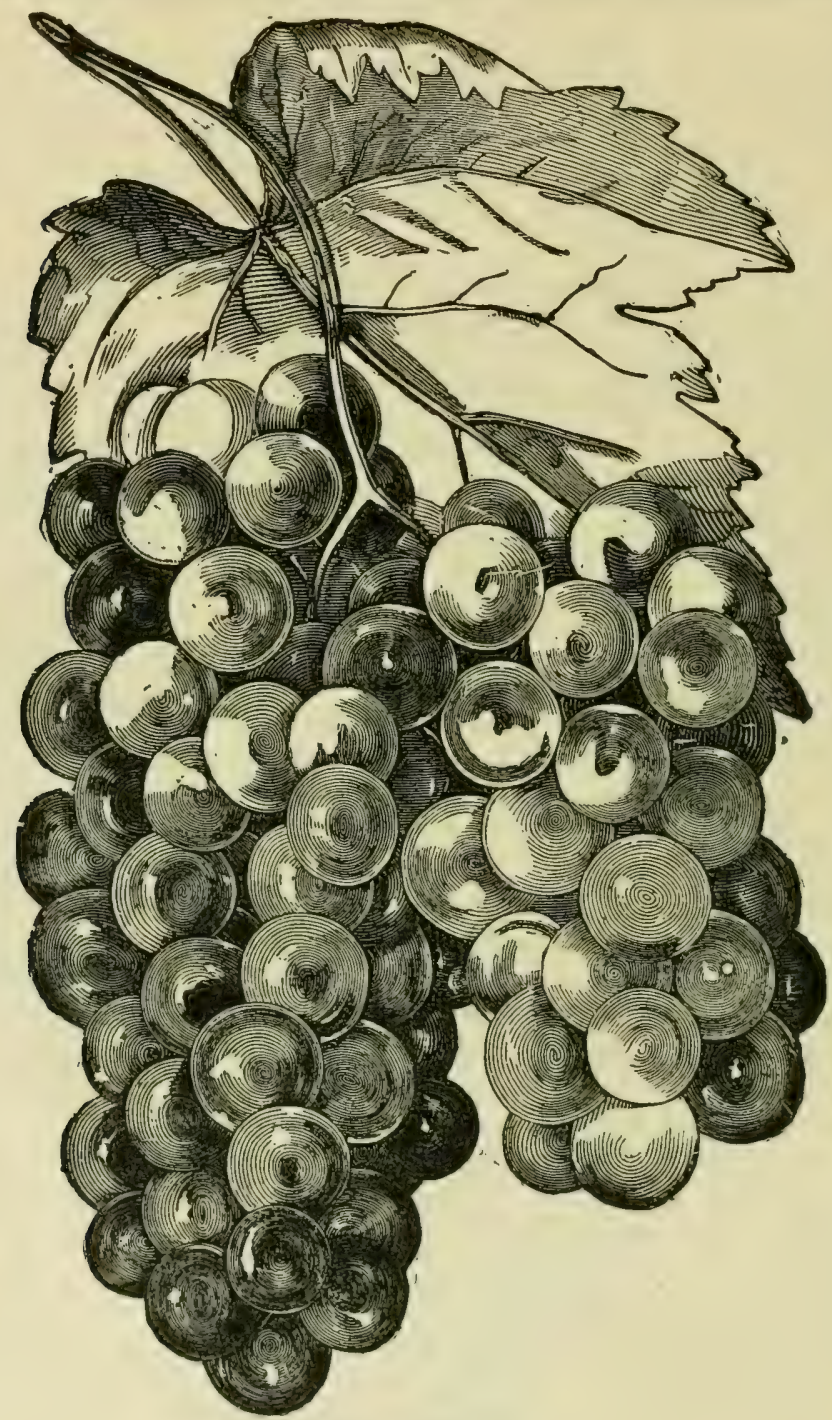

DELAWARE.

crop, wherever soil and location are favorable. Red, bunch small, compact, usually shouldered; berries small, skin thin but firm, flesh juicy, very sweet and refreshing, of hest quality for both table and wine ; ripens before Concord ; vine hardy, productive, moderate grower; it is regarded by many the best American grape, all things considered; it should be in every garden and vineyard. 


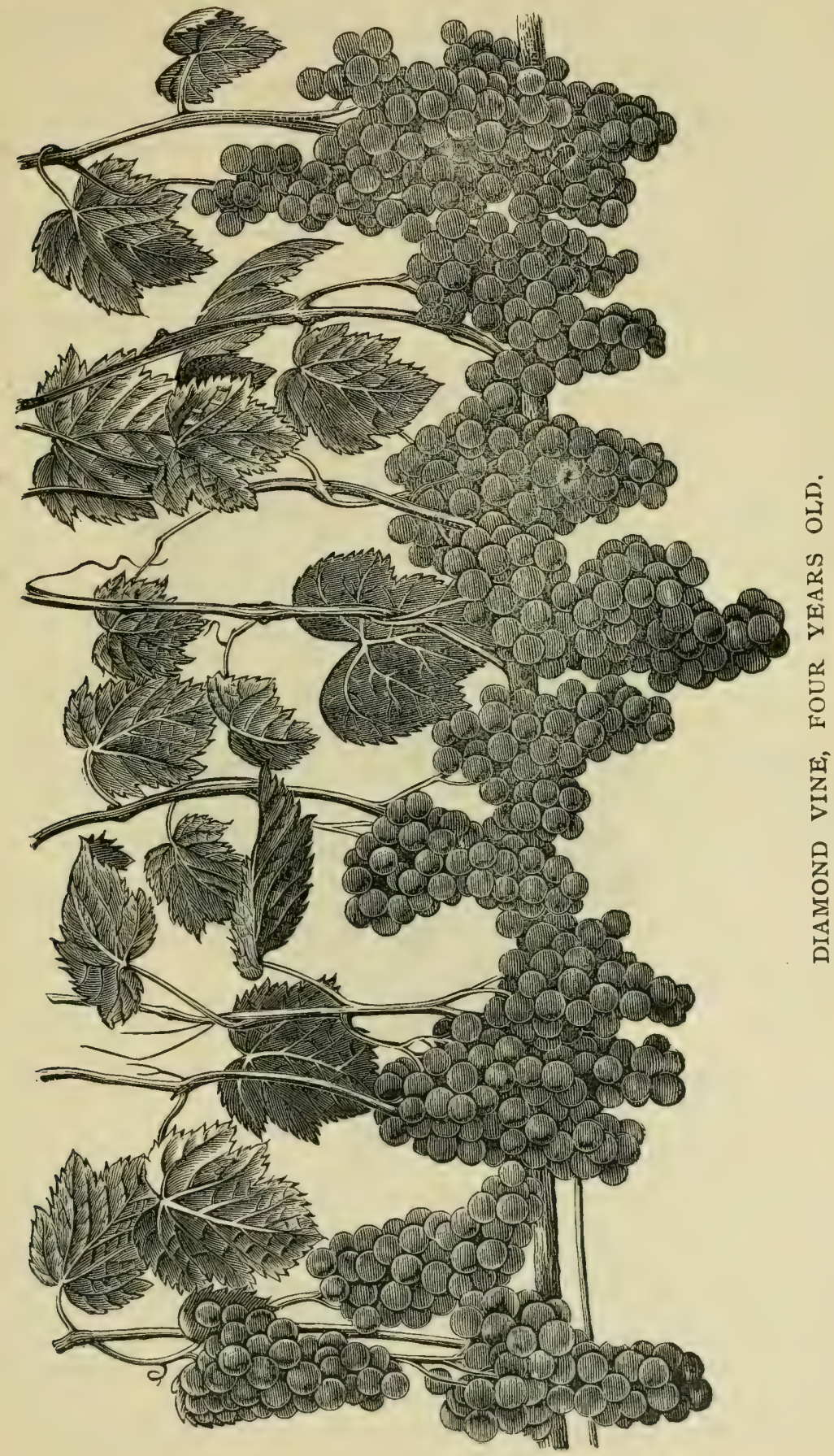


DELAWARE SEEDLINGS. (Hyb) Jacob Rommel of Morrison, Mo, has produced several seedlings from the Delaware, which still unnamed, are known by numbers. The following two are the best :

No. 9. Vine moderate grower, healthy and hardy ; bunch and berry medium size, black, very compact, very productive ; ripens before Concord ; berry very firm; skin thick, sweet, covered with a beautiful bloom; a good keeper and shipper; has never been attacked by rot.

No. 16. White Delaware. A never fail in Grapes. Vine healthy but moderate grower, very productive. As it overbears and overtaxes the vine one-half of its clusters should be removed early in season; bunch and berries medium size, covered with a most beautiful white bloom; very sweet, pure flavor, delicious; skin tough, pulpless; fine keeper and shipper; not subject to rot; ripens with Concord; an acquisition in Grapes.

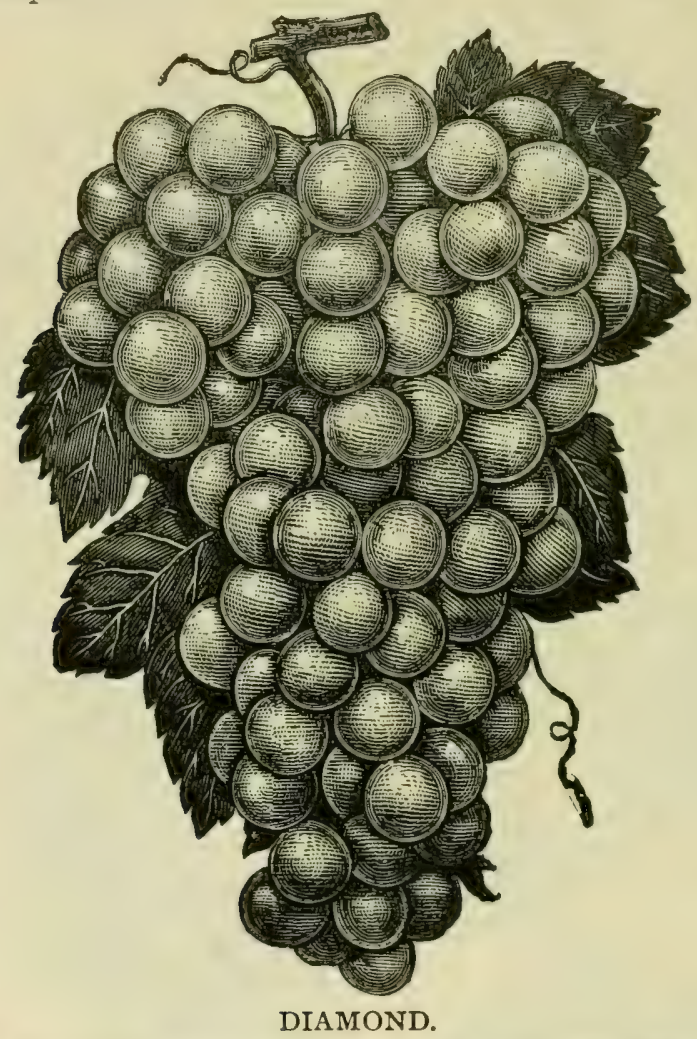

DELAWBA. $(H y b$.$) Originated by Dr. L. C. Chisholm near Nashville, Tenn.$ It is a cross of Delaware and Catawba. It fruited first in I885. This Grape is a complete blend of its parents. In growth and foliage it resembles Catawba very much, being somewhat more vigorous, very healthy and hardy. Bunch and berry about one-third larger than Delaware; color purplish red; in flavor it is also a mixture of the two Grapes, not so much tanin as found in Catawba, very sweet ; superior quality; ripens several days before Catawba.

DEMPSEY'S SEEDLING. See Burnett. 
D'ELBOUX. $(H y b$.$) Produced by C. J. Copley, Stapleton, N. Y., by crossing$ Telegraph with Black Hamburg. A very strong, rampant grower with very large, thick leaves; bunch and berries are of the largest size, black, with thick skin; a very rich Muscat flavor, pure, sweet, no foxiness; makes a splendid wine of dark red color and rich aroma ; ripens with Hartford; very productive and hardy ; free of all diseases.

DELGOETHE. $(H y b$.$) Seedling from Delaware crossed with Goethe (Rogers$ No. I), originated by T. V. Munson. Is still under further testing.

DELMAR. $\left(H y b_{0}\right)$ Seedling from Delaware crossed with Martha, produced also by T. V. Munson. No description can be given at present.

DENISON. (Labr.) Seedling from Moore's Early, raised by T. V. Munson. Not offered for sale yet.

DETROIT. (Labr.) A seedling from Catawba produced and introduced by T. R. Chase, of Detroit, Mich. Bunches large, compact ; berries large, very dark claret, round, very little pulp; Catawba flavor. Ripens a few days after Concord.

DIAMOND. (Labr.) This choice new white Grape originated with Jacob Moore, the well known originator of the Brighton Grape. It is a pure native, being a cross between Concord and Iona. The vine is a vigorous grower, with even jointed wood, which always matures perfectly and retains its foliage, even in the most unfavorable seasons. The leaf is large, dark, glossy green, resembling its parent Concord. The clusters are large, always well filled, moderately compact, generally shouldered; berry about the size of Concord, and retains its full size to the end of the cluster; it adheres firmly to the stem even when over ripe; flesh melting and juicy, sweet to the center, and entirely free from foxiness ; skin thin, but sufficiently tough to bear packing and handling well. The color is a delicate greenish white, with a rich yellow tinge, when fully ripe. It is very productive and perfectly hardy. The parent vine has been in fruiting the past ten years, standing in the open ground near Rochester, N. Y., without the least protection, ripening its wood and coming out sound and bright to the very tip every spring, even during severe winters, when other varieties considered hardy have killed badly. In quality, no other white Grape in the market can compare with it. It is far superior to the other leading white Grapes.

DIANA. (Labr.) A seedling of Catawba raised by Mrs. Diana Crehore of Milton, Mass. An old and still popular variety, generally healthy and productive. Bunch and berry medium to large, usually quite compact; skin rather thick; color light red, slightly pulpy; sweet, rich, vinous, with peculiar musky flavor; good quality for both table and wine.

DIANA HAMBURG. (Hyb.) Raised by Jacob Moore; a cross between Diana and Black Hamburg; very large; resembles the Hamburg in color and flavor; berries large, slightly oval, of a rich fiery red; flesh tender, very sweet flavor; needs protection during the winter in the north. Ripens shortly after Concord.

DINGWALL'S WHITE. (Labr.) Origin unknown. Vigorous, healthy grower; bunch short, compact; berry large, round, dull white; skin medium, pulpy, flavor and quality poor; late.

DINKEL. (Labr.) Catawba seedling raised by T. V. Munson. Vigorous grower; the general appearance of vine and leaf much like Catawba; bunches medium, compact, slightly shouldered; berries medium, round, deep coppery red, with thick bloom; skin thick, berry adhering firmly to the stalk, a rather tough pulp, flavor quite rich and sweet, slightly acid next to the skin ; ripens with Catawba.

DR. BAIN. (Labr.) A seedling of Concord, originated in Illinois. A white Grape, but not enough is yet known to justify a conclusion. 
DR. COLLIER. $(H y b$.) Post-Oak crossed with Lindley, produced by T. V. Munson. Vigorous growth; large, conical cluster; berries large, dark red; thin, but tough skin; tender pulp, juicy, red, good flavor; very prolific and perfectly hardy.

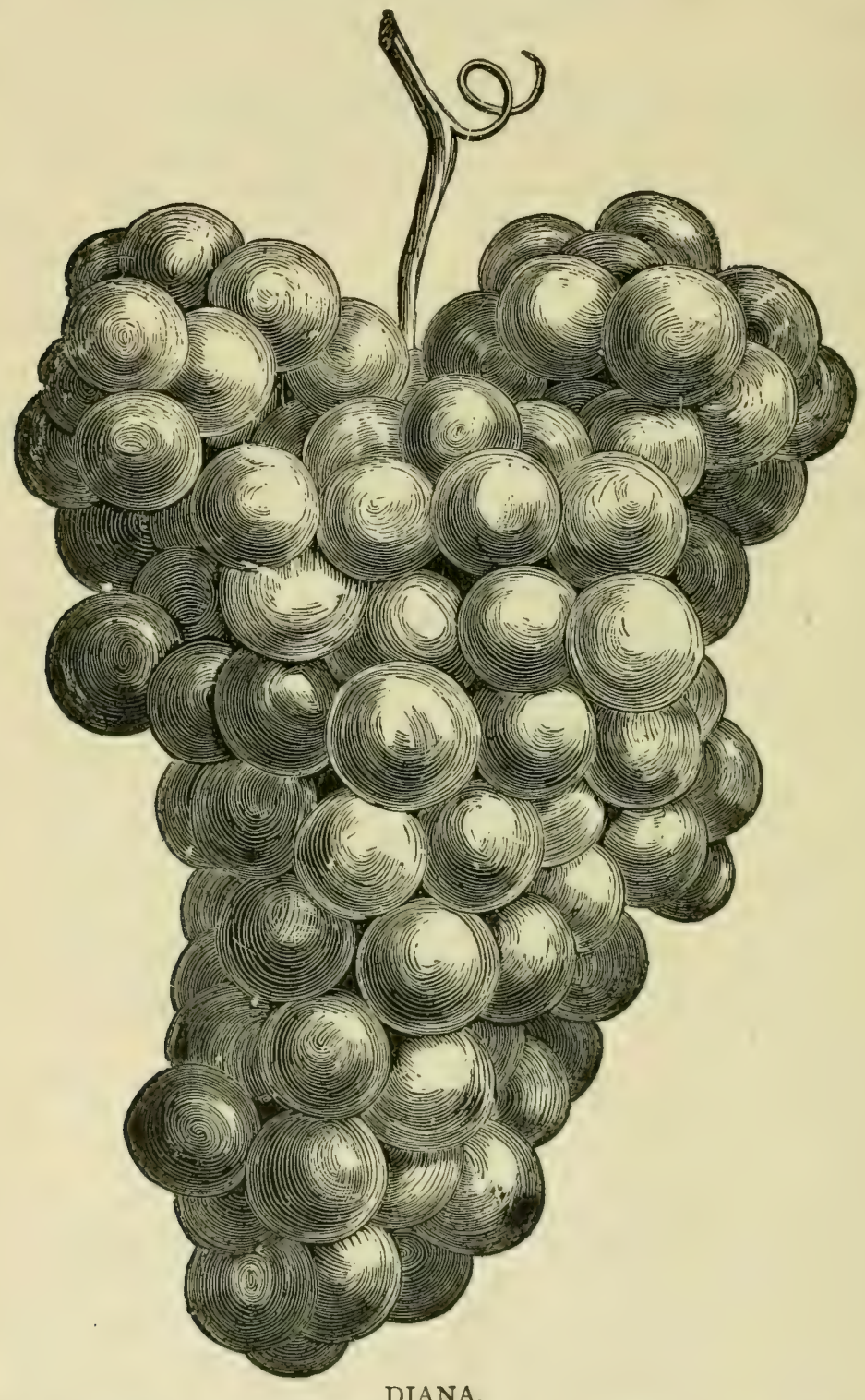

DR. HEXAMER. $(H y b$. $)$ Originated by T. V. Munson, from a cross of PostOak with Triumph. Bunch large, cylindrical; large, black berries; tough skin; pulp tough, juicy; flesh red; quality very good; vigorous, prolific and hardy. 
DR. WILEY. (?) Origin unknown. Named by Judge Sam. Miller of Bluffton, Mo., who received from the late Dr. Wiley a number of unnamed seedlings, among which was this, the most valuable one. Double the size of Diana, darker red; vine productive and healthy, never had a rotten berry, while surrounded by others all rotten.

DR. WARDER. (Labr.) Originated by T. Huber, of Illinois, from Concord. Bunch very large; berries large, black; skin thick, melting, juicy; quality better than Concord; ripens two weeks earlier; improves on the vine.

DON JUAN. (Labr.) Seedling of Iona, introduced by J. H. Ricketts, Newburgh, N. Y. Bunch large; berries large, dark red; flesh vinous, sweet and aromatic; ripens with Concord.

DORINDA. (Labr.) Seedling from Rebecca, produced at Hudson, N. Y. Was never disseminated.

DORR'S SEEDLING. (Hyb.) Seedling of the Delaware, raised in Livingston Co., N. Y. Promised well at one time, but was not propagated to a great extent.

DOWNING. $(H y b$.$) Obtained by J. H. Ricketts, from Croton fertilized with$ Black Hambug. Not satisfactory. Its growth is good but has too much of the foreign Grape in its composition to be recommended for general planting. In favorable locations it will probably be found a fine amateur Grape, very handsome, of good quality and of the largest size.

DRACUT AMBER. (Labr.) Originated by J. W. Manning. Dracut, Mass. Red, very early; bunch and berry large ; flesh quite foxy ; vine hardy, very vigorous and productive. Valuable in high latitudes where better varieties will not ripen.

DUCHESS. (Hyb.) Raised by A. S. Caywood \& Son, of Marlboro, N. Y., produced by crossing a White Concord seedling with Delaware or Walter, the pollen of both being applied at the same time. This white Grape has been received with much favor in western New York. It ripens medium early; white; bunch medium to large, long, compact, shouldered; berries medium, quality best. Its quality is so fine it will pay to be at considerable trouble to grow it. In its original locality it is hardy and free from disease, a strong grower and very productive. One of the most delicious varieties, a fine shipping grape and a long keeper.

DUNLAP. (Hybr.) One of J. H. Ricketts' seedlings. Fine red Grape; was never disseminated.

Dunn. (Est.) Obtained from a Mr. Dunn in W. Texas, and named after him by $\mathrm{G}$. Onderdonk. Vine a vigorous grower, in habit and foliage like the Herbemont, not shouldered, and berries paler in color; too tender for the North.

EARLY AMBER. See Dracut Amber.

EARLY AUGUST. (Labr.) A twin seedling of Pocklington from Concord, introduced by Jno. Charlton, of Rochester, N. Y. Vigorous, healthy, Concord foliage, perfectly hardy; bunch medium to large, moderately compact, sometimes shouldered; berry round, deep golden yellow with delicate white bloom, translucent; skin thin but tough, fully sweet with slightly acid flavor, melting with no pulp or foxiness; productive and good bearer ; ripens before Jessica or Moore's Early.

EARLY BLACK. (Hybr.) A seedling of Delaware, originated by Jacob Rommel, Missouri. Vine very healthy, strong grower, very productive; bunch compact, shouldered, medium; berries medium, black skin, firm, sweet not subject to rot; ripens early with Hartford.

EARLY CHAMPION. See Champion. 


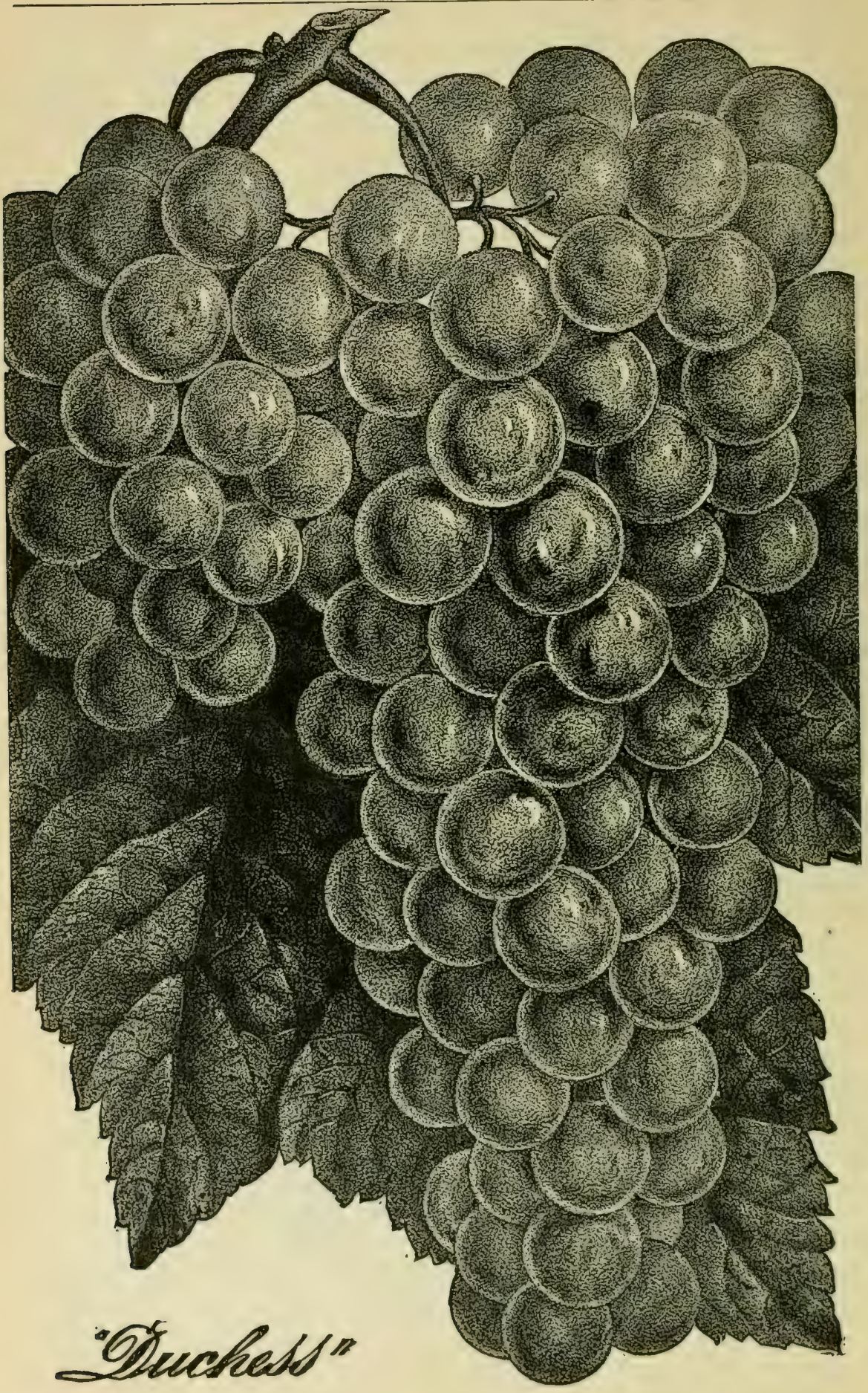




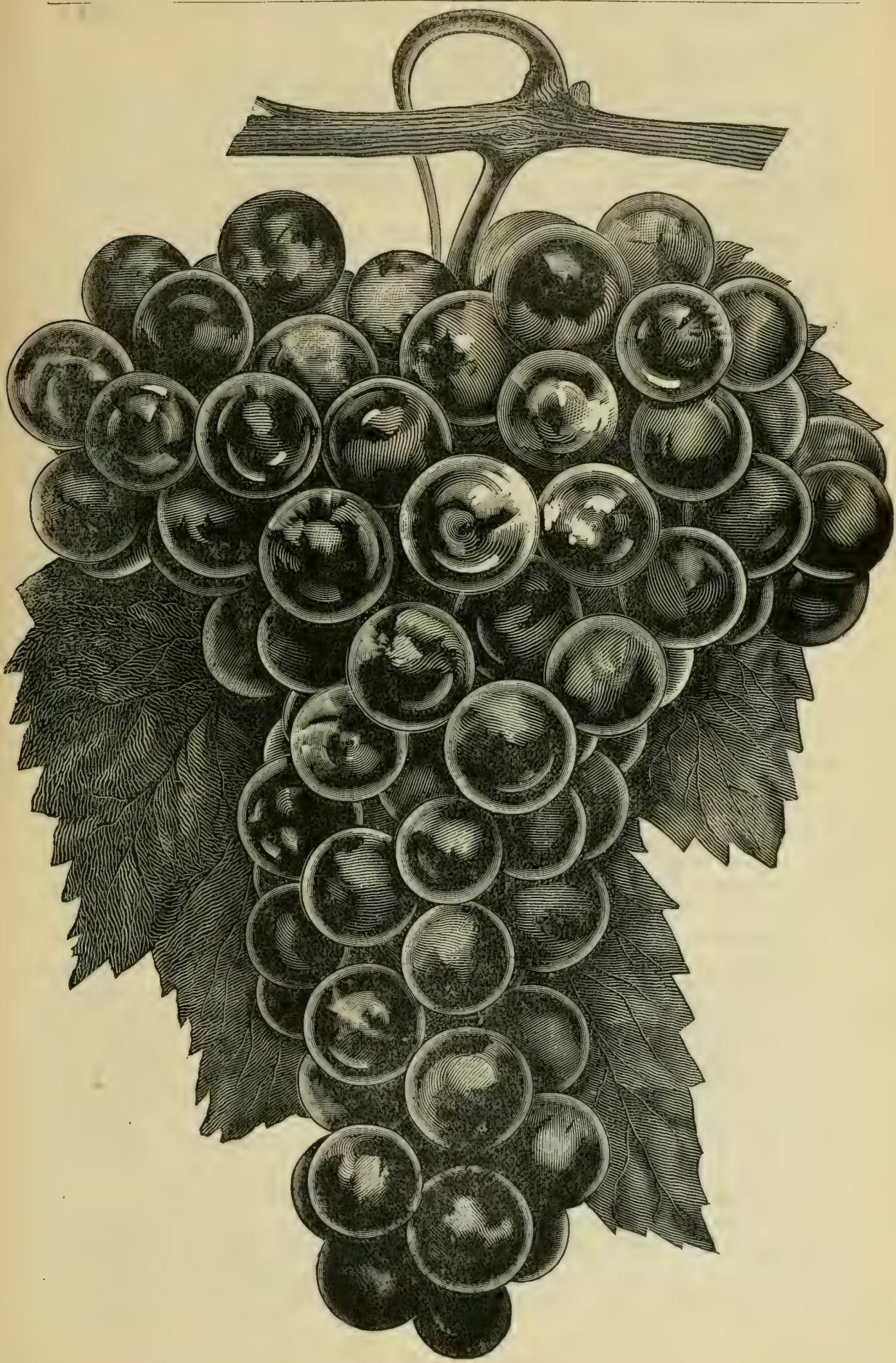

EARLY OHIO. 
EARLY DAISY. See Daisy.

EARLY DAWN. (Hybr.) Originated with the late Dr. Wm. A. M. Culbert, of Newburgh, N. Y. An early, black Grape vigorous and productive; leaves large, thick and firm ; bunch medium to large, long, shouldered; berry medium, round, with thick, blue bloom ; skin thin, firm ; flesh tender, juicy, sweet, slightly vinous, and of very good quality; ripens early; a hybrid cross of Muscat Hamburg and Isabella ; an amateur or garden variety.

EARLY HUDSON. (?) Origin unknown. An early, round, black Grape of little value, except as a curiosity, inasmuch as many of the berries contain no seeds.

EARLY MARKET. $(H y b$.$) Cross of Elvira with Triumph, originated by T$. V. Munson. Vines dark brown, sleuder; berries small, round, black, of wild Grape texture and flavor ; ripens early ; needs further testing.

EARLY OHIO. (Hyb.) Originated at Euclid, Ohio, by R. A. Hunt. Several years ago Mr. R. A. Hunt, of Euclid, O., discovered ten or twelve chance seedling Grapevines growing in his vineyard, among Concords and Delawares. He took them up and set them out, and when they came into bearing, one of them proved to be very early and of excellent quality. He began propagating it, and for five or six years past has sold these Grapes in the Cleveland market, ahead of all others, and hence, realizing the highest prices. The berry is black, one size smaller than Concord, firm in texture, of a spicy, pleasant flavor, and hang to the stem with a persistency that makes its shipping qualities of the highest order. The vine is thrifty, a strong, rapid grower, fully as much so as the Concord, and an abundant bearer. Mr. Hunt had Moore's Early and Worden growing in the same vineyard. The former was just beginning to color and the latter was still as green as ever in appearance. Mr. Hunt says the new Grape is one week to ten days earlier than Moore's Early, ten days to two weeks earlier than Worden, and three weeks earlier than Concord. The soil in which the vines are growing is ordinary clay, in rather poor condition, and no manure has been applied, and yet the growth and bearing has been all that could be desired. It is the best Grape of its season, and the best early black Grape we have yet seen or tested. Its exceeding earliness, along with its other good qualities, make it a decided acquisition, and will push it at once into popular favor with all who grow Grapes for profitable marketing. It has been named the Early Ohio, and its control for propagation and distribution, has passed into the hands of the C. S. Curtice Company, of Portland, N. Y., well known and enterprising nurserymen who make Grapevines a specialty.

EATON. (Labr.) A seedling from Concord grown by the late Calvin Eaton of Concord, N. H. Bunch very large - of four exhibited, the largest was shouldered and weighed eighteen and one-half ounces-compact; berries very large, round, black, covered with a thick blue bloom ; the stem pulls out white like the Concord. The general appearance of the bunch and berry strongly resembles that of Moore's Early. The skin is quite as thick as that of the Concord. Very juicy, with some, but not hard pulp. INot as sweet as the Concord, but has less of the native odor. Vine is of coarse growth, vigorous, wood dark brown; foliage resembling that of Concord; ripens with Concord.

ECLIPSE. $(H y b$.$) A white Grape; bunch large, double shouldered, not very$ compact; berry very large, tender, juicy, sprightly, rich, vinous, sweet, of most excellent quality; very vigorous, hardy, healthy and productive; not entirely free from rot on our grounds; ripe about with Concord. We want no better Grape than this when properly grown; originated by John Burr from unknown seed. 


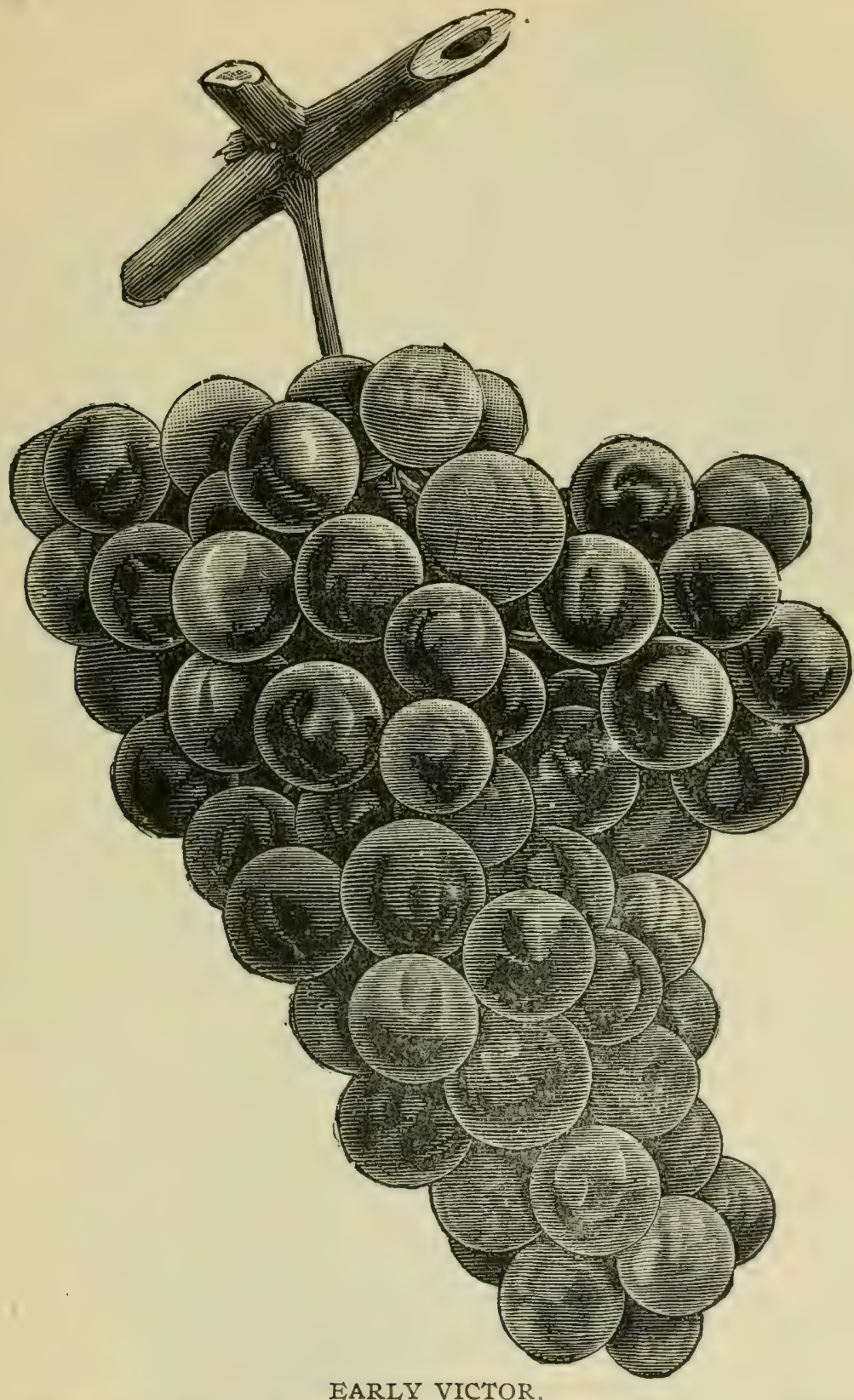

EARLY VICTOR. (Labr.) A black Grape; bunch above medium, shouldered, compact ; berry medium, juicy, sweet, rich, sprightly, vinous, of good quality ; vig. orous, hardy, healthy and productive; subject to rot more or less; ripe about with Moore's Early ; originated by John Burr. 
EDMISTON. (Labr.) A Concord seedling grown by D. G. Edmiston, Adrian, Mich. Bunch large, larger than Concord, slightly shouldered, very compact; berries large with tough skin, black, tender pulp, juicy, sweet; good grower, entirely bardy; ripens a few days before Concord.

EDW ARD. (Labr.) Introduced by $T$. Huber in Illinois. Berry and bunch larger than Concord; white, sweet, good quality ; medium early.

ELAINE. $(H y b$. ) Seedling of Salem, introduced by C. Engle, Paw Paw, Mich. Vine a strong grower, long jointed, hardy; bunch below medium ; berry large, oval, red, nearly the color of a ripe Catawba; skin thin and tough ; flesh very rich, having nearly as perfect a commingling of the acids and sweets as is possible; not an extra bearer.

EL DORADO. $(H y b$.$) One of Rickett's seedlings, produced by crossing Con-$ cord with Allen's Hybrid. A strong-growing, healthy vine; a handsome white Grape, of the same parentage as the Lady Washington, generally bearing handsome large clusters of medium herries, high flavored, tender and juicy, with scarcely any pulp and very few seeds; ripening with the Hartford.

ELIZABETH. (Labr.) Originated near Rochester. Bunch large, compact; berries large, roundish, oval, greenish white; flesh rather pulpy, acid.

EL PASO. See Lenoir.

ELSINBURGH. (Est.) Originated in a town of the same name, of New Jersey. Bunch large, loose and shouldered; berries small, round, black, fine quality, sweet and melting.

ELVIBACH. $(H y b$.$) One of T. V. Munson's productions. Cluster medium,$ compact; berries round, medium, black; skin medium thick, heavy bloom; flesh greenish, firm ; wine flavor.

ELVICAND. $(H y b r$. $)$ Originated by T. V. Munson, a cross of Elvira with Mustang. Bunch small, shouldered, berries large, dark red; skin thin but tough, tender pulp, good quality; vigorous grower, productive, only good for the South.

ELVIRA. (Rip.) A seedling of Taylor, produced by Jacob Rommel, Mo. White; ripens about with Catawba ; a very strong, healthy and robust grower, and as productive as anything we have seen yet; bunch and berry of medium size, and very compact; highly prized as a wine Grape.

EMILY. (Vin.) Raised by Peter Raabe, Philadelphia. Bunch large, berries medium, sound, pale red; flesh juicy ; tender.

EMMA. (Labr.) Originated by T. Huber, Jr., Illinois. Bunch medium large, zompact; berries larger than Delaware, white, becoming a glosșy yellow when fully ripe; no pulp, vigorous, productive and healthy ; ripens with Concord.

EMPIRE STATE. (Labr.) Originated by J. H. Ricketts, from seed of Hartford, fertilized with Clinton. Healthy and productive, vigorous in growth, and fine in quality; in health of foliage and habit of growth it resembles our hardy native varieties, while in the quality of its fruit it has something of the fine flavor of the foreign Grape; its color is white, tinged with yellow, and covered with thick, white bloom; bunches long, large and handsome, generally shouldered; flaror, sweet, rich and sprightly without foxiness, and keeps well long after being gathered; should not be permitted to over-bear.

ESSEX. (Hybr.) Rogers, No. 4I. Black; ripens with Concord; medium sized bunch of very large berries, teuder, sweet and of an aromatic flavor; healthy, vigorous and productive. 


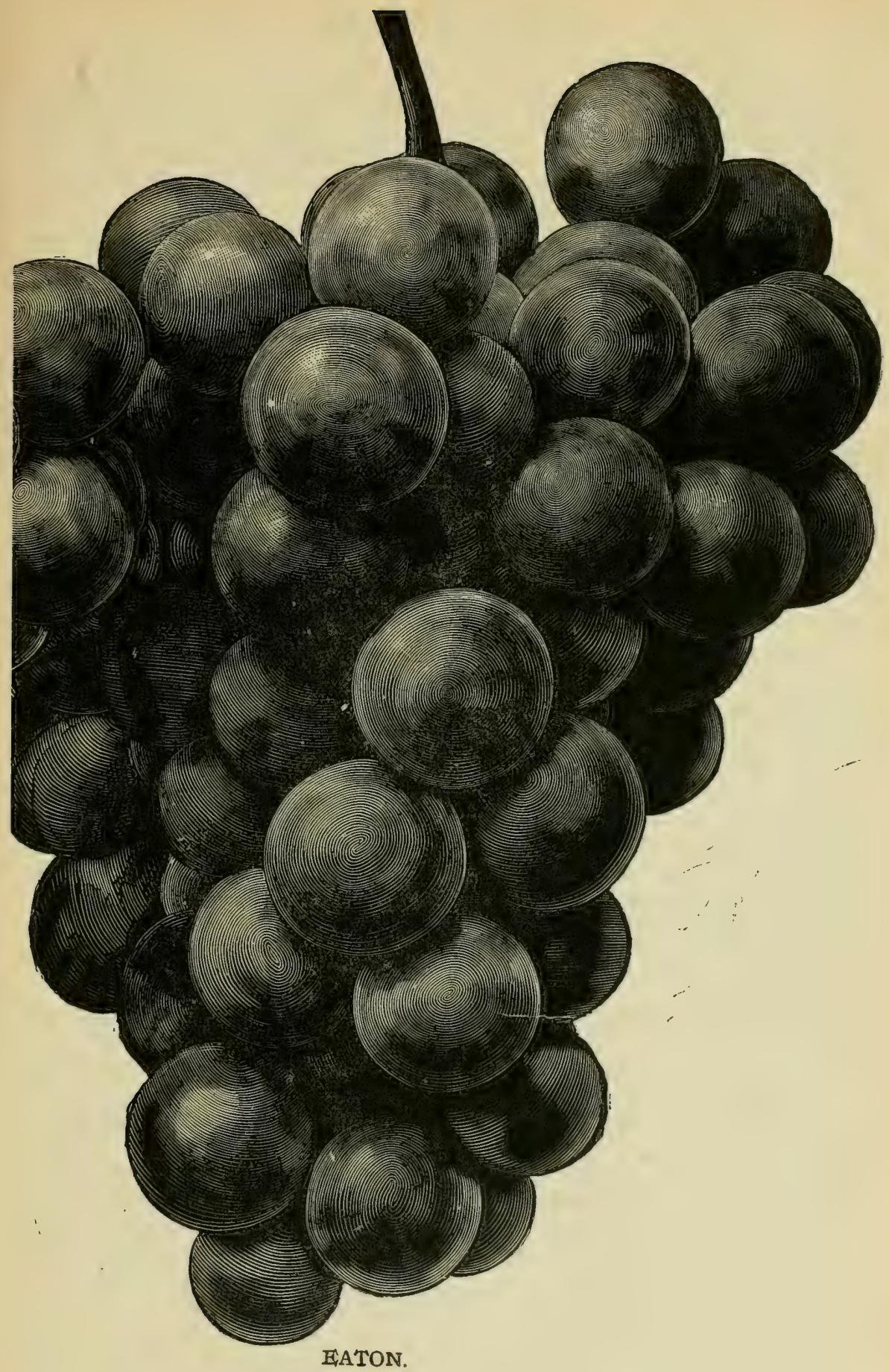


EOLIA. ( $L a b r$. $)$ A new seedling from Concord, originated by the late Robert Linville of Forsyth, Co., N. C., disseminated by N. W. Craft, of Shore, N. C. Bunch large, compact, shouldered; berry medium, greenish white; flesh tender and sweet; vine of the most hardy character, grows readily from cuttings; it makes the most beautiful white wine; ripens with Concord.

ESTHER. (Labr.) Originated by E W. Bull, Concord, Mass; a seedling from Concord. Bunch medium compact, shouldered; berry large, white, skin tender but tough, sweet, quality good, fine aroma; vigorous, liable to mildew in some localities.

ETTA. (Rip.) A seedling of Elvira, introduced by Jacob Rommel. It is an improvement of Elvira in quality, larger berries with firmer skin ; not so compact or crowded in bunch; not so liable to crack and free from rot; vine healthy, strong grower, very productive; ripens after Concord.

EUGENIA. (Labr.) One of the late T. B. Miner's seedlings. White; bunch and berry medium; quality fair ; early ; vine vigorous and hardy.

EUMELAN. (Est.) A chance seedling found at Fishkill, N. Y. Bunch good size, generally compact, shouldered; berry medium; flesh tender, sweet; quality excellent ; vine moderately vigorous ; ripens just after the Hartford ; one of the best table Grapes, and valuable for the amateur.

EUREKA. (Labr.) There are two Grapes under this name. A seedling originated by S. Folsom, Attica, N. Y., from Isabella ; closely resembling its parent.

EUREKA. $(H y b$.$) Originated by Dr. Stayman from Delaware. A red Grape;$ bunch large, shouldered, compact, very handsome; berry medium, tender, juicy, sweet, rich, sprightly, vinous, of pure flavor, fully equal to Delaware ; good grower, hardy, healthy and productive; free from rot and mildew ; foliage heavy and healthy ; does not drop in unfavorable seasons; ripens with Delaware.

EVA. (Labr.) Originated by Judge Sam. Miller, Missouri. White ; seedling of Concord, quite similar to Martha and therefore not disseminated.

EVALINE. $(H y b$.) A white Grape; bunch medium, compact, handsome; berry medium, very tender, juicy, sprightly, sweet, without pulp; pure as an European Grape ; medium grower, hardy, healthy and productive ; free from rot and mildew ; ripe before Concord ; originated by John Burr from Ideal.

EWING. (Labr.) A seedling of Isabella, from Jefferson City, Mo. Not healthy ; worthless.

EXCELSIOR. $(H y b$.$) Originated by J. H. Ricketts, from Iona fertilized with$ the pollen of Vinifera. Vine vigorous; bunch large to very large ; berry medium to large, roundish, oval, pale red, sweet, with a rich, Muscat flavor; a fine, long keeper, suitable for amateur culture in favorable localities.

EXQUISITE. $(H y b$.$) A black Grape; bunch medium, compact; berry small to$ medium, very juicy, sweet, red, vinous, sprightly, without pulp; the most delicious pure Grape we have; moderate grower, hardy, healthy and productive; free from rot and mildew ; ripe with Delaware; originated with Dr. Stayman from Delaware.

FAITH. $(H y b$.) Originated by Jacob Rommel, Missouri. Seedling of Elvira. Vine of the strongest growth, productive ; clusters medium, long shouldered; berries small to medium, white, juicy, sweet with a pure flavor; ripens with Hartford.

FANCHER. (Labr.) Introduced by T. B. Fancher, Lansingburgh, N. Y. A seedling of Catawba and very similar to it.

FAR WEST. (Est.) Originated by the late Fired Muench. Bunch fair size and shouldered; berries medium, black; skin tough with a fine blue bloom; flesh soft, meaty, melting, very sweet and spicy ; very late. 
FARRELL. $(H y b$.$) A white Grape ; bunch very large, long, shouldered ; berry$ above medium, very tender, sweet rich and sprightly, of the best quality; very vigorous, tolerably hardy, healthy and productive; so far free from rot and mildew ; ripe about with Concord; originated by Dr. Farrell, who stated that it was a seedling found on his grounds.

FENA. $(H y b$.) A seedling of Jewell, produced by Ludwig Hencke, Collinsville, I11. Larger both in bunch and berry than the parent; bunch compact; black; quality very fine, equal to Jewell.

FERN MUNSON. $(H y b$. $)$ Produced by T. V. Munson by crossing Post-Oak with Triumph Vine very vigorous and productive; bunch and berry large, black, tender skin, juicy ; flesh tender, red, fine flavor ; hardy.

FISK. $(H y b$. $)$ A hybrid, originated with the late J. F. Allen, of Salem, Mass. Not a very desirable Grape.

FLORA. (Labr.) Origin, Philadelphia. Bunch small, compact; berry small, roundish, purplish red; flesh pulpy, acid at center, juicy, vinous; vine hardy and productive; ripens with Isabella.

FLORENCE. (Labr.) Originated by Marine, supposed to be a cross of Union Village and Eumelan. Black ; bunch small, imperfect; berries medium, very early ; vine hardy, vigorous ; quality resembles Hartford.

FLOWER OF MISSOURI. (Hyb.) A Delaware seedling grown by William Poeschel, Herman, Mo. Not disseminated;

FLOWERS. (Rotun.) A variety of the Scuppernong type. Berries large, growing in clusters of ten to twelve, black, sweet ; ripens very late; hangs upon the vine until frost ; good only for wine; Southern Grape.

FRAMINGHAM. (Labr.) Identical with Hartford Prolific, at least closely resembling it.

FRANCIS B. HAYES. See Hayes.

FRANKLIN. (Rip.) A small black Grape, good for wine but not for a table Grape; bunch and berry small, black, juicy.

FRITZ. $(H y b r$.) A seedling of Roenbeck, produced by F. Roenbeck, New Jersey. Strong and vigorous in growth; bunch large, somewhat compact; berries white with a fine bloom; skin thin but tough, juicy; ripens with Concord.

GAERTNR. (Hybr.) Rogers No. I4. One of Rogers' hybrids which has been partially neglected, but is now attracting attention as one of the best and most valuable; bunch and berry large; color purplish red; skin thin; flavor sweet, rich, aromatic; ripens early; a fine grape.

GALLUP'S SEEDLING. (Hybr.) Probably a seedling from Salem, which it resembles in appearance; berries are a little larger ; quality good, fine flavor with very little foxiness; an excellent keeper; ripens with Concord. Originated near Adams Basin, N. Y.

GARNET. (Hybr.) One of the late Dr. Wylie's seedlings (Clinton and Red Frontignac). Bunch and berries larger than Clinton, of beautiful deep garnet color ; flavor and texture foreign, but native foliage.

GAZELLE. (Hybr.) One of Ricketts' seedlings. Bunch large ; berries medium, white almost translucent, sweet and delicious ; vigorous grower.

GENESEE. $(H y b r$.) Seedling of Delaware and Iona, originated near Rochester, N. Y. Bunch large, compact; berries large, red, healthy and of fine quality and flavor; foliage yellowish green, hardy, almost like Amber Queen. 


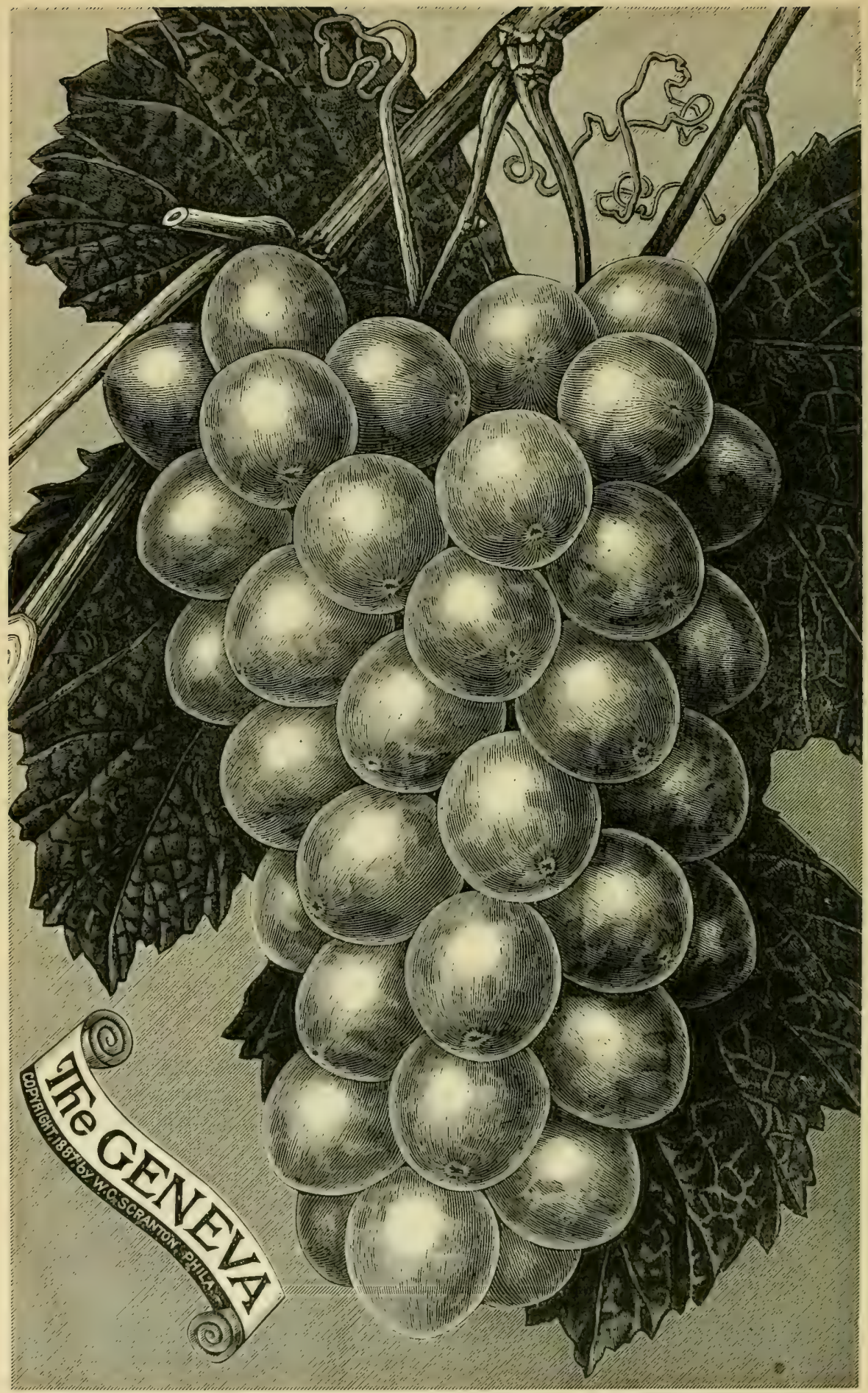


GENEVA. $(H y b$.$) Originated by Jacob Moore, New York. The Geneva, was$ produced, the first cross, seed of the Wild Black Fox Grape, fertilized with Muscat Alexandria ; that one of the progeny was a red Grape, very large, hoth in bunch and berry; this hybrid he re-crossed with Iona. The berry is rather large and inclined to be oblong or even obovate in shape, though nearly round. It ripens early-say a week after the Greeu Mountain - is of a green color with little bloom, adheres firmly to the stem. The skin is firm, though not thick, the pulp is for the most part meaty and parts freely from the seeds, which though rather large, are generally but two in number, and often but one. It is pure in flavor, sprightly and excellent. Grapes of the Geneva that have grown in bags are exceptionally beautiful, being so transparent that one may almost count the seeds; while in the sun the skin reflects, though feebly, of course, different in colors. Vine perfectly hardy, good cropper, the fruit will not drop from the stem however long it is left on the vine, and grows better and sweeter the longer it hangs. R. G. Chase \& Co., of Geneva, N. Y., have the sale of this variety.

GERBER. $\left(H y b_{.}\right)$One of Dr. Wylie's seedlings named by Judge Miller of Missouri. A black Grape of medium size in bunch and berry; very early, hardy and productive ; in quality it is between Concord and Clinton ; rots but very little.

GIANT LEAF. See Riesenblatt.

GILT EDGE. $(H y b$.$) A seedling of the Delaware, grown by Dr. L. C. Chisholm$ at Springfield, Tenn. It is very unlike its parent in all respects except size of bunch and berry. A strong grower, long jointed with dark green tri-lobed foliage. The bunches are somewhat like Dela sare, one-third larger, slightly shouldered; berry cream or buff-colored when fully ripe, translucent ; flavor quite peculiar, very sweet, with slight sub-acid, resembling the banana.

GOETHE. $\left(H y b_{0}\right)$ Rogers No. I, produced by E. S. Rogers, Massachusetts. Light red; bunch large; berries very large; flesh sweet and juicy; ripens about with Catawba ; vine a vigorous, rank grower and generally healthy; good keeper ; highly esteemed for table and wine.

GOLD COIN. $(H y b$.$) Cynthiana crossed with Martha, produced by T. V. Mun-$ son. Rank grower, wood dark red-brown; bunches compact, slightly shouldered; berries above medium, round, dull golden green with heavy white bloom ; skin tough ; prominent, tough pulp with a flavor very sweet, at the same time quite acid.

GOLD DUST. $(H y b)$ Another seedling of T. V. Munson, Lindley crossed by Delaware. No description given out.

GOLDEN BERRY. (Hyb.) Originated by Dr. Culbert, Newburg, N. Y. Seedling of Hartford and Gen. Marmora. Hardy and a free bearer. Not disseminated

GOLDEN CLINTON. (Rip.) A seedling of Clinton and resembles that variety except in color of fruit, which is yellowish white.

GOLDEN CONCORD, (Labr.) Produced by John Valle, New Haven, Mo.; a poor grower, inferior to Martha.

GOLDEN GEM. $(H y b$.$) Originated by J. H. Ricketts; seedling of Delaware$ and Iona. A medium small grape of exquisite flavor, ripening very early; vine slender, wood short-jointed, leaves small, but healthy. A superior Grape, of the first excellence; berry small, of a rich golden color, flesh tender and juicy; worthy of trial where Iona and Delaware succeed ; ripens early.

GOLDEN GRAIN. $(H y b$. $)$ Seedling of Lindley and Delaware, produced hy T. V. Munson. Still under trial. 


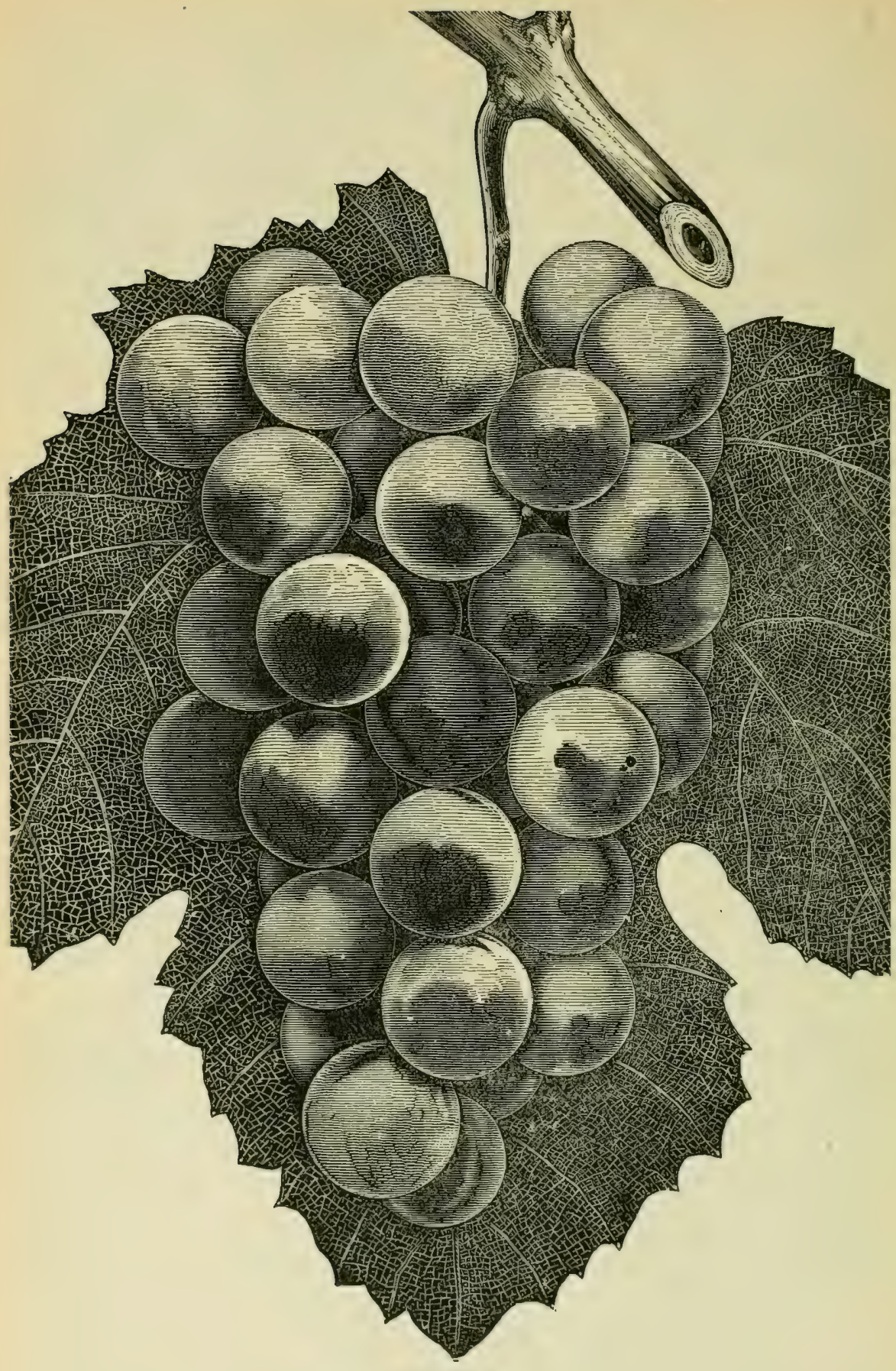

GOETHE. 
GOLDEN DROP. $(H y b$.$) Raised by Pringle from the Adirondack fertilized with$ Delaware. Yellowish white; bunch small, loose ; berry small, round; quality very best; ripens with Catawba; vine vigorous, healthy, with small foliage resembling clinton.

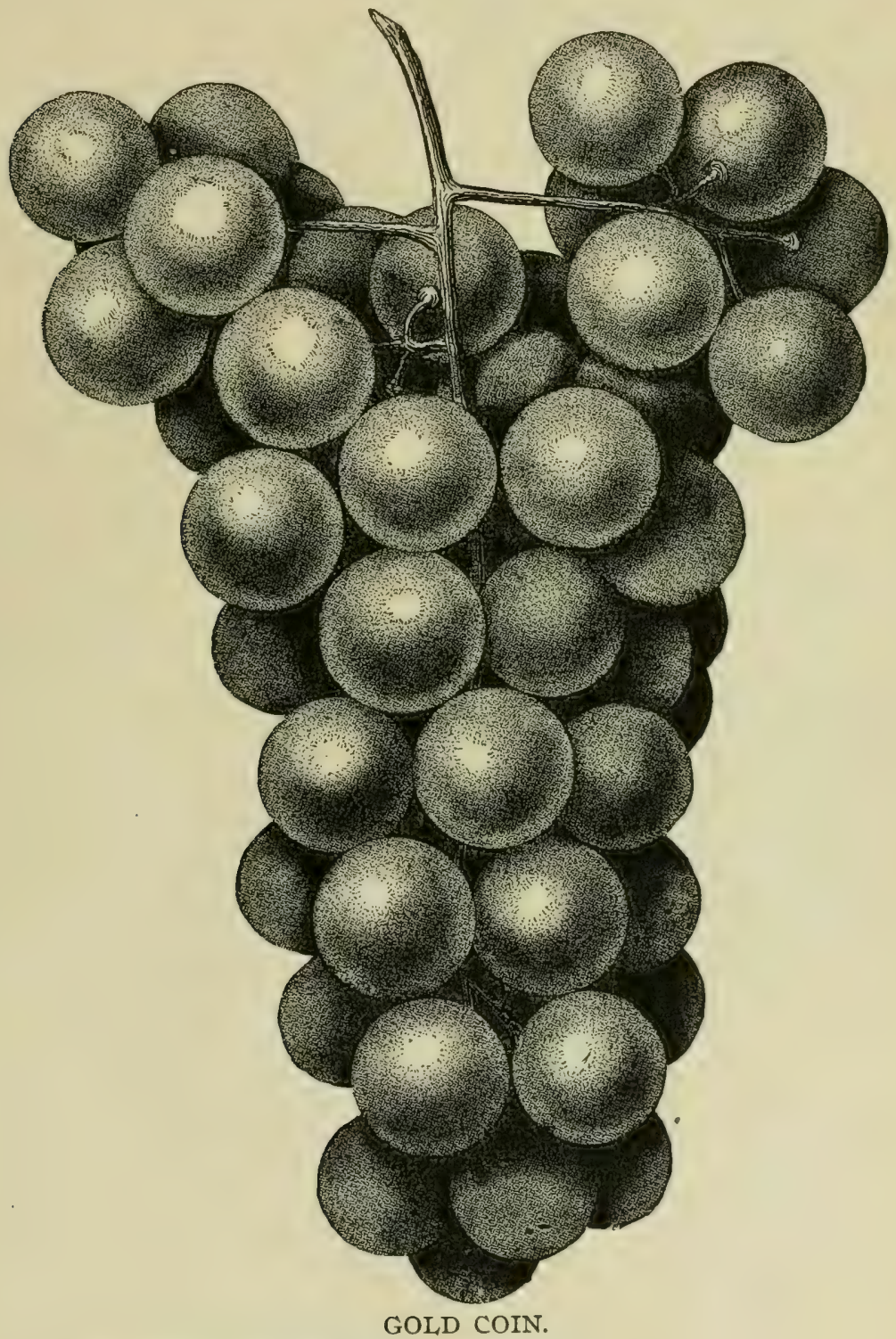

GOLDEN POCKLINGTON. See Pocklington.

GOV. IRELAND. $((H y b$.$) Originated by T. V. Munson, Texas. Bunch and$ berry large, dull black, whitish bloom; skin tender, pulp firm, slightly vinous, not juicy; not recommended. 
GoV. RoSS. $(H y b$.$) Seedling of Triumph, raised by T. V. Munson. Cluster$ very large, conical; large yellow berries, thin skin but tough, melting pulp, excellent quality ; medium growth and moderate bearer; perfectly hardy.

GRAHAM. (?) A chance seedling introduced by Wm. Graham, of Philadelphia, Pa. A small dark colored grape; sweet, sprightly and good; requires a warm, protected situation.

GRAY'S SEEDLINGS. (Labr.) W. C. Gray of Atwood, Ill., has raised a number of very fine seedlings from Concord, some of which are promising.

No. 1. Bunches large, sometimes shouldered and loose on stem; black with bloom on fruit; good flavor; perfectly hardy ; a medium grower; large leaf, short joints ; ripens very early.

No. 2. Bunches something like Delaware, very compact, shouldered; black; a very abundant bearer, but wants to hang on the vine sometime after coloring; a slow grower; hardy; ripens early.

No. 3. A very late Grape, ripens after all others are gone; a strong grower and hardy with good sized bunches, sometimes shouldered; berries good sized of a pinkish green color; large leaf; a good and valuable variety.

No. 4. A very large berry and bunch, nearly all shouldered; black; fine flavor; good grower, perfectly hardy; ripens a few days before Concord.

No. 5. A strong, rampant grower, long joints; bunches and berries large, yellowish red color; excellent flavor; ripens with Concord. This is the best of his seedlings,

GRAYSON. (Labr.) A seedling of Moore's Early, produced by T. V. Munson, Texas. Bunch medium, compact, slightly shouldered; berry large, black, whitish bloom, no pulp, sweet, pleasant, not vinous, no decided flavor.

GREEN CASTLE. See Marine's seedlings.

GREEN MOUNTAIN. (Labr.) It stands at the head of the list for earliness, full bearing, superb quality, vigorous, healthy growth. It was found growing in a garden on one of the slopes of the Green Mountains of Vermont, at an altitude of $I, 400$ feet, where the vine ripened its fruit perfectly and proved entirely hardy and very vigorous. The vine is a young as well as a very profuse bearer. The blossom is perfect and the bunches are of good size, handsomely formed and heavily shouldered. The berries are of medinm size; color greenish white; skin thin, and leaving no unpleasantness whatever in the mouth when eaten; pulp tender and sweet, with a slight inclination towards the vinous. The seeds are small, only one or two to a Grape, separate from the tender pulp with the slightest pressure after leaving the skin. It is entirely free from foxiness, and resembles a hot-house Grape more nearly than any out-door Grape we have ever seen. It is without exception far ahead of any variety yet introduced. Very early, being fully ripe the last week in August, at least one week earlier than any other variety under cultivation. The Green Mountain will mature fruit over a larger territory than any other Grape. It is the Grape for everybody and should be planted largely. Stephen Hoyt's Sons, New Canaan, Conn., introducers and propagators. It is sold under the trade mark seal, which is a guarantee of the genuineness of the vines sent out by them.

GROVE. (Labr.) A seedling of Concord and Clinton, originated by Thomas Grove, Tecumseh, Neb., and introduced by N. R. Harris of the same place. Bunch medium to large, sometimes shouldered; berries medium, round, white, turning amber in the sun; skin thin but very tough; pulp tender and sweet; productive and hardy ; ripens a few days later than Concord. 


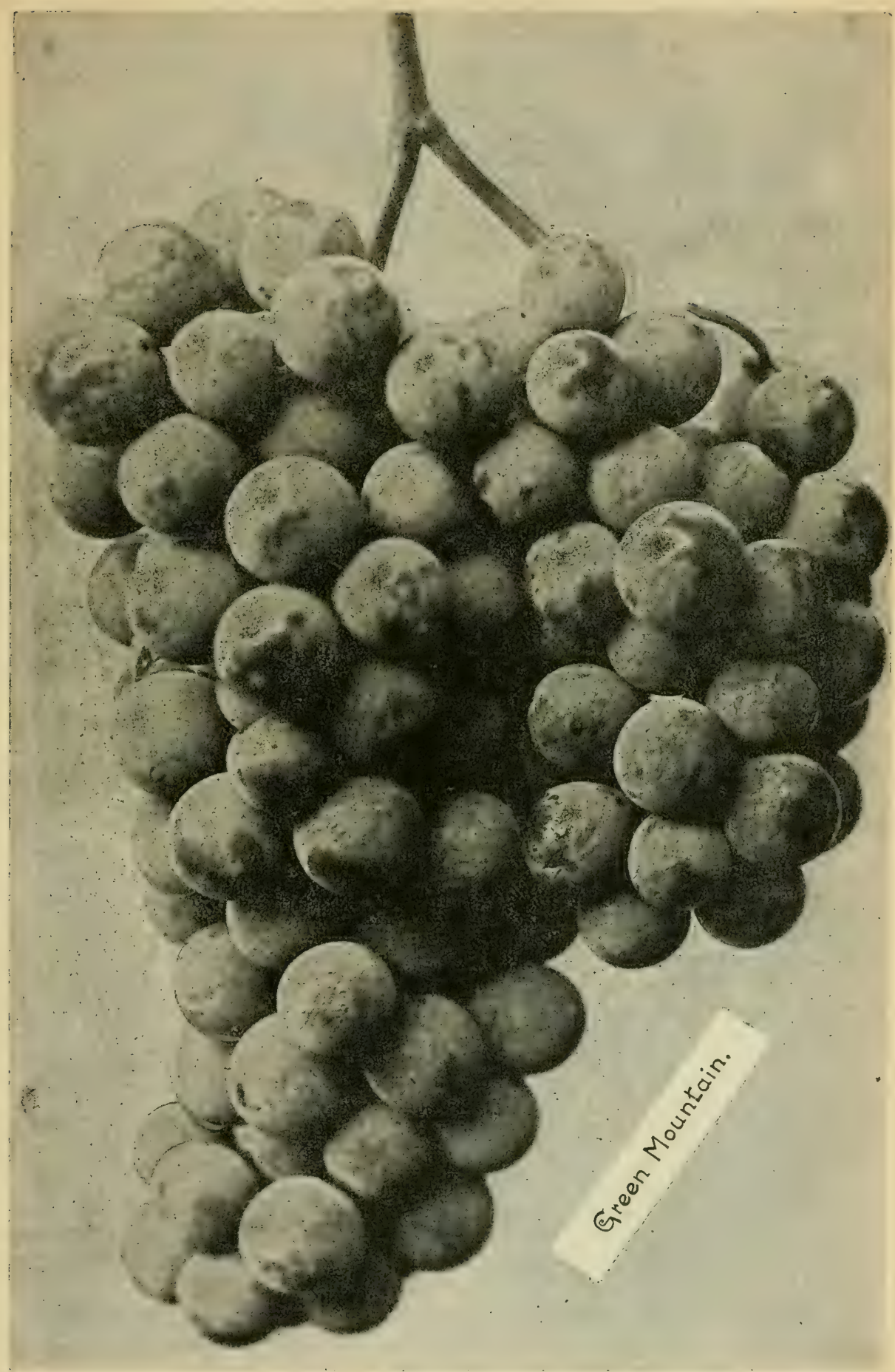


GREIN'S SEEDLINGS. (Rip.) Raised by the late Nicholas Grein, Herman, Mo., supposed to have been produced from seed of the Riesling.

No. I. See Missouri Riesling.

No. 2. GREIN'S GOLDEN. A table Grape ripening with Concord and nearly as large ; of a beautiful golden yellow color and good quality, better than Concord; a strong, healthy grower and productive. wine.

No. 3. Similar to Missouri Riesling in bunch and berry ; good for table and

No. 4. A very fine wine Grape of excellent flavor; bunch medium, moderately compact ; berries medium, juicy and sweet; fair grower.

No. 7, GREIN'S EXTRA EARLY. Vine vigorous, healthy and hardy, moderately productive; bunch and berry medium; light yellow color, good flavor and ripening a little before Concord.

GUINEVRA. $(H y b$.$) A seedling from Salem, originated by C. Engle, Paw Paw,$ Mich. Vine a rampant grower with long joints, quite hardy ; bunch very large, long, compact, often as firm as an ear of corn, slightly shouldered in the largest bunches ; berry quite large, round, white, with tough skin; flesh juicy, hardy, good; immensely productive; quality better than Niagara having none of that foxy or pungent taste.

HADDEN'S SEEDLING. (Labr.) Parentage unknow11, originated by $\mathrm{Mr}$. Hadden, of Pulteney, N. Y. Vine vigorous and strong; clusters small and compact, not shouldered; berries red, with a peculiarly wrinkled skin; pulp does not dissolve well, but has a pleasant sweet muscat flavor; only worthy as a curiosity, but not for general culture.

HAGAN. See Alvey.

HALIFAX HYBRIDS.' See Dr. Wylie's seedlings.

HALL. A variety grown by D. Hall, Urbana, Ohio. Berries medium, dark, almost black, better than Clinton, not equal to Isabella, but earlier.

HARMER. ( $\mathrm{Labr}$ ) Was found growing in Hartford Co., Conn, by D. Allerton, Marlboro, N. Y. It is a cross between the wild Vitis Labrusca and Riparia. A very rampant grower, large leaf of bright green color slightly downy underneath ; healthy; bunch small to medium; berry medium, black; hard pulp, very sweet with peculiar spicy taste; makes a very fine red wine; not very productive; late.

HARRELL. ( $L a b r$.) A chance seedling originated by Obed Harrell, Chrisman, I11. Cluster medium, compact ; berry medium, white, round, very sweet, vigorous and productive.

HARRISON. (Labr.) A seedling of Concord, produced by Isaac Staples, Dayton, O. Bunch medium to large, moderately compact; berries wedium, red, pure flavor, no foxiness; grows as thrifty as the Concord ; leaf is thick and very healthy ; no signs of mildew or rot; ripens with Concord; very hardy.

HART or HARTSTAFF. See Lincoln.

HARTFORD PROLIFIC. (Labr.) Raised by Mr. Steel, of Hartford, Conn. An old, popular Grape, very early and reliable; bunches large, shouldered; berries round, medium, black; vine healthy, hardy and immensely productive ; its tendency to drop from the bunch impairs its value largely for market growing.

HARWOOD. (Est.) Obtained from Major Harwood, Gonzales, Tex. Similar to Herbemont, except berry which is almost double the size of that of Herbemont ; color like Diana. 


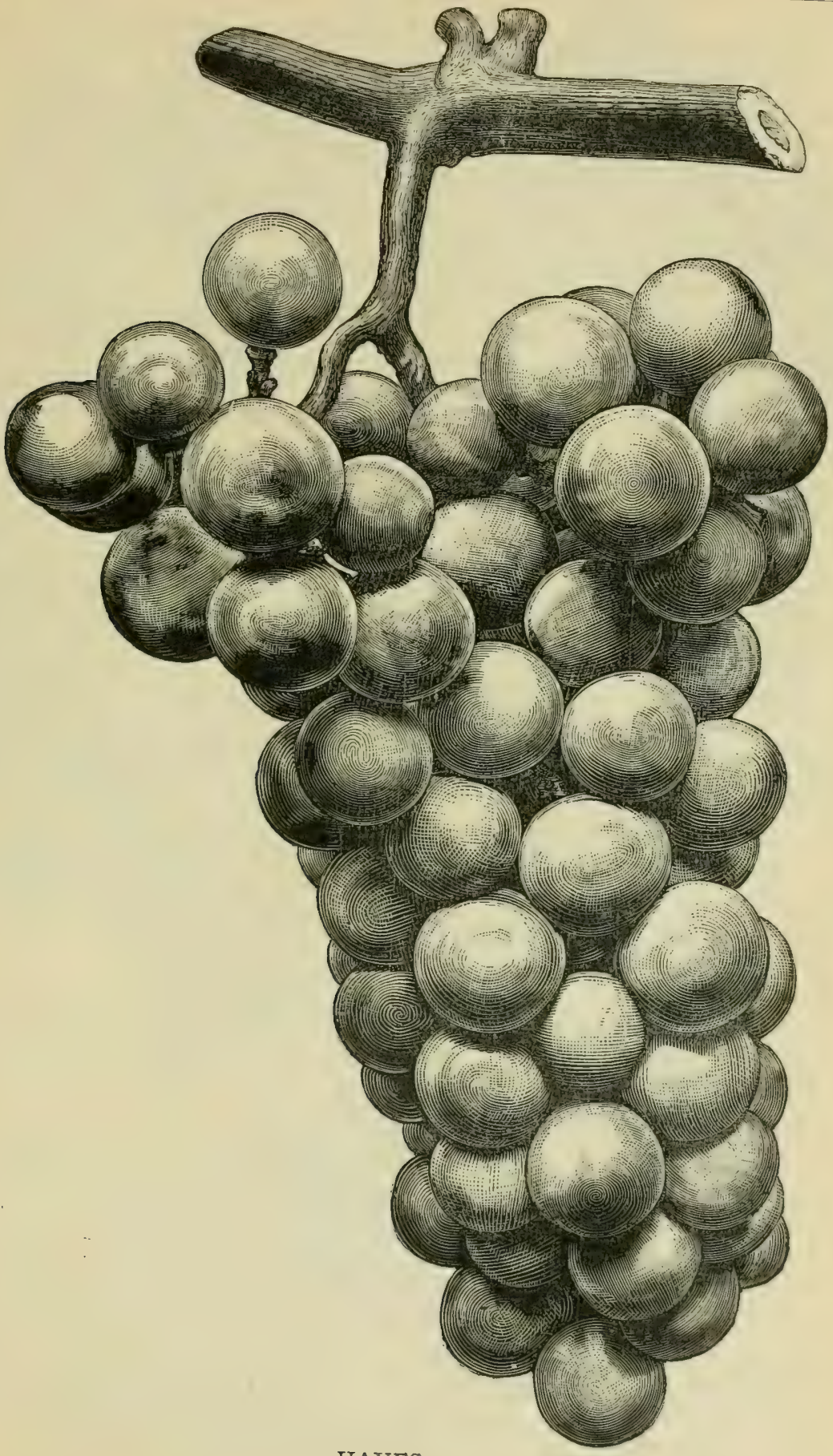

HAYES. 
HASKELL'S SEEDLINGS. $(H y b$.) Produced by Geo. Haskell, Ipswich, Mass. They have proved of little value being too tender. Hybrids between the foreign Black Hamburg, Frontignan and Chasselas, and native Black Fox, Amber Fox and Pigeon.

HATTIE. ( $L a b y^{r}$ ) Supposed to be a seedling of Concord, raised by Benj. Stratton, Richmond, Ind. Nearly identical with Concord and therefore never propagated.

HATTIE. (Labr.) A chance seedling grown by J. A. Putnam, Fredonia, N. Y. Bunches short and compact; berries medium size like Concord, black, quality first class, very sweet, flavor similar to Amenia (Rogers 39 ) ; prolific ; ripens with Moore's Early or earlier.

HAYES. (Labr.) Originated by Jno. B. Moore, Concord, Mass. Comes from the same lot of seedlings as the Moore's Early. Bunch medium to large, moderately compact, partly shouldered; berry medium, globular; color greenish white, changing to a fine amber yellow, when fully ripe; skin very fine; flesh tender, juicy, and of a very delicate texture and fine flavor, no foxiness; foliage healthy, thick and free from disease; vine vigorous and very hardy; a prolific bearer; ripens from seven to ten days before Concord.

HELFER. (Labr.) Produced by T. Huber, Sr., Illinois. Bunch and berry large, white; good quality but not very hardy ; late.

HENRY. (Labr.) Produced by T. Huber, Sr., Illinois City, Ill. Bunch size of Concord; berry large, round, white, sweet and juicy, foxy ; ripening about with Concord.

HERBEMONT. (Est.) Origin claimed for many localities. The best authorities class it as a member of the Estivalis family of the south, a native Grape. Bunches large, compact; berries small; skin black with blue bloom; flesh juicy, sweet, aromatic, vinous, rich; vine a very vigorous grower with a beautiful foliage; ripens late.

HERBEMONT'S MADEIRA. Syn. with Herbemont.

HERBERT. $(H y b$.$) Rogers 44. Produced by E. S. Rogers, Salem, Mass.,$ fertilizing Mammoth with Black Hamburg; is one of the best of Mr. Rogers' black Grapes; sweet and rich but sprightly, with tender flesh, fine in flavor without foxiness ; vigorous, healthy in growth and productive, bearing clusters of good size, both in bunch and berry; ripens early.

HERCULES. $(H y b$.$) A seedling from one of Rogers' hybrids, grown by G. A.$ Eusenberger, Bloomington, Ill. Bunch large to very large, sometimes shouldered, and quite attractive in appearance ; berry large to very large, round, black with blue bloom ; pulp firm, moderately juicy, of good flavor; ripens with Concord; a good amateur Grape.

HERMAN. (AEst.) A seedling of Norton's Virginia, raised by T. Langendoerfer. Herman, Mo. Black; bunch long, narrow; berries small, round, ripening very late ; vine vigorous, very productive ; valuable wine Grape in the Southern States.

HERMAN JAEGER. $(H y b$. $)$ A hybrid produced by T.V. Munson, Tex., by using pollen of the Herbemont upon one of the best varieties of Vitis Lincecumii found wild in that vicinity. Vine exceedingly vigorous, healthy and prolific. It will probably endure the winters as far north as $40^{\circ}$. Bunch very large, shouldered or doubleshouldered, compact; berry medium, of a dark purple, covered with a rich bloom, very persistent to the stem ; skin thin, tough; pulp melting, very juicy, sweet and sprightly, of best quality; seeds small; a very attractive and valuable Grape for market, table or wine; ripens with or a few days later than Concord. 



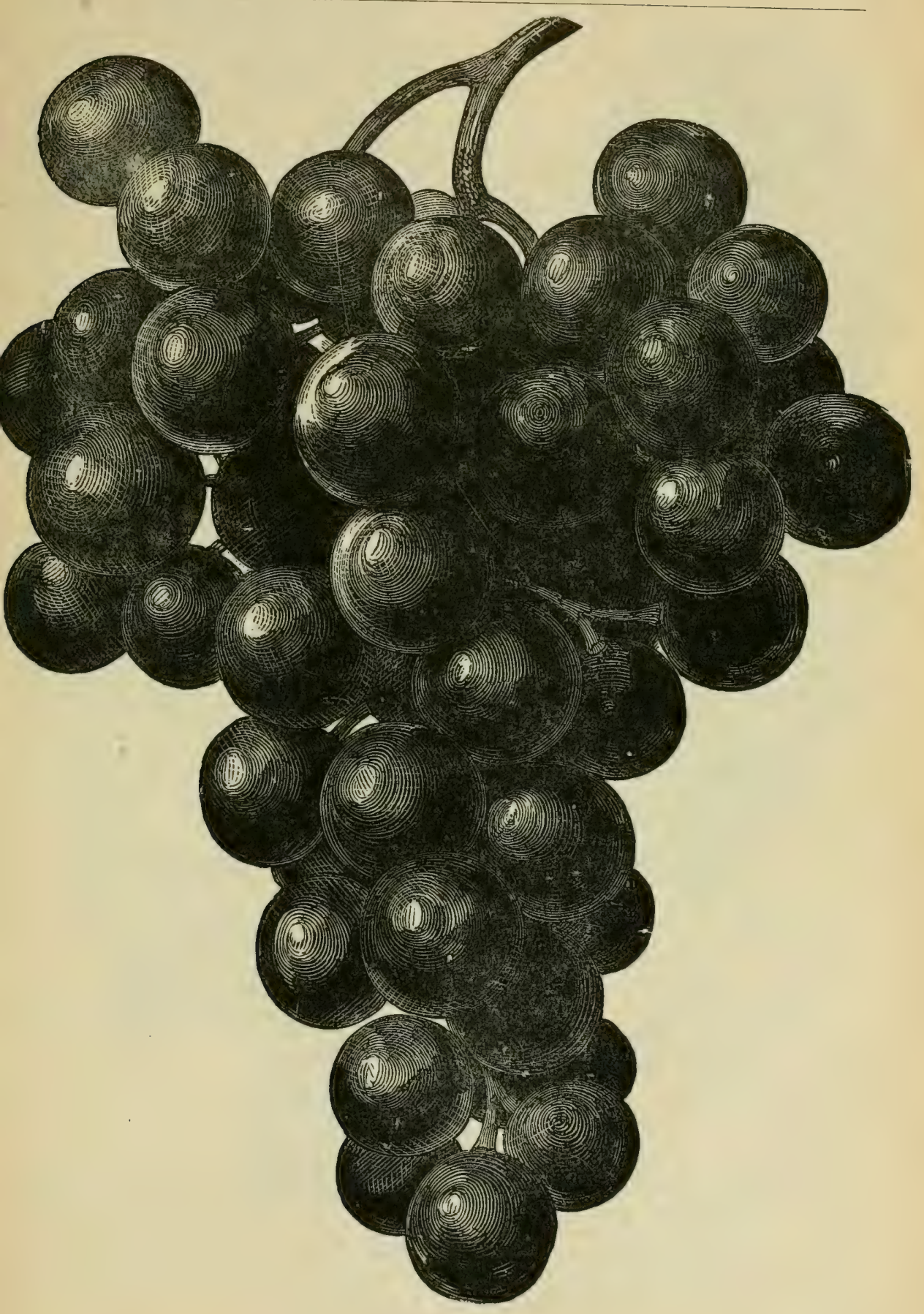

HERCULES. 
HERO. (Labr.) A seedling of Concord, produced by Ludwig Hencke, Collinsville, Ill. Bunch and berry large to very large, melting pulp, sweet and of fine quality.

HETTIE. (Labr.) Originated with Mrs. N. R. Haskeil, Monroe, Mich. Bunch medium, long and loose; berries medium, round, bright red, translucent, with a bloom. juicy, vinous; ripens with Concord.

HIGHLAND. $\left(H_{y}, b\right.$. $)$ Originated by J. H. Ricketts, New York, by fertilizing Concord with pure Muscat. Vine vigorous, leaves large, thick, coarsely serrated; bunch very large, long, compact, heavily shouldered; berry round, black, with a heavy blue bloom; flesh soft; pulp juicy, slightly vinous, but very late in ripening. Only suited to favorable localities, where it can have a long season to mature.

HINE. (Labr.) Seedling of Catawba, raised by Judson Brown, at Put-in-Bay, Ohio. Bunch good sized, compact, shouldered; berries medium, dark, rich claret, brown with a purple bloom; flesh juicy and sweet; ripens with Concord.

HONEY. $(H y b r$.) Originated by C. Engle, Paw Paw, Mich., raised from seed of Salem. Bunch medium, compact, often shouldered; herry large, round, white. translucent; skin and pulp of honeyed sweetness; medium vigorous, hardy and prolific; ripens early.

HOPECON. (Est.) Introduced by D. S. Marvin, Watertown, N. Y., from Eumelan and Elvira. Bunch medium to large, compact, slightly shouldered; berry medium, pale green, light bloom ; pulp tender, not very sweet or juicy, good flavor ; skin thin; medium late.

HOSFORD. (I.abr.) Probably a seedling from Concord grown by Geo. Hosford, Ionia, Mich., known also under the name of Hosford's Mammoth. Bunch large, slightly shouldered, tapering; berries very large, round, dark blue black with delicate bloom ; pulp clear, tender, juicy ; skin tender; flavor sweet, pure, brisk, not foxy ; a vigorous grower, prolific, healthy and hardy; ripens a few days earlier than Concord.

HOWELL. (Labr.) Origin unknown. Bunch and berry medium, oval, black ; skin thin ; flesh with firm pulp, pleasant; good ; ripens medium early.

HUBER'S SEEDLINGS. All originated from Concord, by Theo. Huber, Sr., I11., which have not been named yet and are still under trial, some promising well.

HUDSON. (Labr.) Originated at Hudson, N. Y. Similar to Isabella ; berries less sprightly and not so rich.

HULL. See Oporto.

HUMBOLD. (Rip.) A seedling of the Louisiana, raised by T. Muench. Vine very vigorous, healthy and hardy; bunch below medium; berries medium, light green, changing to rose tint when fully ripe ; fiue quality.

HUNTINGDON. (Rip.) A Clinton seedling, not valuable on account of being too small.

HUSSON. See Devereux.

HUSMAN. $(H y b$.) Produced by T. V. Munson, hybridizing Vitis Lincecumii with 'Triumph and named in honor of Prof. Geo. Husman of Napa, Cal. The vine is robust and healthy with scarcely a perceptible trace of foreigu character. The clusters are large to very large, sufficiently compact; the berries are medium to large size, black, of good quality with no foxincss or other objectionable flavor; very prolific ; ripens a week later than Concord. 


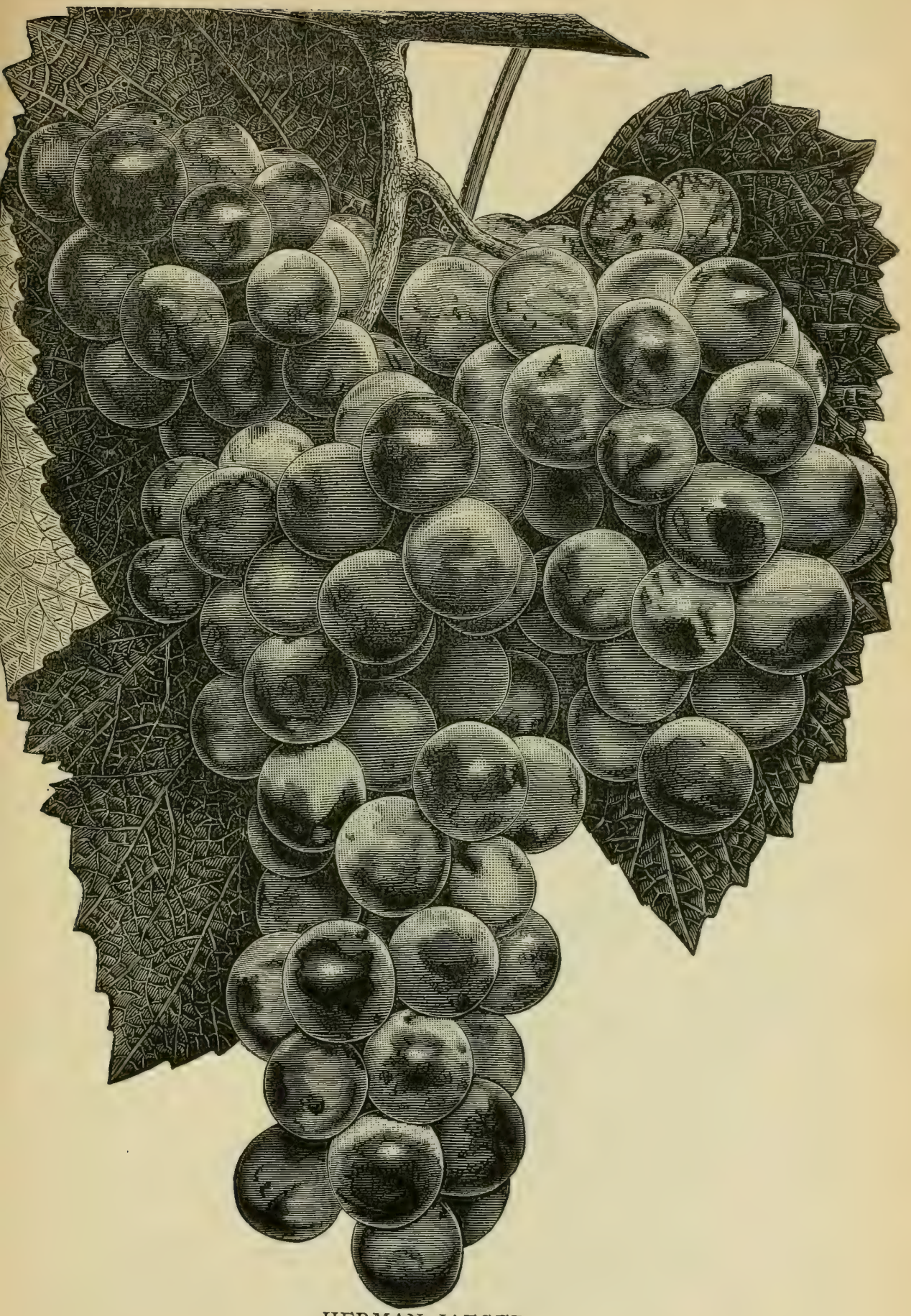

HERMAN JAEGER. 
HYDE'S ELIZA. A chance seedling originated with Eliza Hyde, Catskill, N. Y. Vigorous and productive; bunch medium, compact, with small shoulder; berries medium, round, black, juicy and vinous ; a little earlier than Concord.

IDA. $(H y b$.$) A seedling of the late T. B. Miner, New Jersey. White; bunch$ and berry large; quality good; vine vigorous, hardy but not productive; ripens after Concord.

IDEAL. (Hyb.) A red Grape; bunch large, shouldered, rather compact; very handsome; berry large, tender, juicy, sprightly, vinous, rich, sweet, without puIp; better than Delaware; vine strong, hardy, healthy and very productive ; ripe about with Concord; with us it rots and mildews some but with Mr. Burr it has never done either; this is without a doubt the finest red native Grape known; originated by John Burr from Delaware.

ILLINOIS CITY. (Labr.) Introduced by T. Huber, Illinois. Bunch and berry very good size; white, sweet and juicy; ripens with Concord.

IMPERIAL. $(H y b$. $)$ A white seedling from Iona and Sarbelle Muscat, raised by J. H. Ricketts, New York. Vigorous, late, hardy and of best quality.

\section{IMPROVED WARREN. See Harwood.}

IONA. (Labr.) Originated by the late Dr. C. V. Grant of New York. a seedling of the Catawba. Pale red; bunch large, long, shouldered, rather loose; berries medium; skin thin, firm; flesh tender with rich vinous flavor; very best quality for table or wine; vine only a moderate grower, requiring rich soil and high culture; ripens a little before Catawba ; succeeds only in favored localities ; short-jointed and inclined to overbear, requiring short pruning and thinning of fruit.

IOWA EXCELSIOR. (?) Raised by Prof. Matthews of Iowa. Bunch medium to large; berries large, red; skin medium thick; pulp soft, sweet and sprightly ; vigorous grower; ripens soon after Concord.

IRVING. $(H y b$.$) Originated by S. W. Underhill, N. Y.; grown from Concord$ fertilized with Frontignan. White: bunch and berry large ; vine only moderately vigorous or healthy ; ripens after Concord.

IRVIN'S OCTOBER. ( $L a b r$.) An old variety found in a Dutch settlement in middle North Carolina, but only three years ago brought to notice and introduced by J. Van Lindley, Pomona, iv. C. Bunches large, shouldered; berries medium, moderately loose, dark, dingy red; very good quality; vigorous grower, large, strong leaves ; ripens late.

ISABELLA. (Labr.) A native of South Carolina and brought north by Mrs. Isabella Gibbs. It is too well known to need an exhaustive description. Bunch large, compact, shouldered; berries large, oval, black, fair quality ; vine vigorous ; ripens late; leaves often drop just at the time when needed to aid in ripening the fruit.

ISRAELLA. (Labr.) Seedling raised by the late Dr. Grant, probably from the Isabella, which it resembles in growth and character of fruit; black; bunch long, compact; berry large, pulpy, fair quality ; ripens before Concord.

ITHACA. $(H y b$.$) Seedling produced by Dr. S. J. Parker, Ithaca, N. Y. Bunch$ and berry large, greenish yellow; foreign flavor; hardy, healthy and vigorous.

IVES. (Labr.) Originated by Henry Ives of Cincinuati, Ohio, probably from the seed of Hartford. Black; bunch and berry large, compact, shouldered; sweet, juicy, slightly foxy and vinous; esteemed as one of the best for red wine. It colors some time before it is ripe, and is often sent to market unfit for use. Vigorous, healthy, hardy; a very reliable variety, of good flavor when fully ripe; generally free from mildew or rot. 


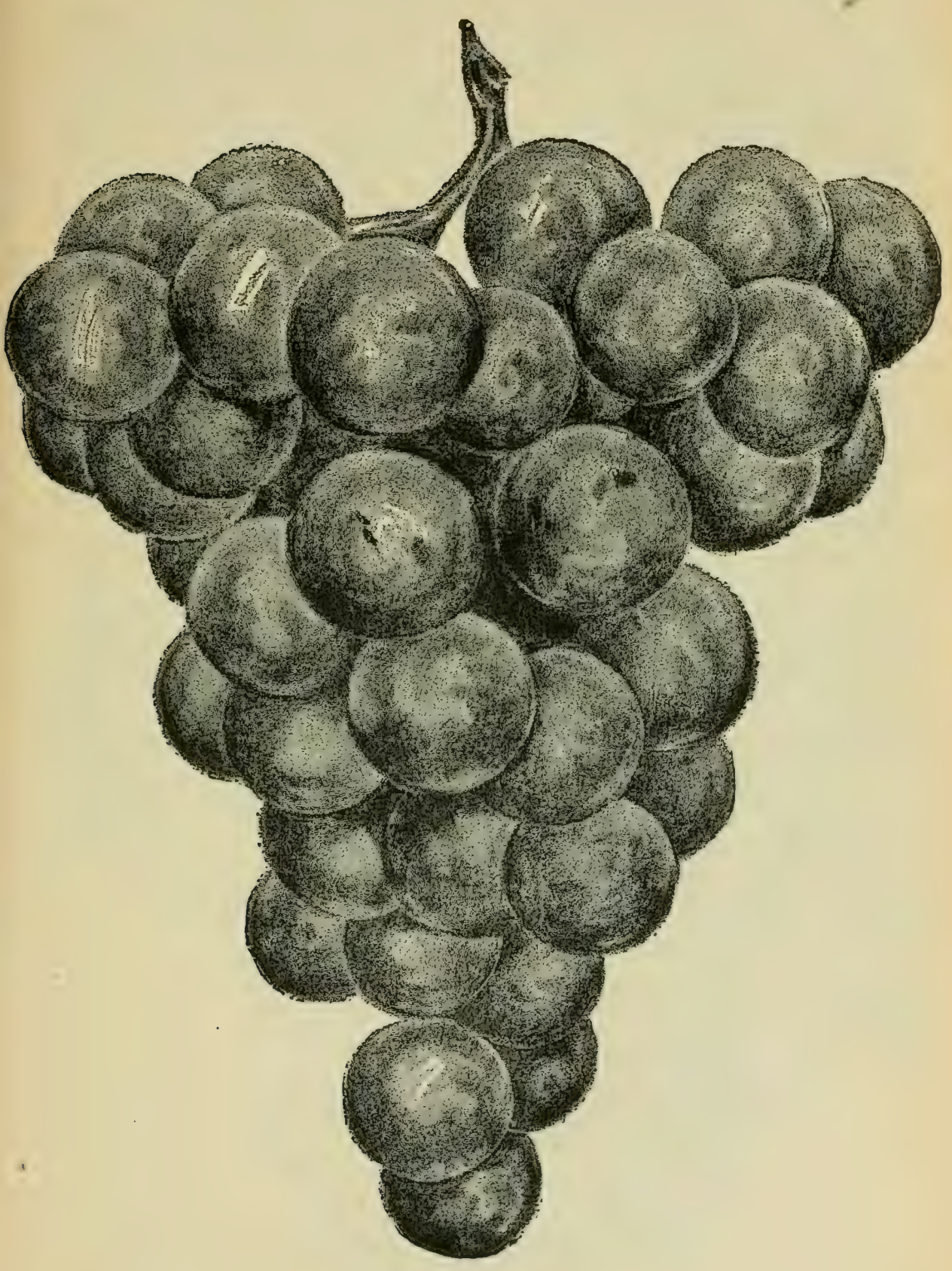

HOSFURD. 
JAEGER'S NEW VARIETIES. Introduced by Herman Jaeger, Neosho, Mo. Vitis Astivalis type Lincecumii, popularly known as Summer Grape in Missouri, and as Post Oak Grape in Texas grows wild from South Missouri to Southern Texas. It was the first among our various species of native wild vines to attract his attention, and he selected over one hundred of the best varieties he could find and tried them under cultivation. Many of them had produced heavy crops in their wild state, blooming near male plants of the same family, while cultivated they were shy bearers. Others proved quite productive in the vineyard, and the best of these he still cultivates to some extent, especially Neosho, Racine, Nos. 32, 52, I 3 and 43. The two last ones are as large as Ives and Concord respectively, in size of bunch and berry. They are very hardy and productive, and while considering their quality no better than Concord, he raised some in order to have late Grapes that would remain sound where black rot destroyed the whole crop of Concord and almost all other cultivated Grapes.

Vitis Rupestris is another native species that attracted his attention on account of its perfect immunity from both black rot and Peronospora or downy mildew. Some he shipped to France, where they soon got to be in great demand as grafting stocks of easy propagation and extreme hardiness, almost or quite Phylloxera-proof and adapted to the dryest, thinnest and stoniest soils. Notwithstanding the diminutive size of its fruit, Rupestris is preferred by the French to all other American Grapes in their efforts to produce valuable Franco-American crosses. It owes this preference to its perfect purity, being always free from foxiness or any other native aroma, so objectionable to all, who educated their taste on European Grapes. While getting Rupestris for export, he selected the best and largest to cultivate. Even these are no larger than a fair-sized currant in bunch and berry, and will therefore never become popular. Yet repeatedly he was glad to have these vines, covered with small bunches, yielding a very good and pure claret, while almost all other Grapes were destroyed by rot or mildew. For creating new varieties of extreme hardiness and earliness, and for purifying the flavor of American Grapes, the infusion of Rupestris blood will remain of importance.

JAEGER'S No. 70. Is a seedling of Lincecumii No. 43 crossed with a male vine of Vitis Rupestris. Black, extremely hardy and productive; bunch and berry nearly or quite as large as Ives, but less compact; it colors early and ripens about twelve days before Norton. When full ripe it has some of the peculiar Lincecumii flavor which remains in the wine, a very dark rich claret, much admired in Missouri for its "fruity" aroma.

No. 72. Is of the same parentage as No, 70. Foliage and wood resemble Lincecumii more than 7o, (which retains more of Rupestris.) Black with pale bloom : bunch very compact and smaller than 70 with larger berries; ripens just before Norton and hangs long on the vine; flavor quite pure like Rupestris; productive; a fine table or market Grape making a pure and very good claret.

No. 100. Is a seedling of Elvira, as large as Concord in bunch and berry. Color yellow to greyish pink when very ripe; quality and flavor very similar to Catawba; ripens with Delaware; vine of Labrusca character, very hardy and productive; a good table and white wine Grape; its market value is often impaired by berries bursting when ripe, like Elvira. This Elvira seedling No. 100, he crossed with male Rupestris and also with male Cinereas and Rupestris. The first cross gives early and the second late Grapes, all of great hardiness. fine quality and pure taste; a number of each fruited twice. Further trial is necessary before selecting the best. Among the very first hybrids he produced were Nos. 50 and 56 , 


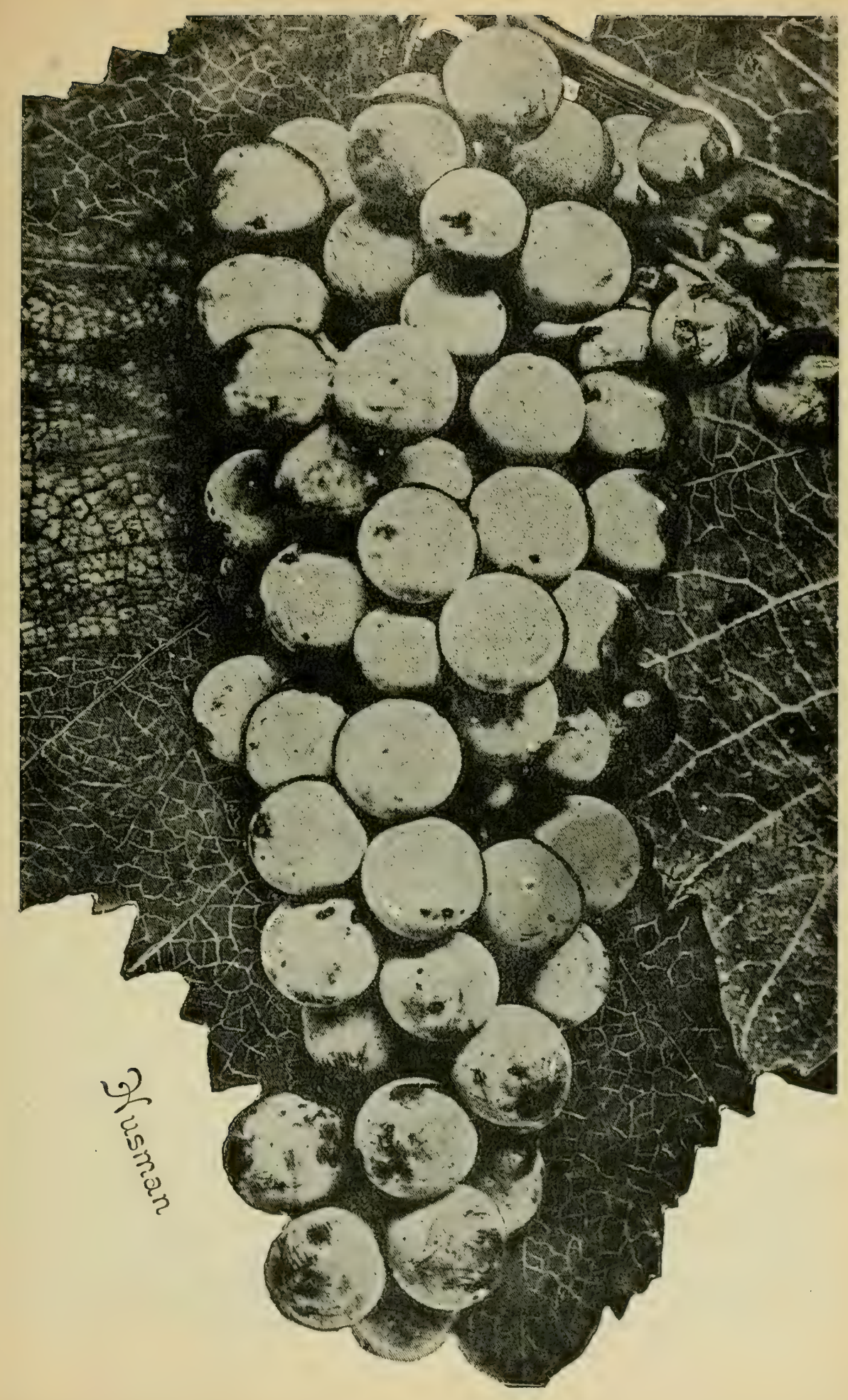


crosses between large wild Lincecumii and the delicious but very tender Herbemont. In quality and character of fruit and vine they closely resemble the various similar crosses now being introduced by Prof. T. V. Munson of Denison, Texas. Besides being subject to rot and mildew, he found 50 and 56 entirely too tender to stand the winters, consequently never propagated them. Of late years spraying has not only kept them free of rot and mildew, but freedom from mildew has allowed the wood and eyes to ripen so much longer and better than formerly, that these vines last winter stood unprotected and without injury a temperature of $22^{\circ}$ below zero Therefore he now considers them most valuable Grapes, the more so because they ripen still later than Norton and keep so well that they extend the Grape season in Missouri six to eight weeks.

No. 50. Is a very compact, medium sized bunch of medium size berries. Black with light bloom and very little color; as sweet, pure, juicy and deliciously sprightly as Herbemont.

No. 56. Is almost as large in bunch and berry as Concord ; of Catawba color with white bloom; no coloring matter. Quite the equal of No. 50 in purity and sweetness and only a trifle less sprightly. One of the finest in appearance as well as quality. Both 50 and 56 will no doubt make fine white wines. These as well as Mr. Munson's new Grapes of similar parentage, he now considers the most exquisite late varieties which can be grown in the Middle and Southern States.

JACK-JACQUES. See Lenoir.

JAMES. (Rotun.) Of the Muscadine class. Originated in eastern North Carolina and introduced by J. Van Lindley, Pomona, N. C. Berries very large, five to ten berries to the cluster ; black ; thin skin ; quality good, superior to the well know:1 Scuppernong; 1ate.

JANESVILLE. (Labr.) Supposed to be a cross of Hartford and Clinton, originated in Wisconsin. Black; bunch aud berry medium; vine very hardy, healthy and productive; second or third quality, not much better than Champion; ripens with Concord.

JEFFERSON. (Labr.) Produced by J. H. Ricketts, Newburgh, N. Y. One of the finest Grapes, of good, healthy growth, holding its foliage and bearing well. A native cross between Concord and Iona, grown from Concord seed. The fruit resembles Iona in appearance, and is fully equal to it. The clusters are large, often double-shouldered and very handsome. Endures $13^{\circ}$ below zero. Ripens ten days to two weeks after Concord.

JEMINA. (Labr.) Produced by D. S. Marvin, Watertown, N. Y. Bunch small, compact ; berry rather large, no pulp, black; vigorous and healthy ; ripens early.

JENNIE MAY. (Labr.) A seedling of Concord, grown by John Laws, Genera, N. Y. Too near like Concord.

JESSICA. (?) Originated with D. W. Beadle, Canada. Is recommended especially for productiveness, early ripening and fine quality. The growth of the vine is good, and foliage healthy; clusters and berries not above medium in size; color white; quality good; has proven generally satisfactory, and is highly recommended.

JEWELL. $\left(H y b_{0}\right)$ A hlack Grape; bunch medium, compact, shouldered; berry ahove medium ; skin rather tough; slightly pulpy, sweet, rich, sprightly, vinous ; of the very best quality, equal to the Delaware; vine not vigorous until well established ; free from rot and mildew ; the earliest and best Grape of high quality, fully tested ; colors and ripens all at once, at least a week before Moore's Early ; will hang on the vines long after ripening; ships well. Seedling of Delaware, originated by John Burr of eavenworth, Kan. 


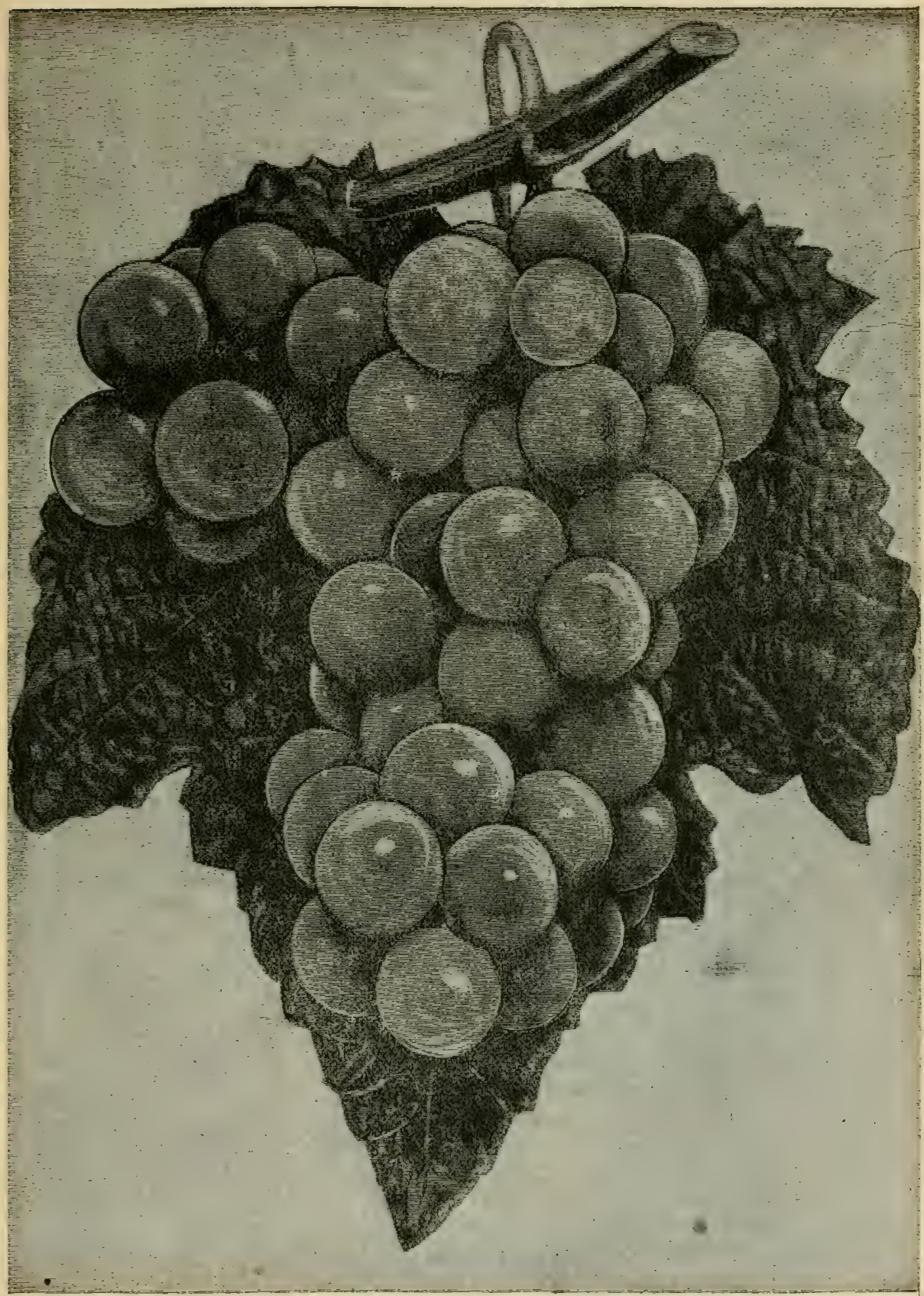

JEWELL. 
JOHN BURR, (Labr.) A Concord seedling grown by the late John Burr of Leavenworth, Kas. Has not been disseminated.

JORDAN. See Moyer.

25th OF JULY. (Rip.) Originated by Jacob Rommel, Morrison, No. Seedling of Elvira. Still under trial.

JUMBO. (Labr.) Probably a seedling from Concord, grown by Mrs. R. Rose, Marlboro, N. I. Bunch very large, compact, shouldered; berry very large, almost the size of a blue plum; clusters have weighed I $1 / 4$ pounds; blue black with a very fine blue bloom; fine quality, sells good in New York market; earlier than Concord.

JUNO. $\left(H_{y^{\prime}} b.\right)$ A cross of Muscat Hamburg and Belvidere, produced by G. WV. Campbell, Delaware, Ohio. A very fine Grape for amateurs; black with large, long clusters, oval; berries medium to large; flesh not pulpy but tender and meaty, with fine, high flavor; ripens before Concord.

KALAMAZOO. ( $L a b r$.) Raised from seed of Catawba by Mr. Dixon, Steubenville, $\mathrm{O}$. Vine vigorous, hardy and productive; bunch large, rich blue bloom; flesh soft and sweet; a little earlier than Catawba.

KALISTA. $(H y b$.$) Delaware seedling produced by J. Sacksteder, Kentucky.$ White, of rich flavor and fine quality; bunch and berries size of the parent, but better grower.

KAY'S SEEDLING. A seedling of Herbemont. Very little is known about it.

KELLER'S WHITE. (Labr.) Seedling of Catawba. No value.

KENDELL. (Labr.) Originated in Brooklyn, supposed to be a seedling of Isabella, but greatly improved. Vigorous; bunch large, moderately compact ; berry large, black, oval; flesh juicy, rich and of good quality.

KEUKA. See Ne 9 .

KEYSTONE. (Labr.) Originated near Mt. Joy, Lancaster Co., Pa., on the premises of John Kready, supposed to be a seedling of Concord. Vine a strong grower, healthy and vigorous, and holds its foliage until fruit is fully ripe; bunches large, uniform, compact and generally shouldered; berries about the size and shape of Concord; color black, with bluish bloom; skin tough; quality good, ripening with Concord; keeps well in a cool, dry place until March.

KILVINGTON. (?) Origin unknown. Bunch medium, tolerably compact; berries small, round, dark red with a bloom ; flesh pulpy, half tender, vinous.

KiNG. See Golden Clinton.

KINGSESSING. (Labr.) Bunch long, loose shouldered; berry medium, round, pale red with a bloom; flesh pulpy.

KING WILLIANi. See Marine's Seedlings.

KINNEY'S SEEDLING No. I. (Labr.) Originated by I. Kinney, Zanesville, Ohio. Seedling of Vergennes. Bunch medium to large, compact; berries large, round; skin tough; very fine flavor; good keeper; ripens early.

KINNEY'S SEEDLING No. 2. (Labr.) A seedling from Concord, grown by I. Kinney, Zanesville, O. Bunch medium, compact ; berries small, round, white, transparent, but few seeds, very sweet without any disagreeable taste; leaf similar to Concord; healthy, good grower.

KITCHEN. (Rip.) Seedling of Franklin; bunch and berry medium; berry round, black; flesh acid, juicy.

KITTREDGE. See Ives. 


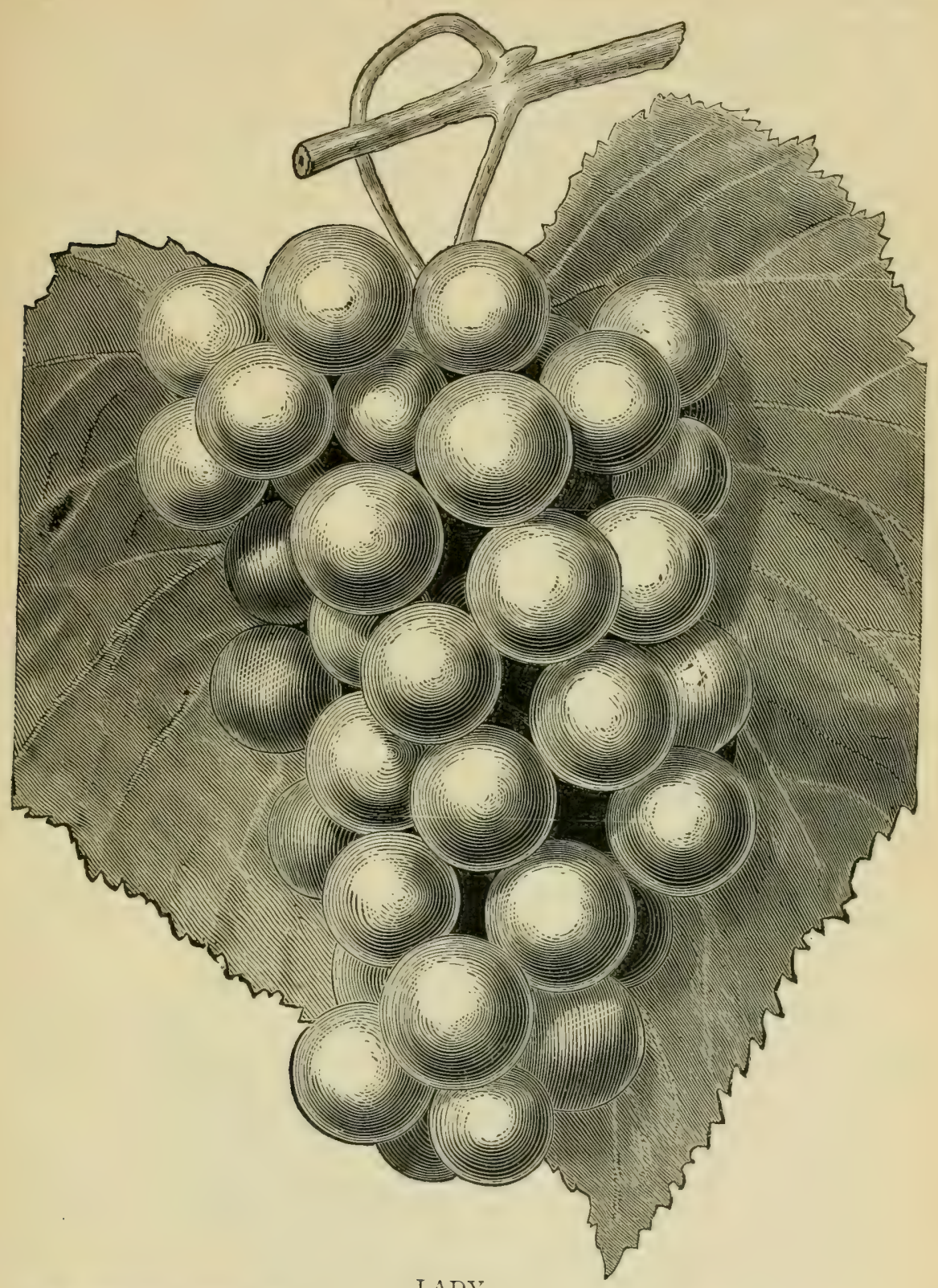

KRAMER SEEDLING. (Labr.) Originated by C. Kramer of La Crescent, Minn., from seed of Concord. Like Concord in appearance, more thrifty in growth; berries nearly black, vinous, with a prickling, sweet taste; good for wine.

LABE. (?) Bunch rather small, short, oblong; herries medium, loosely set, black ; flesh half tender, pulpy, sharp, sweet. 
LACRISSA. (Hyb.) A Delaware seedling grown by J. Sacksteder, Ky.; of fine flavor and excellent quality; white; in appearance and size like the Delaware, but better grower and does not drop foliage.

LADY. ( $L a b r)$ A pure Concord seedling, first offered by G. W. Campbell, Delaware, $O$. The very best extra early white Grape. As healthy and hardy as Concord, or any of our hardiest kinds. In quality regarded by many as best, and it certainly is the best of its season. Has shown much less liability to rot than Concord in the same localities. The demand for the vines has steadily increased, and it is now planted quite largely for early market, being the earliest and most reliable good white Grape yet fully tested, and seems to be growing in public estimation every year. Bunch medium, compact; berries large; skin thin, sometimes cracks badly; vine only a moderate grower, but perfectly healthy and hardy, with Concord foliage; moderately productive; ripens very early, about with Moore's Early; should be planted on rich land.

LADY CHARLOTTE. (Hyb.) Raised by Mr. Pringle of Vermont, from Delaware crossed by Iona. Bunch large, shouldered, compact; berry medium, round' golden color, juicy, very sweet; vigorous grower, healthy and productive; ripens with Iona.

LADY DUNLAP. $(H y b$.$) Originated by J. H. Ricketts, New York. Bunch$ medium, compact; berry medium, amber, with vinous flavor; quality fine.

LADY HELENE. $(H y b$. $)$ Originated by Fred Roenbeck, N. J. Bunch large, shouldered, sufficiently compact ; berry large, round, white, quality not quite as good as his other seedlings; good grower and prolific ; ripens after Concord.

LADY WASHINGTON. (Hyb.) Raised by J. H. Ricketts, of New York, by crossing Concord with Allen's Hybrid. A late white Grape; bunch very large, compact, double shouldered; berries large, yellow green, with thin white bloom; flesh tender, sweet, juicy; vine vigorous with large foliage, healthy in favorable seasons, with mildew of fruit in unfavorable seasons; ripens rather late for our latitude, but succeeds in some favorable locations.

LAMA. (Est.) Originated by D. S. Marvin, Watertown, N. Y., Eumelan crossed by some Labrusca variety. Bunch medium, compact; berry black, fine flavor, vinous; vigorous, healthy ; ripens with Delaware.

LARGE GERMAN. See York Madeira.

LAUGHLIN. $(H y b$. $)$ A chance seedling grown by W. R. Laughlin, College Springs, Ia., probably Concord and Delaware. Bunches are of good size, shouldered and compact ; berries medium, white, with a decided wine colored tinge with delicate bloom; skin very teuder; sweet, vinous and of peculiar delicate flavor; fine quality ; a good bearer, hardy ; ripens with Moore's Early.

LAURA. $(H y b$.$) Raised by D. S. Marvin, New York. Bunch small, not very$ compact; berry small, light amber, pulpy.

LAUSSELL. $(H y b$.$) T. V. Munson, Texas, originator; Post Oak crossed with$ Gold Coin. Bunch medium, shouldered; berry medium, black; skin thin but tough ; pulp juicy, tender; very good quality ; vigorous grower, productive.

LAWRENCE. (Labr.) Jutrorluced by Dr. R. B. Black, Fay, Pa.; found growing in a fence corner; cluster long, tapering, shouldered, broad at base compact; berry tnedium to large, round, black; skin medium thick. reddish purple black, thin bloom, holding well on cluster without cracking ; pulp very firm, separates readily from the seeds; flavor vinous, almost sub-acid; not equal to Concord. 
LEADER. ( Labr.) Originated by B. F. Merriman, Ohio. Similar to Niagara; loose in bunch, smaller in berry, of same color and amount of "native aroma," but richer in flavor; vigorous, healthy and productive.

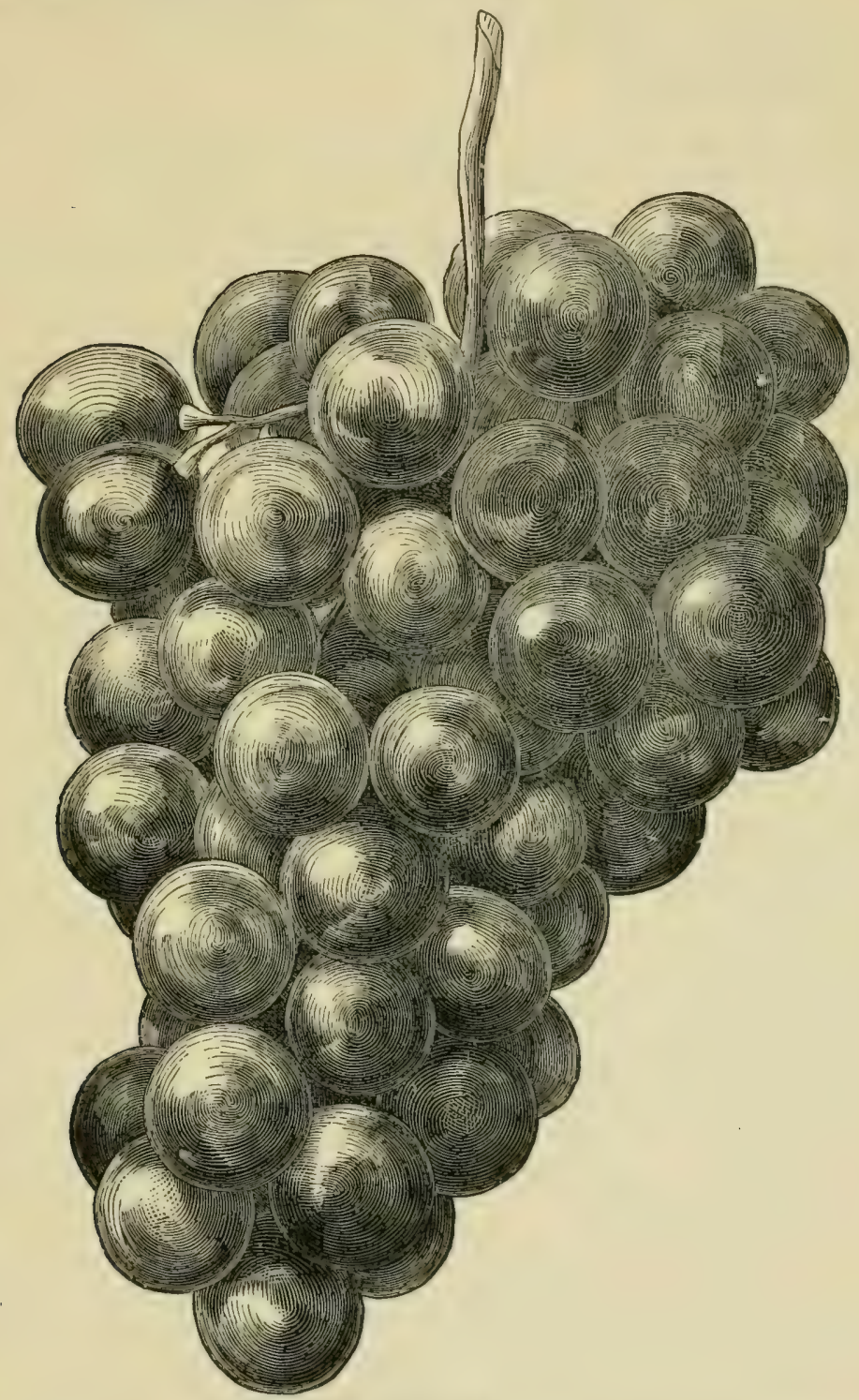

LINDLEY.

LENOIR, (Esst.) Takes its name from Lenoir Co.. N. C., a southern Grape. Bunch medium, compact, shouldered; berry small, round, dark almost black ; flesh tender vinous, juicy, sweet ; desirable for wine and table ; too late in ripening for the north; know'n in Texas under different names. 
LEAVENWORTH. (Labr.) A white Grape; bunch large, compact, handsome: berry large, very firm, but not pulpy, sweet, rich, sprightly, of the most agreeable flavor with some of the native aroma, but suits the taste of nearly every persou; tolerably vigorous, hardy, healthy and productive ; free from rot and mildew ; ripens very early, and will hang on the vines long after ripening; originated in Leavenworth, Kan., from Concord.

LEHIGH. See Berks.

LEXINGTON. (Labr.) Raised by the late T. B. Miner of New Jersey. Bunch and berry size of Concord, black; quality only medium; vine hardy, not very productive.

LIDA. (?) A chance seedling raised by Ludwig Hencke, Collinsville, Ill. Bunch and berry medium; ripens two weeks before Concord; very beautiful ruby color; sweet without foxiness; pulp tough.

LIGHTF00T. (Labr.) Raised by W. H. Lightfoot, Springfield, III., from seed of Niagara. Bunch medium to large, shouldered; berry medium large, roundish. uniform; skin thin but very tough, holding very firmly to the stem; color light green changing to a pale yellow when fully ripe, with a delicate white bloom; flesh melting without pulp, very juicy and sweet, dissolving readily in the mouth, leaving only the skin and seeds ; free from foxiness; perfect in flaror and quality ; vine vigorous and healthy; ripens after Concord.

LIGHTFOOT'S SEEDLINGS No. 34. (Hyb.) Raised by W. H. Lightfoot of Illinois, from seed of Lady Washington. Vine is vigorous and healthy, long jointed; large leaf; juicy and sweet; berries large, round, black; bunch large, compact, shouldered.

LINCOLN. (Est.) Origin unknown. Bunch small, compact; berries small, dark, bluish black; fiesh tender, juicy, vinous ; a good wine Grape.

LINCOLN COUNTY. ( Labr.) Originated in Canada. Similar to Union Village, only larger in bunch and berry and earlier.

LINDEN. (Labr.) Raised by the late T. B. Miner, New Jersey. Cluster small, compact; berry black and hard ; ripens with Cottage.

LINDELL. $(H y b$.$) Raised by T. V. Munson; Lindley crossed with Delaware.$ Still under trial.

LINDLEY. $(H y b$.$) Rogers No. 9. A red Grape of the best quality, and one of$ the most desirable of Rogers' Hybrids. Ripens with Concord and keeps well; medium to large in bunch and berry; flesh tender, sweet and of high aromatic flavor; vine vigorous, hardy and healthy. It seems to be more productive on loam and clay soils than on gravel.

LINILVA. $(H y b$.$) Originated with T. V. Munson, from Lindley crossed with$ Elvira. Not disseminated yet.

LINHERB. $(H y b$.) Lindley crossed with Herbemont, by T. V. Munson. Still under trial.

LINMAR. $(H y b$.$) Another seedling by T. V. Munson, raised from Lindley$ crossed with Martha. Not disseminated.

LITTLE BLUE. $(H y b$. $)$ Originated by A. J. Caywood. Bunch and berry medium, oblong, bluish black, delicate bloom; skin thin; pulp melting, juicy; berries crack on the vine ; vigorous ; early.

LIVINGSTON. (Labr.) A chance seedling grown by D. W. Babcock, Dansville, N. Y. A black Grape. Still under trial. 
LOGAN. (Labr.) Supposed to have originated in Ohio. Bunch medium, shoul dered; berry medium, round, black, juicy, sweet; vine moderate grower and bearer; ripens early.

LONG. See Cunningham.

LORAIN. (?) Originated in Ohio; black. Was never disseminated.

LOUISA. Originated in Pernsylvania ; similar to Isabella; ripens a few days earlier.

LOUISE. $(H y b$.$) Seedling from Roenbeck; originated in New Jersey. Bunch$ large, medium, compact; berry large, white, juicy and sweet; vigorous and healthy grower; an excellent table Grape.

LOUISIANA. (Ast.) Introduced by Freä Muench, Missouri. Bunch medium. compact, shouldered; berry small, round, black, juicy, sweet and vinous ; ripens late and requires winter protection.

LUCILE. (Labr.) A seedling of Wyoming Red, grown by J. A. Putnam, Fredonia, N. Y. Bunch and berries one-third larger than its parent, red; very compact ; flavor better; very prolific ; earlier than Wyoming Red.

LUNA. See Marine's Seedlings.

LUTIE. (Labr.) Originated by L. C. Chisholm, Tenn. Vine of the strongest Labrusca type, strongly resembling Dracut Amber in many respects and ripening same time; vine vigorous, hardy, healthy, productive; bunch very compact, medium ; berry large, pinkish at first, dark red when fully ripe, sweet when first turning, but foxy when ripe.

LYDIA. Labr.) A chance seenling originated on Kelly's Island and introduced by Chas. Carpenter. Similar to Isabella in growth and hardiness, but not as productive; bunch short, compact ; berry large, oval, light green with salmon tint when exposed to the sun ; skin thick; pulp tender, sweet, of fine flavor, slightly vinous ; ripens a few days later than Delaware.

LYMAN. (?) Origin unknown. Hardy and productive; bunch small, rather compact; berry round, black with a heary bloom, similar in flavor to Clinton and ripens about the same time.

LYONS. (Labr.) Originated in Michigan by a Mr. Chichester. A fine red Grape much like the Delaware but larger the appearance being quite similar to the Catawba with a flavor nearly its equal; medium in season.

MABEL. (Labr.) Originated by A. J. Caywood; a seedling of Walter. Cluster medium and compact; berries round, small, black; skin quite thin, light bloom; pulp melting, juicy, wine flavor; vigorous grower; a good amateur Grape ; ripens with Concord.

MACEDONIA. (Labr.) Seedling from Concord raised by Sam. Miller, similar to Martha and therefore never disseminated.

MADELINE. ( $(a b r$.) A chance seedling grown by G. Henderson, Eddyville, N. Y. Bunch medium to large, compact, often shouldered; berry large, round, greenish white with a white bloom ; skin medium thin but tough, translucent ; sweet, juicy, with a pleasant flavor; ripens early.

MAGEE. (Labr.) A chance seedling grown by J. E. Anthony, gardener to Gen. Magee, Watkins, N. Y. Bunch and berry large, not always shouldered; when fully ripe its color is a bronzy green with a purplish tinge; peculiar and decided flavor to itself; a heavy bearer and good keeper; strong, robust grower; ripens with Salem. 
IIAGNATE. $H, b)$ A white Grape ; bunch very large, shouldered, compact ; berry large, tender, sprightly, sweet, with some of the native aroma : vigorous, hardy, heaithy, and very productive ; ripeus with Concord, and will hang on the rines long after ripening; free from rot and mildew; one of the most reliable Grapes; better than Victoria, Hayes, or any of that class; originated from Concord in Leavenworth, Kan.

MAGUIRE. (?) Originated at Lansingburg, N. Y. A rery early, black Grape, sweet and moderately good, but too foxy to be popular.

MA.MUTH SAGE. Found sereral years ago growing wild, by a boy in the town of Geddes, Onondaga Co., N. Y. In course of time a stock of vines was secured from cuttings and the boy's father, who was an expert vineyardist, disseminated the new Grape throughout the western part of Syracuse. It is still grown in large quantities, being highly prized for sweet preserves. Bunch very large, compact, shouldered; berry large, bright coppery red, sweet and juicy, highly odorous: vig. orous and healthy grower. This is undoubtedly the original Grape, upon which Mr. E. S. Rogers produced his series of hybrids, found considerable in New England, where it is known in some sections under the name of "Mammotl."

MANHATTAN. (Labr.) Originated near New York. Bunches small; berries medium, round, grtenish white with a bloom ; flesh sweet, rather pulpy ; poor bearer and drops the berries.

MA.NSFIELD. (Labr.) Seedling from Concord fertilized with Iona, raised by C. J. Pringle of Vermont. Bunch large, compact, shouldered; herry purplish black with a bloom, large, rich flavor; ripens before Concord.

MARGUERITE. $\left(H_{y}, b\right.$. ) A seedling produced by T. V. Munson by crossing Post Oak with Herbemont. Bunch medium, cylindrical; berry medium, purple, tender skin but tough; flesh juicy, melting, best quality; very vigorous grower, prolific.

MARGUERITE. (Labr.) Originated by T. Huber, Sr., Inlinois. Bunch and berry Concord size, white, quality good, with Catawba flavor.

MARIA LOUISA. (Labr.) Originated by Theoph. Huber, Sr., Illinois City, Ill. Bunch large, shouldered, compact; berry size of Concord, round, yellowish when ripe; flesh tender, juicy, sweet; skin thin but tough; ripens a little before Concord.

MARINE'S SEEDLINGS. (Labr.) These Grapes are crosses between purely native varieties claimed to be produced by a new and very simple process. Among the seedlings are some quite peculiar and very interesting; some are of the Estivalis family but with berries of quite a large size :

NELUTUM. Fine large bunch; berries abore medium, black; leaf very large, leathery and strong.

GREENCASTLE. Same as the former; berries still larger.

LUNA. White; in appearance almost like Martha, but the gain in size seems to be coupled with a loss in quality, compared to our delicious juicy, small, Estivalis Grapes. A large number of his seedlings are of the Labrusca type, and among these his U. B., black ; Mianna and King William, white.

MARSALA. (?) A red Grape; bunch very large, compact ; berry very large ; skin tough; not very juicy or sweet, pulpy, with a strong native aroma; very vigorous, hardy, healthy and immensely productive; free from rot and mildew; the best Grape for jelly and canning in Kansas. Ripe about with Concord; origin unknown; introduced by Dr. Stayman. 
MARION. (Rip.) Origin unknown. Clusters compact, shouldered; berries nearly round, medium, purplish black; skin quite thin, light bloom ; flesh separates freely from seeds; wine flavor.

MARION PORT. See York Madeira.

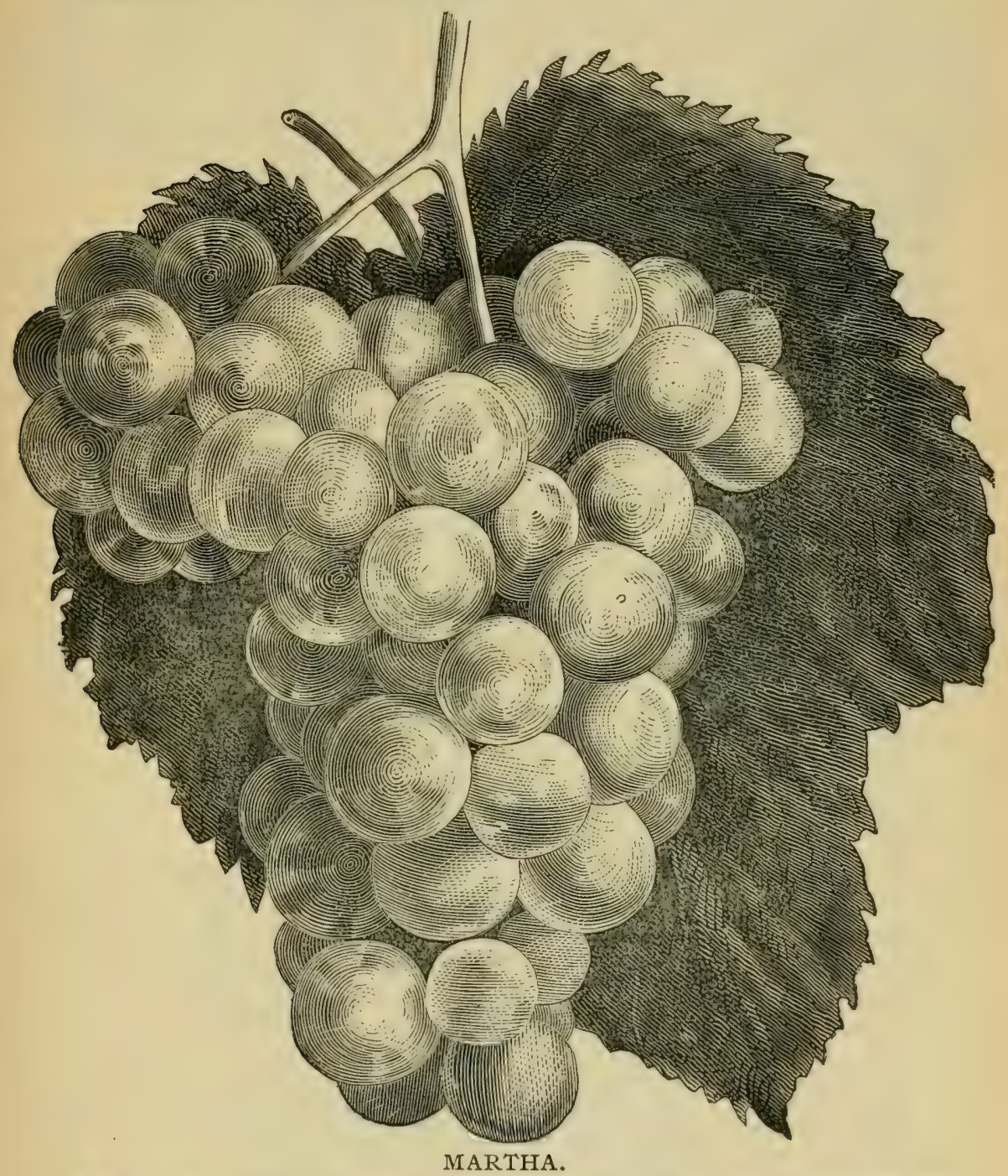

MARTHA. (Labr.) A seedling from Concord, raised by Judge S. Miller, Bluffton, Mo. White; bunch and berry medium, shouldered, compact ; pulp tender, sweet, rich, juicy, slightly vinous, quality good-generally considered better than Concord; vine hardy, healthy and productive; ripens with Concord, or a little earlier; one of the reliable and popular white Grapes for general use.

MARY ANN. (Labr.) Originated by J. B. Garber, Columbia, Pa. An early black Grape, with large buuches; berries oblong, oval, quite sweet but very foxy. 
MARY. (?) Raised by Chas. Carpenter, Kelly's Island, O. Bunch medium, moderately compact; berries medium, round, greenish white with a bloom; flesh tender, slightly pulpy, juicy and sweet; vine hardy, strong grower; ripens late.

MARY MARK. (Hyb.) A red Grape; bunch medium, compact; berry medium, tender, juicy, rich, sweet, sprightly, of the best quality; medium grower, hardy, healthy and productive ; free from rot and mildew ; ripe about with Eureka; originated by Dr. J. Stayman, from Delaware.

MARY'S FAVORITE. (Labr.) Grown by J. F. Coffin, Westland, Ind. Clusters small, shouldered; berry, small, round, black with bluish bloom, juicy, sweet, vinous pulp; thin skin but tough; fine table Grape; vigorous, productive; ripens with Concord.

MARY WYLIE. $(H y b$.$) Originated by the late Dr. Wylie, South Carolina, from$ Clinton and Red Frontignac. Bunch large; berries above medium, white, slightly red; fine quality and hardy; medium late.

MASON. (Labr.) A seedling from Concord, raised by B. Mason, Mascoutab, I11. Bunch large, medium, moderately compact; berries large, round, greenish white, yellowish when ripe with a white bloom; skin thin; flesh melting, sweet, vinous ; free from rot; productive ; ripens before Concord.

MASSASOIT. (Hyb.) Rogers No. 3. Red; bunch and berry large; flavor sweet, rich and sprightly ; vine a strong grower and hardy. One of the earliest and best of the hybrids.

MATCHLESS, (?) A new black Grape; bunch very large, compact, handsome; berry very large, pure, sweet, sprightly, vinous, with a slight pulp; ripe about with Jewell; vigcrous hardy, healthy and productive; free from rot and mildew; will hang on the vines long after ripening; will handle and ship well. A very attractive and desirable Grape for market. This remarkable Grape has a bright future; must become popular when known. Originated from unknown seed by John Burr

MAXATAWNEY. (Labr.) Originated at Eagleville, $\mathrm{Pa}$, a chance seedling. Bunch and berry medium, of a pale yellow color; ripens with Catawba; quality good for table and wine; vine vigorous, healthy and hardy.

MATHILDA. (Labr.) Originated by G. A. Ensenberger, Bloomington, I11. Bunch large, very compact, sometimes shouldered; berry medium to large, round, handsome, dark red, light bloom, very juicy, vinous, nearly sweet, good quality ; pulp tender and melting; skin thin ; vigorous and productive ; medium late.

McCOWAN. See Cowan.

McKEE. See Herbemont.

MCLEAN. See Devereux.

MCLURE. $(H y, b$.$) Produced by the late Dr. Wylie, by crossing Clinton and$ Peter Wylie. Bunch medium not very compact, shouldered, berries medium, white, very vigorous; good for table use.

McNEIL. See Lyman.

MEAD'S SEEDLING. See Catawba.

MEDORA. (Est) Originated by G. Ondeidonk, Texas. A seedling from Lenoir crossed with Croton. Medium; white, with sometimes purple veins; cluster small, shouldered; very sweet; vine not a vigorous grower; foliage shows strongly its natural origin - a southern grape. 


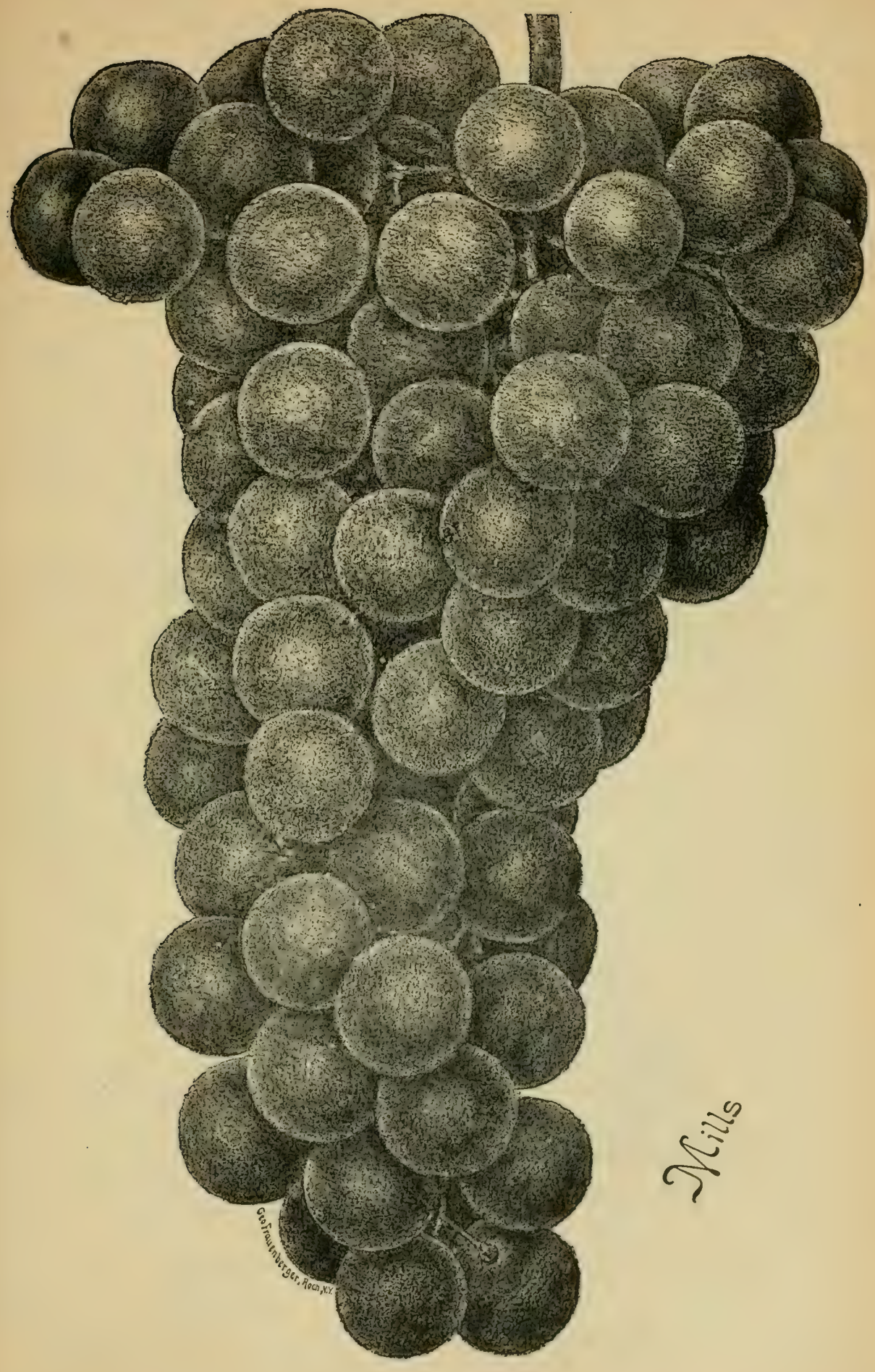


MENDOTA. (?) A new black Grape; bunch about medium, compact, handsome; berry medium to large; tender, juicy, sweet, sprightly, with but very little pulp; of good quality; very vigorous, hardy, healthy and productive; free from rot and mildew; ripe about with Jewell; will hang on the vines long after ripening; easily grown from cuttings; originated from unknown seed by John Burr.

MERCERON. See Catawba.

MERRIMAC. (Hyb.) Rogers, No. I9. Mammoth, crossed with Black Hamburg. Black; bunch very large, shouldered, compact; berries large, flesh sweet, tender, good. Vine a good grower, hardy, productive. It strongly resembles the Wilder (Rogers No. 4).

META. (Hyb.) A seedling of Jewell produced by L. Hencke, I11. Bunch large, compact, shouldered; berry large, red, sweet and juicy. Quality good. Ripens before Concord.

METTERNICH. (Rip.) Seedling of Clinton and Poughkeepsie. Originated by A. J. Caywood, N. Y. Bunch small to medium, compact; berry medium, round, light red, translucent, skin thin ; pulp tender, sweet, refreshing, sprightly ; vigorous grower, productive; ripens a few days after the Delaware; liable to mildew.

MIANNA. See Marine's Seedlings.

MICHIGAN. (Hyb.) Originated by C. Engle, Paw Paw, Mich., from seed of Salem. Vine very vigorous, making abundance of wood; hardy and prolific. Bunch large, compact, seldom shouldered, berry large, round, white ; sweet for eating. Ripens with Concord.

MILES. (Labr.) Originated in Westchester Co., Pa. Bunch medium; berries medium to large; oval, black, sweet. Very early. Vine a strong and healthy grower.

MILLS. (Hyb.) Raised by William H. Mills, of Hamilton, Ont., and introduced by Ellwanger and Barry, Rochester, N. Y, by crossing Muscat Hamburg with Creveling Bunch very large, compact, shouldered, some clusters weighing over twelve ounces. Berry large, round, jet black, covered with thick bloom; flesh firm, meaty, juicy, breaking with a rich. sprightly flavor. Skin thick; berries adhere firmly to the peduncle. Vine vigorous and productive; foliage large and healthy. Ripens about with the Concord, or a little later, and is a long keeper.

MINEOLA. $(H y b$.$) Seedling of Telegraph aud Chasselas Musque, originated$ by C. J. Copley, Stapleton, N. Y. Bunch medium to large ; berry large, round, white or pale yellow, transparent, un pulp, very rich, pure Muscat flavor. A imedium strong grower; healthy and productive. Ripens very early ; will hang on the vines in good condition until frost.

MINNEHAHA. A white grape, Bunch very long, shouldered, compact; berry medium, tender, juicy, very sweet and vinous, of the most delicious quality; very vigorous, not hardy, very productive ; free from rot and mildew. It requires winter protection. Originated by Marshall P. Wilder of Boston, and is a European hybrid.

MINNESOTA MAMMOTH. (Labr.) Introduced by L. W. Gratton, of Minnesota. Origin unknown. Bunch and berry large, black, fine flavor; prolific and hardy; ripens medium late.

MISSOURI. (Rip.) Origin unknown. Bunch and berries small, black, juicy, vinous ; late.

MODENA. (Labr.) Concord seedling raised by A. J. Caywood, New York. No merits. 


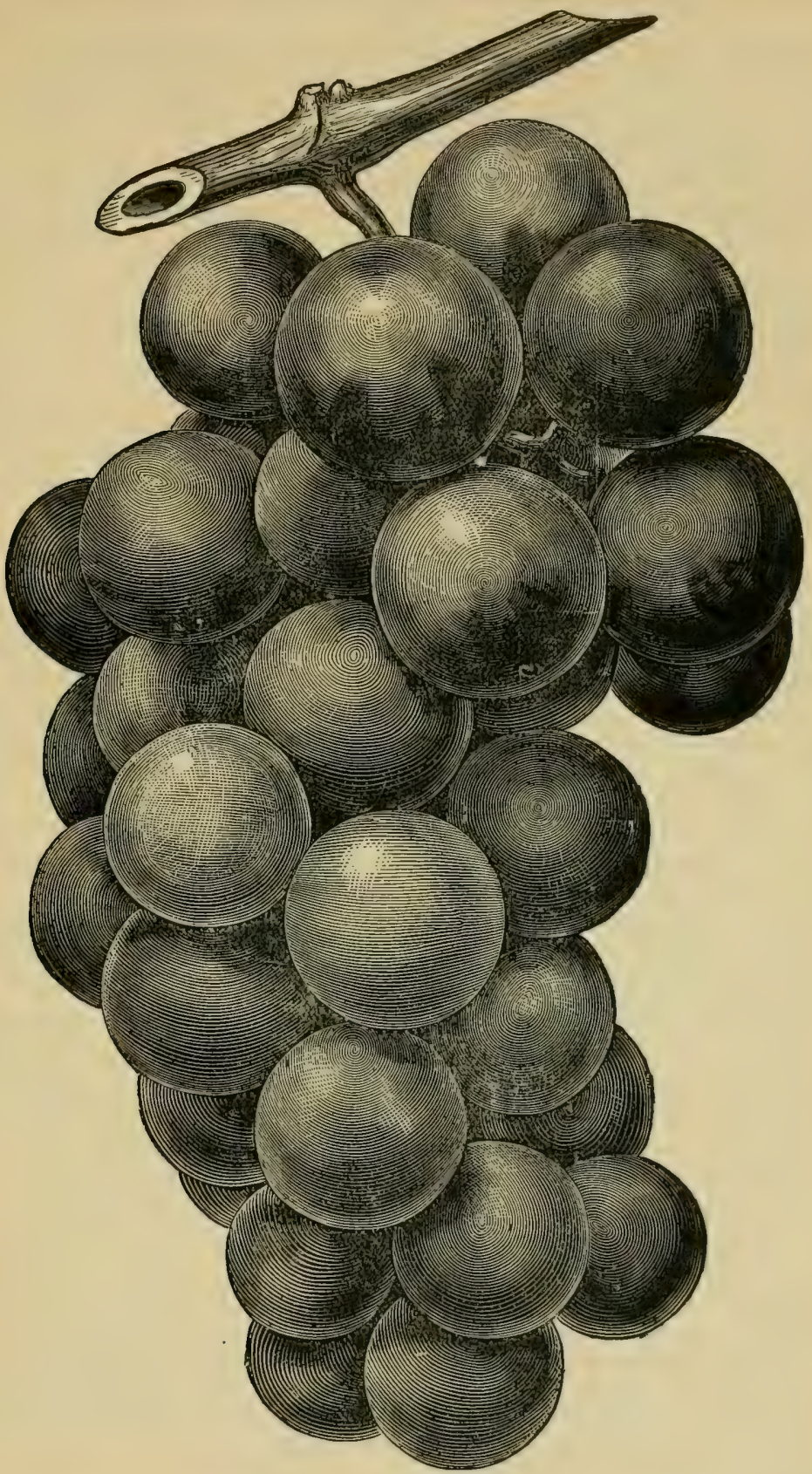

MOORE'S EARLY.

MISSOURI RIESLING. (Rip.) One of Grein's Seedlings. A fine, light. pale red, or pinkish colored Grape ; hardy, healthy and strong grower ; productive ; considered valuable for both table and wine; quite late in ripening. 
MONROE. (Hyb.) Raised by Ellwanger \& Barry, Rochester, N. Y., from a cross between Delaware and Concord. Bunch medium to large, shouldered; berries large, round, black with a white bloom, juicy, sweet, vinous ; ripens early with Hartford; a good table Grape ; very hard to propagate.

MONTEFIORE, (Rip.) Produced by J. Rommel, Missouri. A cross of Elvira with Ives; resemble the latter in bunch and berries ; vine healthy, hardy, very productive; free from mildew or rot; makes a fine red wine, ripens after Concord.

MONTEITH. See York Madeira.

MOORE'S EARLY. (Labr.) Originated at Concord Mass., by Jno. B. Moore. Bunch large; berry round, large, color black, with a heavy blue bloom ; quality better than Concord; vine exceedingly hardy; has never been covered in the winter, and has been exposed to a temperature of more than twenty degrees below zero without injury. It is entirely exempt from mildew or disease. Its earliness makes it desirable for an early crop, and more particularly adapts it to New England, and the northern portion of the United States. Ripens before Hartford.

MOORE'S DIAMOND. See Diamond.

MOORE'S NEW SEEDLINGS. The old veteran originator, Jacob Moore, who brought out the Diamond, Brighton, Geneva and other well known grapes, sends us the following description of new hybrids: Two new seedlings of Brighton, fertilized by Hartford. Both red and of fine quality and both will beat the Brighton, because they have erect stamens and are, judging from the past season's fruit, superior in flavor, more spicy and aromatic. One ripened before and the other at the same time with the Brighton. The berry of one is the same size as Brighton, the other, the most spicy of the two, is a little smaller.

$A$ New White Grape from seed of Pocklington fertilized by Vergennes. Berry large, flattened like Pocklington, white, flesh meaty and excellent without foxiness. Bunch medium. Ripens with Concord.

A New Seedling from Creveling by Worden. Ripens with Champion and is superior to it or Moore's Early in quality. The berry is large, black; bunch medium, compact; flesh melting and good.

A New Seedling from seed of Jefferson fertilized by Vergennes. Berries medium size, red, flesh tender, vinous and rich. Ripens in good season; strong grower. Besides these Mr. Moore has a lot of seedlings claiming to be his best varieties coming from the Vinifera species crossed by Muscat Alexandria. These Hybrids were made the seed parents of other varieties by recrosses with the best natives such as Iona and Jefferson. He also has many seedlings from Cynthiana fertilized by Hartford, Pocklington, Jefferson and a few from seed of Hartford, Jefferson and others fertilized by Cynthiana. A few have borne and are valuable having larger berries than Cynthiana and of good quality. Time will be required to make a selection of the best sorts.

MOTTLED. (Labr.) A seedling of Catawba grown by Chas. Carpenter, Kelly Island, Ohio. Bunch medium, very compact, slightly shouldered; berries medium to large, round, distinctly mottled when held to the light, with different shades of red or maroon while ripening, uniform dark Catawba color when fully ripe. Sweet, juicy, vinous; brisk sprightly flavor, pulpy and acid to the center, skin thick. Vine healthy, hardy, moderately vigorous. A better wine than table grape. Ripening earlier than Catawba.

MOUNT LEBANON. (Labr.) Originated in Columbia Co., N. Y. Supposed to be a cross of Spanish Amber and Isabella. Bunch medium to large, berry round, reddish; flesh pulpy, tough but sweet. 
MOYER. $(H y b$.$) It originated some 8$ years ago with Allen Moyer of Lincoln Co., Ont., Canada, as the formerly known Jordan Grape, and seems to be a cross between the Delaware and some purely native variety. It ripens with the very earliest varieties, some three weeks before the Concord. It is of the best quality, equal to the Delaware which it much resembles, but is even sweeter, though not quite as high flavored, and without a trace of fox. Pulp very juicy and tender to the center. Skin thin but tough, to which characteristic, in part, it owes its good keeping, handling and shipping qualities. Bunches medium, about the same as Delaware, shouldered, the berries are a little larger and adhere tenaciously to the stem. When overripe it gradually shrivels and dries up into raisins. The color is a rich dark-red, even better than that of the Delaware. This grape is sweet, tender and good as soon as colored.

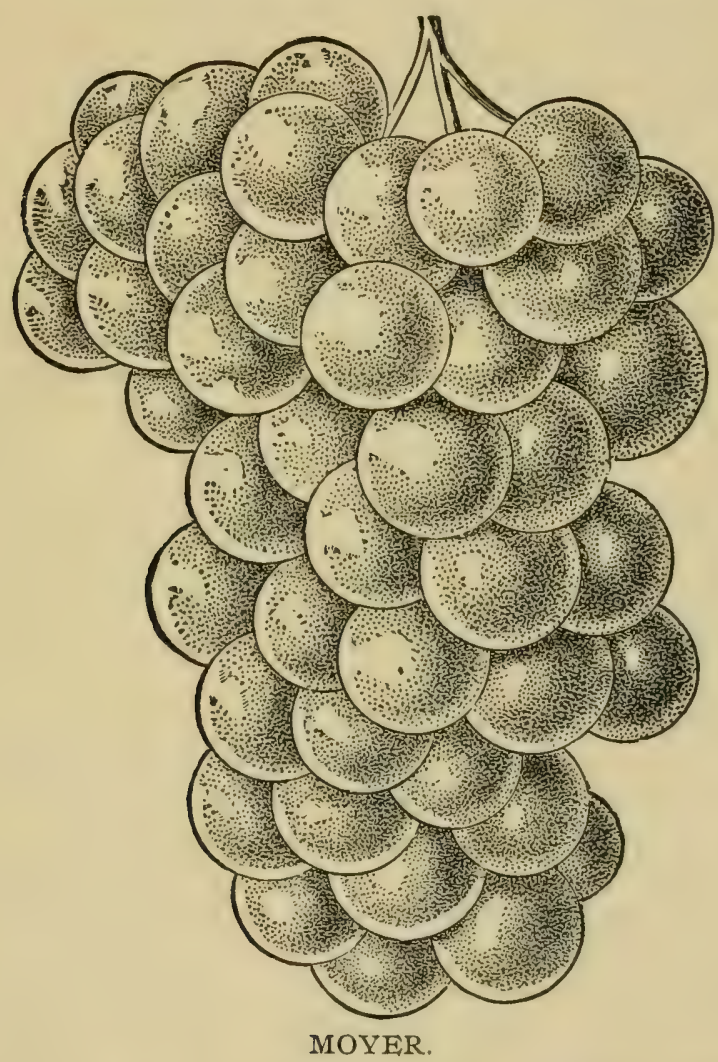

The vine is a vigorous, though rather short jointed and compact grower, and may be planted a little closer than Concord or other rambling growers. Very hardy, having stood 35 degrees below zero unprotected and unhurt. Neither the leaf nor fruit has ever been known to mildew, not even in seasons and places where everything around it was affected. It was introduced and is now for sale by Lewis Roesch, Fredonia, N. Y.

MRS. MUNSON. (Est.) Produced by T. W. Munson by crossing Neosho with Herbemont. Vine vigorous grower; large, shouldered bunch, berries medium, purple, with thin, but tough skin ; melting pulp; best quality, very productive. An excellent grape for the South. 
MRS. STAYMAN. $(H y b$.$) A red grape; bunch large, compact, berry above$ medium; tender, juicy, rich, sweet, with some little pulp and native aroma, but very good; berry strong and vigorous, hardy, healthy and productive; free from rot and mildew ; ripens about with Concord; originated from Delaware by Dr. G. Stayman.

MUENCH. (LEst.) Originated with T. V. Munson, Denison, Tex., from Neosho crossed with Herbemont. Large conical bunches, medium; berries of purple color with thin but tough skin; melting pulp ; fine quality ; vigorous and productive. A Southern Grape.

MUSCOGEE. See Herbemont.

NAOMI. $(H y b$.) Produced by J. H. Ricketts, of New York, from Clinton and one of the Muscats. Vine vigorous and productive, medium short jointed; leaves large, deeply lobed, coarsely serrated; bunch large, shouldered; berry medium, roundish, oval, often with a tinge of red in the sun, covered with a thin whitish bloom; flesh tender, juicy, melting, rather crisp, sweet and sprightly, with a trace of Muscat flavor; quality very good; ripens with the Concord; a good amateur Grape.

NEBRASKA. (?) Origin unknown. A strong grower; very ornamental but fruit of no value.

NECTAR. $(H y b$. $)$ A new black Grape, originated by the late A. J. Caywood. A seedling cross of Concord and Delaware. A good grower and hardy, with healthy foliage; very productive; does not crack or fall from the stem, and is a remarkably good, long keeper; clusters handsome and medium large ; quality fine ; flavor pure, rich and slightly vinous; an excellent Grape, very promising and worthy of trial.

NEFF. (Labr.) Originated by Mr. Neff, near Keuka, N. Y. Bunch and berry medium, dark copper red, pulpy and somewhat foxy ; early.

NEOSHO. (Est.) Was found growing wild near Neosho, Mo., and cultivated by Herman Jaeger of Missouri. Bunch large, compact, shouldered; berries large, black with a fine bloom; thin skin; very sweet and spicy; very vigorous grower, productive, resisting mildew and rot; produces a fine wine with a peculiar aroma.

NERINTON. See Marine's Seedlings.

NEVA MUNSON. (Est.) Produced by T. V. Munson, from Neosho, crossed by Herbemont. Large, shouldered bunches with small, purple berries; thin skin but tough; good quality; very vigorous grower, productive; only good for the south.

NEVERFAIL. (Labr.) This variety was found in Roanoke Co., Va., and introduced by the Salem Nursery Co., Va. A feeble grower at first, but grows rapidly when older. This never shows a particle of rot. Bunch and berry medium, black, juicy and vinous. Too late for the North.

NEWARK. $(H y, b$.$) Raised in Newark, N. J., of Clinton and Vinifera. Bunch$ long, loose, shouldered; berries medium, almost black, sweet, juicy, and vinous. Vine vigorous, hardy and very productive. Rots badly and cannot be recommended.

NEWBURGH. $(H y, b$.$) One of Ricketts's seedlings. Concord crossed with$ Trentham Black. Bunch and berry of the largest size, bunch heavily shouldered, berries large, black, with hluish gray bloom, flesh tender, juicy with peculiar flavor, very vigorous. A fine amateur grape.

NEW HAVEN. (Labr.) Produced by J. Valle, Mo. Similar to Concord, ripens earlier, bunch and berry medium. Good quality.

NEW MARY. (Hyb.) Undoubtedly Rogers No.9-Lindley, under a new name. 
NEWPORT. (Est) Seedling from Herbemont and very similar to it.

NEW YORK EXP. STA. SEEDLINGS. The N. Y. Experiment Station at Geneva, N. Y., has several seedling grapes of its own growing, of which the following are so far the most promising:

No. 9. (Labr.) A chance seedling. Bunch medium to large, moderately compact; berries medium, round, reddish purple, blue bloom; skin thin, tender pulp ; pleasant flavor, sprightly, vinous; vigorous, ripens a few days after Delaware.

No. 34. (Rip.) A chance seedling. Bunch medium, sometimes shouldered; berry small, round, dark purple, little or no pulp, juicy, vinous, sprightly. Flavor like Wild Riparia ; vigorous and productive ; ripens with Concord.

NIAGARA. (Labr.) Originated about I5 years ago with Hoag \& Clark of Lock port, N. Y., and is undoubtedly a fine looking grape, being planted the most extensively. White; bunch very large and handsome, sometimes souldered, compact; berries large, round; skin thin, tough, does not crack, and carries well; not much pulp when fully ripe; melting, sweet, with a flavor and aroma peculiarly its own, and agreeable to most tastes ; ripens with Concord, sometimes a little earlier. Vine rery vigorous and very productive, succeeding well both North and in many parts of the South; is being very largely planted. It is subject to rot fully as much as is Concord.

NINA. (Labr.) A seedling of Diana, raised by C. H. Woodruff Ann Arbor, Mich. Vine very hardy, and productive. Bunch medium to large, berries medium, dark red, very sweet and good quality. Ripens early with Champion and Moore's Early, in quality better than either.

NOAH. (Rip.) Introduced by Otto Wasserzieher, Nauvoo, Ill, raised from Taylor. Medium clusters, sometimes shouldered; berries medium, round, greenish white, turning to yellowish white in sun, with little bloom, transparent, not very juicy, pulp hard but melting ; good quality.

NONANTUM. (Labr.) A variety raised by Francis Dana near Boston, Mass. In appearance similar to Isabella. Bunch small, shouldered; berries medium with no pulp, good flavor.

NORFOLK. (Labr.) Raised by White of Norwood, Mass. Red; bunch and berry above medium; quality good, ripening about with Concord ; vine moderately vigorous and healthy, flavor rich and pleasant.

NORFOLK MUSCAT. $(H y b$.$) A good grower with healthy foliage; bunch small$ and not well filled; berries large, black; skin quite tough; tender pulp, sub-acid; ripens with Concord or a trifle earlier.

NORTH AMERICA, (Labr.) Origin unknown. Medium bunch. shouldered; round, black berry, sweet but very foxy ; vigorous ; ripens early.

NORTH CAROLINA. (Labr.) Bunch medium to large, shouldered, compact; berry large, black, oblong, pulpy, but sweet and good; vine very productive, hardy and healthy, strong grower; ripens a few days after Hartford.

NORTHERN LIGHT. (Labr.) A chance seedling which originated in the garden of John D. Cameron, L'Original, Ont. Berries are green with green bloom; bunch large. compact, not shouldered, but conical from top to point; berries medium to large, round, sweet, firm, melting, not fleshy or pulpy, very slightly acid, not foxy; ripens with Champion or a little later.

NOTHERN MUSCADINE. (Labr.) Raised near New Lebanon, N. Y. Dark amber color; bunch and berry medium; flesh pulpy and quite foxy; vine vigorous. hardy and productive; ripens with Moore's Early. 
NORTON. (Est.) Introduced by Dr. D. N. Norton of Virginia. Black; bunch long, compact, shouldered; berries small; flesh tender, melting, without pulp and vinous; ripens too late for most northern localities, but is very highly esteemed at the south and southwest, and considered their best red wine Grape; vine a very healthy, vigorous grower, hardy and productive; very difficult to propagate and does not bear transplanting as well as most varieties.

NORWOOD. (Labr.) Originated by T. B. White of Niorwood, Mass. Resembles Concord in color, but berries and clusters are large, vigorous and hardy, good keeper and very promising; ripens before Concord.

OBED. (Labr.) A chance seedling grown by Obed Harrell, Chrisman, III. Cluster medium to large, moderately compact ; berry medium, round, whitish green with delicate bloom; vigorous grower and productive.

OBERON. $(H y b$.$) Originated by G. W. Campbell, Delaware, Ohio, from Con-$ cord fertilized with Muscat Hamburg; bunch and berry large, black, moderately compact ; good quality ; not hardy enough for the north.

OHIO. (?) Origin unknown. Vine vigorous, long jointed, not hardy at the north; bunch large, rather loose, shouldered; berries small, round; skin thin, purple with blue bloom ; flesh tender and melting, brisk and vinous.

OLD FORD. (Labr.) This Grape was found growing wild in the mountains of North Carolina. It is a pure Labrusca of remarkable health and vigor with thick and leathery leaves; entirely free from mildew; bunches medium; berries large, round, of an unique dark wine color, pulpy but still juicy, sweet, with a great deal of aroma which is pleasant instead of being repulsive, as in over-ripe Perkins ; very early and prolific.

OLD HUNDRED. (?) Introduced by J. A. Francis, Salem, Va. Bunch medium, not very compact; about the size of Clinton, black; very prolific; good table and wine Grape ; contains Cinerea blood in large quantity, with probably Eistivalis.

OLITA. $(H y b$.$) Originated by T. V. Munson, from Delaware crossed with Irving.$ Owing to lack of productiveness this new Grape is not very promising as a profitable variety for vineyardists, though it is fine in quality.

OWEGO. (?) A red Grape ; bunch medium, compact; berry very large, tender, juicy, sprightly, rich, vinous, sweet, of the best quality; vigorous, hardy, healthy and very productive; free from all rot and mildew; the largest red Grape we have, originated here from unknown seed, by John Burr.

ONDERDONK. (Est.) One of T. V. Munson's new white seedlings of Herbemont. Vine a very vigorous grower; large conical bunch; small white berries; thin but tough skin. The general appearance and growth of the vine is like that of Herbemont; very productive.

ONEIDA. $(H y b$.$) Raised by Thacker of Oneida Co., N. Y., from Agawam,$ (Rogers I5); red; a strong healthy grower; bunch and berry medium; very sweet and of a delicate flavor; skin thin but tough; an excellent keeper and fair bearer. Should be in every garden.

ONONDAGA. $(H y b$.$) Originated at Fayetteville, Onondaga Co., N. Y., from a$ cross of Diana and Delaware. Bunch medium, compact; berries medium, amber, sweet, flavor similar to Delaware, ripening at the same time; a good keeper.

ONTARIO. See Union Village.

OPAL. $(H y b$.) Seedling of Lindley, originated by T. V. Munson. Bunch medium, shouldered; large, yellow berry with thin but tough skin; vigorous hardy and prolific 
OPORTO. (Rip.) Origin unknown. Bunch small; berries medium, round, black, pulpy and very acid; strong, vigorous grower; should be pruned very long.

ORIENTAL. $(H y b$.$) Produced by Mr. White of Massachusetts, from a cross of$ Catawba and Black Hamburg. In bunch and berry similar to the Rogers varieties; black; good quality; ripens with Concord; vine vigorous, hardy.

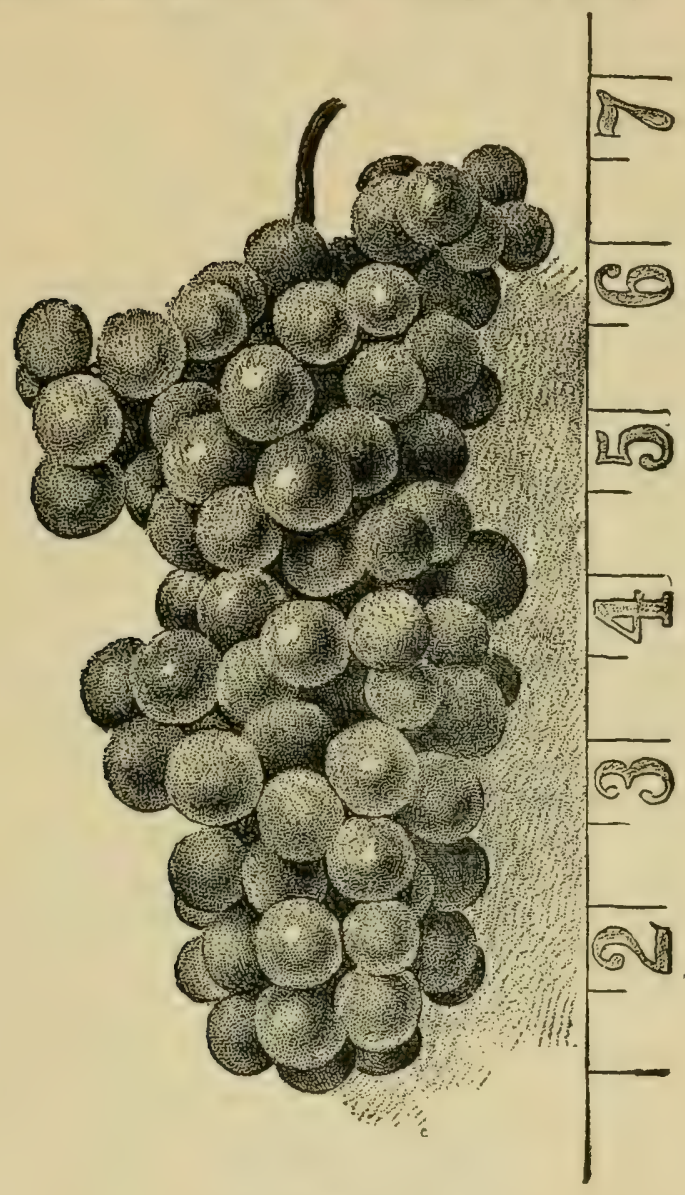

ONDERDONK.

ORIOLE. ( $H y b$.$) Raised by T. V. Munson from a cross of Post Oak with Dev-$ ereux. 'Vine vigorous and productive. Bunch large, shouldered, small black berries, pulp tender. A southern Grape.

ORPHAN BOY. (Hyb.) Introduced by J. H. Dawson, Weatherford, Texas. A cross between Delaware and Wilder. Bunch about the size of Concord, but more shouldered; berry large, black with fine bloom, quality much like Delaware, with a little more foxiness. Leaf healthy ; ripens a little after Delaware.

OSAGE. (Labr.) A black Grape; bunch large, shouldered; berry large, juicy, sweet, sprightly, of good quality; vigorous, hardy, healthy, productive; ripens about a week before Concord; rots some ; originated from Concord seed. 
OSCEOLA. $(H y b$.$) A white Grape; bunch large, compact; berry large, ten-$ der, rich, sweet, meaty, with some little native aroma, but of very fine quality ; berry strong, stalky, handsome grower; very hardy, healthy and productive; free from rot and mildew ; one of the earliest to ripen and will hang on the vines long after ripen. ing ; a very desirable Grape ; originated from Standard by Dr. J. Stayman.

OSEE. (Rip.) A white Grape ; bunch short, thick, compact; berry very large, tender, juicy, sprightly, tolerably sweet, of a peculiar flavor; very vigorous, hardy and immensely productive ; free from rot and mildew. This Grape is only fit for wine, jelly and canning. The wine is of the very finest quality; originated in Leavenworth, Kas., from Grein's Golden of the Riparia class.

OSKALOOSA. (Hyb.) A black Grape; bunch medium, compact, berry large, tender, juicy, sprightly, sweet, of excellent quality ; vigorous, hardy, healthy, and productive; free from rot and mildew ; ripens with the Ozark ; originated from Delaware by Dr. Stayman.

OSMOND. (Rip.) A seedling from Franklin, raised by O. T. Hobbs, Randolph, $\mathrm{Pa}$. Bunch and berry small, round, black, blue bloom; vinous, harsh.

OSWEGO. (Labr.) A black Grape; bunch very large, compact, shouldered; berry very large, tender, juicy, sweet, sprightly, with some pulp and native aroma; better than Concord and ripens about the same time, but will hang on the vines until November and improve in quality; free from rot and mildew, vigorous, hardy, healthy and productive ; this is one of the most valuable Grapes for Kansas ; origin unknown, but no doubt a seedling of Concord.

OTHELLO. $(H y b$.$) Originated by Chas. Arnold, Ont. Black, skin thick, flesh$ solid with little pulp; bunch long, loose; berry medium, quality fair ; vine a vigorous grower; ripens late.

OWASSO. (Labr.) A chance seedling of Catawba, Bunch large and compact; berries medium to large, dark amber, sweet and sprightly, fine quality; good keeper; ripens with Delaware.

OZARK. (Est.) A black Grape of the Estivalis type; bunch very large shouldered, compact ; berry large, tender, rich, sweet, sprightly, meaty, of a peculiar pleasant flavor, unlike any other grape ; remarkably vigorous ; very hardy and pro ductive; free from rot and mildew ; ripens after Concord and will hang on the vines until destroyed by frost; very heavy foliage. This is the best and most valuable late market and wine Grape. Originated by Dr. J. Stayman from some unknown variety on his place, yet it appears impossible to get such a distinct variety from any one he had.

PAGAN. (?) Still on trial to find whether it is a chance seedling or an old variety.

PAIGN'S ISABELLA. See Isabella.

PARADOX SEEDLING, No. 502. (Labr.) Grown by W. D. Barnes, Middle Hope, N. Y. Bunch medium or above, compact, slightly shouldered; berry medium, black, blue bloom, pulp thick, seeds separate easily ; flavor sweet, aromatic ; not a very strong grower; ripens in September.

PARAGON. (?) A black Grape; bunch large, shouldered, very compact, handsone ; berry large, very tender, juicy, rich, sweet, sprightly, vinous, without pulp ; a bag of delicious juice; vigorous, hardy, healthy and productive ; free from rot and mildew ; ripens with Concord, but will hang on the vines until hard frost; one of the most delicious and valuable market Grape we have; easily propagated; will stand all kinds of weather; originated from unknown seed by John Burr. 
PARAGON. (Hyb.) Seedling of Telegraph and Black Hamburg grown and introduced by C. J. Copley, Stapleton, N. Y. Bunch very large, shouldered. Berries very large, sets well, rather close, splendid flavor, the best quality, quite as good as the parent Hamburg. No pulp, but quite meaty like a raisin, dark purple almost black, a good grower, hardy; ripens, with Concord.

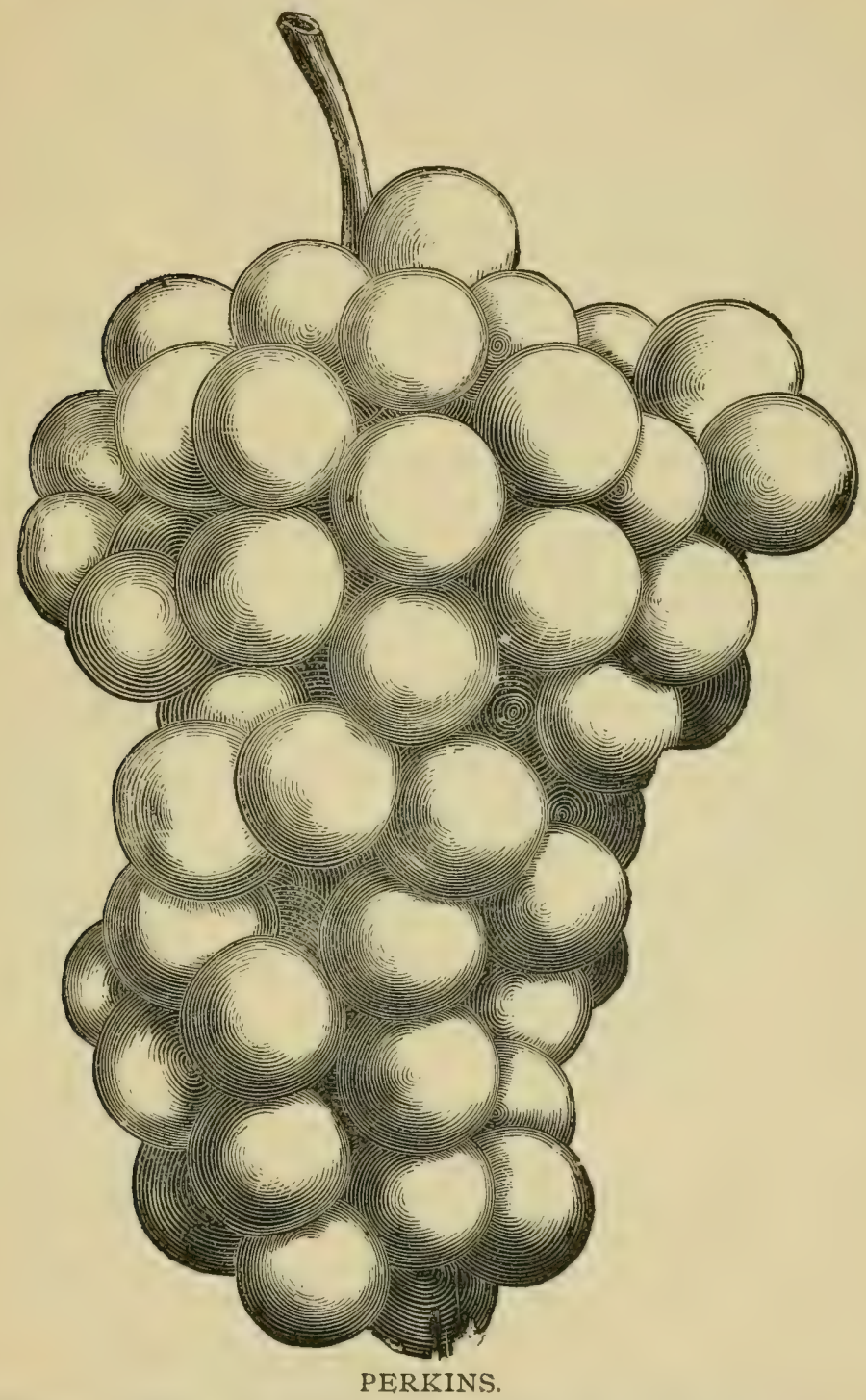

PAWNEE. (Fst.) A black Grape; bunch very large, double shouldered, very compact and heavy; berry large, tender, rich, sprightly, sweet, not very juicy; of the peculiar flavor of Ozark . very vigorous, immensely productive, hardy, and healthy, somewhat subject to rot; later than Ozark; originated from the same seed by Dr. J. Stayman. 
PAULINE. (Est.) A southern Grape of the Lenoir family. Bunch large, long, shouldered; berries below medium, compact, pale amberwith fine bloom; flesh brisk, vinous, sweet and aromatic. Excellent for wine and table. Moderate grower.

PAXTON. (Labr.) Raised by F. F. Merceron of Catawissa, Pa.; is identical with Concord

PEABODY. (Rip.) Seedling of Clinton, originated by Jas. H. Ricketts of New York. Hardy in vine and fruit; bunch medium to large, and quite compact; berry the size and shape of Iona, black, with blue bloom ; flesh tender and sprightly. The fruit is unlike that of any other Grape now cultivated.

PEARL. (Rip.) A seedling of Elvira, raised by J. Rommel, Morrison, Mo. Bunch larger than Elvira, shouldered, compact; berries medium, round, pale yellow covered with a delicate bloom; skin thin and transparent; pulp soft and melting, juicy, high flavor; strong grower, hardy and prolific.

PEARSON'S IRONELAD. (Labr.) Introduced by Col. A. W. Pearson of Vineland, N. J., who obtained cuttings from the original vine, growing wild near Darby, Delaware Co., Pa. It is apparently an accidental cross between Labrusca and Riparia. Strong grower, hardy, light green foliage : clusters small, compact; berries in size between Concord and Clinton, of a rich, royal purple, round, juicy, somewhat acid and has a little foxiness of the Concord, \&c.; makes an excellent wine.

PEOLA. (?) A black Grape; bunch medium, compact, handsome; berry medium, very tender, juicy, sweet, vinous, sprightly; vigorous, hardy, healthy and productive; ripe before Concord; free from rot and mildew; a fine desert Grape; originated from unknown seed by John Burr.

PERFECTION. (Hyb.) A red Grape; bunch long, shouldered, compact, handsome; berry medium, tender, rich, sprightly, with very little pulp and native aroma; vigorous, hardy, healthy and very productive; free from rot and mildew; this is the earliest and best red Grape in Kansas; much like Delaware, but larger in bunch and berry ; ripe about with Jewell ; originated from Delaware by Dr. J. Stayman.

PERKINS. (Labr.) Originated in Massachusetts. Pale red when fully ripe; bunch medium to large, shouldered, compact ; berries medium to large ; skin thick; flesh sweet, juicy but foxy ; ripens early, before Concord; vine very vigorous, hardy, very healthy and productive; quite exempt from rot except in extreme cases.

PERRY. $(H y b$.$) A southern Grape originated by T. V. Munson; a cross of Post-$ Oak with Herbemont. Very vigorous grower; large conical bunches; berries small to medium, purple, melting, juicy, fine quality; very productive ; medium to late.

PETER WYLIE. $(H y b$.) Originated by the late Dr. Wylie. White; bunch and berry above the medium; meaty, good quality with a delicate Muscat flavor; valuable at the south.

PIERCE. (Labr.) A Grape from Isabella found growing on the grounds of Mr. J. P. Pierce, Santa Clara, Cal. Described in the Pacific Rural Press as follows: One cane of an Isabella vine was found to be bearing heavier clusters and larger berries than the other portion of the vine. The wood from this cane was grafted on other vines and found to retain the qualities of the original cane. The fruit is black and retains the characteristic aroma, flavor and bloom of its parent, but instead of being medium sized, oval berries, they are rouad and the cluster is more compact and heavier than the Isabella. The foliage is remarkably large, and the vine an exceedingly strong grower and prolific bearer. The berries, like the leaves, are of extraordinary size, twice as large as those of its parent, black with light bloom, and when ripe are exceedingly sweet, delicious and slightly aromatic, the pulp readily dissolving. This Grape is now on trial in Western New York. 


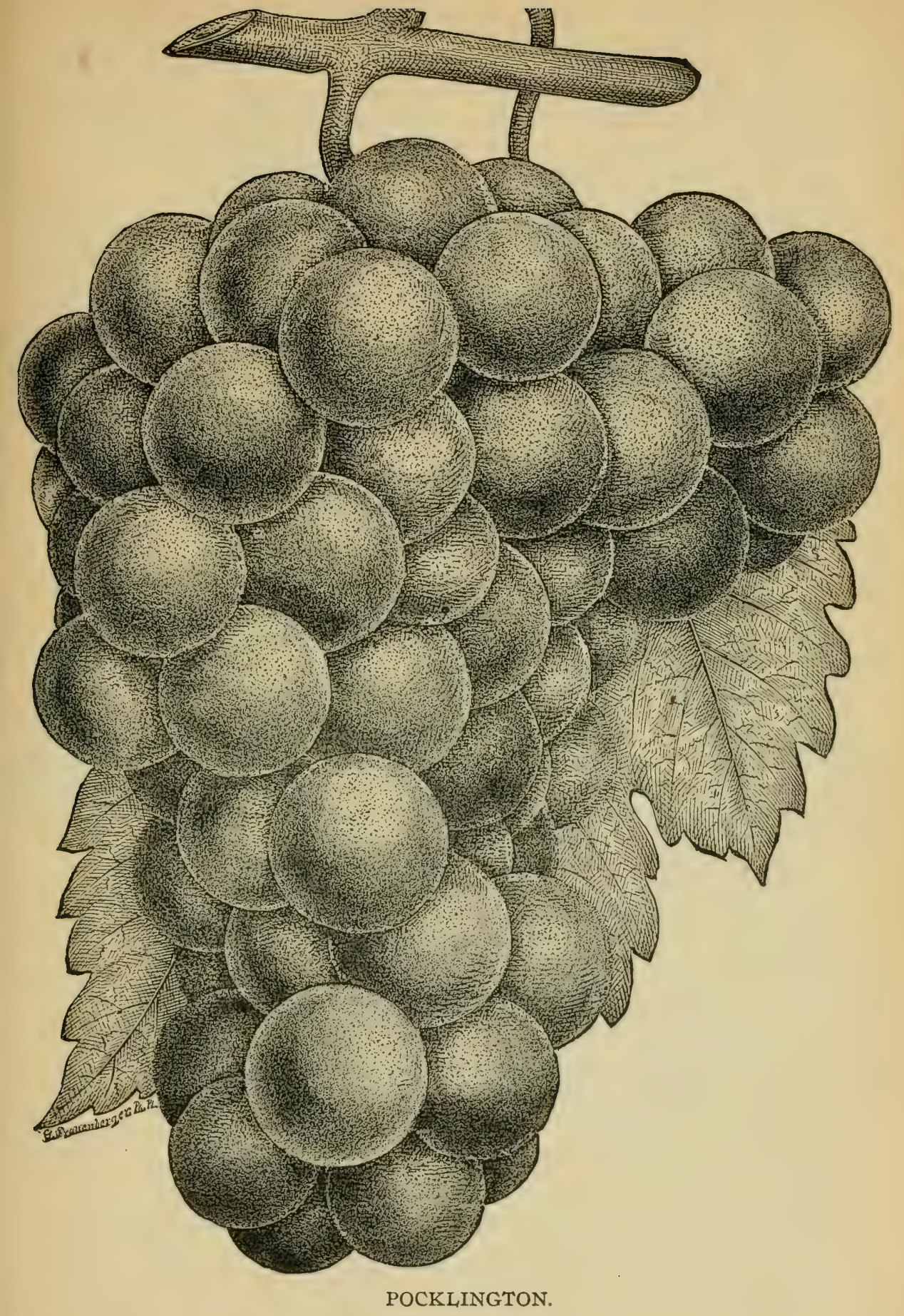


PIONEER. (Labr.) A seedling of Isabella and very similar to it.

PIZARRO. $(H y b$.$) Raised by Jas. H. Ricketts of New York, from Clinton$ fertilized with Vinifera. Bunch long, loose and shouldered; berry medium, black with blue bloom, juicy, very rich, spicy, vinous and aromatic; good wine Grape of great richness.

PLANET. $(H y b$.$) Another of Ricketts' seedlings, produced from Concord and$ Black Hamburg. Bunch large, loose, shouldered; berry medium to large ; tender pulp, juicy, sweet, fine flavor; healthy and productive.

POCKLINGTON. (Labr.) Originator, Jas. Pocklington of Sandy Hill, Washington Co., N. Y. A seedling of Concord and a pure native vine. Very popular Grape and has taken its place as a valuable standard variety. Pale green with tinge of yellow where exposed to sun; bunch large, hard, very compact; berries very large and covered with beautiful white bloom; flesh juicy, sweet with considerable pulp and foxiness. Foliage large, leathery, healthy. A seedling of Concord ripening soon after it, and considered its equal in quality. Vine a moderately good grower, but very healthy and very hardy, its buds withstanding severe cold even better than Concord. It produces a heavy crop of fine, healthy, showy clusters, and on account of its attractive appearance and many good qualities, is yearly increasing in popularity. Requires rich soil and good culture.

POLLOCK. (Labr.) Raised by Mr. Pollock, Tremont, N. Y. Bunches large as Concord, compact; berries large, dark purple or black ; flesh free of pulp ; vinous, not too sweet.

PONELL. See Bland.

POTTER'S EARLY. (Labr.) Originated in Rhode Island by a Mr. Potter. A chance seedling. It is a pure native of the Labrusca type. A black Grape of remarkable qualities. Bunch small, oval ; berries medium size, exceedingly sweet, in fact, the sweetest American grape, quality best. Plant more healthy than even the Ioncord. An excellent dessert Grape. Its pretty bunches of odd form and neat size make it unique for this use. It will do well in any situation. Perfectly hardy and free from any disease thus far.

POUGHKEEPSIE RED. $(H y b$. $)$ Raised by A. J. Caywood \& Son from Walter crossed with Delaware. An early Grape of superior quality, somewhat resembling Delaware, but with longer and more shouldered clusters; vine not very healthy but very productive. Flesh tender with a little tough pulp, but mostly melting in the mouth; flavor sweetish, but not pronounced and rather insipid.

PRAIRIE STATE. (Labr.) Originated by J. Christian, Mount Carroll, I11. A chance seedling of Martha. Bunches good size and very compact; berries large, yellowish white with fine bloom ; skin thin but never cracks ; sweet, no pulp, pleas. ant flavor and fine quality. Very hardy, productive; ripens ten days ahead of Concord ; very promising.

PRENTISS. (Labr.) Originated by J. W. Prentiss, Pulteney, N. Y., growu from seed of Isabella. Yellowish green with often a rosy tint on side next to sun; bunch medium to large, compact, not shouldered; berries medium to larga, skin thin but very firm, flesh tender, sweet meiting, very little pulp, juicy with a delightful aroma. A good shipper and keeper. Somewhat resembling the Rebecca in quality and appearance, but a better grower. Is inclined to overbear and clusters should be thinned. In some favored localities it succeeds well, but in other localities the foliage mildews and growth is not satisfactory.

PRES. LYONS. (Hyb.) Produced by T. V. Munson. Still under trial. 


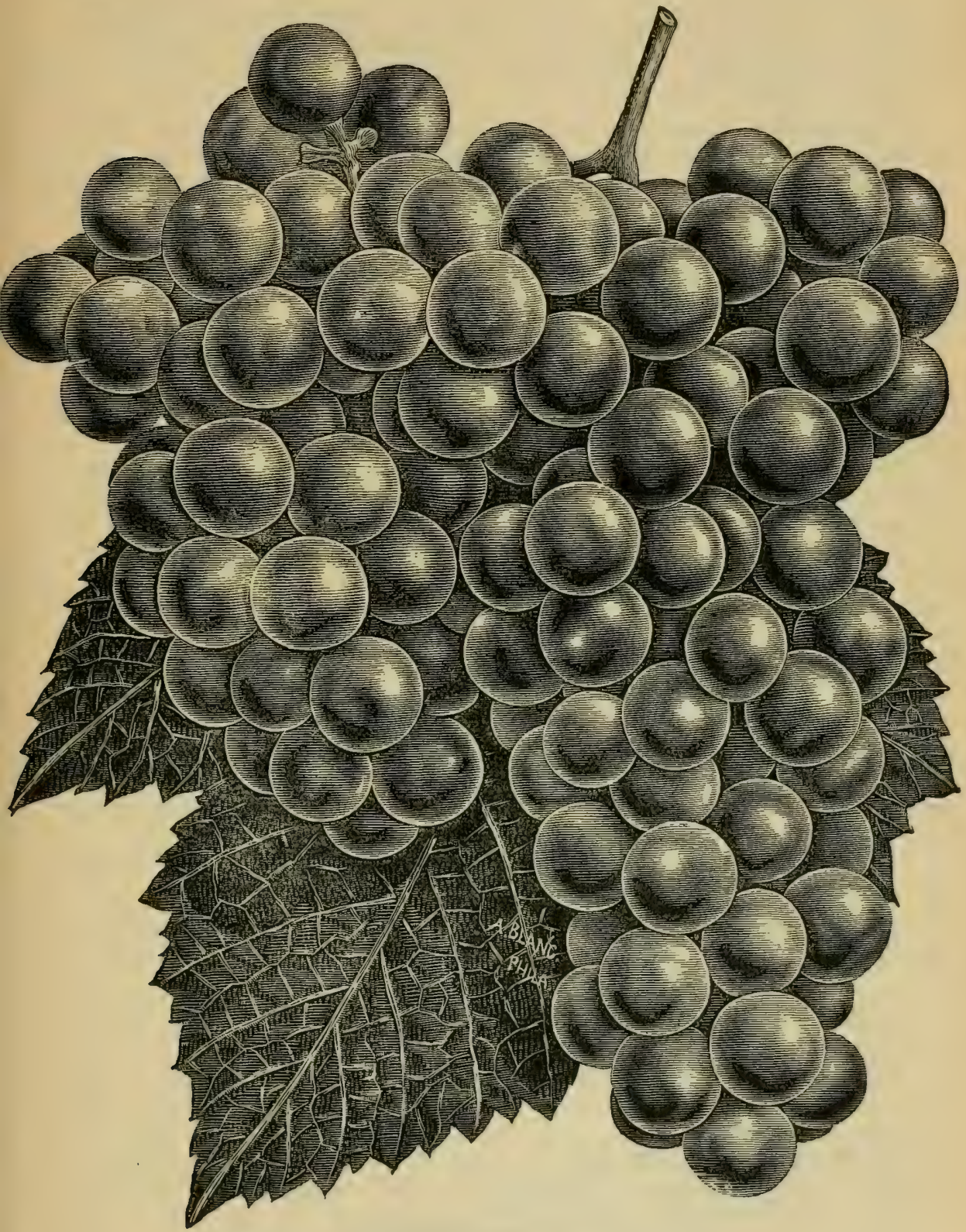

\section{POUGHKEEPSIE RED.}

PRIMATE. (?) A red Grape ; bunch long, compact, handsome ; berry medium or above; firm but tender, juicy, rich, sprightly, vinous, sweet, of the very best quality ; vigorous, hardy, healthy and productive; free from rot and mildew ; a very promising late Grape ; originated from unknown seed by John Burr. 
PROF. HILGARD. (Hyb.) Originated by T. V. Munson from Post Oak crossed with Herbemont. Purple, medium berry, large cluster, shouldered, compact, very juicy, sweet and sprightly. Medium to late.

PROF. BAILEY. See Bailey.

PROFITABLE. (Hyb.) Originated by T. V. Munson, Dennison, Texas. Clusters large, quite long, moderately compact, shouldered; berry slightly oblong, pale red, fine bloom, skin quite thick with heavy bloom ; flavor not pleasant. Pulp tender but adhering to skin. Good grower and productive.

PROGRESS. (?) A red Grape; bunch large, rather compact, berry large, tender, juicy, rich, sprightly, sweet, of the Catawba flavor and quality ; very vigorous, tolerably hardy, healthy and productive ; somewhat subject to rot, much better than Catawba, origin unknown.

PULPLESS. $(H y b$.$) Originated by C. Engle, Paw Paw, Mich., from seed of$ Salem. Vine vigorous, hardy, prolific. Bunch medium to large ; berry large, oval, black. More vinous than sweet, very rich. Seeds seems to be floating in the juice ; almost pulpless, very fine, ripens with Concord.

PURITY. $(H y b$.$) Originated with Geo. W. Campbell, Ohio. Bunch medium,$ compact, berry white, of the finest quality, in flavor better and finer than Delaware ; strong and healthy grower.

PURPLE BLOOM. (Hyb.) Produced by the late Dr. Culbert, Newburgh, N. Y. from a seedling of Hartford crossed with some foreign variety. Bunch large and showy ; berries medium to large, purple with delicate bloom ; vine vigorous and prolific. Has been neglected in propagating.

PUTNAM. (Labr.) A cross of Delaware and Concord produced by J. H. Ricketts, N. Y. Bunch medium to large, moderately compact, berry round, sweet and rich. Good quality.

QUASSAIC. $(H y b$.$) Also raised by J. H. Ricketts from Clinton and Muscat$ Hamburg. A vigorous grower, healthy and productive. Large, shouldered bunch; berries medium to large, roundish, oval, black with thick blue bloom; sweet, juicy and rich, medium early.

RAABE. (Fst.) Raised by Peter Raabe of Philadelphia, Pa. Bunch and berries small, color like Delaware, very juicy; good quality.

RACHEL. (?) Origin unknown. Bunch medium, moderately compact; berries medium, round, white, sweet, of fine quality ; moderate grower, healthy foliage.

RACINE. (Est.) Introduced by H. Jaeger, Neosho, Mo. Bunch long, compact ; berries small, round, black; hardy and healthy with a fine foliage; poor bearer; good only for wine.

RARITON. $(H y b$.$) One of Ricketts' seedlings, Delaware and Concord. Bunch$ and berries medium, black, vinous and juicy; flesh tender and juicy with very few seeds ; a good wine Grape.

RAUTENBERG'S SEEDLINGS. E. F. L. Rautenberg, of Lincoln, I1l,, well known among the Grape growers, has under cultivation a large number of crosses of his own origin, of which the following have been tested:

No. I. $(H y b$.$) Salem crossed with Concord. Bunch medium; berry about$ like Agawam, which it resembles in color and size, but quality much better; season about with Delaware; foliage healthy, exceedlingly productive; should be covered in extreme cold winters; tough skin, hangs well on the peduncles; good shipper and keeper. 
No. 2. (Hy3.) Unlike its sister (No. I), resembles the Concord both in size and color of berry as well as in foliage, but will mildew like the Rogers' Hybrids. Berry black, round with fine bloom; bunch medium to large; quality like Eumelan, fine; hardy, very early ; worthy of a trial.

No. 3. (?) A chance seedling. Vine hardy, strong grower, foliage strong and of a peculiar yellowish tint, very productive; berry medium, color of Delaware; bunch medium, compact, often double shouldered ; skin thin but tough ; promises to be a good shipper ; quality fine, sweet, juicy, with but little of native aroma when ripe.

No. 4. $(H y b$.) A cross between Ives and Rommel's Faith. A very early pro. ductive, black Grape of good quality and extra hardy. Not sufficiently tested to other qualities.

No. 5. $(H y b$.$) Salem crossed with No. I. This Grape is of the most exquisite$ quality. Color white, but as it was somewhat crowded, could not be judged as to other qualities.

RAY'S VICTORIA. See Victoria.

REAGAN. (Hyb.) Produced by Post Oak crossed with Triumph, by T. V. Munson. Vigorous grower, productive; large clusters with medium berries, black, juicy, melting; thin skin; hardy, fine quality.

REBECCA. (Labr.) Found accidentally in the garden of E. M. Peake, Hudson, N. Y. White; bunch medium, compact; berry medium, of very fine quality and very desirable for home and market use. Vine not very vigorous.

RED BIRD. $(H y b$.$) Originated by T. V. Munson, by crossing Lindley with$ Champion; cluster quite long, shouldered; berries reddish purple, large, nearly round; skin thick with thin bloom; flavor foxy.

RED EAGLE. $(H y b$.) Seedling of Black Eagle produced by T. V. Munson. Clusters medium long, berries dark red, medium and nearly rouud, skin quite thick with heavy bloom, flavor very good, with little foxiness,

RED ELBEN. See Rulander.

RED LENOIR. See Pauline.

RED MUNCY. See Catawba.

RED RIVER. See Cynthịana.

RED SHEPHERD. (Rip.) Introduced by Mr. Estell of Ind. Bunches small but compact, berries, small, red, round and sweet, very rank grower.

RELIANCE. (Hyb.) Originated by J. G. Burrows, Fishkill, N. Y., a cross of Delaware and Iona, vine vigorous, hardy and very productive, with thick, healthy foliage. Bunch resembling Delaware but larger. Berry medium, light red, flesh tender, very juicy and almost without pulp, of a sprightly sweet sub-acid flavor. Ripens with Delaware.

RENTZ. (Labr.) Raised by the late S. Renz of Ohio. Bunch large, compact, berries large, black, sweet and juicy. Early, good market and wine grape.

REQUA. $(H y b$.$) Rogers No. 28. Produced by E. S. Rogers, Mass., from$ Mammoth crossed with Black Hamburg. Red, large bunch, medium berry, vigorous, early and productive. Sweet and good.

RIESENBLATT. (Est.) A chance seedling raised by M. Poeschel, Herman, Mo. A strong grower with large leaf, small bunch and berries, dark. Has been tried only at Herman, Mo. 


\section{ROANOKE. See Scuppernong.}

ROBESON'S SEEDLING. See Louisiana.

ROCHESTER. (Labr.) A seedling raised by Ellwanger \& Barry, Rochester, N. $\mathrm{Y}$., from seed taken from vines on a wall where Delaware, Diana, Concord and Rebecca were planted and trained together. About 60 seedlings were raised, but one after another was rejected until two were left, Monroe and Rochester, which were offered for sale. Bunch large, shouldered, frequently double shouldered, very compact. Berries medium to large, round, dark purple or purplish lilac, peculiar, with thin white bloom. Flesh very sweet, vinous, rich and aromatic. Vine a remarkably vig. orous grower; wood short-jointed and hardy ; foliage large, thick, healthy. It requires ample room and rather long pruning. Ripe usualiy first week in September. The fruit always sets well, and it has never failed to ripen in the worst of seasons since it first bore.

ROCKINGHAM. (Hyb.) Originated by the late T. B. Miner, of N. J. Bunch and berry medium, black; quality like Concord. Vine hardy, vigorous, productive.

ROCKLAND FAVORITE. (Labr.) A seedling of Concord introduced by E11wanger \& Barry, Rochester, N. Y. Bunch and berry large, black with fine bloom, sweet and juicy, earlier and of better quality than Concord. Vine vigorous and healthy.

ROCKWOOD. (Labr.) Seedling of Concord raised by E. W. Bull of Concord. Large cluster, medium, compact, shouldered, berries large, black, sweet and juicy, quality similar to Concord. Vine healthy; hardy and prolific.

ROENBECK. $(H y b$.$) Origin unknown; raised on the grounds of Jas. W.$ Trask of Bergen, N. J. Bunch medium, compact, shouldered; berries medium, pale green and as fine as Chasselas Royal. Vigorous grower, very prolific; must be pruned very short. An excellent Grape for the table.

ROGERS' HYBRIDS. $(H y b$.$) E. S. Rogers, Salem, Mass. These Grapes were pro-$ duced by hybridizing the Mammoth, one of the best and earliest of the wild species of New England, with the foreign Black Hamburgh and Chasselas. All the numbers between 4 and I4 including were Chasselas and Mammoth parentage and all the others Black Hamburgh and Mammoth. There were 45 in all, two or three of the vines died out of the lot before coming into bearing and were never disseminated. Some of these seedlings have been named and will be found in the proper places, while those still unnamed are described below:

No. 1. See Goethe.

No. 2. Bunch and berry large, black, ripening very late. Vine vigorous with heavy foliage. Productive.

No. 3. See Massasoit.

No. 4. See Wilder.

No. 5. One of the best and should be better known. Bunch medium to large, berry large, round, red, sweet and rich, hardy and healthy. Ripens early.

No. 8. Valuable for wine making. Bunch and berry large, pale red, strong grower, hardy and productive, ripens late.

No. 9. See Lindley.

No. 11. Somewhat like Lindley, having a close set bunch and rather smaller berry; like it in growth, general qualities, color, etc.

No. 13. Mr. Rogers says has borne only a few berries before it died. It was a light colored reddish grape. 


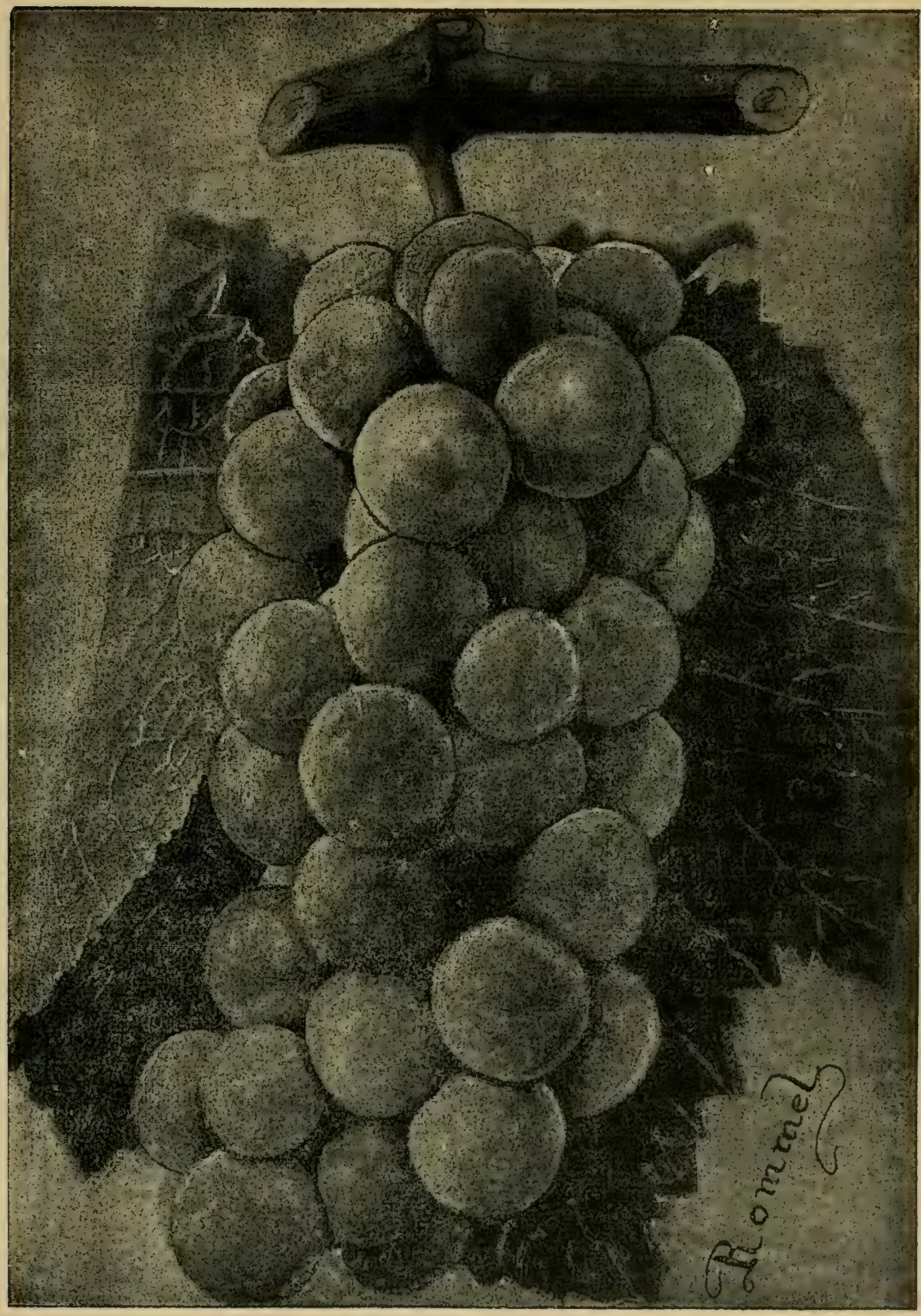


No. 14. See Gærtner.

No. 15. See Agawam.

No. 17. Died before bearing,

No. 19. See Merrimac.

No. 22. Changed later on to No. 53. See Salem.

No. 24. Bunch poor, berry large, red. Not satisfactory,

No. 28. See Requa.

No. 30. A light red grape of fine quality. Bunch medium, and herry medium large; flavor much like the foreign Chasselas. A good grower, productive, and ripens early. Has proven generally satisfactory

No. 32. Vine not very vigorous, but hardy and productive. Bunch very large and berry large, red; quality fair ; ripens quite late.

No. 33. Vine vigorous, healthy, productive. Bunch large, shouldered; berry very large, black. Quality better than Wilder.

No. 34. The largest and most showy black grape of the collection, Bunch large, shouldered; berry very large, oval ; quite acid, juicy and high-flavored. Vine vigorous, prolific, late.

No. 36. A black grape ; large bunch and berry ; rather high acid flavor, juicy. Good bearer, strong grower, late.

No. 39. See Aminia.

No. 41. See Essex.

No. 43. See Barry.

No. 44. See Herbert.

No. 53. See Salem.

ROMMEL. $(H y b$.$) Produced by T. V. Munson by crossing the Triumph upon$ Elvira. Vine very vigorous, free from disease, not even attacked by the Leaf Roller ; cluster medium, simple or shouldered, compact, handsome; berry medium to large, yellowish white, translucent; skin thin and tough; pulp melting; seeds few and small ; quality best, pure, sprightly, vinous; season about the same as Delaware; the vine is very hardy to resist cold or heat and very productive. Named after Jacob Rommel, of Missouri.

ROSCOE. (Hyb.) Originated by T. Munson. No description given yet. Still under trial.

ROSWITHER. $(H y b$.$) A seedling of Jewell produced by L. Hencke, Collins-$ ville, Ill. Bunch and berry medium to large; color dark purplish, nearly black; fine quality, very productive and hardy. Ripens about ten days before the Concord. Will make a profitable market Grape.

ROTENT SEEDLING. (Labr.) Originated by C. F. Rotent, Put-in-Bay, Uhio, from Pocklington fertilized with Brighton, resembling the Pocklington in color and size. Berry somewhat larger than Pocklington, deep yellow color when fully ripe. Pulp very juicy and delicious; skin firm, good shipper. Vine vigorous and productive.

ROTHROCK. See Alexander.

RUBY. (Hyb.) One of Geo. Haskell's Seedling but named by S. Miller of Mo., on account of its color. Bunch and berry about medium, round, ruby red, quality unsurpassed. 


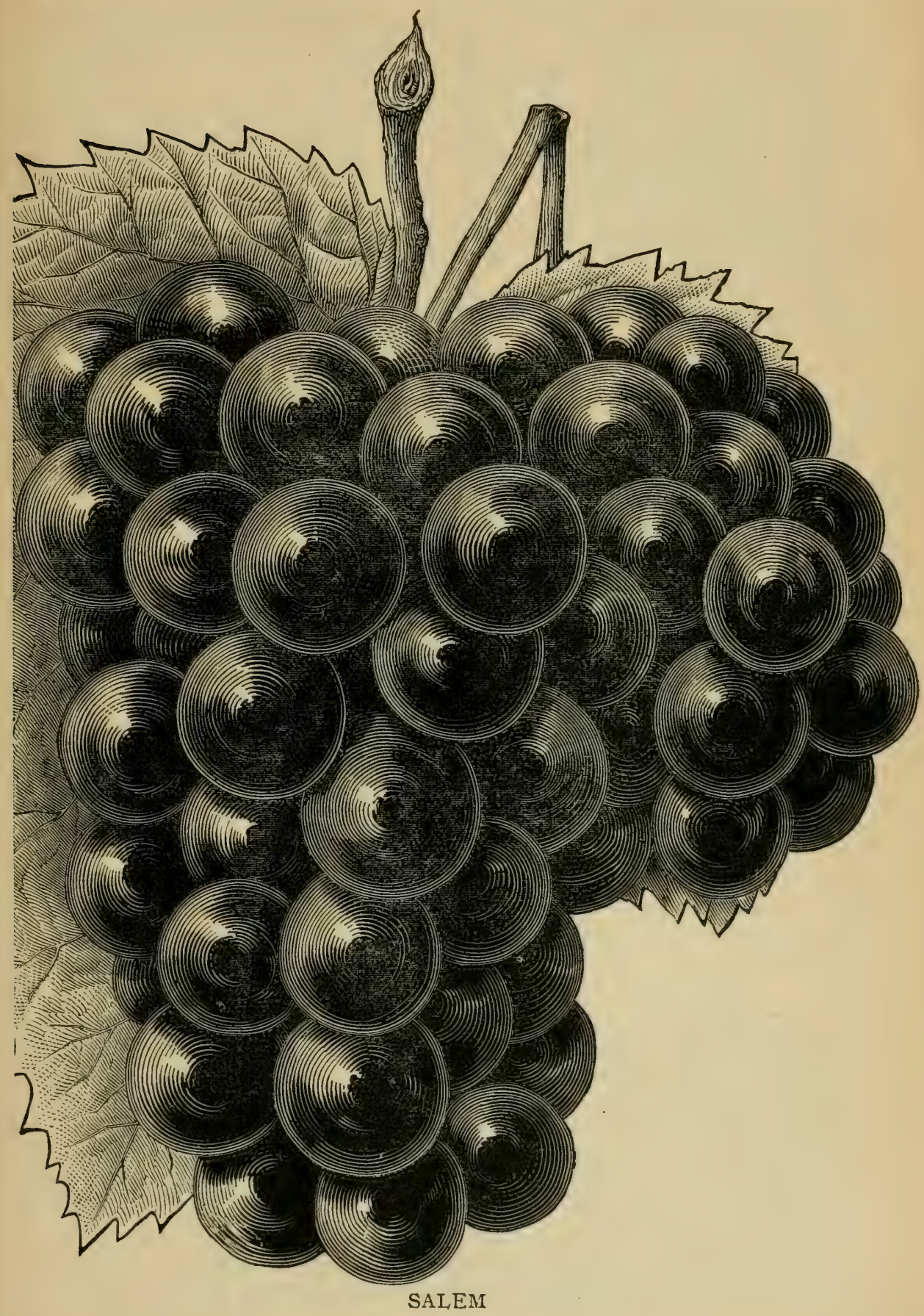


RULANDER. (Est.) Origin unknown, but supposed to come from a foreign variety. Bunch small, compact, shouldered; berry small, black, without pulp, juicy and sweet. Vine strong grower. Excellent wine grape.

RUSTLER. $(H y b$.$) Produced by T. V. Munson from Lindley crossed with Del-$ aware. No description given yet Several of these crosses raised from the finer varieties such as Salem, Agawam, Lindley, etc., have given size and richness of flavor to others of our best species.

RUTLAND. (Hyb.) Originated by D. S. Marvin, of Watertown, N. Y. Bunch and berry Eumelan size, blue-black; vincus, sprightly, pulp melting, but seeds do not separate easily. Good quality. Ripens with Concord.

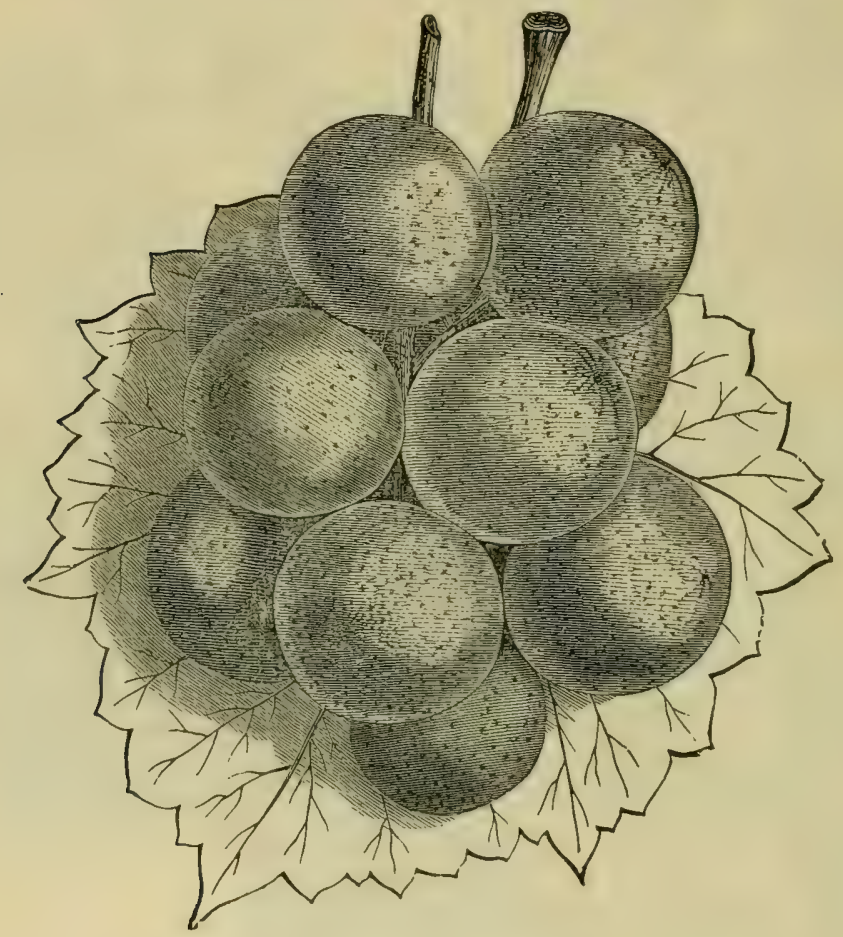

\section{SCUPPERNONG.}

SALEM. (Hyb.) Rogers; No. 53. Produced by E. S. Rogers. Dark red; bunch large, compact, shouldered; berries large, round, skin thick and firm, flesh very sweet, tender, with a rich aromatic flavor. Vine moderately vigorous, hardy, lealthy ; ripens earlier than Concord when not permitted to overbear. Is a splendid, keeper, a good shipper, and of best quality for both table and wine.

SALLY. $\left(H y b_{0}\right)$ Produced by D. S. Marvin, N. Y. A hybrid between Delaware and Sherman. Berry size of Delaware, bunch smaller, white; vigorous, healthy vine. More saccharine than Delaware. Fine for table, but more promising for champagne. Very early.

SANBORNTON. (Labr.) Aseedling of Isabella, far superior. Bunch large, compact, sometimes shouldered, berry medium to large, blue-black, sweet, juicy, and fine flavor. Late; origin unknown. 
SARATOGA. See Fancher.

SCHILLER. (AEst.)A seedling of Louisiana raised by F. Muench, Mo. Viue hardy; vigorous, healthy and productive. Berry purplish blue. Not disseminated.

SCHUYLKILL MUSCAT. See Alexander.

SCUPPERNONG. (Rotun.) This Grape is a pure southern Grape, a Vitıs Rotundifalia, found growing wild in Virginia, Mississippi, Florida. It is easily known from other Grapes by its small leaves, being glossy and smooth on both sides. Too tender for the North, but in the South very productive and an excellent wine Grape. Bunches small, loose, very seldom having more than six berries. Berries large, round ; quite pulpy, juicy, sweet with a strong musky flavor.

SECRETARY. (Hyb.) One of J. H. Ricketts' seedlings, from Clinton crossed with Muscat Hamburg. Bunch and berry large, black, quality fine. Vine vigorous and hardy; medium early ; subject to mildew.

SEGAR BOX. See Ohio.

SELMA. (Rip.) Originated by G. Segesseman, Amazonia, Mo., a seedling of Elvira and probably Concord. Large, perfect bunches nearly size of Concord, shouldered. Berry size of Ives, black, adheres firmly to the stem, keeping a long time, nearly round, juicy, sprightly, pleasant flavor; skin quite thick and firm. Makes a good claret wine. Perfectly hardy, productive and healthy. Ripens a few days after Moore's Early.

SENASQUE. $(H y b$.$) Raised by S. W. Underhill, N. Y. from Concord and$ Black Prince. Bunch large, long, very compact, berry medium to large, black. Fine quality, vine moderately vigorous and productive. Ripens a little after Concord.

SENECA. (Labr.) A seedling of Hartford raised by Mr. Simpson, N. Y. It is a fact that Hartford seedlings do not give rise to anything much superior to its parent nor to variations in color and seasons. No value in this Grape.

SHAKER. See Union Village.

SHARON. (Labr.) A seedling of Adirondack introduced by D. S. Marvin N. Y., which it resembles, but sweeter, hardier and more reliable; ripens at same time.

SHEPPARD'S DELAWARE. See Delaware.

SHERMAN. See Lyman.

SHERRY. See Devereux.

SILVER DAWN. ( $H y b$.) Raised by the late Dr. Culbert of Newburgh, N. Y., from Isabella crossed with Muscat Hamburg. Vine hardy and vigorous, fiue white Grape of best quality. Not disseminated.

SINGLETON. See Catawba.

SMALL GERMAN. See York Madeira.

SPARKLER. $(H p b$. $)$ A seedling of Delaware produced by T. V. Munson. No description given; not disseminated.

SPOFFORD SEEDLING. See To-Kalon.

SPRINGMILL CONSTANTIA. See Alexander.

ST. CATHARINE. (Labr.) Raised by J. W. Clark, Framingham, Mass. A Grape with strong foxy flavor. Bunch large, berries large, sweet, dark red, hardy, vigorous and productive.

STELTON. (Hyb.) Introduced by W. Thompson of New Brunswick, origin unknown. Bunches medium to large, shouldered; berries medium, whitish green, with white bloom, juicy, sweet and fine aroma. Vigorous, ripens about wilh Concord. 
ST. GENEVIEVE. See Rulander.

STANDARD. $(H y b$.$) A black Grape ; bunch large, shouldered ; berry large,$ tender, sweet, juicy, sprightly, vinous, with but little pulp ; vigorous, hardy, healthy, and productive ; an excellent market and very superior wine Grape ; subject somewhat to rot. Originated from Delaware by John Burr.

STORM KING (Labr.) A seedling of Concord raised by E. P. Roe, Cornwall, N Y., resembling Concord, but berries are larger and have less foxiness.

SUELTER. (Rip.) Originated by L. Suelter, Carver, Minn., from Riparia crossed with Concord.

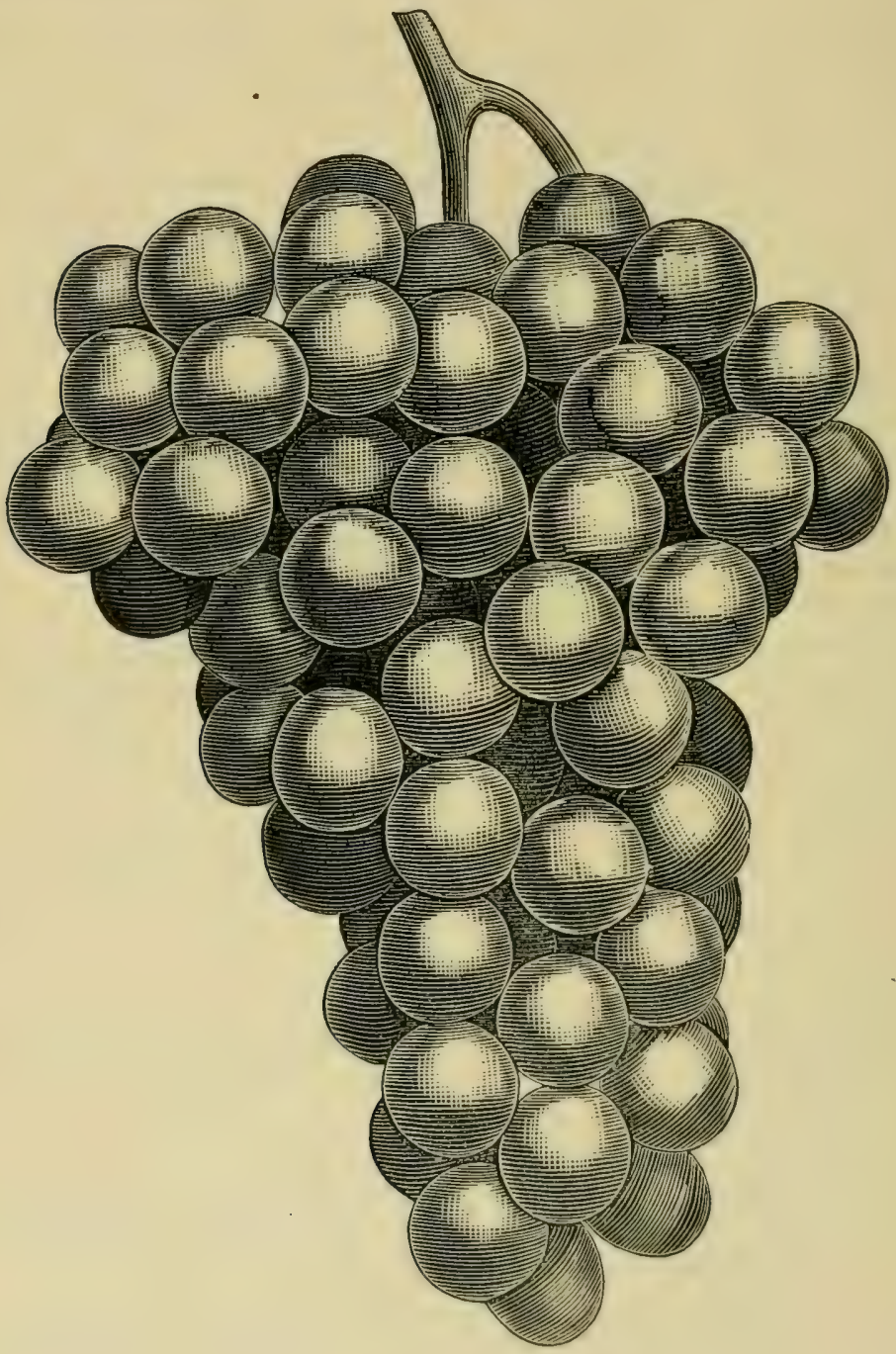

SUPERB. 
SUPERB. (EEst.) Originated with A. F. Rice, Griswoldville, Ga., from seed of the Eumelan raised at Weymouth, Mass. Vine hardy and a good grower, with short jointed stocky, fine grained wood; leaf large, thick dark green, and very healthy ; bunch large ; berry medium; color black, with blue bloom; seeds medium, quality superb, best, sweet and rich ; flavor pure and delightful, not a particle of ac$i^{d}$ taste in the seeds or skin ; pulp tender, brittle, juicy ; skin thin, but tough ; flesh firm next to the skin; a little similar to the Malaga, does not crack or drop. It is very productive. It starts late, thus escaping late Spring frosts; it ripens early, two weeks earlier than the Concord, and is an excellent keeper and shipper. Very productive, needs thinning.

SUPERIOR. (Hyb.) A new black Grape ; bunch medium, compact, handsome; berry medium, very tender, sweet, rich, sprightly, vinous, without pulp and of the very best quality, superior to Supreme or Jewell ; very strong grower, hardy, healthy and productive ; free from rot and mildew; a very valuable grape ; seedling of Jewell originated by John Burr.

SUPREME. $(H y b$.$) A new black Grape; bunch medium, compact; berry$ medium, tender, without pulp, sweet, rich, sprightly, vinous; quality better than Jewell, and about a week earlier; hardy, healthy, vigorous and productive, free from rot and mildew ; seedling of Delaware, originated by John Burr.

TALLMAN. See Champion.

TASKER GRAPE. See Alexander.

TAYLOR. (Rip.) Introduced by Judge Taylor, of $\mathrm{Ky}$. This grape needs planting among some varieties from which its flowers will fertilize in order to produce fair bunches. Some pruning is also recommended. Bunches small, compact; berries small, pale amber, round, sweet ; strong, healthy grower, and hardy.

TAYLOR'S BULLET. See Taylor.

TEKOMA. See Catawba.

TELEGRAPH. (Labr.) Raised by Mr. Christine of Westchester, Pa. It is one of the most promising of the new early Grapes, Black ; bunch and berry medium large and compact ; very little pulp; very productive, hardy and healthy. Ripens as early as the Hartford, and is of better quality.

THEMIS. $(H y b$.$) Originated with E. Engle, Paw Paw, Mich., seedling of Sa-$ 1em- Vine a strong grower, short jointed, hardy, large leaves. Berries large, round, red, thick skin, flesh firm, meat rich with hard pulp. Bunch medium, sometimes shouldered.

THEODOSIA. (EEst.) Raised from a chance seedling by E. S. Salisbury, Adams, N. Y. Bunch medium, compact, sometimes shouldered; berries small to medium, black, juicy and acid. Very early; good wine grape.

THEOPHILE. (Labr.) Originated by $T$. Huber, Sr., Ill. Bunch large, compact, sometimes shouldered. Berry large, white, with delicate bloom; juicy, sweet, vinous. Very good quality; ripens before Concord.

THOMAS (Rotun.) Introduced by D. Thomas, S. C., a variety of the Scuppernong. Berries large, oblong, purplish violet, thin skin, transparent, sweet and tender, vinous ; superior to Scuppernong.

THOMPSON'S SEEDLING. No, 1. (Labr.) A seedling of Brighton grown by J T. Thompson, Oneida, N. Y., resembling it very closely, fully equal in quality and so far as tested, early and better keeper.

THURMOND. See Devereux. 


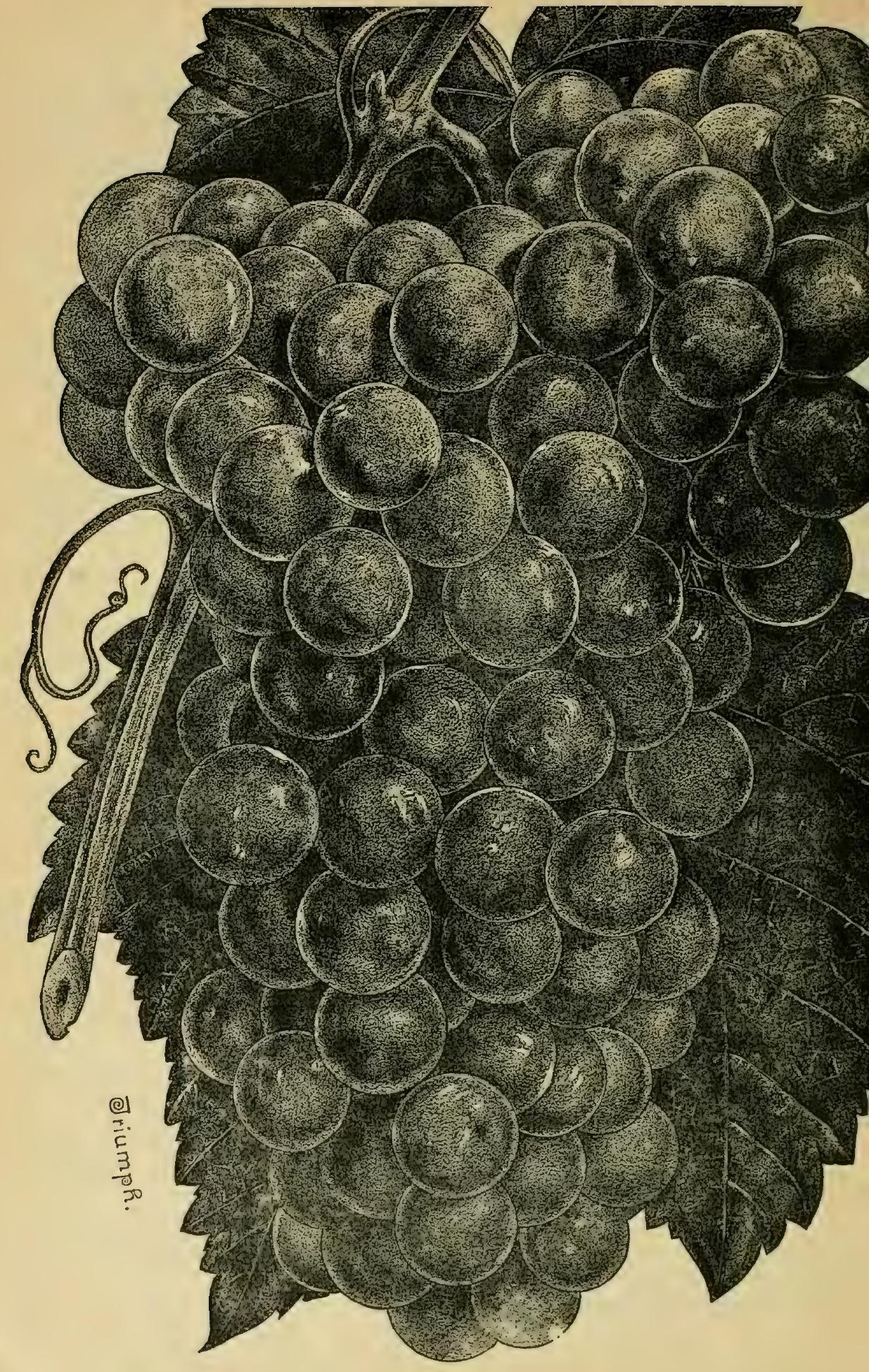


THOMPSON'S SEEDLING, No. 2. (Hyb.) A seedling of Agawam. Fruit very sweet, skin and pulp a little tough; a most excellent keeper. Very strong grower and productive. Ripens a few days before Concord.

TO=KALON. (Labr.) Originated with Dr. Spofford, Lansingburg, N. Y. Bunch medium to large, compact, shouldered, berries medium black. Vine vigorous, healthy and hardy, quality excellent. Early but shy bearer.

TOLMAN. See Champion.

TRANSPARENT. (Rip.) One of Taylor's Seedlings. Bunch and berry small to medium, white, transparent; very juicy, sweet and of fine flavor. Vine a rank grower; a wine Grape of high character.

TRASK. $(H y b$.$) A chance seedling raised by F. Roenbeck, N. J. Large$ bunch, moderately compact; berries medium, brownish red when fully ripe, sweet and juicy ; vigorous grower, hardy and prolific. Fruit needs thinuing out. Early.

TRIUMPH. (Hyb.) Originated by George W. Campbell, Delaware, O., from Concord and Chasselas Musque. A very fine white Grape, very large in bunch and berry, and of fine quality south and where the season is long enough for it to ripen. It is a late Grape, requiring a long season, and suited specially to southern latitudes. A large demand exists for it throughout the South. Ripens about with the Catawba. Not suited to the far North.

TROWBRIDGE. See Isabella.

TRYON. See York Madeira.

TULEY. See Devereux.

U. B. See Marine's Seedling.

UHLAND. (Rip.) A seedling of Taylor raised by W. Weidemeyer, Mo. Greenish yellow, delicate, very sweet and fine flavor. Strong grower, ripens a few days after Concord.

ULSTER PROLIFIC. (Labr.) A very desirable new red variety. A seedling of Catawba crossed with a native wild variety of the Aistivalis class. Originated by A. J. Caywood of N. Y. Medium bunch and berry, skin thin but tough. Very sweet and of exquisite flavor. It ripeus with the Concord; keeps and carries well. The vine is very hardy, healthy, vigorous and productive.

UNDINE. (Lab'r.) Originated by J. H. Ricketts, N. Y. A seedling of Concord and Clinton. Clusters large, shouldered, berries size of Concord, pale green inclining to cream color as it fully ripens. Quality very fine, sprightly, vigorous grower with healthy foliage. A promising Grape for a southern climate.

UNDERHILL. (Labr.) Introduced by Dr. A. K. Underhill, of Charlton, N. Y. A wild red Fox Grape, of no value and discarded.

UNION VILLAGE. (Labr.) Originated among the Shakers of Union Village, O. Large, compact bunches, shouldered, very large berries, round, black with delicate bloom, juicy, rich and vinous; pleasaut flavor, vigorous grower, ripens late.

UNA. (Labr.) A seedling from Concord raised by E. W. Bull, Concord Mass. Eunches and berries medium to large, pure white, changing to golden amber when ripe. Hardy and prolific.

UNO. See Juno.

URBANA. (Labr.) A seedling from Concord raised in Indiana. Bunch medium, shouldered, berries medium, round, yellowish white, juicy and vinous. Ripens after Concord. 


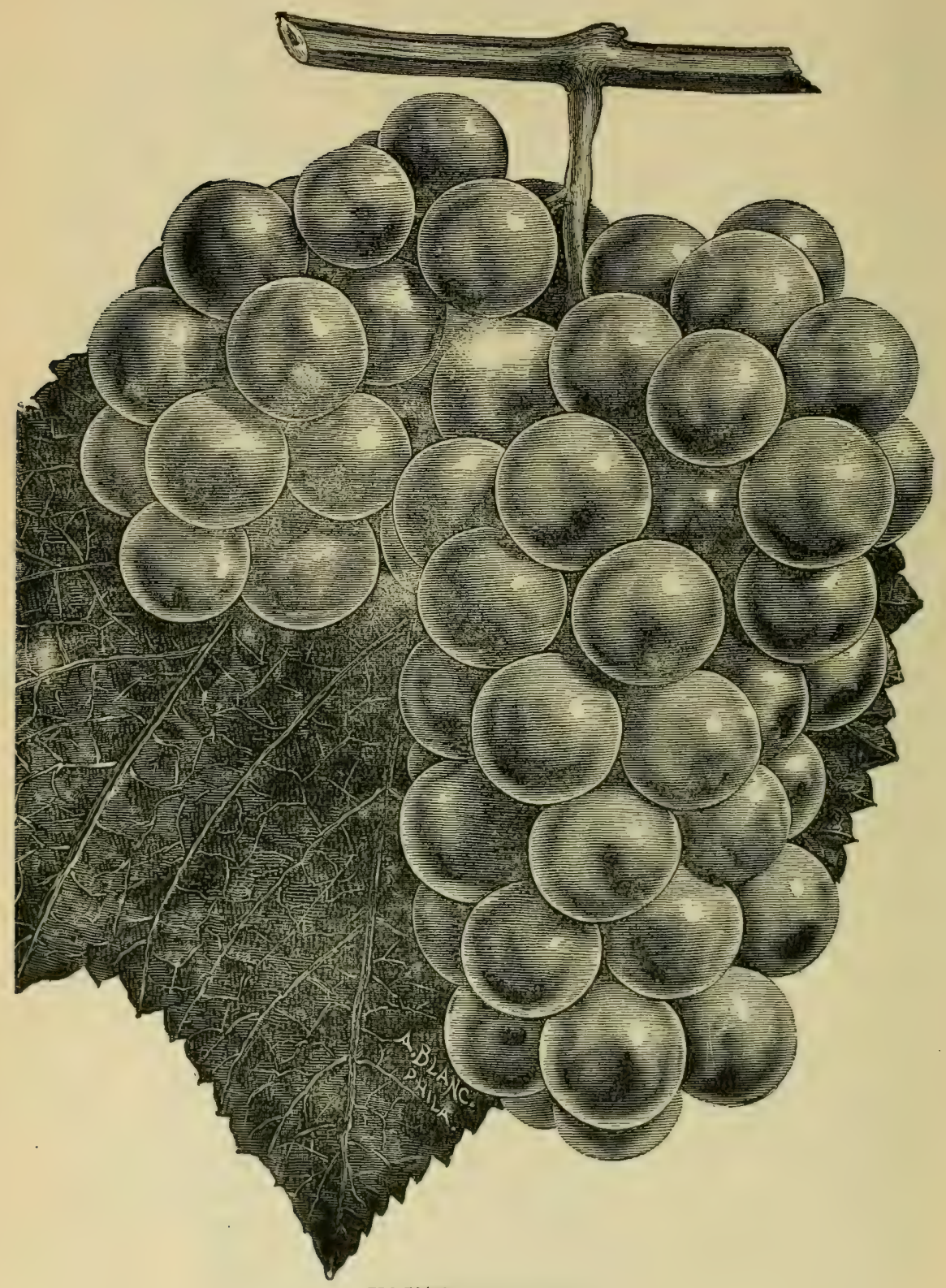

ULSTER PROLIFIC. 
URSULA. (Labr.) Produced by T. Huber, Sr., Ill. Bunch small, compact, berries small, white, flesh melting, juicy and sweet. Fine quality, vigorous grower, ripens with Concord.

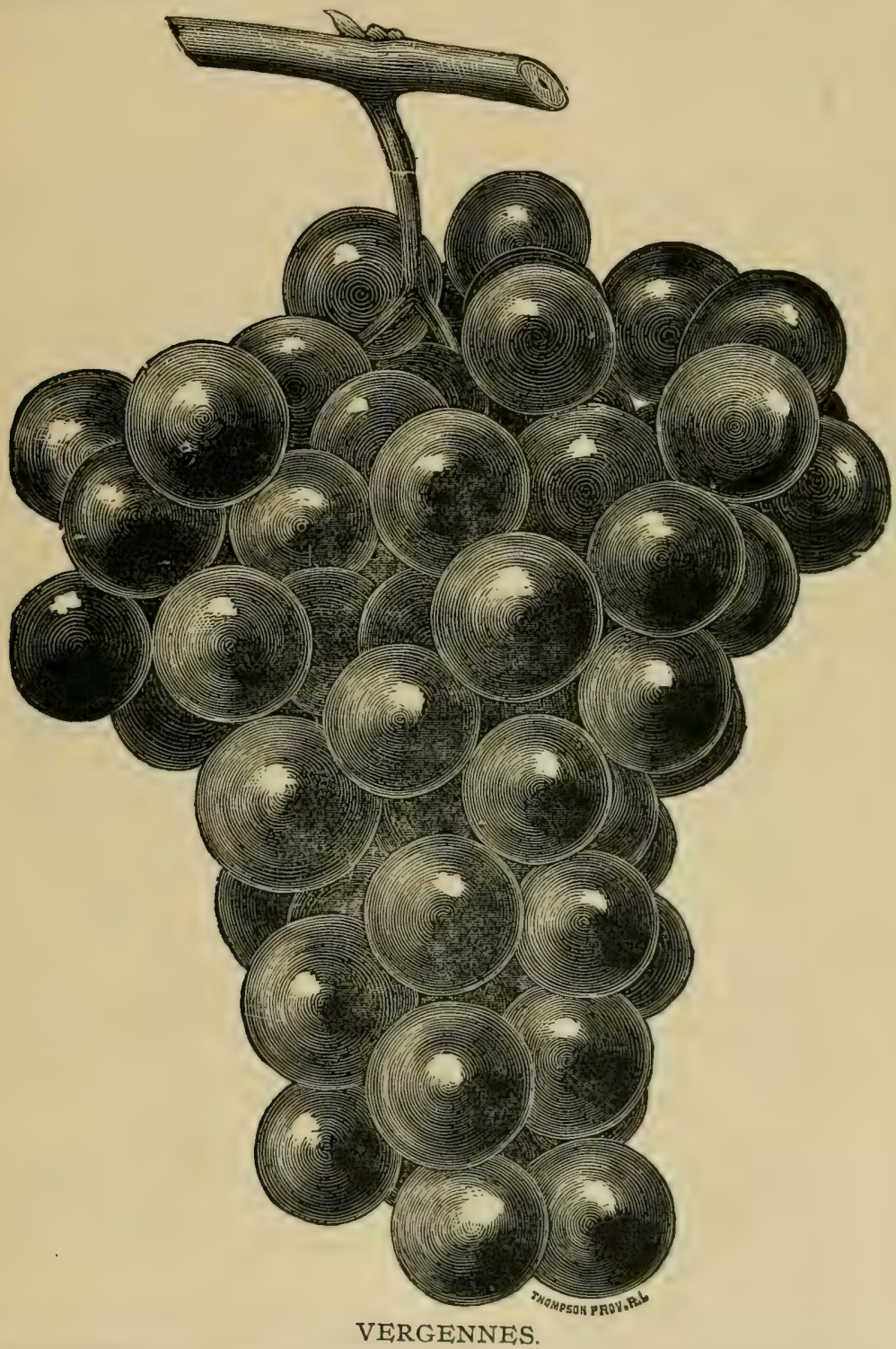

VERGENNES. (Labr.) Originated with Wm. E. Green, Vergennes, Vt. A chance seedling found growing in his garden. Ripens after Concord; bunch of medium size, berry large, skin thick and tough. Vine very vigorous, healthy and productive, hardy ; quality excellent; a splendid keeper and shipper. This is a Grape which growers will be inclined to keep and cultivate. A good market Grape vine- 
yardists have been looking forward to. The Vergennes is on the way to become as popular and useful in the sense that the Concord is.

VENANGO. (Labr.) An old variety said to be cultivated by the French at Fort Venango many years ago. A vigorous grower and hardy, medium bunch, compact, berries medium, pale red, white bloom, sweet and foxy.

VEVAY. See Alexander.

VICTOR. See Early Victor.

VICTORIA. (Hyb.) Produced by the late T. B. Miner. Bunch large, shouldered ; berries large, white, skin thick, flesh sweet, juicy, somewhat pulpy ; quality good, about the same as Lady. Vine a good grower, hardy and healthy, with thick, heavy Concord foliage. The best of Miner's seedlings.

VICTORIA, RAYS. (Labr.) Introduced by M. M. Samuels of Clinton, Ky., resembling the Venango. Bunch and berry medium, round, pale red, sweet and highly flavored. Vine vigorous, prolific.

VICTORIA. (Labr.) Another Grape of the same name originated by Dr. $\mathrm{H}$. Schroeder. Bloomington, Ill, from Champion. It resembles its parent in growth, color and fruit. Bunches and berries larger, a remarkably fast grower, with the strongest tendrils of all Grapes. Earlier than Champion. Excellent wine Grape, making a fiery, brilliant red wine.

VINITA. (Hyb.) Raised by T. V. Munson from Post Oak crossed with Herbemont. A southern Grape of vigorous growth, very prolific, best quality. Large clusters, shouldered, berries small to medium, purple, thin skin but tough, juicy, melting.

WALTER. (Labr.) Originated by A. J. Caywood \& Son, N. Y., from crossing the Delaware with Diana. One of the best introduced by them and very valuable for wine; bunch medium, compact, shouldered; berries medium, light red, round, juicy, sweet, of the very best quality, subject to mildew in some localities. Vine vigorous and hardy, ripens with Concord.

WARDER. See Dr. Warder.

WARREN. See Herbemont.

WARRENTON. See Herbemont.

WATERTOWN, $(H y b$.$) Produced by D. S. Marvin, Watertown, N. Y. Buuch$ medium, sometimes shouldered, berry medium, white, slightly oblong, sweet, fine quality, good grower, fine table Grape.

WAVERLY. (Hyb.) Raised by J. H. Ricketts from Clinton and one of the Muscats. Black, very vigorous, hardy, healthy and productive.

WELLS. (Labr.) Originated by C. I. Robords, Butler, Mo. The fruit is as large as Pocklington, oval, bronze or dark wine color, sweet and aromatic, hanging well to the vine for weeks in perfect condition. A healthy, good grower with large substantial foliage. A good shipper and keeper, ripens a little after Concord.

WEMPLE. See Cuyahoga.

WHITE ANN ARBOR. (Labr.) Introduced by C. H. Woodruff, Ann Arbor, Mich. A Concord seedling. Color pure white, in quality very fine, moderately productive, free from disease and very hardy, ripens nearly two weeks ahead of Concord.

WHITE CAPE. (Labr.) Similar to Alexander, only that its color is a greenish white. 
WHITE BEAUTY. (Hyb.) A white Grape; buuch very large, long, shouldered, compact, handsome; berry medium to large, firm but tender, sprightly, rich, vinous, of a pure refined quality, very vigorous, hardy, healthy and immensely productive; free from rot and mildew. This is the most perfect late white Grape in Kansas; ripening with the Concord, and will hang until hard frost; will ship anywhere ; a valuable market Grape ; originated from Duchess, by Dr. J. Stayman.

WHITE CATAWBA. (Labr.) Raised by John E. Mottier and abandoned by him as being inferior to its parent.

WHITE CLOUD. (Hyb.) A white Grape; bunch large, compact, handsome; berry large, tender, juicy, sprightly, sweet, of best quality; vigorous, hardy, healthy and very productive; free from rot and mildew, ripe about with Concord, and will hang on the vines long after ripening; a fine, valuable grape; originated from Duchess by Dr. J. Stayman.

WHITE DELAWARE SEEDLINGS. There are several white seedlings of the Delaware, of which the following two are the best under this name :

White Delaware. (Hyb.) Originated by G. W. Campbell, Delaware, O. A pure Delaware seedling. Bunch like its parent, compact and shouldered, berry greenish white with thin white bloom. Vigorous grower, foliage large, thick and heavy; ripens early.

White Delaware. $(H y b$. $)$ Produced by J, Rommel, Morrison. Mo. Del. Seedling, No. 16). Vine healthy, but moderate grower, very productive, bunch medium, compact, shouldered, berry medium, covered with a most beautiful white bloom. Very sweet, pure flavor, delicious, skin tough with no pulp, fine keeper and shipper. not subject to rot ; one half of its clusters should be removed early in the season, liable to overbear and overtax the vine; ripens with Concord.

WHITEHALL. (Labr.) Originated in Washington Co., N. Y., with Geo. Goodale. A chance seedling; bunch large and compact; berries medium, dark purple, almost black ; melting and sweet ; ripens a week or two before Hartford.

WHITE IMPERIAL. (Hyb.) A white Grape; bunch large and compact, handsome; berry medium, firm, tender, sweet, rich, sprightly, vinous; of the most exquisite, refined, indescribable flavor; very vigorous, hardy, healthy and productive; very nearly free from rot and has never mildewed; ripe very early and will hang on the vines long after being ripe; originated from Duchess by Dr. J. Stayman.

WHITE JEWELL. (Rip.) Introduced by Dr. Stayman. A white Grape of the Riparia class; bunch medium, long, very compact, handsome; berry medium, very juicy, sweet, sprightly, of good quality, very vigorous, hardy, healthy and im. mensely productive; free from rot and mildew, the earliest white Grape in Kansas. Originated from Elvira.

WHITE MUSCADINE. See Scuppernong.

WHITE'S NORTHERN MUSCAT. (Hyb.) Originated by W. T. White, Troy, O. A seedling of the Brighton fertilized by Muscat, which it very much resembles in size and aroma. Berries medium, round, amber in color, and sweet; hardy and vigorous; also known as the Culinary Grape.

WHITE VIRGINIA SEEDLING. (Hyb.) Produced by J. Balsiger, Highland, I11. Probably the product of an accidental cross between Norton's Virginia and some other variety. Wood, foliage and growth very similar to Nortons; good throughout, excessive bearer of medium sized bunches and berries, ripening a little later than Concord; vine healthy, vigorous; fruit sweet when ripe; white, best suited for wine. 


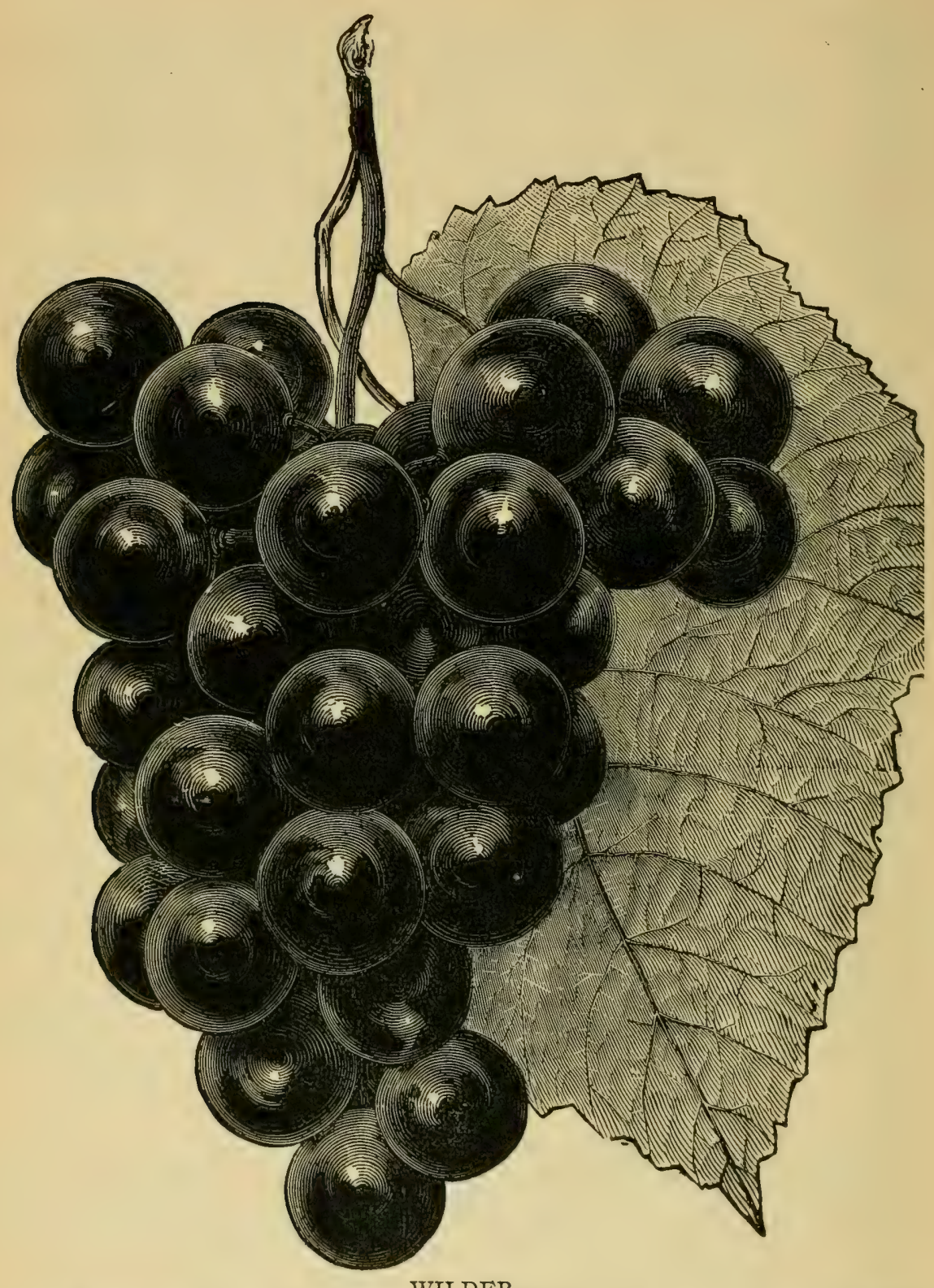

WILDER.

WILDER. (Hyb.) Rogers No. 4 ; originated by E. S. Rogers, Salem, Mass. Bunch very large, compact, shouldered; berry large, round, black; flesh tender, slight pulp at center, juicy, sweet. Ripens about with Concord. Vine vigorous, hardy and a good bearer. Regarded as one of the best of the black varieties, and on account of its size and beauty is very valuable for market. 
WHITE MUSCAT OF NEWBURG. (Labr.) Raised by the late Dr. W. A. Culbert from Hartford hybridized with Iona. Vine hardy and vigorous grower, bunch and berry of fair size with a fine Muscat aroma.

WILDING. (Rip.) Introduced by J. Rommel of Mo. A sport of a wild seedling Grape. Vine very vigorous, healthy; bunch and berry medium size; berry light straw color almost transparent, sweet, juicy, and without pulp, skin thin and tender, productive vine, hardy, not subject to mildew or rot. Ripens with Concord.

WILLIE. (Labr.) A half sister to the Lutie, a seedling of Northern Muscatine crossed with Concord, produced by Dr. I. C. Chisholm at Nashville, Tenn. Fruit larger than Concord both in cluster and in berry, very showy, dark or nearly black with whitish bloom ; skin not as thin as Concord; vinous and sprightly, not foxy, an excellent wine Grape ; vine a vigorous, healthy grower, very productive, ripens with Concord.

WILLIS. (Del.) A Delaware seedling originated with W. W. Jones, Canargo, Ill. Bunch medium to large, compact; berry medium, round, amber, rich and sweet. Vigorous grower, foliage thick and healthy.

WILIINGTON. (?) Originated on the farm of Mr. Jeffries near Wilmington, Del. Vine very vigorous, hardy, bunches large, loose, sometimes shouldered, berries large, round, greenish white; ripens late.

WILMINGTON RED. (Labr.) Raised by Dr. S. J. Parker, Ithaca, N. Y. See Wyoming Red.

WINCHELL. (Labr.) Introduced by Ellwanger \& Barry, Rochester, N. Y. A new white Grape, very valuable on account of its fine quality and earliness; vigorous, hardy and productive; it is considered a variety of great merit.

WINNE. See Alexander.

WINSLOW. (Rip.) Originated in the garden of Chas. Winslow, Cleveland, O. The vine resembles Clinton, is hardy and productive, bunch medium, compact, berry small, round, black, vinous and juicy, very early.

WITT. (Labr.) Originated by Mr. Witt, Columbus, Ohio. Probably the best of all the white Concord seedlings. Large iu bunch and berry; healthy in growth and foliage ; very productive, pure flavored, and best in quality. It ripens early, and has every requisite for a first-class Grape for general use in all Grape growing localities.

WOLF. See York Madeira.

WOODBURY WHITE. $(H y b$.) Originated and introduced by D. B. Woodbury, Paris, Me. Grown from hand fertilized seed from a white seedling of Delaware. The vine as a grower resembles the Delaware. Bunch medium to large, compact; berry as large as the Concord, slightly oblong, greenish white with fine bloom; skin thin but tough, adhering to the flesh, almost transparent ; juicy and sweet, good quality very mild in flavor, an extra good keeper, ripens two weeks before Concord; a fine acquisition to our early white Grapes.

WOODWARD. See Isabella.

WOODRUFF RED. (Labr.) Originated with C. H. Woodruff, Ann Arbor, Mich. A chance seedling, probably a cross between Concord and Catawba. A new grape of ironclad hardiness. A rank grower and very healthy. The fruit is large in bunch and berry, attractive, shouldered, sweet and of fair quality, but somewhat foxy. Does not crack nor drop from stem. Desirable as a market variety where many others fail. 
WOODRUFF SEEDLING, No. 4. (Labr.) Also raised by C. H. Woodruff, Mich., from seed of Latawba ; in quality about like Delaware; bunch and berry much larger, hardy and productive. Color like Delaware, very promising

WOODRUFF SEEDLING No. 5. (Hyb.) Raised from seed of Gœthe (Rogers No. r). Color white with little pink on the sunny side; a Grape of fine quality, but too late to grow with profit in the North. Hardy and productive, bunch and berry large and handsome, sweet and juicy ; ripens with Catawba.

WORDEN. (Labr.) Originated by S. Worden, of Minetta, N. Y. Raised from Concord seed. This excellent Grape has come to the front by merit alone. A fine, large, handsome black Grape, of the Concord character, large in bunch and berry; and very haudsome. In quality distinct from Concord, generally regarded as better, and ripens a week or ten days earlier. Vine vigorous, healthy, very productive and hardy. A valuable early variety, becoming very popular, and taking the place of the Concord at the North, where Concord does not always ripen perfectly. It is in reality an important gain for the Grape grower.

\section{WORTHINGTON. See Clinton.}

WRIGHT'S ISABELLA. See Isabella.

WYMAN. See To-Kalon.

WYOMING RED. (Labr.) Raised and introduced by Dr. S. J. Parker, Ithaca, N. Y. A very early red Grape; a good grower, very healthy and hardy, bunch and berry small to medium; coppery red, sweet but a little foxy; desirable for garden and vineyard.

WYNANT. (Labr.) A chance seedling grown by D. W. Babcock, Dansville, N. Y. Very similar, almost identical to Duchess.

YANKEE. (Labr.) A seedling of Concord grown by J. W. Gray, Atwood, Ill. Bunch medium, often shouldered, compact, transparent; berries large, round, pea green with fine bloom ; good flavor, sweet ; a slow, light grower, hardy, large leaf, ripens a little before Concord.

YELLOW MUSCADINE. See Scuppernong.

YORK LISBON. See Alexander.

YORK MADEIRA. (Labr.) Supposed to be a seedling of Isabella, originated at York, $\mathrm{Pa}$. Bunch medium, compact, shouldered; berry medium, round, black, $\mathrm{s}_{\text {weet, }}$ sprightly, pleasant; colors early, but does not ripen quite as early as Isabella; vine hardy, vigorous and productive.

YOUNG AMERICA. (Labr.) A Concord seedling raised by S. Miller, resembling the Concord.

YONKERS HONEY DEW. (Labr.) Originated on the Hudson. It is a pure native ripening with the Hartford and in some respects superior to that variety; berry large, round, black with blue bloom ; bunch large, long, compact, skin thick, flesh pulpy but sweet. Vine vigorous and productive, Concord foliage, healthy, early.

ZELIA. $(H y b$.$) Produced by C. J. Copley, Stapleton, N. Y. Telegraph crossed$ with Black Hamburg ; bunch very large, medium compact, berries very large, black with a fine bloom, skin thin but tough and does not crack. Very rich sherry flavor, medium vigorous grower, productive, ripens early.

ZINNIA. ( $L a b r$.) Origin unknown, bunch very large, loose, shouldered; berry medium, round, black with a rich bloom; worthless. 


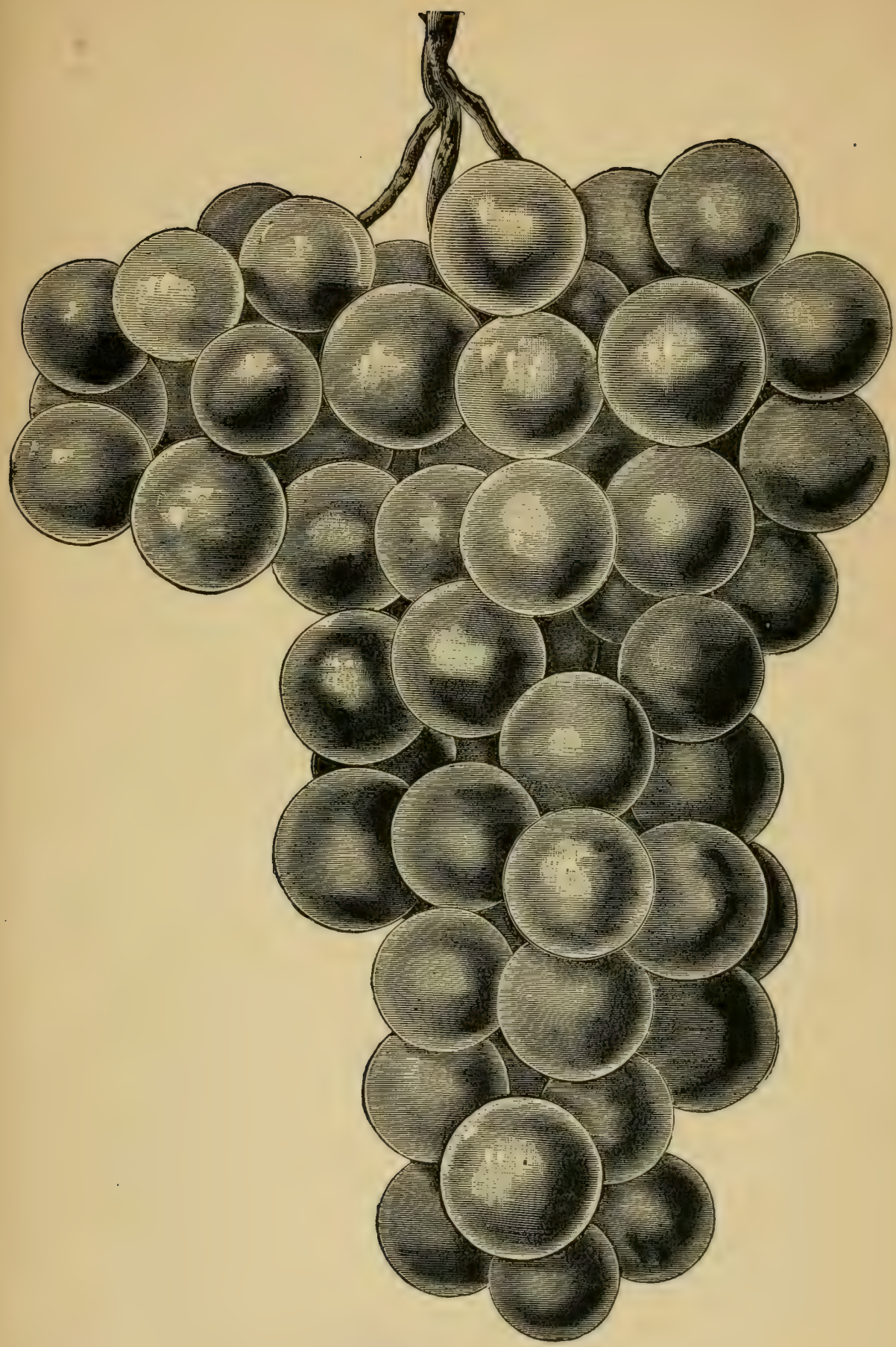

COLERAIN-See page II6. 



\section{Contents.}

Introduction

$\ldots \ldots$

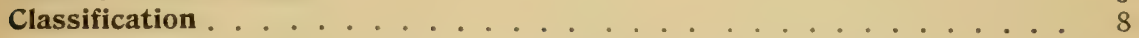

Propagation ............................. Io

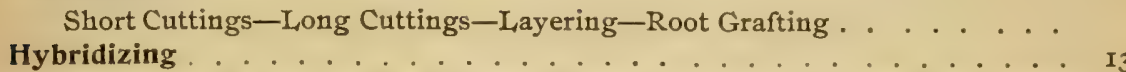

Production of New Seedling Grapes-Proposition to Protect the Originators.

The Soil

Vineyard Planting.

Location and Soil-Planting-Second Year-Trellises-Third Year-Fourth

Year-Selection of Varieties-Imperfect Fertilization .

Grape Growing at Home .

Pruning and Training.

Kniffin System-Fan System-Munson's Alternate Renewal System-Single Post System-Caywood Overhead System-Summer Pruning-Thinning Grapes.

Grafting the Grape

Layer Grafting-Whip Grafting-Wagner System-Cleft Grafting-A New

Girdling . Method of Grafting

Fertilizers

Commercial Fertilizer-Manure-Wood Ashes

Diseases of the Grape .

Black Rot-Downy Mildew-Powdery Mildew-Anthracnose-Bitter RotWhite Rot-Rougeot-Ripe Rot-Bordeaux Mixture-Ammoniacal Solution of Copper Carbonate-Eau Celeste-Modified Eau Celeste-Treatment of Black Rot-Mildew-Anthracnose-Spraying Outfits

Chemicals .

Bagging of Girapes .

Injurious Insects .

Phylloxera-Grape Leaf Hoppe:-Grape Vine Flea Beetle-Rose ChaferGrape Berry Moth-Grape Vine Scale Insect-Grape Leaf Galls-Grape Seed Midge-Grape Curculio-Grape Leaf Folder-Lady Bird-Thrips-Birds Injuring Grapes-Insecticides .

Harvesting of Grapes

Marketing of Grapes .

Commission Men .

Keeping Grapes .

Fruit Houses and Fruit Rooms .

Cold Storage .

Preservative Fluids .

Wine Making .

Red Wine-White Wine-Sweet Wine-Unfermented Grape Juice-Homemade Grape Juice . 



\section{THE CULTIVATOR}

. AND . .

\section{Country Gentleman.}

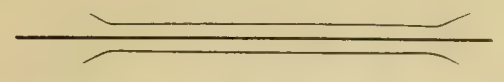

THE BEST OF THE

A grigutitrati WEekies.

DEVOTED TO

Farm Crops and Processes, Horticulture and FruitGrowing, Live-Stock and Dairying.

While it also includes all minor departments of Rural interest, such as the Poultry Yard, Entomology, Bee-Keeping, Greenhouse and Grapery, Veterinary Replies, Farm Questions and Answers, Fireside Reading, Domestic Economy, and a summary of the News of the Week. The Horticultural Department (under the editorship of the veteran John J. Thomas), is a special and leading feature. Its MARKET REPORTS are unusually complete, and much attention is paid to the Prospects of the Crops. It is liberally illustrated, and it contains more reading matter than ever before. The subscription Price is $\$ 2.50$ per year, but we offer a SPECIAL REDUCTION in our

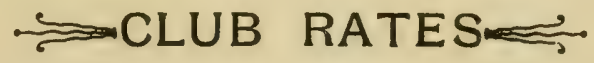

Two Subscriptions, in one remittance, - - $\$ 4.00$ Six Subscriptions, " " $\quad$ " $\quad$ - $\quad$ - 10.00 Twelve Subscriptions," SPECIMEN COPIES FREE. Address

\section{LUTHER TUCKER \& S๑N, Publishers}

\section{ALBANY, N. Y.}




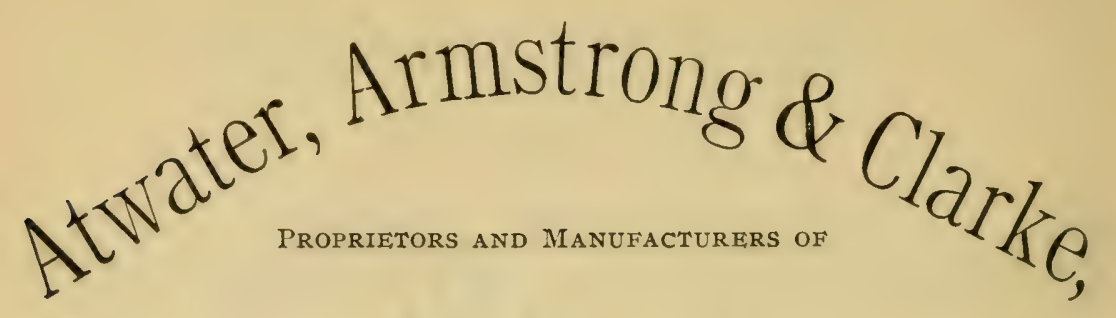

The Perfecto

Spripg Fruit Crate.

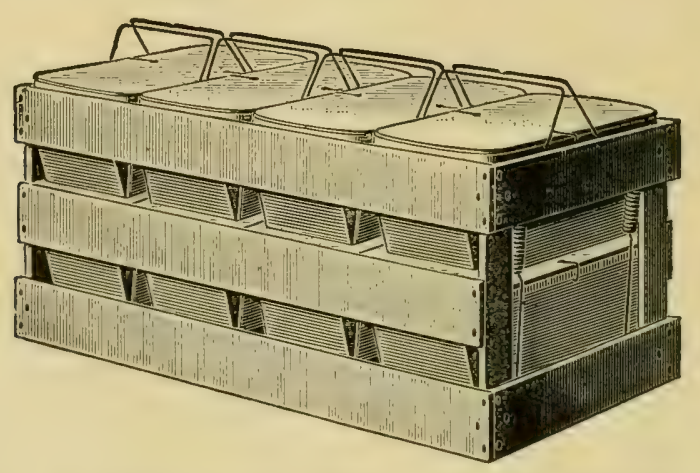

THE AVERAGE OF ALL ACCOUNT.

๑ALES OF GRAPES DURING FALL OF 1892 WAS I $21 / 2$ PER CENT. OR I $3 / 4$ CENTS PER BASKET HIGHER THAN IN ANY OTHER PACKAGE.

WRITE FOR CIRCULARS AND INFORMATION TO

Atintater Artistrong \& Clarke, 45 ILAREHOUSE ST., ROCHESTER, N. Y. 


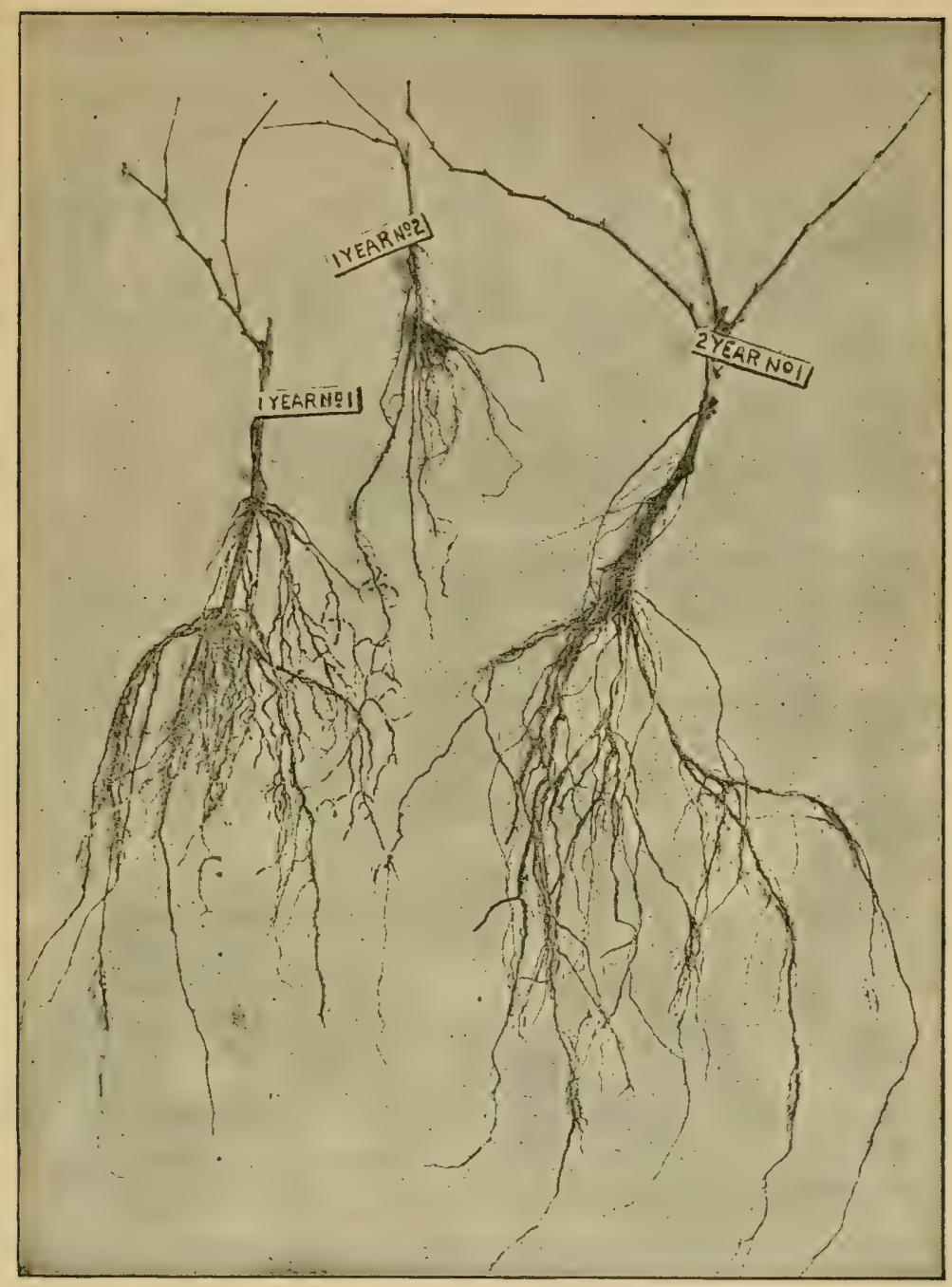

This illustration was made from a photograph of fair samples of the different grades of our Vines rerluced to one-tenth their natural length. We take great pride and comfort in our ability to furnish strong, fibrous rooted stock so well appreciated by intelligent and experienced fruit growers.

Wholesale Trade Especially Solicited. CATALOGUE FREE.

\section{LEWIS ROESCH, - - FREDONIA, N. Y. GRAPE VINE SPECIALIST, AND GENERAL NURSERYMAN.}

When writing state where you saw this advertisement. 


\section{TIE IF}
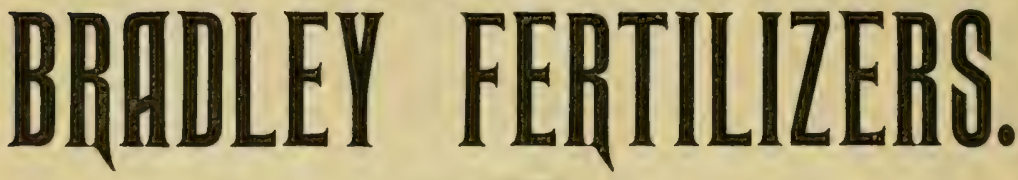

THE increased yearly sales of BRADLEY'S FERTILIZERS for the past thirty=one years, since I86I, are illustrated by these pyramids. The sales in 1861 were about 500 tons, as represented by this SMALLEST PYRAMID

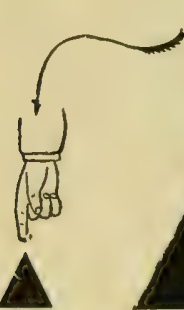

1861. This Pyramid indicates the 1892 sales of Bradley's Fertilizers.

\section{THE REASONS FOR THIS INCREASE:}

The BRADLEY FERTILIZER CO. use only the best of crude materials, which are carefully prepared by approved machinery according to formulas based upon thorough field tests, thus furnishing the best plantfood possible to secure. These essential requisites, combined with liberal dealings with the farmers, have made the BRADLEY FERTILIZER CO. the largest manufacturers of Commercial Fertilizers in the world.

For full information and I/lustrated Pamphlets, address

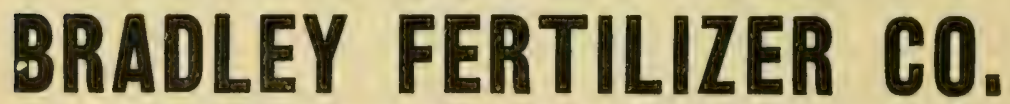

No. 92 State St., BOSTON, MASS. 


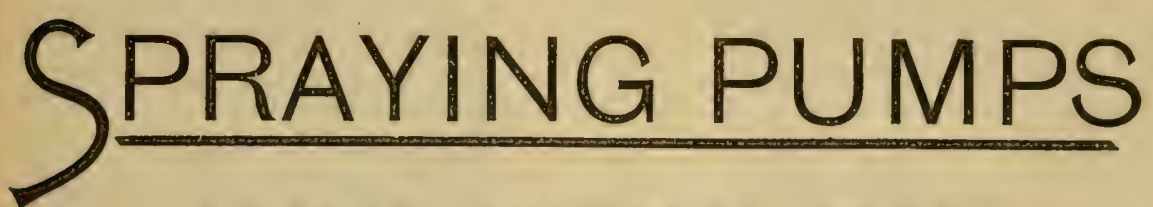

\section{LATEST, CHEAPEST, BEST.}

Spraying has paid others, it will

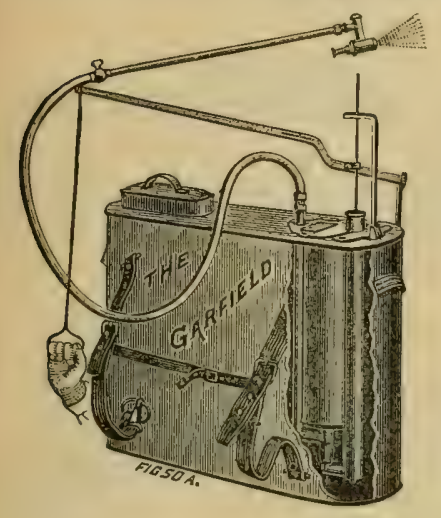

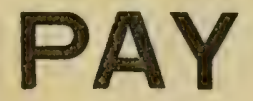

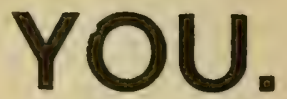

We can furuish you OUTFITS ranging in price from $\$ 3.00$ to $\$ 70.00$.

Guaranteed satisfactory in every respect. Recommended by the Department of Agriculture.

OUR REFERENCES.-G. T. Powell, Conductor of Institutes; Mortimer Whitehead, Grange Lecturer; J. S. Woodward, Lecturer.

\section{READ! READ! READ!}

Spraying Apparatus.-He who attempts to grow fruits nowadays without a spraying outfit, goes into the work handicapped. Blight and bugs, rot and dust, mold and mildew-all conspire to damage the crop, and in all cases succeed to a greater or less extent if the horticulturist does not spray. The very best goods in this line are made by the FIEID ForCe PUMP COMPANy, of Lockport, N. Y. Pamphlets giving formulas for all the best spraying compounds sent on application.-Rural Neze-Yorker.

"I value your pumps very highly. A. J. COOK, Agricultural College, Mich."

"We are well pleased with the Outfits purchased of you last season. W. M. MUNSON, Agricultural Station, Maine."

"I have no hesitation in recommending your Knapsack Sprayer as the best for our people, and have written the State Business Manager of the Farmers' Alliance to that effect. GERALD MCCARTHY, Botanist, N. C. Experiment Station, Raleigh, N. C."

CATALOGUE AND BOOK OF INSTRUCTIONS FREE.

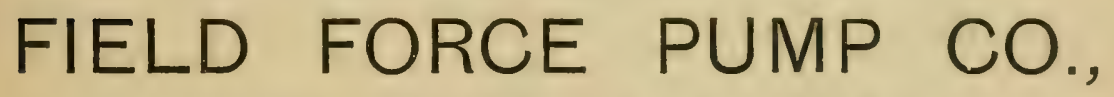

20 BRISTOL SQUARE, LOCKPORT, N. Y. 


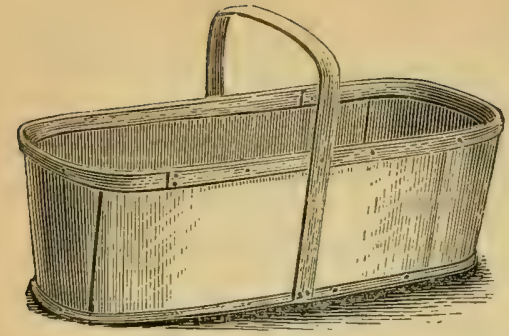

GRAPE BASKET.

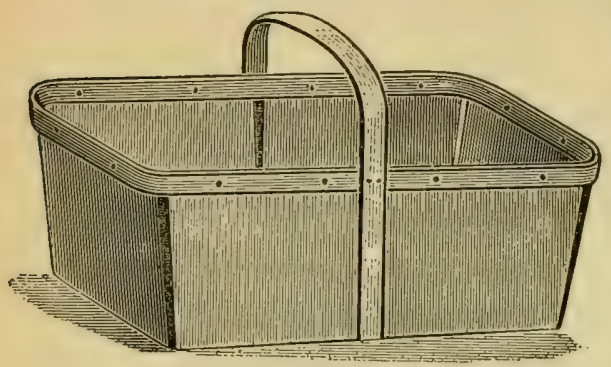

SPLINT GRAPE BASKET.

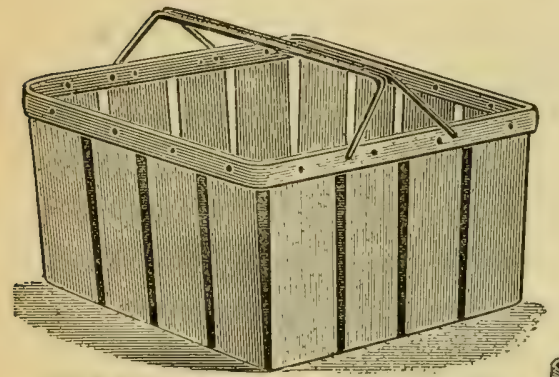

Peck Fruit Basket.-Pat. Nov. 30, 1896.

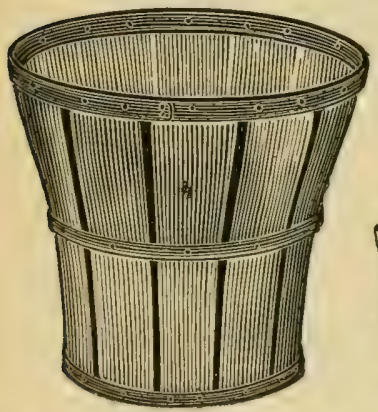

BOARD BOTTOM PEACI BASKeT

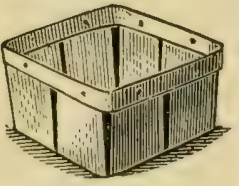

LOW GRADE GIFT BERRY BASKET.

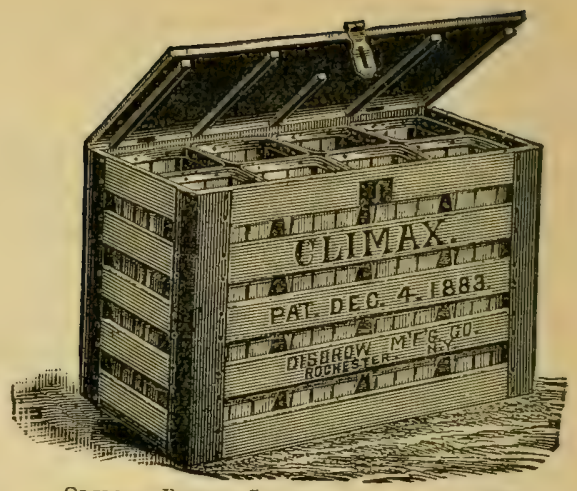

Climax Berry Crate.-Pat. Dec. 4, 1883.

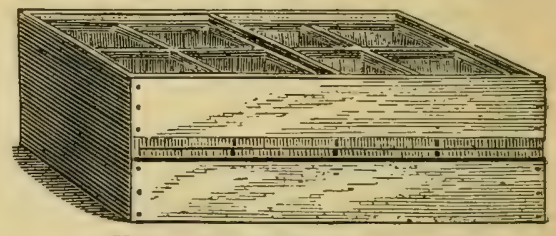

HALLOCK GIFT BFRRY CKATE.

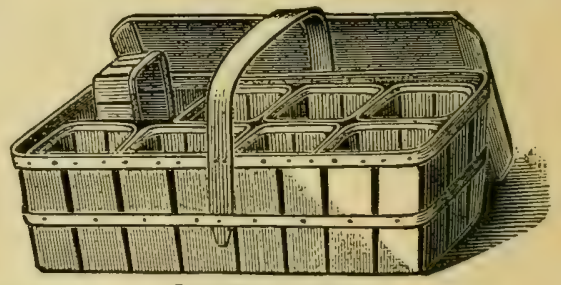

SHIPPING BASKET.

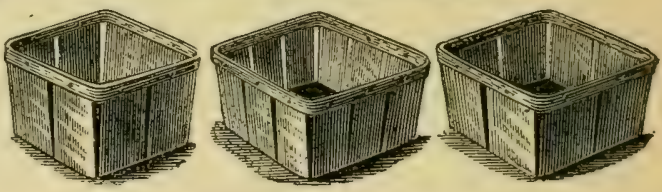

Climax BERRY BOXES.

THE ABOVE ARE SOME OF THE MANY GOOD THINGS WE MAKE FOR FRUIT GROWERS. STRICTLY FIRST-CLASS GOODS.

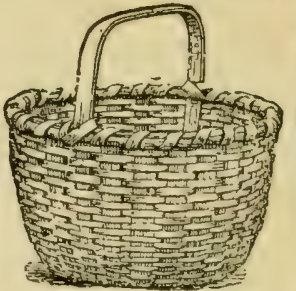

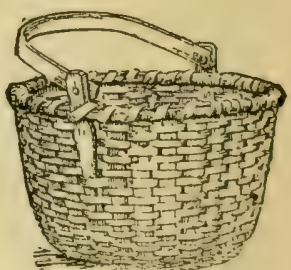

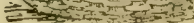

REASONABLE PRICES.

\section{If You Want Anything in the tie of frit packegess, write us before busing IOIBIROW IMFG. CO. \\ INCORPORATED 1878.




\section{Bushbero, Grape Nursprips,}

\section{ATTERICAN \\ GRAPE VINES.}

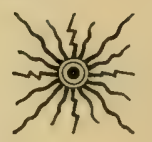

OUR SPECIALTY

\section{Largest Alssortment,}

\section{Best Quality,}

Lowest Prices.

E GROW OUR VINES IN OPEN FIELD CULTURE WITH GOOD CULTIVATION AND PLENTY OF ROOM FOR FULL DEVEI,OPMENT OF STRONG HEALTHY ROOTS AND GOOD TOPS. SEND FOR PRICE-LIST. .

ADDRESS

\section{BUSH \& SOM \& MEISSMER,}

..... BUSHBERG, MO. 


\section{General \\ Nursery

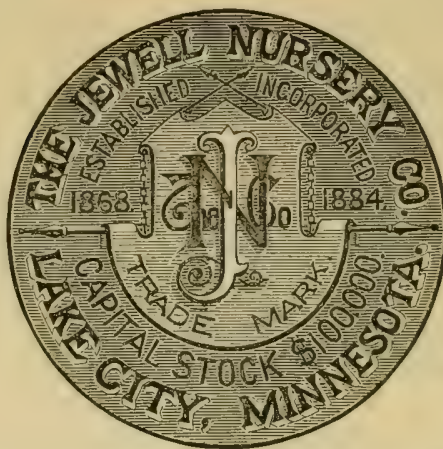 \\ Reфistered \\ Stock. \\ Holstein \\ eattle.}

\section{HARDY FRUITS FOR THE NORTH WEST. INTRODUCERS OF}

\section{THE NORTH Star CURRANT.}

The "North Star Currant" is an accidental seedling, probably of the Victoria, as, like that variety, it is seldom affected by the borer. Its bunches are much larger than any other currant and in consequence it can be much quicker harvested. It exceeds all other varieties in productiveness and, were it not for its great vigor of growth, it would, by overbearing soon become exhausted.

We have spent five years in giving "The North Star" as rigorous a test as the extremes of climate, to be found in a scope of territory ranging from New England to the Rocky Mountains, would afford.

We take pleasure in presenting herewith a few testimonials of our " North Star." These reports, coming from all parts of the country, only strengthen what we already $\mathrm{knew}$, that it is far ahead of any currant ever offered to the public.

JeWEl, NuRsery Co., LAke City, MinN.

NEW CaRlisle, Aug. 3, I89I.

GENTLEMEN : The "North Star" is perfectly at home on my place. Did not lose a single plant out of the Ioo sent me. They have made a good strong growth, notwithstanding the severe drouth. I expect much from them.

Yours truly,

W. N. SCARFF.

JEWELI, NURSERY Co., LAKE CITY, MINN.

SPRINGFIEID, MASS., July I6, I89I.

GENTLEMEN : Our plants have produced several bushels in such quantities and quality that we are more than ever pleased with them. Merchants have come to the nursery for them, paying us from Io to 12 cents per quart, and we have had to refuse many orders.

Yours truly,

J. W. ADAMS \& CO.

From the Florist Exchange:

"The 'North Star Currant' put on the market two years ago by the Jewell Nursery Co., of Minnesota, has evidently proved to be quite an acquisition to our list of Standard varieties, for we notice that in many of the spring catalogues it is highly spoken of by leading nurserymen who seldom catalogue any new fruit or give it words of praise until fairly well tested upon their own grounds. This variety has the faculty of holding its foliage until very late in the fall, thus aiding to develop the strongest possible fruit buds.

STATE BOARD OF AGRICULTURE, Rhode Island-Report I892-93.

Among those currants which I value both for market and home use, a new sort, called "North Star," and at present held at high prices, stands very near the head of the list.

Each plant bears a metal seal as a guarantee that it is genuine. Corres= pondence solicited.

LAKE CITY, MINN.

THE JEWELL NURSERY CO. 
ESTABLISHED 1877.

\section{POTTER \& WILLIAMS,}

COMMISSION MERCHANTS,

Elk Street Market, Buffalo, N. Y.

(2) SIVE SPECIAL ATTENTION TO THE SALE OF GRAPES. A All CONSIGNMENTS SOLD PROMPTLY AND SHIPPERS PAID OFF PROMPTLY. OUR LOCATION IS EQUAL TO ANY IN BUFFALO.

\section{DE WITT \& CO., \\ COlumbus, OHIO.}

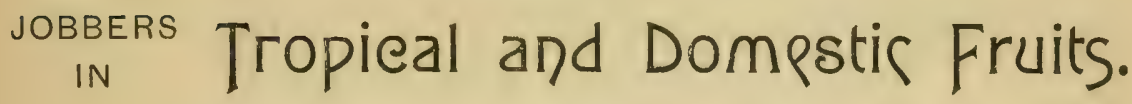

GENERAL COMMISSION MERCHANTS.

II S. FOURTH ST. (MARKET SQUARE.)

236 NORTH THIRD ST.

Ship your GRAPES and other Fruits to

Palimer, Rivenburg \& Go.,

SUCCESSORS TO G. S. PALMER.

INLHOLESALE COMTMISSION TMERCHANTS,

166 READE STREET, NEW YORK.

Established in 1869. Prompt and Rellable. Write them for rubber stamps, market reports, etc., and give them a good trial, and you will be perfectly satisfied with results.

REFERENCES: Chatham National Bank, Mercantile Agencies and all the principal Grape shippers. 
SHIP YOUR FRUIT TO BUPFALO'S REPRESENTATIVE FRUIT HOUSE.

\section{F. BRENNISON \& SON, \\ General Commanission $7 M_{\text {Ierchants. }}$}

44 in. MIARKET St. BUFFAL $\odot$, N. Y. 103 MichigAN St.

RUBBER STAMPS FURNISHED ON APPLICATION.

REFERENCES: Queen City Bank, Buffalo, N. Y. : Yates County National Bank, Penn Yan, N. Y. ; Geneva National Bank, Geneva, N. Y. ; McKechnie \& Co. Bank, Canandaigua, N. Y.; State Bank Brocton, N. Y.; Fredonia National Bank, Fredonia, N. Y. ; J. H. Butler, Ed., Vineyardist, Penn Yan, N. Y. ; Hollowell \& Wise, Penn Yan, N. Y.

ESTABLISHED 1849.

OLD AND RELIABLE.
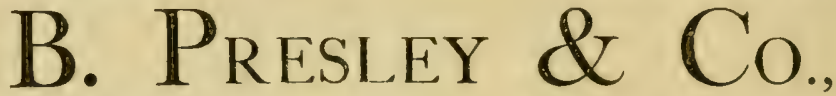

The Leading Wholesale Fruit and Commission House in the North West.

\section{ST. PAUL, MINN.}

GRAPE SALES: $\{$ Season 1891 , Seventy-Three Car loads.

\{ Season 1892, Ninety-One Car Loads.

\section{Stecher Lithoøraphie (o.,}

ROCHESTER, N. Y.

ARTICULAR ATTENTION GIVEN TO PLAIN
SERYMEN,
BEST THA'T CAN BE MADE.




\section{WILLOW BASKETS. ROCHESTER BASKET CO.,}

OFFICE AND FACTORY, 164 to 176 ORCHARD and 171 to 183 MAGNE STS., ROGHESTER, N. Y.

BASKETS.

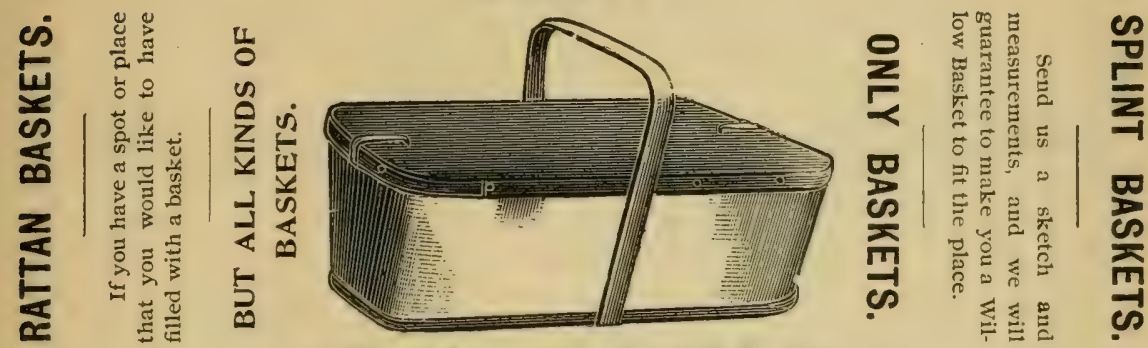

JUST BASKETS THAT'S ALL.

Our Line Comprises Over 400 Different Kinds, Styles and Sizes. SEND FOR CATALOGUE.

BAMBOO BASKETS.

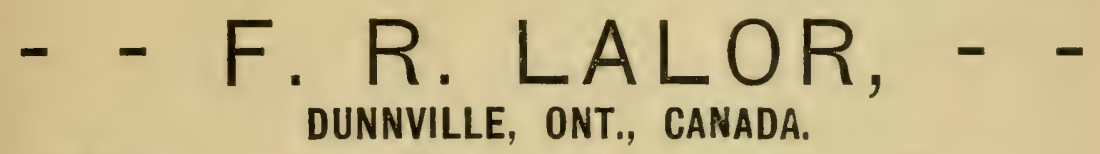

Exporter of Canada Hard Wood Ashes.

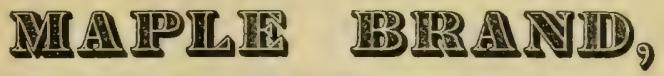

THE GREATEST GRAPE FERTILIZER.

WRITE FOR PAMPHLETS AND PRICES.

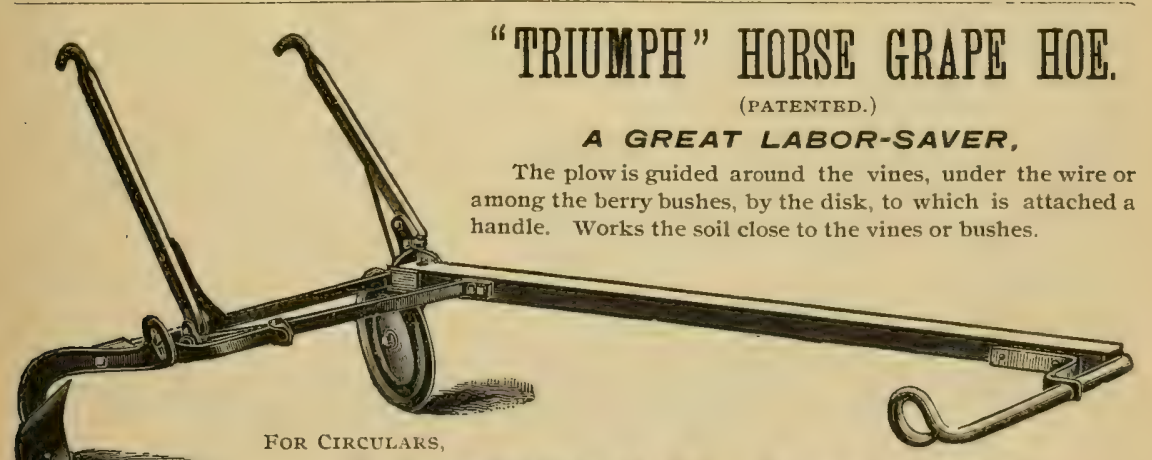

D. S. MORGAN \& CO., Brockport, N. Y.

Manufacturers of Latest Novelties in Implements. 
IS THE COUNT RIGHT?

I. More than Soo beautifully printed pages of fresh, bright, readable, practical matter.

2. About 900 choice illustrations that illustrate.

3. The benefit of several large experiment gardens and orchards in widely spread localities.

4. The work of scholarly editors who are skillful horticulturists.

5. A magazine for the fruit grower, garden and commercial florist, for every lover of nature; the man or woman who owns a geranium, a flower bed, or a costly lawn ; every one who "sits under his own vine or fig tree;" the suburban resident and country gentleman.

6. Artistic plans by landscape architects for laying out readers' grounds, in every issue, such as cost hundreds of dollars in the usual way.

7. An inquiry department which answers all questions from readers.

S. All in all the most complete and profusely illustrated gardening journal in the world. Iet it costs only \$ a year. The Rural Publishing Company,

Cor. Chambers \& Pearl Sts.,

NEW YORK. 


\section{Rochester Eithoфraphing @ompany,}

176 North Water St,, Rochester, N. Y.

MANUFACTURERS OF AI.L KINDS OF

\section{NURSERYMEN'S : SUPPLIES,} INCLUDING

FRUIT

Catalogues, Price-lists, Order Blanks, Etc.

Aurserymen's @orrinfing a Specialfy.

\[RITE FOR TERMS when getting up a Calalogue, Price-List or Circular. We have a large line of Cuts which can be used for this work without extra charge.

Colored Frontispieces and Colored Plates for Catalogues.

New Fruits Drawn From Nature and Accurately Printed in Colors.

6 HROMO LITHOGRAPHY. We are prepared to do all styles of Color Printing, Especially Fruits, Flowers, Trees, Show Bills F.tc., as well as office printing for Nurserymen and Horticultural Societies.

Send \$2.50 for the “Rochester Directory" containing ten thousand, classified names and addresses of Nurserymen, Florists and Seedsmen, in the United States and Canada.

$=$ SEND FOR CATALOGUE. $\quad=$

ADDRESS ALL . . RORHESTER LITHOGRAPHING communications to ROCHESTER 


\section{A NEW ERA IN -}

IS INAUGURATED BY THE INTRODUCTION OF

\section{T. V. MUNSON'S}

\section{HYBRIDS AND SEEDLINGS}

In which New, Vigurous, Hardy, Healthy varieties, produced and selected from heretofore unused species, but far superior in many points to the old Labrusca and Vinifera varieties, resistant to Phylloxera and most other maladies, have been secured, embodying

\section{BEAUTY,}

\section{. . QUALITY, . .}

\section{PRODUCTIVENESS,}

\section{PROFIT FOR MARKET,}

\section{TABLE AND WINE.}

The ideal, universally successful Grape has been regarded as an impossibility in producing these, and it has been the constant object to produce the very best possible varieties specially adapted to the regions for which they are recommended.

A careful, accurate Illustrated Descriptive Circular, telling for what region each variety is adapted, and giving prices, will be mailed on application to

$$
\text { T. V. MUNSON, }
$$

- $\quad$ - _ _ _ _ _ _ DENISON, TEXAS. 
HARDY NATIVE GRAPES.
WE desire to call the attention of Planters to our large and complete stock of Grape Viues.

We propagate and offer for sale upwards of sixty varieties, embracing the popular old sorts as well as the new ones which seem to have merit. Our catalogue contains accurate descriptions, and classifies the different varieties according to color.

Besides the above we offer an immense collection of all kinds of Fruit and Oruamental Trees, Shrubs, Roses, Hardy Plants, etc. Our General Catalogue (160 pages), embellished with numerous engravings of the most popular Trees, Shrubs, etc. and enclosed in an illuminated cover, will be mailed free to all who have not received it.

Our Supplementary Catalogue (28 pages) of Rare and Choice Trees, Shrubs, etc, including several valuable novelties and many specialties of superior merit, will also be mailed free.

\section{ELLWANGER \& BARRY,} MOUNT HOPE NURSERIES.

53RD YEAR.

ROCHESTER, N. Y.

\section{A NEW PEDIGREE WHITE} Early, Healthy, Hardy, Productlve, Good.

H. HYATT, Penn Yan, N. Y., says: "There is no mildew or rot on vine or fruit. It is an excellent keeper.

Rural New Yorker, Feb. 4th, 1893, says: "The $R . N$. Y. desires that all of its readers who are interested in grape growing may try the Geneva Grape. It is one of the few varieties of partly Vinifera origin that thrive in the trying climate of the Rural Grounds. It ripens with us early, a week or more before the Concord, though earliness is not one of the excellencies claimed by those who offer the variety for sale. The vine has proved hardy thus far, and free of mildew."

JOSIAH HOOPES, of West Chester, Pa., a most trustworthy authority, says that the Geneva on his grounds perfected last season the largest crop of any variety in his collection. He describes it as follows: "Color, translucent, clear amber, with a very thin skin and of the best quality. It is an act of simple justice to place it a mong the best of our native grapes."

\title{
R. G. CHASE \& CO., Geneva, N. Y. INTRODUCERS.
}

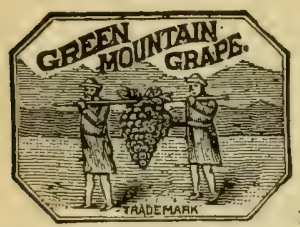

\section{"A TREASURE AND A WONDER IN THE HORTICULTURAL WORLD."}

SPLENDID! DELICIOUS! EXCELLENT! Are the exclamations from those who have fruited the Green Mountain, the earliest and best of all grapes. Ripens in August, yet of most delicate texture and exquisite flavor. Be not misled into buying this Grape under other mames, Every Genuine VIne is sealed with our Trade Mark Seal as above. Send for circulargiving full information. Agents wanted in every state and county. ADDRESS

\section{STEPHEN HOYT'S SONS, NEW CANAAN, CT.}

\section{BANNOCKBURN NURSERIES,}

\author{
ROCHESTER, N. Y. \\ AUGUST BLAUW, Proprietor.
}

A FULL LINE OF NURSERY STOCK. PEACH TREES A SPECIALTY.

Valuable New Varieties. STEPHENSON, HARRIS, ELBERTA, GLOBE. 


\section{EARLY OHIO GRAPE.}

The earliest of all to ripen. Ten days earlier than Moores Early, three times as productive. Ioo other varieties, Niagara, Worden, Diamond, etc.

\section{ROSES. $x$}

Flowering Shrubs. Trees.

Small Fruits. Send for Catalogue.

Address C. S. CURTICE Co., PORTLAND, N. Y.

\section{GRAFT \\ Your GRHPE VIMES.} WITH .

\section{THE WAGENER SAW.}

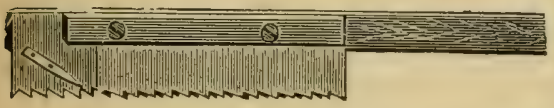

No man who has an orchard or Vineyard should be without one. They will graft Apple, Pear or Cherry BETTER THAN THE OLD WAY OF SPLITTING and much quicker. Any man with ordinary skill can use one, They will be sent to any address in the United States, with full instructions for using on receipt of $\$ 2,00$. Address,

J. H. BUTLER, Agent,

Penn Yan, N. Y.

REFERENCES :

I used the Wagener Saw and find it indispensible in the vineyard. No practical vineyardist should be without it.-C. H. BRONSON.

I have used the Wagener Saw for fourteen years, I consider the Wagener System of graftiug decidedly the best way of changing a vineyard.-J. F. CROSBY.

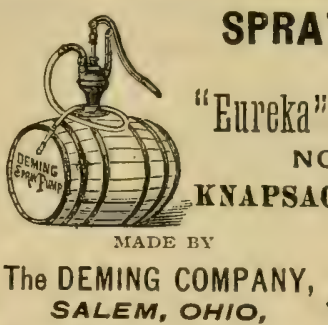

Henion \& Hubbell, West. Agts., CHICAgo, ILLS.

Write for illustrated Catalogue and Treatise. 


\section{THE VINEYARDIST}

Published Monthly at Penn Yan, N. Y., by J. H. BUTLER, its Editor ana' Proprietor.

\section{At 50 cents a Year in Advance.} T. 1 HIS is the only Journal in the United States, conducted principally in the Industry, being its specialty, and all other Fruit Culture, treated of generally. The VINEYARDIST is Devoted to Grape Culture and Kindred Interests; and, as Wine Making is inseparably connected with grape production, in extensive vineyard regions, that subject receives such attention as its importance demands.

In the columns of the VINEYARDIST will be found copious Agricultural, Grape, Fruit, Wine and Health notes and numerous ably written articles on all these and other subjects, interesting and valuable to the Farming, Fruit-Growing, WineMaking and Nursery rocations, and to the public at large.

This carefully edited monthly circulates in all sections of the Union, and is one of the rery best and cheapest periodicals of its general class, and a most desirable Advertising medium, at very low cash rates.

Address all communications, remittances, etc., to

\section{THE VINEYARDIST,}

$\cdot \cdot \cdot \cdot \cdot \quad$ PENN YAN, N. Y.

51 st $\mathrm{YAAR}$.

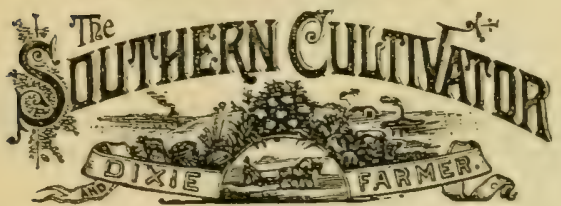

The Great Farm, Industrial and Stock Journal of the South.

The Best Advertising Medium. Rates of advertising sent on application.

ONE YEAR FOR \$I.

Sample copies will be mailed FRE, on applica tion to THE CULTIVATOR PUBLISHING CO., Box 415, Atlanta, Ga.

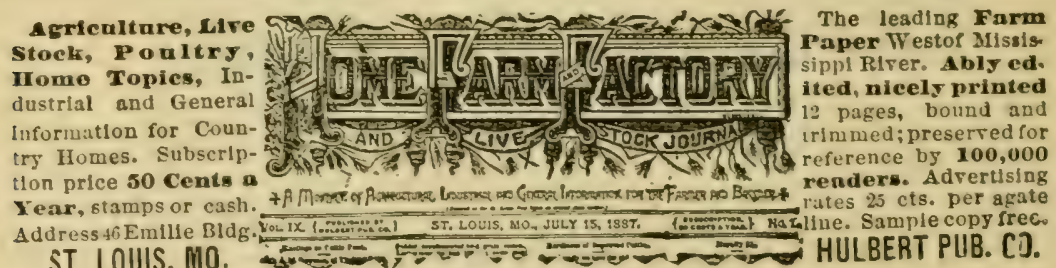

ST. LOUIS, MO. 


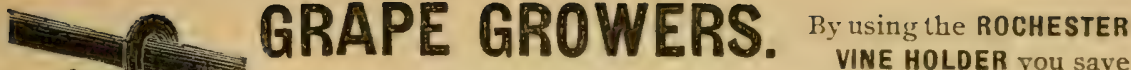

TIC

TIME by hooking the vine to the trellis, when you trim.

$\angle A B O R$ by not having to tie the viues.

MONEY in buying them at about half the cost of other material.

Tested and approved by practical men. Ask your dealer for them, or order direct from us.

ROCHESTER RADIATOR CO.,

25 Furnace St., ROCHESTER, N. Y.

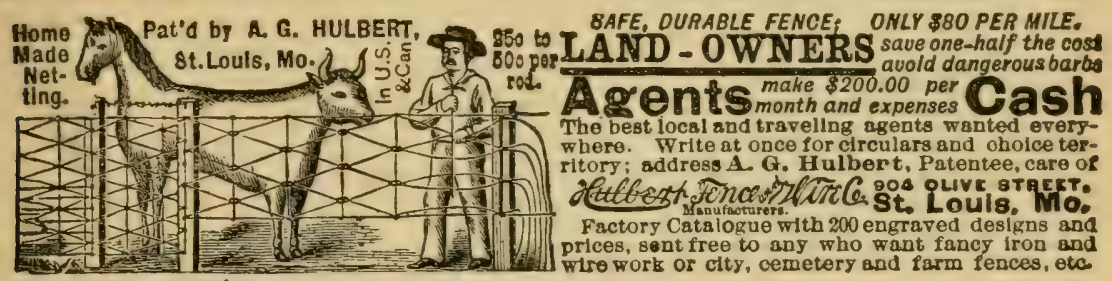

ONLYONE TRIUMPH SNAP THAT IS-COVIERT'S EVERY FEATURE TRIOMPH

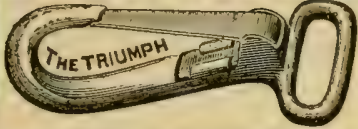
ACCEPT NO OTHER

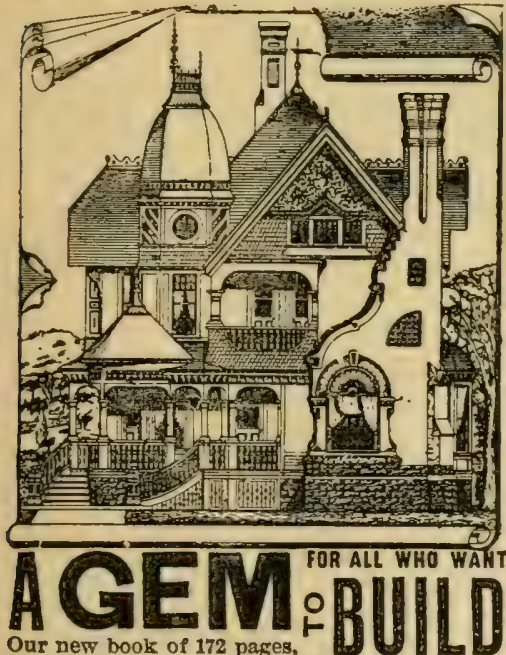

Our new book of 172 pases, 10 l 10 inches The "Cottage Souvenir," containing a great variety of Designs and Plans of

Artistic Dwellings costing from $\$ 500$ to $\$ 10,000$.

The Beruty and Completeness of these Desicns, combining so many $x$ es features has given this book a wonderful nale, and hundreds given this book a wonderful sale, and hundreds
of Beautiful Homes are being built in all parts of our land from its designs. Price \$2.00. Send for prospectus and sample pages, FREE.

GEO. F. BARBER \& CO., Architects, KNOXVILLE, TENN.

\section{F. SCHIRCK,}

191 W. Main St., ROCHESTER, N. Y. DIFFICULT BICYCLE REPAIRING,

Metal Pattern Making, Dice Making, Lawn Mowers Sharpeved and Repaired. Experimental work. General Light Jobbing.

All Orders Given Prompt Attention.

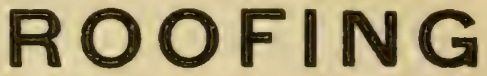

GUM-ELASTIC ROOFING FELT costs only $\$ 2.00$ per 100 square feet. Makes a good roof for years, and anyone can put it on.

GUM-ELASTIC PAINT costs only 60 cents per gallon in barrel lots, or $\$ 4.50$ for 5 gallon tubs. Color dark red. Will stop leaks in tin or iron roofs that will last for years. Try it.

Send stamp for samples and full particulars GUM-ELASTIC ROOFING CO.

39 \& 41 WEST BROADIVAY, NEW YORK

Local Agents Wanted.

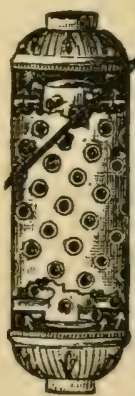
COAL COMBINE CONOUEREDI 7 using our (stove pipe) Rad ator which saves $1 / 2$ the fuel. Send for phofs from many prominent men. It has $\mathbf{8}$ cross tubes directly over the current here nearly $3,000 \mathrm{sq}$. inches of iron ge intensely hot, making one stove do the work of two. Scientists say you nok burn 4 tons of coal or cords of wood to get the heat on one. 75 per cent of the heat is lost up the chimney. It does not in jure the draft, clog, nor leak gas. Look at the price: to introduce, first order from each neighborhood filled at wholesale rates, and secures an agency. Who gets this chance, why not you? Write at once. ROCHESTER RADIATOR CO. ROCHESTER, N.Y. 
38 พ 


